\title{
Deposition Velocities of Non-Newtonian Slurries in Pipelines: Complex Simulant Testing
}
AP Poloski
HE Adkins
ML Bonebrake
J Chun
AM Casella
KM Denslow
MD Johnson
ML Luna
PJ MacFarlan
JJ Toth
JM Tingey

July 2009 


\section{DISCLAIMER}

This report was prepared as an account of work sponsored by an agency of the United States Government. Neither the United States Government nor any agency thereof, nor Battelle Memorial Institute, nor any of their employees, makes any warranty, express or implied, or assumes any legal liability or responsibility for the accuracy, completeness, or usefulness of any information, apparatus, product, or process disclosed, or represents that its use would not infringe privately owned rights. Reference herein to any specific commercial product, process, or service by trade name, trademark, manufacturer, or otherwise does not necessarily constitute or imply its endorsement, recommendation, or favoring by the United States Government or any agency thereof, or Battelle Memorial Institute. The views and opinions of authors expressed herein do not necessarily state or reflect those of the United States Government or any agency thereof.

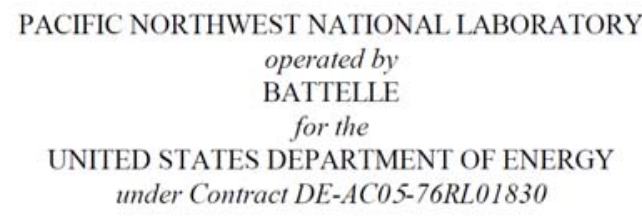

Printed in the United States of America

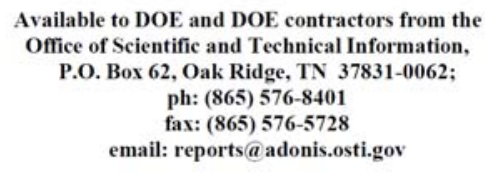

Available to the public from the National Technical Information Service, U.S. Department of Commerce, 5285 Port Royal Rd., Springfield, VA 22161

$$
\begin{aligned}
& \text { ph: }(800) 553-6847 \\
& \text { fax: }(703) 605-6900
\end{aligned}
$$

email: orders@ntis.fedworld.gov

online ordering: http://www.ntis.gov/ordering.htm

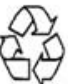

This document was printed on recycled paper.

(9/2003) 
PNNL-18316

WTP-RPT-189 Rev. 0

\title{
Deposition Velocities of Non- Newtonian Slurries in Pipelines: Complex Simulant Testing
}

\author{
AP Poloski \\ HE Adkins \\ ML Bonebrake \\ J Chun \\ AM Casella \\ KM Denslow \\ MD Johnson \\ ML Luna \\ PJ MacFarlan \\ JM Tingey \\ JJ Toth
}

July 2009

Prepared for

the U.S. Department of Energy

under Contract DE-AC05-76RL01830

Test Scoping Statement(s): SCN 023; 24590-WTP-RTD-RT-07-0002, Rev 0

Test Specification: 24590-WTP-TSP-RT-07-005, Rev. 0

Test Plan: TP-RPP-WTP-493, Rev. 1

Test Exception(s): 24590-WTP-TEF-RT-08-00008, Rev. 0

Pacific Northwest National Laboratory

Richland, Washington 99352 
PNNL-18316

WTP-RPT-189 Rev. 0

\section{Completeness of Testing}

This report describes the results of work and testing specified by Test Exception 24590-WTP-TEF-RT-0800008, Rev. 0, Test Specification 24590-WTP-TSP-RT-07-005, Rev. 0, and Test Plan TP-RPP-WTP-493, Rev. 1. The work and any associated testing followed the quality assurance requirements outlined in the Test Specification and the Test Plan. The descriptions provided in this test report are an accurate account of both the conduct of the work and the data collected. Test plan results are reported. Also reported are any unusual or anomalous occurrences that are different from expected results. The test results and this report have been reviewed and verified.

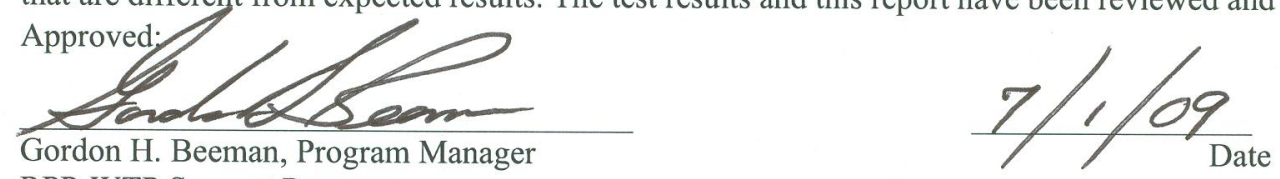

RPP-WTP Support Program 


\section{Contents}

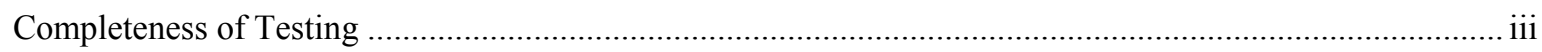

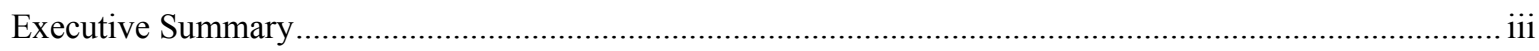

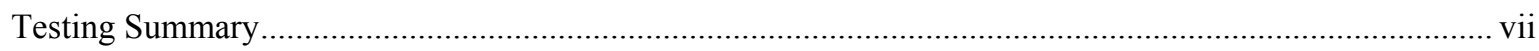

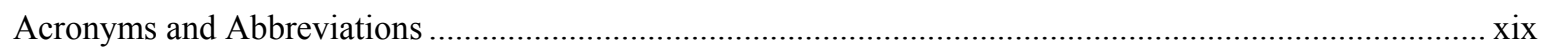

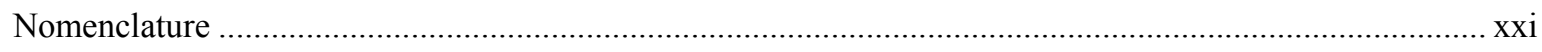

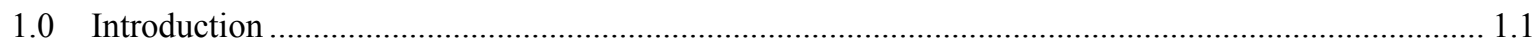

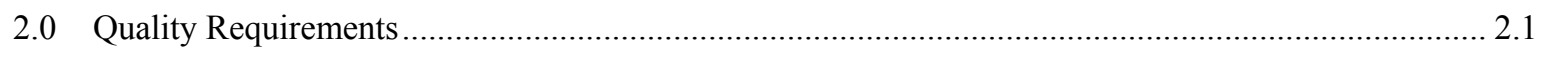

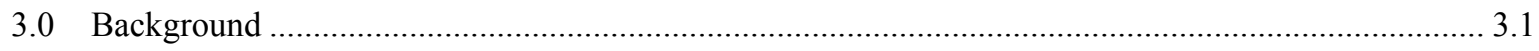

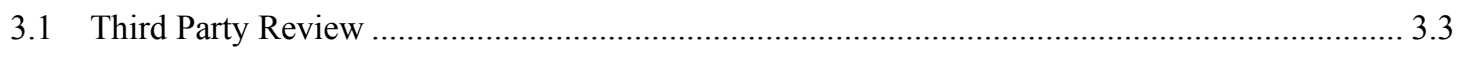

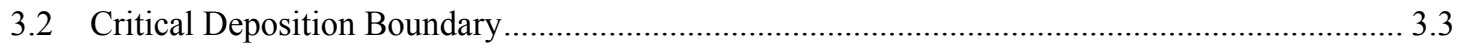

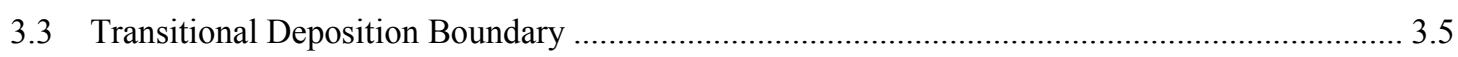

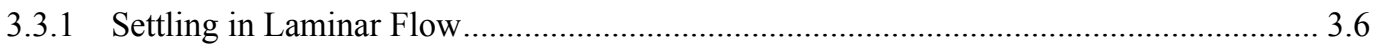

3.3.2 Operational Data from Pipelines in Laminar Flow.......................................................... 3.7

3.3.3 Experimental Data on Particle Sedimentation in Laminar Flow ……............................. 3.8

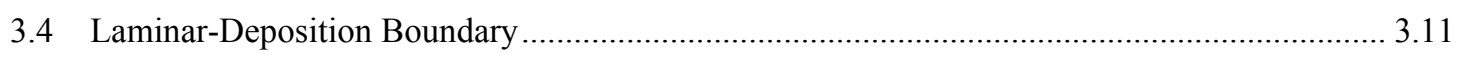

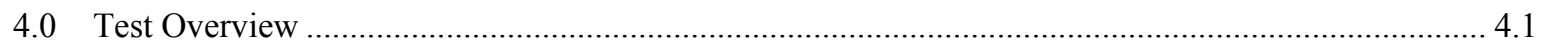

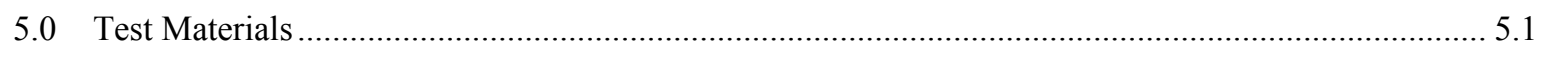

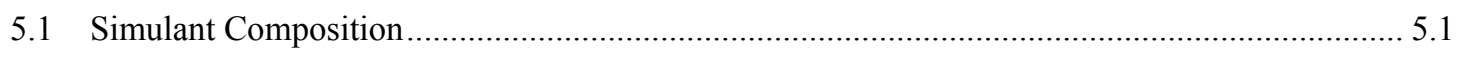

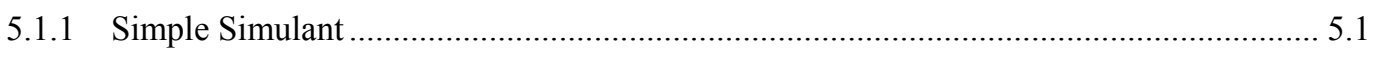

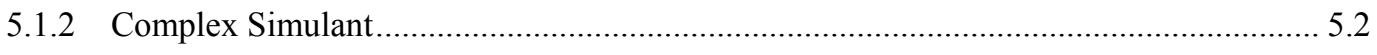

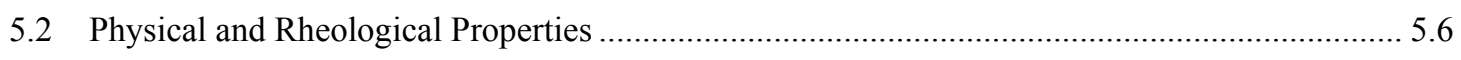

5.2 .1 Density ..................................................................................................... 5.10

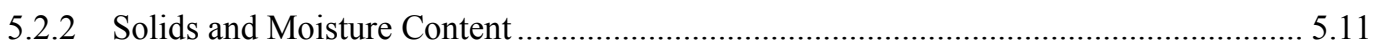

5.2.3 Particle-Size Distribution ......................................................................................... 5.12

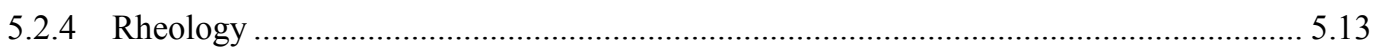

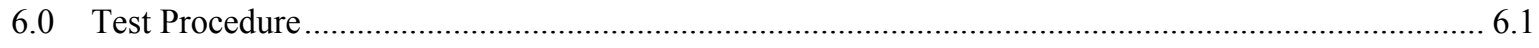

7.0 Deposition-Velocity Test Results and Discussion......................................................................... 7.1

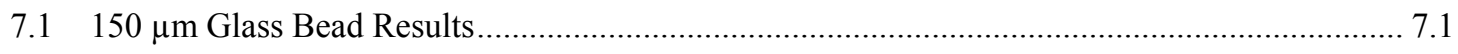

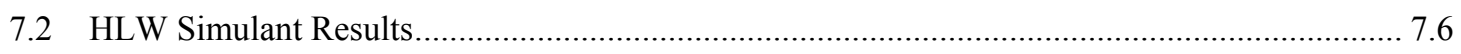

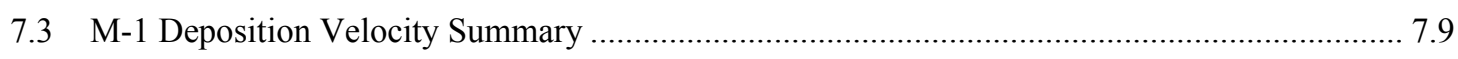

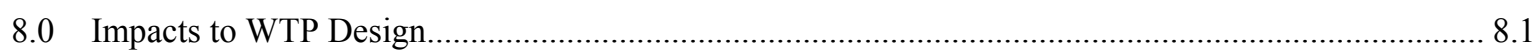

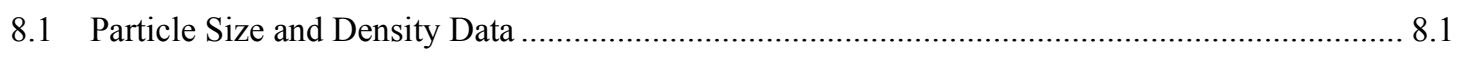

8.2 EFRT Issue M-12 Physical and Rheological Property Data........................................................... 8.4

8.3 Minimum Design Velocity for non-Newtonian Pipeline Transport Systems in the Waste

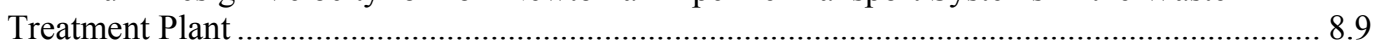

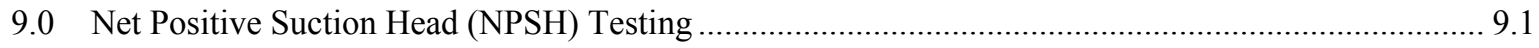

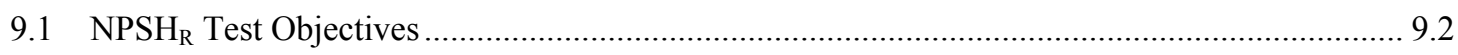

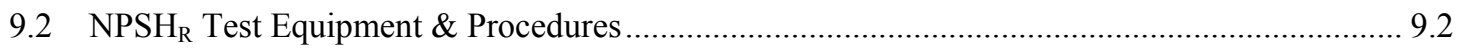

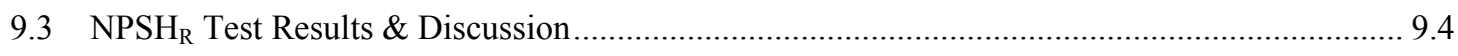




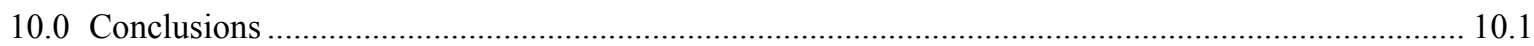

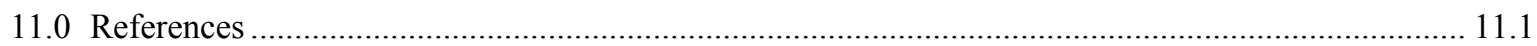

Appendix A Velocity, Pressure, and Time Signatures for $150 \mu \mathrm{m}$ glass bead and kaolin clay simulant .......A.1 Appendix B Velocity, Pressure, and Time Signatures for AZ-101 pretreated HLW simulant .......................1

Appendix C Technical Information on PulseEcho Ultrasonic Sensors ...................................................... 1

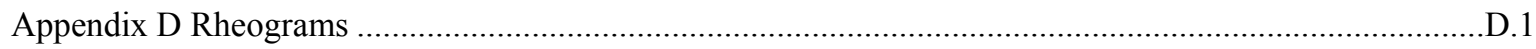

Appendix E Third Party Review of WTP-RPT-175 Rev. A ................................................................... 


\section{Figures}

Figure 3.1. Graphical Interpretation of Four Major Slurry-Transport Flow Regimes ................................. 3.1

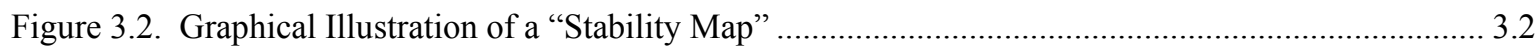

Figure 3.3. Laminar-Settling Test Data in Couette Flow; Source: Cook (2002) ........................................ 3.8

Figure 3.4. Relationship Between Deposition Velocity and Transition Velocity for an Example Slurry;

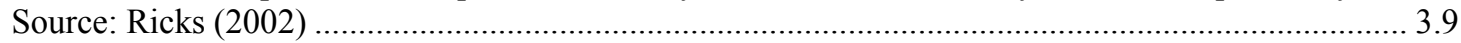

Figure 3.5. Sand-Clay Slurry Deposition Data in a Rectangular Pipeline; Arrows show the testing progression starting and ending with a superficial velocity of zero; Source: Song and Chiew (1997) 3.10

Figure 3.6. Copper-Tailings Deposition-Velocity Data; Source: Cooke (2002)....................................... 3.11

Figure 4.1. Photograph of Flow Loop System with Major Equipment Identified; Arrows and Numbers

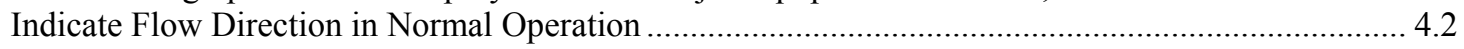

Figure 5.1. Micrograph of Fastest-Settling Particles in the Complex Simulant ......................................... 5.5

Figure 5.2. Micrograph of Slower-Settling Particles in the Complex Simulant ........................................... 5.6

Figure 6.1. Example Data Showing Pressure Drop as a Function of Pipeline Superficial Velocity .............. 6.2

Figure 7.1. Stability Map for $150 \mu \mathrm{m}$ Glass Beads and Corresponding Measured Deposition Velocity....... 7.2

Figure 7.2. Stability Map for Simulant of AZ-101 HLW Pretreated Sludge With Deposition Velocities Determined by Pressure Signatures and Visual Observation in Transparent Pipe Section.................... 7.7

Figure 7.3. Thickness of Stationary Bed of Particles in Pipeline With Simulant of AZ-101 HLW Pretreated Sludge at Different Yield Stresses As Measured by Ultrasonic Pulse-Echo Technique; These data are considered "For Information Only."

Figure 7.4. Plot of Reynolds Number at Deposition for all Experimental Data from the M-1 Project; Reynolds Number at the Laminar to Turbulent Transition is also Plotted......................................... 7.10

Figure 8.1. Solid Particles and Soft and Hard Agglomerates, From Ilievski, D. and E.T. White. (1994) ..... 8.1

Figure 8.2. Wells et al. (2007; WTP-RPT-153 Rev. 0) Case 3 (Top-Left), Case 4 (Top-Right) and Jewett et al. (2002; RPP-9805; Bottom) Particle Size and Density Distributions............................................ 8.3

Figure 8.3. M-12 PSDD From Unleached (Left) and Leached (Right) Group 5 Composite With Data From Fiskum et al. (2008; WTP-RPT-157 Rev. 0 ).

Figure 8.4. Schematic Showing a Design Approach for Newtonian Slurries of Setting a Maximum Velocity at which Turbulent Deposition Can Occur and Determining the Volume Fraction of Slurry Particles in Unstable Turbulent Flow ... 8.10

Figure 8.5. Fraction of Slurry Particles in Unstable Turbulent Flow in 3" Pipe (Top) and 4" Pipe (Bottom) at Various Velocities and PSDDs

Figure 8.6. Schematic Showing a Design Approach for Non-Newtonian Slurries of Setting a Maximum Velocity at which Turbulent Flow Can Occur and Determining the Volume Fraction of Slurry Particles in Unstable Laminar Flow.....

Figure 8.7. Fraction of Slurry Particles in Unstable Laminar Flow in 3" Pipe (Top) and 4" Pipe (Bottom) at Various Velocities and PSDDs

Figure 9.1. Principal Components of a Centrifugal Pump.....

Figure 9.2. $\mathrm{NPSH}_{\mathrm{R}}$ Testing Data for Casson-Fluid Yield Stress of Approximately 3.1 Pa. the Manufacturer's Pump-Performance Curve and $\mathrm{NPSH}_{\mathrm{R}}$ Curves Are Shown, as well as $\mathrm{NPSH}_{\mathrm{R}}$ Data Points Collected. Head is Calculated on a Head-of-Slurry Basis

Figure 9.3. $\mathrm{NPSH}_{\mathrm{R}}$ Data for Casson-Fluid Yield Stress of Approximately $3.1 \mathrm{~Pa}$; T Approximately $25^{\circ} \mathrm{C}$. This test was conducted on 1/9/09. Head is calculated on a head-of-slurry basis.................................. 9.5

Figure 9.4. $\mathrm{NPSH}_{\mathrm{R}}$ Data for Casson-Fluid Yield Stress of Approximately $0.9 \mathrm{~Pa}$; T Approximately $24^{\circ} \mathrm{C}$. This test was conducted on 1/10/09. Head is calculated on a head-of-slurry basis... 
Figure 9.5. $\mathrm{NPSH}_{\mathrm{R}}$ Data for Process Water (Casson-Fluid Yield Stress $0 \mathrm{~Pa}$ ); T Approximately $19^{\circ}-23^{\circ} \mathrm{C}$. This test was conducted on 1/19/09. Head is calculated on a head-of-water basis.

Figure 9.6. Apparent $\mathrm{NPSH}_{\mathrm{R}}$ Data for HLW Simulant (With Entrained Air) at Casson-Fluid Yield-Stress Range of 28.0 Pa to 2.6 Pa; All tests conducted at a $60 \mathrm{~Hz}$ VFD Setting. These tests were conducted from $12 / 10 / 08$ to $1 / 6 / 09$. Head is calculated on a head-of-slurry basis...... 


\section{Tables}

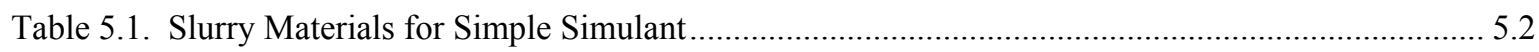

Table 5.2. Chemical Composition of the Complex Simulant Compared to Actual Tank Waste ................... 5.2

Table 5.3. Chemical Composition of the Complex-Simulant Supernatant .................................................... 5.4

Table 5.4. Properties of the Simple Simulant ......................................................................................... 5.7

Table 5.5. Properties of the Complex Simulant .............................................................................................. 5.9

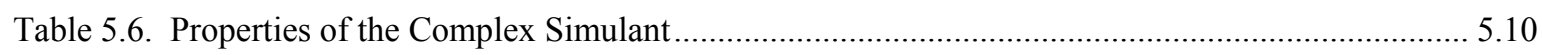

Table 5.7. Particle-Size Standard for the Malvern Mastersizer 2000 Analyzer............................................. 5.13

Table 5.8. Comparison of Bingham and Casson Model Fits ......................................................................... 5.16

Table 7.1. Electrical-Resistance Tomograms (ERT) of Slurries of $150-\mu \mathrm{m}$ Glass Beads and Kaolin at Different Casson Yield Stresses. These images are considered "For Information Only."...................... 7.3

Table 7.2. Electrical-Resistance Tomograms (ERT) of Simulant of AZ-101 Pretreated HLW Slurries at Different Casson Yield Stresses. These images are considered "For Information Only."...................... 7.8

Table 8.1. Composite Particle-Size Distribution Under Minimal-Disturbance Conditions From Seven Hanford Waste Tanks As Reported by Jewett et al. (2002; RPP-9805).

Table 8.2. Unsonicated PSD Data From WTP M-12 Actual-Waste Samples. When duplicate samples were

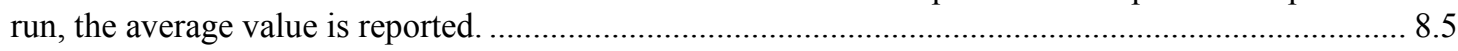

Table 8.3. Rheological Data From WTP M-12 Actual-Waste Samples ................................................... 8.5

Table 8.4. XRD Data Showing Observed Crystalline Compounds in WTP M-12 Actual-Waste Samples... 8.7

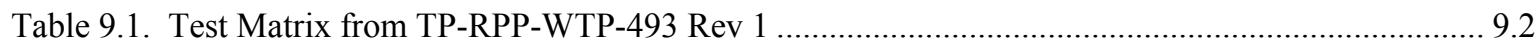

Table 9.2. Summary of Apparent $\mathrm{NPSH}_{\mathrm{R}}$ Data Under Various Conditions When Compared to the Pump Manufacturer Data for Water. Head is calculated on a head-of-slurry basis; water head calculated on head-of-water basis. 



\section{Executive Summary}

One of the concerns expressed by the External Flowsheet Review Team (EFRT) is about the potential for pipe plugging at the Waste Treatment and Immobilization Plant (WTP). Per the review's executive summary, "Piping that transports slurries will plug unless it is properly designed to minimize this risk. This design approach has not been followed consistently, which will lead to frequent shutdowns due to line plugging." To evaluate the potential for plugging, deposition-velocity tests were performed on several physical simulants to determine whether the design approach is conservative. Deposition velocity is defined as the velocity below which particles begin to deposit to form a moving bed of particles on the bottom of a straight horizontal pipe during slurry-transport operations. The deposition velocity depends on the system geometry and the physical properties of the particles and fluid.

An experimental program was implemented to test the stability-map concepts presented in WTP-RPT-175 Rev. $0^{1}$. Two types of simulant were tested. The first type of simulant was similar to the glass-bead simulants discussed in WTP-RPT-175 Rev. $0^{1}$; it consists of glass beads with a nominal particle size of $150 \mu \mathrm{m}$ in a kaolin/water slurry. The initial simulant was prepared at a target yield stress of approximately $30 \mathrm{~Pa}$. The yield stress was then reduced, stepwise, via dilution or rheological modifiers, ultimately to a level of $<1 \mathrm{~Pa}$. At each yield-stress step, depositionvelocity testing was performed. Testing over this range of yield-stress bounds the expected rheological operating window of the WTP and allows the results to be compared to stability-map predictions for this system.

The second simulant was a precipitated hydroxide that simulates HLW pretreated sludge from Hanford waste tank AZ-101. Testing was performed in a manner similar to that for the first simulant over a wide range of yield stresses; however, an additional test of net-positive suction-head required $\left(\mathrm{NPSH}_{\mathrm{R}}\right)$ was performed at each yield stress condition. Unlike the previous simulant, the sizes and densities of the particles that can deposit in the piping are a result of the simulant precipitation process; there is expected to be a complex mixture of particles of various sizes and densities that make it difficult to predict a stability map. The objective of the testing is to observe whether behavior consistent with the stability-map concept occurs in complex simulants with mixtures of different sizes and densities.

The major findings of this testing are as follows:

- Experimental results substantiate literature claims of a stable laminar-flow regime for non-Newtonian fluids.

Gillies et al. $(2007)^{2}$ recently published a paper on the topic of particle transport in laminar, non-Newtonian slurries. Industry standard was to use a "rule of thumb" of a $\sim 1.5$ - to $2-\mathrm{kPa} / \mathrm{m}$ pressure-gradient threshold to transport solids in laminar flow. A new criterion was established that relates the ratio of the wall shear stress, $\tau_{\mathrm{w}}$, to the average surficial-particle shear stress, $\tau_{\mathrm{p}}$. Gillies et al. (2007) conclude that "a slurry's proclivity to experience laminar flow settling is greatly reduced when $\tau_{\mathrm{w}} / \tau_{\mathrm{p}}>60$ and nearly eliminated when $\tau_{\mathrm{w}} / \tau_{\mathrm{p}}>100$." This behavior was observed in both simulants with a dramatic rise in deposition velocity as yield stress was decreased from $30 \mathrm{~Pa}$ to moderate values of yield stress in the 5 to $15 \mathrm{~Pa}$ range.

- Experimental results substantiate literature claims of particle deposition occurring near the laminar-to-turbulent transition for non-Newtonian fluids.

\footnotetext{
${ }^{1}$ Poloski AP, HE Adkins, Jr, MJ Minette, J Abrefah, AM Casella, RE Hohimer, F Nigl, JJ Toth, JM Tingey, and ST Yokuda. 2009. Deposition Velocities of Newtonian and Non-Newtonian Slurries in Pipelines. PNNL-17639, WTP-RPT175 Rev. 0, Pacific Northwest National Laboratory, Richland, WA.

${ }^{2}$ Gillies RG, R Sun, RS Sanders, and J Schaan. 2007. "Lowered Expectations: The Impact of Yield Stress on Sand Transport in Laminar, Non-Newtonian Flows." Journal of the South African Institute of Mining and Metallurgy 107(6):351-357.
} 
Cooke (2002) ${ }^{1}$ states the following on the topic of sedimentation in non-Newtonian laminar flows:

It is often assumed that low operating velocities are not a problem for high density thickened tailings and paste mixtures as they are inherently stable and pipelines may be started and shutdown without fear of blockage. However, this is not necessarily the case and when an apparently nonsettling suspension is subjected to shear in laminar flow, the settling rate of the coarse particles is increased significantly. For commercial pipelines operating in laminar flow, there is no effective mechanism for re-suspending settled particles and it is possible that the pipeline may block.

This statement is confirmed for both simulants by the experimental findings of the previous M-1 effort, WTPRPT-175 Rev. $0^{1}$ as well as those presented in this report. Non-Newtonian simulants repeatedly settled at velocities near the predicted laminar-to-turbulent transition. This typically occurred at yield stresses in the range of 1 to $15 \mathrm{~Pa}$. As the yield stress was reduced, the deposition velocity was observed to decrease with the laminar-to-turbulent transition velocity.

- A rheological condition exists in which the deposition velocity reaches a maximum; this should be considered in the design of non-Newtonian pipelines.

The increasing deposition velocity during the transition from stable-laminar to unstable-laminar flow coupled with the decreasing deposition velocity when yield stress drops further and reduces the laminar-to-turbulent transition velocity results in a maximum predicted deposition velocity for non-Newtonian slurries. This is referred to as point $Y$ on the stability maps presented in WTP-RPT-175 Rev. $0^{1}$. Experimental results for the deposition of both simulants tested in this report indicate that this peak occurs at moderate levels of yield stress in the range of 5 to $15 \mathrm{~Pa}$. A robust pipeline design should consider design correlations for Newtonian and nonNewtonian transport. An assessment was performed using this design philosophy on several particle-size and density distributions proposed for the WTP. A summary of the assessment findings follows:

- Within the WTP, a significant fraction of particles is predicted to settle to a stationary bed in the 4-6 ft/sec range under both Newtonian and non-Newtonian conditions

- The settled particles will be predominately of high density or large particle size

- A transport velocity of approximately $10 \mathrm{ft} / \mathrm{sec}$ will maintain turbulent flow in a 3" pipe at the upper end of the rheological operating window (maximum of $30 \mathrm{~Pa}$ Bingham-plastic yield stress and $30 \mathrm{cP}$ consistency). If this is not achievable, a minimum velocity of $6 \mathrm{ft} / \mathrm{sec}$ or greater is recommended for operation under laminar conditions.

- During slurry transfers in the WTP, it is expected that a sediment bed will gradually develop that must be aggressively/periodically flushed to mitigate potential line plugging. Sediment beds are expected to develop faster in larger-diameter pipes. Development of a basis for an aggressive flushing frequency should be supported by further testing.

- The presence of a sliding bed on the pipe bottom is expected to result in increased wear and erosion of the pipe invert (bottom). This problem has been noted in industry $y^{2,3,4,1}$ and other DOE sites ${ }^{2}$. This increased wear on the pipe wall due to sliding bed should be accounted in the WTP piping design calculations.

\footnotetext{
${ }^{1}$ Cooke R (2002) "Laminar flow settling: the potential for unexpected problems." BHRG 15th International Conference on Slurry Handling and Pipeline Transport, Hydrotransport 15; Banff, June. 121-133.

${ }^{2}$ Ricks BL "Slurry Pipeline Transportation" in: AL.Mular, DN.Halbe, DJ.Barratt (editors). 2002. Mineral Processing Plant Design, Practice and Control: Proceedings Society for Mining, Metallurgy and Exploration, Littleton, Colorado.

${ }^{3}$ Miller JE, Schmidt F. 1987. Slurry Erosion: Uses, Applications, and Test Methods: a Symposium. ASTM Committee G-2 on Erosion and Wear. ASTM International

${ }^{4}$ Henday, G. 1988. A comparison of commercial pipe materials intended for the hydraulic transport of solids. Research Report 2988, BHRA, The Fluid Engineering Centre, Cranfield UK
} 
- Flushing at $10 \mathrm{ft} / \mathrm{sec}$ or more should be sufficient to remove the sediment beds. However, re-suspension of particles from a stationary bed involves different mechanics from deposition. The design-basis value for the minimum flush velocity to remove a stationary bed should be supported by further testing.

- Flushing should be performed in the same direction as normal process flow: from the source tank to the destination tank. Back-flushing pipes to source tanks should not be permitted because particles will accumulate in vessels and pipes.

- Flush-system design should be reviewed to assure that all process lines in the WTP meet the conditions listed above.

- Net Positive Suction Head required $\left(\mathrm{NPSH}_{\mathrm{R}}\right)$ is significantly higher for non-Newtonian slurries than that for water.

Test results indicate significant increases in $\mathrm{NPSH}_{\mathrm{R}}$, on the order of 1.5-2 times that for water, can be expected for slurry flows when air is not retained in the slurry. When air is retained in the slurry, the apparent NPSHR increases by a factor of 2-3 times that specified for water. Additionally, pump manufacturers typically report "slurry" pump performance capability with the discharge side wide open and using water as the test fluid. As such, additional engineering margins over accepted industrial practice should be added for $\mathrm{NPSH}_{\mathrm{R}}$ design specifications in the WTP.

\footnotetext{
${ }^{1}$ Brown NP, Heywood NI (Editors). 1991. Slurry Handling: Design of solid-liquid systems. Springer.

${ }^{2}$ Poirier MR. 2000. Minimum Velocity Required to Transport Solid Particles from the $2 H$-Evaporator to the Tank Farm. WSRC-TR-2000-00263. Westinghouse Savannah River Company Aiken, SC 29808
} 



\section{Testing Summary}

The U.S. Department of Energy (DOE) Office of River Protection's Waste Treatment and Immobilization Plant (WTP) will process and treat radioactive waste in the underground storage tanks at the Hanford Site. Piping, pumps, and mixing vessels will transport, store, and mix the high-level waste (HLW) slurries in the WTP.

The WTP pipe-plugging issue, as stated by the External Flowsheet Review Team (EFRT) Executive Summary, is as follows: "Piping that transports slurries will plug unless it is properly designed to minimize this risk. This design approach has not been followed consistently, which will lead to frequent shutdowns due to line plugging." Additional details relating to the EFRT summary are provided in a supplemental background document. ${ }^{2}$ The WTP Project is implementing a strategy to address the above EFRT issue identified as "Issue M1—Plugging in Process Piping."

An initial phase of M-1 testing produced a report (WTP-RPT-175 Rev $0^{3}$ ) which shows that pipeline transport of moderately thick, non-Newtonian slurries may result in a higher deposition velocity than diluted Newtonian counterparts. This idea was presented in the form of so-called "stability maps" that show different flow regimes that can occur based on the rheological properties of the slurry.

This work presents the results of an experimental program that was implemented to test the stability-map concepts described in the WTP-RPT-175 Rev 0 report. Two types of simulant were tested. The first type of simulant was similar to the glass-bead simulants discussed in WTP-RPT-175 Rev. 0. The simulant consists of glass beads with a nominal particle size of $150 \mu \mathrm{m}$ in a kaolin/water slurry. The initial simulant was prepared at a target yield stress of approximately $30 \mathrm{~Pa}$. The yield stress was then reduced stepwise, via dilution or rheological modifiers, ultimately to a level of $<1 \mathrm{~Pa}$. At each yield-stress step, deposition-velocity testing was performed. Testing over this yield-stress range bounds the expected rheological operating window of the WTP and allows the results to be compared to stability-map predictions for this system.

The second simulant was a precipitated hydroxide that simulates HLW pretreated sludge from Hanford tank AZ-101. Testing was performed in a manner similar to that for the first simulant over a wide range of yield stresses; however, an additional test of net-positive suction-head required $\left(\mathrm{NPSH}_{\mathrm{R}}\right)$ was performed at each yield-stress condition. Unlike the previous simulant, the sizes and densities of the particles that can deposit in the piping are a result of the simulant precipitation process; there is expected to be a complex mixture of particles of various sizes and densities that make it difficult to predict a stability map. The objective of the testing is to observe whether behavior consistent with the stability-map concept is observed in complex simulants with mixtures of different sizes and densities.

An experimental flow loop was constructed of approximately 100 feet of 3-inch schedule 40 piping taken from the WTP excess yard. The flow loop components included a four-baffled, 400-gallon mixing tank with a 25 -inch pitched-blade impeller. A Georgia Iron Works slurry pump, a 150-psig, 400-gallon pneumatic flush system, and a 1,000-gallon capture tank complete the flow-loop system. The flow loop also has instrumentation for determining

${ }^{1}$ WTP Project Doc. No. CCN 132846 "Comprehensive Review of the Hanford Waste Treatment Plant Flowsheet and Throughput-Assessment Conducted by an Independent Team of External Experts," March 2006. Available online at: http://www.hanford.gov/orp/uploadfiles/WTP\%20Flowsheet\%20Background\%20Report FINAL\%20DRAFT March06.pdf. Accessed 03/02/09.

${ }^{2}$ WTP Project Doc. No. CCN 132847 "Background Information and Interim Reports for the Comprehensive Review of the Hanford Waste Treatment Plant Flowsheet and Throughput - Assessment Conducted by an Independent Team of External Experts," March 2006.

${ }^{3}$ Poloski AP, HE Adkins, Jr, MJ Minette, J Abrefah, AM Casella, RE Hohimer, F Nigl, JJ Toth, JM Tingey, and ST Yokuda. 2009. "Deposition Velocities of Newtonian and Non-Newtonian Slurries in Pipelines." PNNL-17639, WTPRPT-175 Rev 0, Pacific Northwest National Laboratory, Richland, WA. 
flow rate with inlet and outlet Micro Motion Coriolis F-Series meters. The pressure gradient and pump inlet and outlet pressures were measured with Rosemount 1151 differential pressure transducers. The particle size chordlength distribution was measured with a Lasentec ${ }^{\mathrm{TM}}$ focused-beam reflectance measurement (FBRM) sensor. Lastly, a cross-sectional pipe tomogram of slurry conductivity was measured using a P2000 electrical-resistance tomography system manufactured by ITS (Industrial Tomography Systems PLC). Further details of test apparatus can be found in WTP-RPT-175 Rev 0.

At the beginning of a test, the slurry flow velocity was nominally set to $8 \mathrm{ft} / \mathrm{sec}$. The flow was then decreased incrementally, and at each flow condition a pressure-gradient-versus-time signature was obtained. A rise in pressure gradient as the flow rate drops indicates that the pipe cross-sectional area was beginning to fill with sediment; this point is referred to as the "deposition velocity." This velocity typically corresponds to the point where a moving bed of particles begins to deposit on the bottom of a straight horizontal pipe during slurry-transport operations. This should not be confused with the laminar-to-turbulent transition velocity, which was referred to as the "transition velocity." $\mathrm{NPSH}_{\mathrm{R}}$ testing using non-Newtonian $\mathrm{HLW}$ simulant was also carried out under conditions and procedures specified by the Hydraulic Institute in the ANSI/HI 1.6-2000 manual, American National Standard for Centrifugal Pump Tests.

Deposition velocity test results for both simulants are shown in Figure S.1. Both sets of results show similar behavior of deposition occurring along the laminar to turbulent transition velocity. Since the transition velocity increases with yield stress, the deposition velocity also increases to a point where the yield stress produces a pressure gradient that is large enough to push the particles through the pipe in a stable laminar flow regime. This results in a maximum deposition velocity that typically occurs under moderate levels of yield stress in the range of 5 to $15 \mathrm{~Pa}$.

A summary of all of the M-1 deposition velocity data is shown in Figure S.2. The data considered include experimental results from Poloski et al. (2009; WTP-RPT-175 Rev 0) and this report. Features from a stability map are clearly seen in this plot. A maximum is observed under Newtonian conditions, when the Casson number is zero. The deposition Reynolds number dramatically drops to a minimum. The majority of the data then follows the transition Reynolds number to a second maximum. When stable laminar flow is achieved, the deposition Reynolds number drops to zero. In the case of the $10 \mu \mathrm{m}$ glass beads, the stable laminar flow regime begins immediately and the only maximum observed is under Newtonian conditions. Due to the presence of two maximum values for deposition in pipelines, a design philosophy that considers both Newtonian and non-Newtonian conditions is appropriate. Also note that segregation of particles by size and density was observed in these experiments. The coarse particles including $10 \mu \mathrm{m}$ stainless steel, $50 \mu \mathrm{m}$ alumina, $100 \mu \mathrm{m}$ stainless steel, $100 \mu \mathrm{m}$ stainless steel, and $150 \mu \mathrm{m}$ glass beads separated from the kaolin particles into a bed at the bottom of pipe. Some fraction of the AZ101 HLW simulant particles also separated from the bulk material into a bed at the bottom of the pipe. The point at which stable laminar flow is attained depends on the physical properties of these segregated particles, which include the size and density of the particles in the bed. 

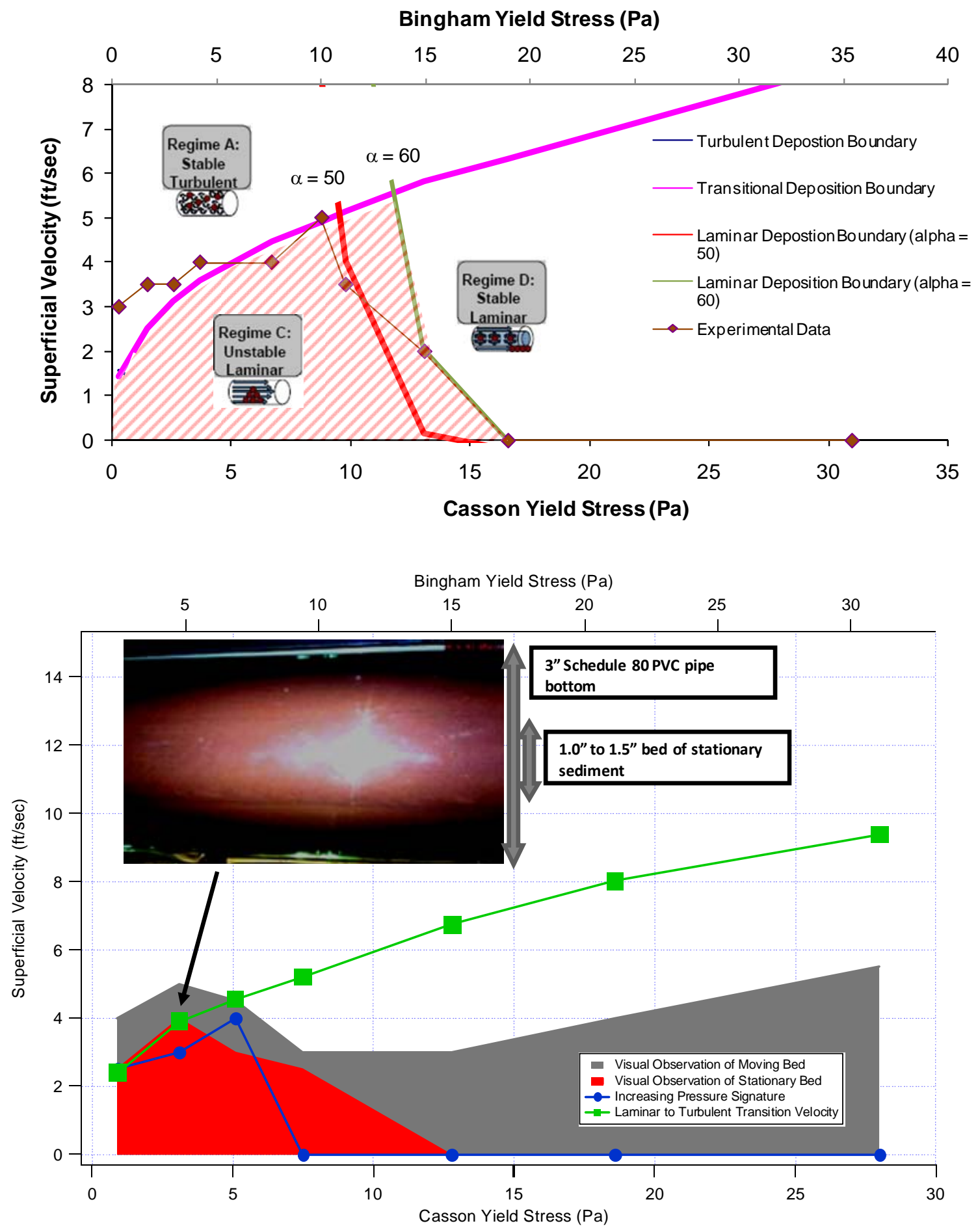

Figure S.1. Deposition Velocity Test Results for $150 \mu \mathrm{m}$ Glass Beads \& Kaolin Slurry (Top) and AZ-101 HLW Pretreated Simulant (Bottom) 


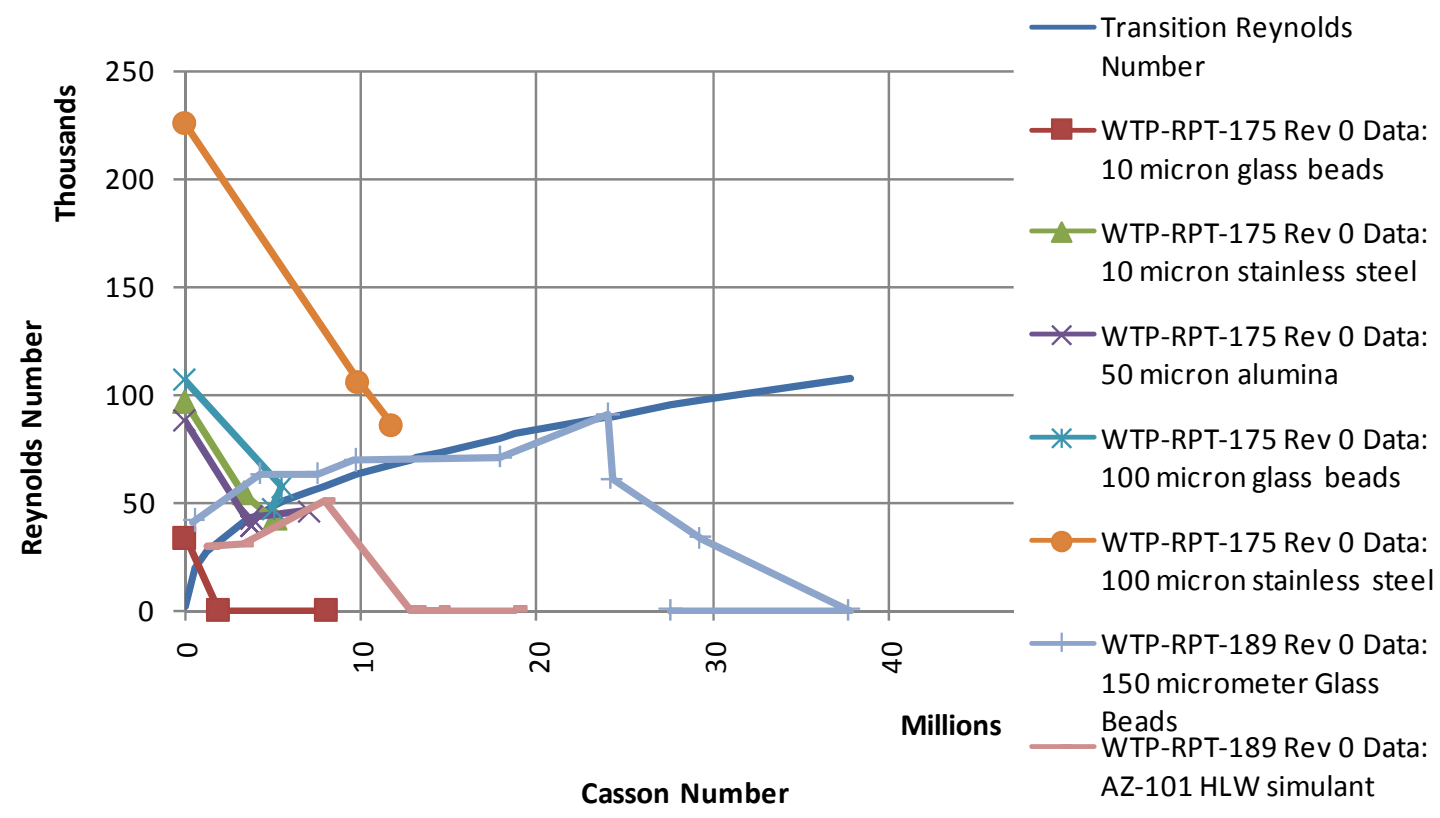

Figure S.2. Plot of Reynolds Number at Deposition for all Experimental Data from the M-1 Project; Reynolds Number at the Laminar to Turbulent Transition is also Plotted.

$\mathrm{NPSH}_{\mathrm{R}}$ test results for AZ-101 HLW pretreated simulant are shown in Table S.1. This simulant had a susceptibility to retain air from the agitation system. The retained air resulted in a substantial increase in apparent $\mathrm{NPSH}_{\mathrm{R}}$. Addition of anti-foam agent (AFA) for the final two tests decreased amount of entrained air and reduced the measured $\mathrm{NPSH}_{\mathrm{R}}$. However, even with the AFA added, the AZ-101 HLW pretreated simulant still showed a significant increase over the values provided by the manufacturer for water. Control tests with tap water confirmed the manufacturers published $\mathrm{NPSH}_{\mathrm{R}}$ data for this pump.

Table S.1. Summary of Apparent Net Positive Suction Head Required (NPSH ${ }_{\mathrm{R}}$ ) Results

\begin{tabular}{llll}
\hline $\begin{array}{l}\text { Casson Yield } \\
\text { Stress (Pa) }\end{array}$ & $\begin{array}{l}\text { Bingham Yield } \\
\text { Stress (Pa) }\end{array}$ & AFA added? & $\begin{array}{l}\text { Average \% increase from manufacturers } \\
\text { NPSH }_{\mathrm{R}} \text { data for water }(>130 \mathrm{gal} / \mathrm{min})\end{array}$ \\
\hline 28.0 & 33.2 & No & $210 \pm 20 \%$ \\
18.6 & 22.7 & No & $170 \pm 23 \%$ \\
12.8 & 15.9 & No & $220 \pm 39 \%$ \\
7.5 & 9.6 & No & $270 \pm 77 \%$ \\
5.1 & 6.9 & No & $290 \pm 69 \%$ \\
2.6 & 4.0 & No & $170 \pm 27 \%$ \\
3.1 & 4.6 & Yes & $51 \pm 15 \%$ \\
0.9 & 1.5 & Yes & $52 \pm 6 \%$ \\
0 (water) & 0 (water) & No & $-7 \pm 3 \%$ \\
\hline
\end{tabular}


Based on these results and subsequent analysis, the following conclusions can be made with respect to the test results discussed in this report:

- Experimental results substantiate literature claims of a stable laminar-flow regime for non-Newtonian fluids.

Gillies et al. $(2007)^{1}$ recently published a paper on the topic of particle transport in laminar, non-Newtonian slurries. Industry standard was to use a "rule of thumb" of a $\sim 1.5$ - to $2-\mathrm{kPa} / \mathrm{m}$ pressure-gradient threshold to transport solids in laminar flow. A new criterion was established that relates the ratio of the wall shear stress, $\tau_{\mathrm{w}}$, to the average surficial-particle shear stress. Gillies et al. (2007) conclude that "a slurry's proclivity to experience laminar flow settling is greatly reduced when $\tau_{\mathrm{w}} / \tau_{\mathrm{p}}>60$ and nearly eliminated when $\tau_{\mathrm{w}} / \tau_{\mathrm{p}}>100$." This behavior was observed in both simulants with a dramatic rise in deposition velocity as yield stress was decreased from $30 \mathrm{~Pa}$ to moderate values of yield stress in the 5 to $15 \mathrm{~Pa}$ range.

- Experimental results substantiate literature claims of particle deposition occurring near the laminar-to-turbulent transition for non-Newtonian fluids.

Cooke $(2002)^{2}$ states the following on the topic of sedimentation in non-Newtonian laminar flows:

It is often assumed that low operating velocities are not a problem for high density thickened tailings and paste mixtures as they are inherently stable and pipelines may be started and shutdown without fear of blockage. However, this is not necessarily the case and when an apparently nonsettling suspension is subjected to shear in laminar flow, the settling rate of the coarse particles is increased significantly. For commercial pipelines operating in laminar flow, there is no effective mechanism for re-suspending settled particles and it is possible that the pipeline may block.

This statement is confirmed for both simulants by the experimental findings of the previous M-1 effort, WTPRPT-175 Rev. 0 as well as those presented in this report. Non-Newtonian simulants repeatedly settled at velocities near the predicted laminar-to-turbulent transition. This typically occurred at yield stresses in the range of 1 to $15 \mathrm{~Pa}$. As the yield stress was reduced, the deposition velocity was observed to decrease with the laminar-to-turbulent transition velocity.

- A rheological condition exists in which the deposition velocity reaches a maximum; this should be considered in the design of non-Newtonian pipelines.

The increasing deposition velocity during the transition from stable-laminar to unstable-laminar flow coupled with the decreasing deposition velocity when yield stress drops further and reduces the laminar-to-turbulent transition velocity results in a maximum predicted deposition velocity for non-Newtonian slurries. This is referred to as point $Y$ on the stability maps presented in WTP-RPT-175 Rev 0. Experimental results for the deposition of both simulants tested in this report indicate that this peak occurs at moderate levels of yield stress in the range of 5 to $15 \mathrm{~Pa}$. A robust pipeline design should consider design correlations for Newtonian and nonNewtonian transport. An assessment was performed using this design philosophy on several particle-size and density distributions proposed for the WTP. A summary of the assessment findings follows:

- Within the WTP, a significant fraction of particles is predicted to settle to a stationary bed in the 4-6 ft/sec range under both Newtonian and non-Newtonian conditions

- The settled particles will be predominately of high density or large particle size

\footnotetext{
${ }^{1}$ Gillies RG, R Sun, RS Sanders, and J Schaan. 2007. "Lowered Expectations: The Impact of Yield Stress on Sand Transport in Laminar, Non-Newtonian Flows.” Journal of the South African Institute of Mining and Metallurgy 107(6):351-357.

2 Cooke R (2002) “Laminar flow settling: the potential for unexpected problems.” BHRG 15th International Conference on Slurry Handling and Pipeline Transport, Hydrotransport 15; Banff, June. 121-133.
} 
- A transport velocity of approximately $10 \mathrm{ft} / \mathrm{sec}$ will maintain turbulent flow in a 3" pipe at the upper end of the rheological operating window (maximum of $30 \mathrm{~Pa}$ Bingham-plastic yield stress and $30 \mathrm{cP}$ consistency). If this is not achievable, a minimum velocity of $6 \mathrm{ft} / \mathrm{sec}$ or greater is recommended for operation under laminar conditions.

- During slurry transfers in the WTP, it is expected that a sediment bed will gradually develop that must be aggressively/periodically flushed to mitigate potential line plugging. Sediment beds are expected to develop faster in larger-diameter pipes. Development of a basis for an aggressive flushing frequency should be supported by further testing.

- The presence of a sliding bed on the pipe bottom is expected to result in increased wear and erosion of the pipe invert (bottom). This problem has been noted in industry ${ }^{1,2,3,4}$ and other DOE sites ${ }^{5}$. This increased wear on the pipe wall due to sliding bed should be accounted in the WTP piping design calculations.

- Flushing at $10 \mathrm{ft} / \mathrm{sec}$ or more should be sufficient to remove the sediment beds. However, re-suspension of particles from a stationary bed involves different mechanics from deposition. The design-basis value for the minimum flush velocity to remove a stationary bed should be supported by further testing.

- Flushing should be performed in the same direction as normal process flow: from the source tank to the destination tank. Back-flushing pipes to source tanks should not be permitted because particles will accumulate in vessels and pipes.

- Flush-system design should be reviewed to assure that all process lines in the WTP meet the conditions listed above.

- Net Positive Suction Head required $\left(\mathrm{NPSH}_{\mathrm{R}}\right)$ is significantly higher for non-Newtonian slurries than that for water.

Test results indicate significant increases in $\mathrm{NPSH}_{R}$, on the order of 1.5-2 times that for water, can be expected for slurry flows when air is not retained in the slurry. When air is retained in the slurry, the apparent NPSHR increases by a factor of 2-3 times that specified for water. Additionally, pump manufacturers typically report "slurry" pump performance capability with the discharge side wide open and using water as the test fluid. As such, additional engineering margins over accepted industrial practice should be added for $\mathrm{NPSH}_{\mathrm{R}}$ design specifications in the WTP.

\footnotetext{
${ }^{1}$ Ricks BL "Slurry Pipeline Transportation" in: AL.Mular, DN.Halbe, DJ.Barratt (editors). 2002. Mineral Processing Plant Design, Practice and Control: Proceedings Society for Mining, Metallurgy and Exploration, Littleton, Colorado.

${ }^{2}$ Miller JE, Schmidt F. 1987. Slurry Erosion: Uses, Applications, and Test Methods: a Symposium. ASTM Committee G-2 on Erosion and Wear. ASTM International

${ }^{3}$ Henday, G. 1988. A comparison of commercial pipe materials intended for the hydraulic transport of solids. Research Report 2988, BHRA, The Fluid Engineering Centre, Cranfield UK

${ }^{4}$ Brown NP, Heywood NI (Editors). 1991. Slurry Handling: Design of solid-liquid systems. Springer.

${ }^{5}$ Poirier MR. 2000. Minimum Velocity Required to Transport Solid Particles from the $2 H$-Evaporator to the Tank Farm. WSRC-TR-2000-00263. Westinghouse Savannah River Company Aiken, SC 29808
} 


\section{S.1 Test Objectives}

The objectives are specified in Test Specification 24590-WTP-TSP-RT-07-005, Rev. 0 (BNI 2007) and Test Exception 24590-WTP-TEF-RT-08-00008, Rev. 0 and test results are discussed in Table S.2.

Table S.2. Test Objectives and Results

\begin{tabular}{|c|c|c|}
\hline Test Objective & $\begin{array}{l}\text { Objective Met? } \\
\text { (Yes/No) }\end{array}$ & Results \\
\hline $\begin{array}{l}\text { Perform deposition velocity tests } \\
\text { with complex simulants with wide } \\
\text { distributions of particle size and } \\
\text { density }\end{array}$ & Yes & $\begin{array}{l}\text { Testing was performed on a simulant of HLW pretreated } \\
\text { sludge. The deposition results over a wide range of yield } \\
\text { stresses exhibit behavior consistent with the stability-map } \\
\text { concept presented in WTP-RPT-175 Rev } 0 \text {. }\end{array}$ \\
\hline $\begin{array}{l}\text { Measure the affect of complex } \\
\text { simulants on pump Net Positive } \\
\text { Suction Head required }\left(\mathrm{NPSH}_{\mathrm{R}}\right)\end{array}$ & Yes & $\begin{array}{l}\text { Test results indicate significant increases in } \mathrm{NPSH}_{\mathrm{R}} \text {, on } \\
\text { the order of } 1.5-2 \text { times that for water, can be expected } \\
\text { for slurry flows when air is not retained in the slurry. } \\
\text { When air is retained in the slurry, the apparent NPSHR } \\
\text { increases by a factor of } 2-3 \text { times that specified for water. } \\
\text { Additionally, pump manufacturers typically report } \\
\text { "slurry" pump performance capability with the discharge } \\
\text { side wide open and using water as the test fluid. As such, } \\
\text { additional engineering margins over accepted industrial } \\
\text { practice should be added for NPSH } \\
\text { in the WTP. Entrained air can be avoided by } \\
\text { incorporifications } \\
\text { dip tubes on return lines, and installing "vacuum } \\
\text { accumulators" to remove bubbles on suction lines of } \\
\text { pumping systems. }\end{array}$ \\
\hline
\end{tabular}




\section{S.2 Test Exception}

A single test exception, 24590-WTP-TEF-RT-08-00008, Rev. 0, was applied to Test Specification 24590-WTPTSP-RT-07-005, Rev. 0 (BNI 2007). The description of the Test Exception is shown in Table S.3.

Table S.3. Test Exception

\begin{tabular}{ll}
\hline Test Exceptions & Test Exception Description \\
\hline 24590-WTP-TEF-RT-08-00008, & The simulants tested during the reference-case tests under the previous \\
Rev. 0 & revision of this test plan were simple in order to avoid complexities \\
associated with the interaction of large/small and dense/less-dense particles, \\
which could make comparison to published correlations difficult. The \\
results stemming from the previously identified scope have been reported in \\
report WTP-RPT-175, Rev. 0 . In these tests, each simulant was made of a \\
single nominal particle size and density, with kaolin clay added to modify \\
rheology. However, when processing the Hanford waste slurries, the size \\
and density pairing of the slurry particles will likely be unknown. Hanford \\
slurry is expected to be complex mixtures of particles with a broad \\
distribution of chemistry, particle density, and particle size. \\
Given this scenario, it would be beneficial to perform tests with a complex \\
Hanford simulant with representative particle size and density combinations \\
in the same geometry (test loop) as the reference case tests were conducted. \\
Performance of this demonstration is supported from within the project, the \\
Department of Energy, and external consultants. As such, Test Exception \\
Number: $24590-W T P-T E F-R T-08-00008$, Rev. 0 was created to facilitate \\
this type of testing. The purpose of these proposed tests is to determine the \\
effect of mixed particle sizes and densities on transport velocity. Since all \\
previous testing has been with narrow distributions, these tests are necessary \\
to close the remaining data gaps. In addition, hands-on experience with \\
materials similar to tank waste, albeit non-radioactive, will be useful in \\
building confidence in the final design.
\end{tabular}




\title{
S.3 Results and Performance Against Success Criteria
}

The success criteria are specified in test exception 24590-WTP-TEF-RT-08-00008, Rev. 0 to test specification 24590-WTP-TSP-RT-07-005, Rev. 0 (BNI 2007), and test results are discussed in Table S.4.

Table S.4. Success Criteria and Results

\begin{tabular}{l} 
Success Criteria \\
\hline Determine the deposition velocity of a complex \\
Hanford simulant with wide distributions of both \\
particle size and density. \\
Determine residual solids accumulation (amount \\
and accumulation trend) in line after prototypic \\
flush (1.5 times pipe volume at slurry deposition \\
velocity) and after transfer at predicted deposition \\
velocity
\end{tabular}

Results

Success criterion was met. The deposition results over a wide range of yield stresses exhibit behavior consistent with the stability-map concept presented in WTP-RPT-175 Rev 0.

\begin{abstract}
Success criterion was not met. The M1 flow loop is a closed-loop system with a 500-gallon maximum capacity. A prototypic transfer at the WTP can consist of several tens of thousands of gallons of simulant. Assume that the volume fraction of slurry that can settle under the minimum transport conditions is $X$. The total volume of material that can settle in the recirculation flow loop is $500 \mathrm{gal} \times X$. Assuming a single batch transfer volume at WTP of 20,000 gallons, the total volume of material that can settle in the recirculation flow loop is $20,000 \mathrm{gal} \times X$. To complicate matters further, the cross section of pipe filled with this sediment depends on the volume of the pipe run. Therefore, the filled cross section of the pipe at the beginning of a flush may not be representative of the WTP operating conditions. Determine the status of the sediment level after several transfer \& flush cycles will be even less representative. For this reason, the residual amount of solids determined through M1 flow loop testing at a specified transfer velocity is ambiguous.
\end{abstract}

Determine the effect of complex simulants on pump NPSH required.

Success criterion was met. Test results indicate that gas retention has a large effect on NPSH required. An increase in the range of 2 to 3 times that of the NPSH required for water was observed with retained gas. After anti-foam agent was added, this value was reduced to around a 1.5 times increase of the NPSH required for water.

\section{S.4 Quality Requirements}

PNNL's Quality Assurance Program is based on requirements defined in U.S. Department of Energy (DOE) Order 414.1C, Quality Assurance, and 10 CFR 830, Energy/Nuclear Safety Management, Subpart A-Quality Assurance Requirements (a.k.a. the Quality Rule). PNNL has chosen to implement the requirements of DOE Order 414.1C and 10 CFR 830, Subpart A by integrating them into the Laboratory's management systems and daily operating processes. The procedures necessary to implement the requirements are documented through PNNL's Standards-Based Management System.

PNNL implements the RPP-WTP quality requirements by performing work in accordance with the River Protection Project-Waste Treatment Plant Support Program (RPP-WTP) Quality Assurance Plan (RPP-WTP-QA- 
001, QAP). Work was performed to the quality requirements of NQA-1-1989 Part I, Basic and Supplementary Requirements, NQA-2a-1990, Part 2.7, and DOE/RW-0333P, Rev 13, Quality Assurance Requirements and Descriptions (QARD). These quality requirements are implemented through the River Protection Project-Waste Treatment Plant Support Program (RPP-WTP) Quality Assurance Manual (RPP-WTP-QA-003, QAM).

\section{S.5 Test Conditions}

Test conditions were controlled with administrative hold points. Several hold points are indentified in the Test Condition section of Test Exception 24590-WTP-TEF-RT-08-00008, Rev. 0 to Test Specification 24590-WTP-TSPRT-07-005, Rev. 0 (BNI 2007). These hold points were translated into PNNL Test Plan TP-RPP-WTP-493, Rev. 1. The status of each of the hold points is summarized in Table S.5.

Table S.5. Status of Project Hold Points

\begin{tabular}{llll}
\hline Test Plan & Hold Point & Approved On & $\begin{array}{l}\text { WTP Project } \\
\text { Document Number }\end{array}$ \\
\hline & $\begin{array}{l}\text { \#4 Ramp down and incremental velocity } \\
\text { comparison. }\end{array}$ & $12 / 4 / 08$ & $\begin{array}{l}\text { WTP/RPP-MOA- } \\
\text { PNNL-00329 }\end{array}$ \\
$\begin{array}{l}\text { TP-RPP-WTP-493, } \\
\text { Rev. 1 }\end{array}$ & $\begin{array}{l}\text { \#5 Data package of physical property } \\
\text { information for the complex simulant } \\
\text { \#6 Calculation package for predicted } \\
\text { Deposition velocities }\end{array}$ & $10 / 22 / 08$ & $\begin{array}{l}\text { WTP/RPP-MOA- } \\
\text { PNNL-00293 }\end{array}$ \\
& 12/4/08 & $\begin{array}{l}\text { WTP/RPP-MOA- } \\
\text { PNNL-00329 }\end{array}$ \\
\hline
\end{tabular}

\section{S.6 Simulant Use}

Physical simulants were used in this testing. The simple simulant (kaolin/glass beads) is not chemically representative of the actual materials being transported in the WTP. The complex simulant (AZ-101 pretreated HLW) is, however, chemically representative of the actual materials being transported in the WTP. In addition, the physical properties of both the simple and complex simulants including the particle size, density, and rheological properties of are representative of a subset of Hanford waste particles that will be transported in the WTP. As discussed in the Test Conditions section, hold point \#5 allowed Bechtel National, Inc. (BNI) to review and accept the test-simulant physical-property data before testing. A detailed description of simulant properties is presented in this report.

\section{S.7 Discrepancies and Follow-on Tests}

- Discrepancy \#1 - During the AZ-101 HLW simulant tests, entrainment of gas in the slurries was observed. For the final two tests, anti-foaming agent (AFA) was added to mitigate this entrainment. The addition of AFA to the simulant corresponds with better agreement in the bulk densities measurements between the in-situ Coriolis flow meters and the gravimetric results from flow loop samples. Entrained gas is a known problem for Coriolis flow meters. Heywood and Mehta (1996) ${ }^{1}$ report that entrained air degraded meter performance, to the point where measured and actual flow rates varied by $15 \%$. AZ-101 HLW simulant tests with AFA and glassbead/kaolin slurry tests appear not to have gas-retention issues.

\footnotetext{
${ }^{1}$ Heywood NI and KB Mehta. 1996. "The performance of Commercially-Available Coriolis Mass Flowmeters Applied to Industrial Slurries.” Proc. Hydrotransport 13, BHR Group, Cranfield, U.K., 719-747
} 
- Follow-on Test Recommendation \#1 - During slurry transfers in the WTP, a sediment bed is expected to develop gradually and must be aggressively flushed to mitigate potential line plugging. Sediment beds are expected to develop faster in larger-diameter pipes. Development of a basis for an aggressive flushing frequency should be supported by further testing.

- Follow-on Test Recommendation \#2 - Flushing at $10 \mathrm{ft} / \mathrm{sec}$ or greater should be sufficient to remove the sediment beds. However, re-suspension of particles from a stationary bed involves different mechanics from deposition. The design-basis value for the minimum flush velocity to remove a stationary bed should be supported by further testing. 



\section{Acronyms and Abbreviations}

BNI Bechtel National, Inc.

BNI-SP BNI Support Program

CFR Code of Federal Regulations

DOE U.S. Department of Energy

EFRT External Flowsheet Review Team

ERT electrical-resistance tomography

HLW high level waste

ITS Industrial Tomography Systems PLC

LAW low-activity waste

NIST National Institute of Standards and Technology

PNNL Pacific Northwest National Laboratory

PSD particle-size distribution

PSDD particle-size and density distribution

QA quality assurance

QAM Quality Assurance Manual

QAP Quality Assurance Plan

QARD Quality Assurance Requirements and Descriptions

RPP River Protection Project

WTP Hanford Waste Treatment and Immobilization Plant 



\section{Nomenclature}

Ar the Archimedes Number can be defined as the ratio of gravitational forces on the particle corrected for buoyancy to viscous forces on the particle

$A r_{\infty}$ the Archimedes Number defined for non-Newtonian fluids using an infinite shear viscosity

$\mathrm{Ca}$ the Casson Number

$d \quad$ particle diameter

$D \quad$ pipe inner diameter

$d_{50} \quad 50 \mathrm{vol} \%$ of particles are smaller than this particle diameter

$d_{95} \quad 95 \mathrm{vol} \%$ of particles are smaller than this particle diameter

$d_{99} \quad 99 \mathrm{vol} \%$ of particles are smaller than this particle diameter

$D_{y} \quad$ separation distance between the particles at the point of yielding

$\mathrm{Fr} \quad$ the Froude Number can be defined as the ratio of inertial forces in the fluid flow to the gravitational forces the particle must overcome to stay suspended in the flow

$g$ gravitational acceleration

$\mathrm{He}$ the Hedstrom number, a dimensionless parameter used for predicting flow regime

NPSH Net Positive Suction Head can be expressed as the difference between the Suction Head and the Liquid Vapor Head; measured in units of head of liquid pumped

$\mathrm{NPSH}_{\mathrm{A}}$ The Net Positive Suction Head made available the suction system for the pump; measured in units of head of liquid pumped

$\mathrm{NPSH}_{\mathrm{R}}$ Net Suction Head as required by the pump in order to prevent cavitation for safe and reliable operation of the pump; measured in units of head of liquid pumped; termed "apparent $\mathrm{NPSH}_{\mathrm{R}}$ " if reduction in pump performance is due to entrained gas

L Length of pipe

Re Reynolds number, the ratio of inertial forces to viscous forces

$R e_{t} \quad$ Reynolds number at the laminar-to-turbulent flow transition velocity

$S \quad$ ratio of the density of the coarse solids to the density of the carrier fluid, $\rho_{S} / \rho_{f}$

$V \quad$ fluid bulk velocity

$v^{\prime} \quad$ eddy-velocity fluctuations

$V_{t} \quad$ the laminar-to-turbulent flow transition velocity

$V_{T} \quad$ the Thomas (1979) deposition velocity

$\alpha \quad$ the ratio of the wall shear stress, $\tau_{\mathrm{w}}$, to the average surficial particle shear stress, $\tau_{\mathrm{p}}$

$\dot{\gamma} \quad$ shear rate

$\Delta \mathrm{P} \quad$ Pressure drop

$\eta \quad$ the Newtonian viscosity

$\mu_{B} \quad$ the Bingham-plastic infinite-shear viscosity

$\mu_{C} \quad$ the Casson infinite-shear viscosity

$\mu_{f} \quad$ carrier-fluid dynamic viscosity 
$\xi \quad$ the dimensionless ratio of fluid yield stress to shear stress at the pipe wall, $\tau_{y} / \tau_{w}$

$\begin{array}{ll}\rho_{f} & \text { fluid or slurry density } \\ \rho_{m} & \text { the slurry mixture density } \\ \tau & \text { shear stress } \\ \tau_{B} & \text { the Bingham yield stress } \\ \tau_{C} & \text { the yield-stress fit to the Casson fluid model } \\ \tau_{p} & \text { average surficial particle shear stress } \\ \tau_{w} & \text { wall shear stress }\end{array}$




\subsection{Introduction}

The U.S. Department of Energy (DOE) Office of River Protection's Waste Treatment and Immobilization Plant (WTP) will process and treat radioactive waste in the underground storage tanks at the Hanford Site. Piping, pumps, and mixing vessels will transport, store, and mix the high-level waste (HLW) slurries in the WTP.

The WTP pipe-plugging issue, as stated by the External Flowsheet Review Team (EFRT) Executive Summary, is as follows: "Piping that transports slurries will plug unless it is properly designed to minimize this risk. This design approach has not been followed consistently, which will lead to frequent shutdowns due to line plugging." Additional details relating to the EFRT summary are provided in a supplemental background document. ${ }^{2}$ The WTP Project is implementing a strategy to address the above EFRT issue identified as "Issue M1—Plugging in Process Piping."

An experimental program that was implemented to test the stability-map concepts is described in Section 3.0 of this report. Two types of simulant were tested. The first type of simulant was similar to the glass-bead simulants discussed in WTP-RPT-175 Rev. 0 (Poloski et al. 2009). The simulant consists of glass beads with a nominal particle size of $150 \mu \mathrm{m}$ in a kaolin/water slurry. The initial simulant was prepared at a target yield stress of approximately $30 \mathrm{~Pa}$. The yield stress was then reduced stepwise, via dilution or rheological modifiers, ultimately to a level of $<1 \mathrm{~Pa}$. At each yield-stress step, deposition-velocity testing was performed. Testing over this yield-stress range bounds the expected rheological operating window of the WTP and allows the results to be compared to stability-map predictions for this system.

The second simulant was a precipitated hydroxide that simulates HLW pretreated sludge from tank AZ-101. Testing was performed in a manner similar to that for the first simulant over a wide range of yield stresses; however, an additional test of net-positive suction-head required $\left(\mathrm{NPSH}_{\mathrm{R}}\right)$ was performed at each yield-stress condition. Unlike the previous simulant, the sizes and densities of the particles that can deposit in the piping are a result of the simulant precipitation process; there is expected to be a complex mixture of particles of various sizes and densities that make it difficult to predict a stability map. The objective of the testing is to observe whether behavior consistent with the stability-map concept is observed in complex simulants with mixtures of different sizes and densities. Details of physical and rheological properties of the simulants can be found in Section 5 .

An experimental flow loop was constructed of approximately 100 feet of 3 -inch schedule 40 piping taken from the WTP excess yard. The flow loop components included a four-baffled, 400-gallon mixing tank with a 25 -inch pitched-blade impeller. A Georgia Iron Works slurry pump, a 150-psig, 400-gallon pneumatic flush system, and a 1,000-gallon capture tank complete the flow-loop system. The flow loop also has instrumentation for determining flow rate with inlet and outlet Micro Motion Coriolis F-Series meters. The pressure gradient and pump inlet and outlet pressures were measured with Rosemount 1151 differential pressure transducers. The particle size chordlength distribution was measured with a Lasentec ${ }^{\mathrm{TM}}$ focused-beam reflectance measurement (FBRM) sensor. Lastly, a cross-sectional pipe tomogram of slurry conductivity was measured using a P2000 electrical-resistance tomography system manufactured by ITS. Further details of test apparatus can be found in WTP-RPT-175 Rev 0 (Poloski et al. 2009).

At the beginning of a test, the slurry flow velocity was nominally set to $8 \mathrm{ft} / \mathrm{sec}$. The flow was then decreased incrementally, and at each flow condition a pressure-gradient-versus-time signature was obtained. A rise in pressure

\footnotetext{
${ }^{1}$ WTP Project Doc. No. CCN 132846 "Comprehensive Review of the Hanford Waste Treatment Plant Flowsheet and Throughput-Assessment Conducted by an Independent Team of External Experts," March 2006.

${ }^{2}$ WTP Project Doc. No. CCN 132847 "Background Information and Interim Reports for the Comprehensive Review of the Hanford Waste Treatment Plant Flowsheet and Throughput - Assessment Conducted by an Independent Team of External Experts," March 2006.
} 
gradient as the flow rate drops indicates that the pipe cross-sectional area was beginning to fill with sediment; this point is referred to as the "deposition velocity." This velocity typically corresponds to the point where a moving bed of particles begins to deposit on the bottom of a straight horizontal pipe during slurry-transport operations. This should not be confused with the laminar-to-turbulent transition velocity, which is referred to as the "transition velocity." $\mathrm{NPSH}_{\mathrm{R}}$ testing using non-Newtonian HLW simulant was also carried out under conditions and procedures specified by the Hydraulic Institute in the ANSI/HI 1.6-2000 manual, American National Standard for Centrifugal Pump Tests. 


\subsection{Quality Requirements}

PNNL's Quality Assurance Program is based on requirements defined in U.S. Department of Energy (DOE) Order 414.1C, Quality Assurance, and Title 10 of the Code of Federal Regulations (CFR) Part 830, Energy/Nuclear Safety Management, Subpart A-Quality Assurance Requirements (a.k.a. the Quality Rule). PNNL has chosen to implement the requirements of DOE Order 414.1C and 10 CFR 830, Subpart A by integrating them into PNNL's management systems and daily operating processes. The procedures necessary to implement the requirements are documented through PNNL's Standards-Based Management System.

PNNL implements the RPP-WTP quality requirements by performing work in accordance with the River Protection Project-Waste Treatment Plant Support Program (RPP-WTP) Quality Assurance Plan (RPP-WTP-QA001, QAP). Work was performed to the quality requirements of NQA-1-1989 Part I, Basic and Supplementary Requirements, NQA-2a-1990, Part 2.7 and DOE/RW-0333P, Rev 13, Quality Assurance Requirements and Descriptions (QARD). These quality requirements are implemented through the River Protection Project—Waste Treatment Plant Support Program (RPP-WTP) Quality Assurance Manual (RPP-WTP-QA-003, QAM). 



\subsection{Background}

The work presented in this document builds off of the correlations presented in a previously published, WTPRPT-175 Rev. 0 (Poloski et al. 2009). The data on which these correlations where based had some limitations: a) the low range of rheological properties tested, up to approximately 6 Pa Casson yield stress; $b$ ) and the simulant tested where simple physical simulants with controlled particle size and density distributions rather than complex chemical simulants with an unknown particle size and density distribution. This report attempts to bridge this technical gap by performing deposition velocity tests on simple and complex Hanford simulants over the range of yield stress values anticipated to be processed within the WTP, up to $30 \mathrm{~Pa}$ Bingham yield stress.

The WTP-RPT-175 Rev. 0 (Poloski et al. 2009) report recommends that three correlations be used to describe the boundaries between stable and unstable flow regions for non-Newtonian slurries. These correlations include: 1) the critical deposition boundary, 2) the transitional deposition boundary, and 3) the laminar deposition boundary. The boundaries correspond to different physical transport or deposition mechanisms. Four of the major regimes are shown schematically in Figure 3.1.

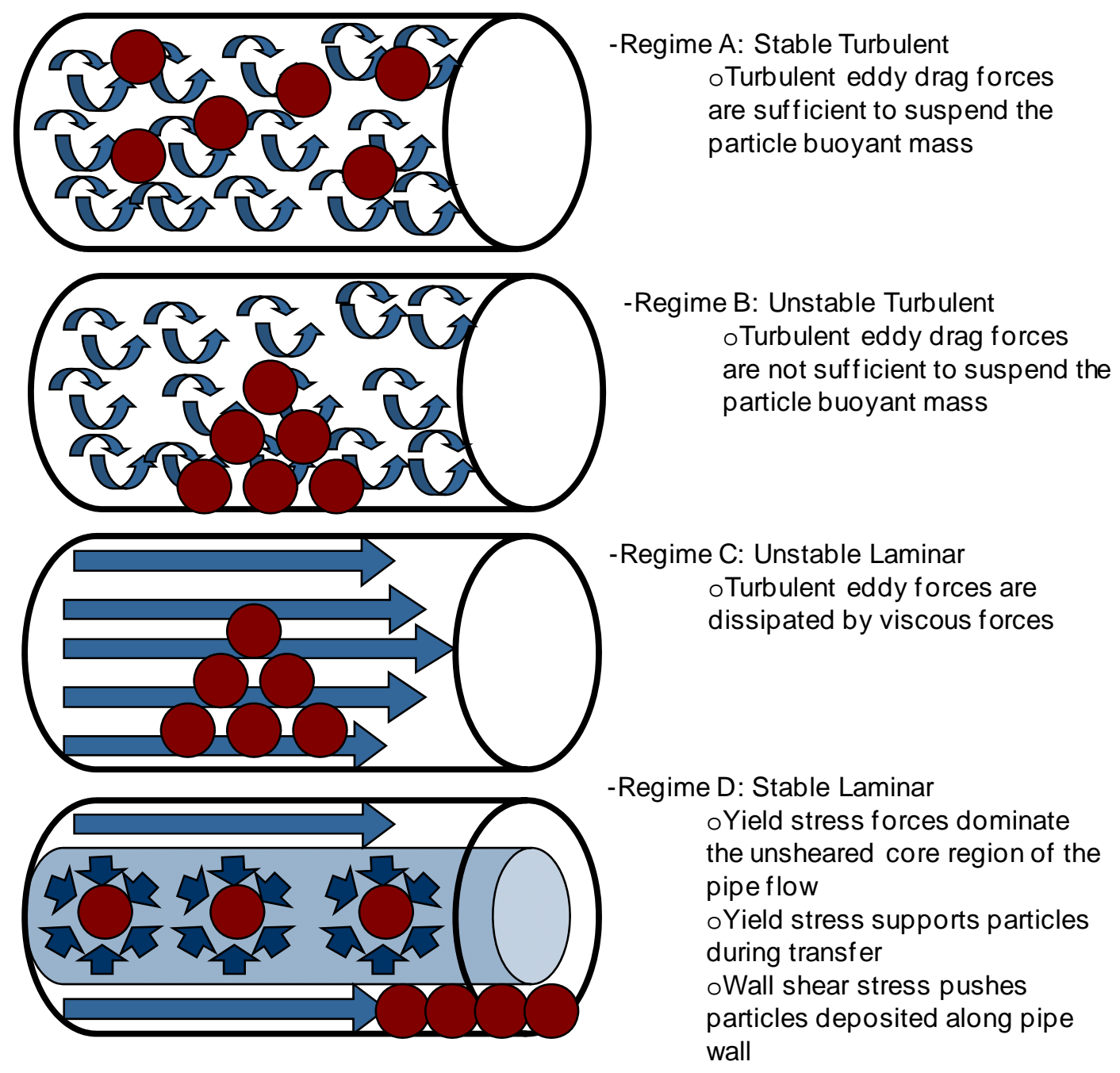

Figure 3.1. Graphical Interpretation of Four Major Slurry-Transport Flow Regimes 
The three boundaries listed above are heavily dependent on slurry rheology. By plotting yield stress on the abscissa and flow velocity on the ordinate, a "stability map" showing these stability regimes can be obtained. An example stability map is shown in Figure 3.2. Point W on the vertical axis on Figure 3.2 represents the Newtonian critical deposition velocity for turbulent flow. This point is predicted by the Oroskar and Turian (1980) and Shook et al. (2002) equations. As the non-Newtonian character of the slurry increases with yield stress, the increased apparent viscosity of the slurry results in more drag on the particles and reduces the flow velocity needed to suspend the particles in turbulent flow. The boundary between the stable-turbulent and unstable-turbulent flow regimes is referred to as the critical deposition boundary and is depicted by path WX on Figure 3.2.

However, the flow velocity required to reach turbulent flow increases with slurry rheological properties because of viscous forces dampening the formation of turbulent eddies. At point $\mathrm{X}$ in

Figure 3.2, the flow becomes dominated by viscous forces rather than turbulent eddies. Since the turbulent eddies necessary for particle transport are not present, the particles will settle when the flow rate is below this boundary, called the transitional deposition boundary. Along path XY, the stable-turbulent and unstable-laminar flow regimes are defined.

As the yield stress continues to increase, the pressure gradient required for flow increases. At point $Y$ on Figure 3.2 , the required pressure gradient is adequate to push the particles along the pipeline, along the pipeline wall. Often yield-stress forces are large enough to suspend the particles in the stagnant core region of a non-Newtonian flow. Along path YZ, the rheological properties continue to increase, which lowers the flow velocity required to achieve the pressure gradient strong enough to push the particles through the pipeline.

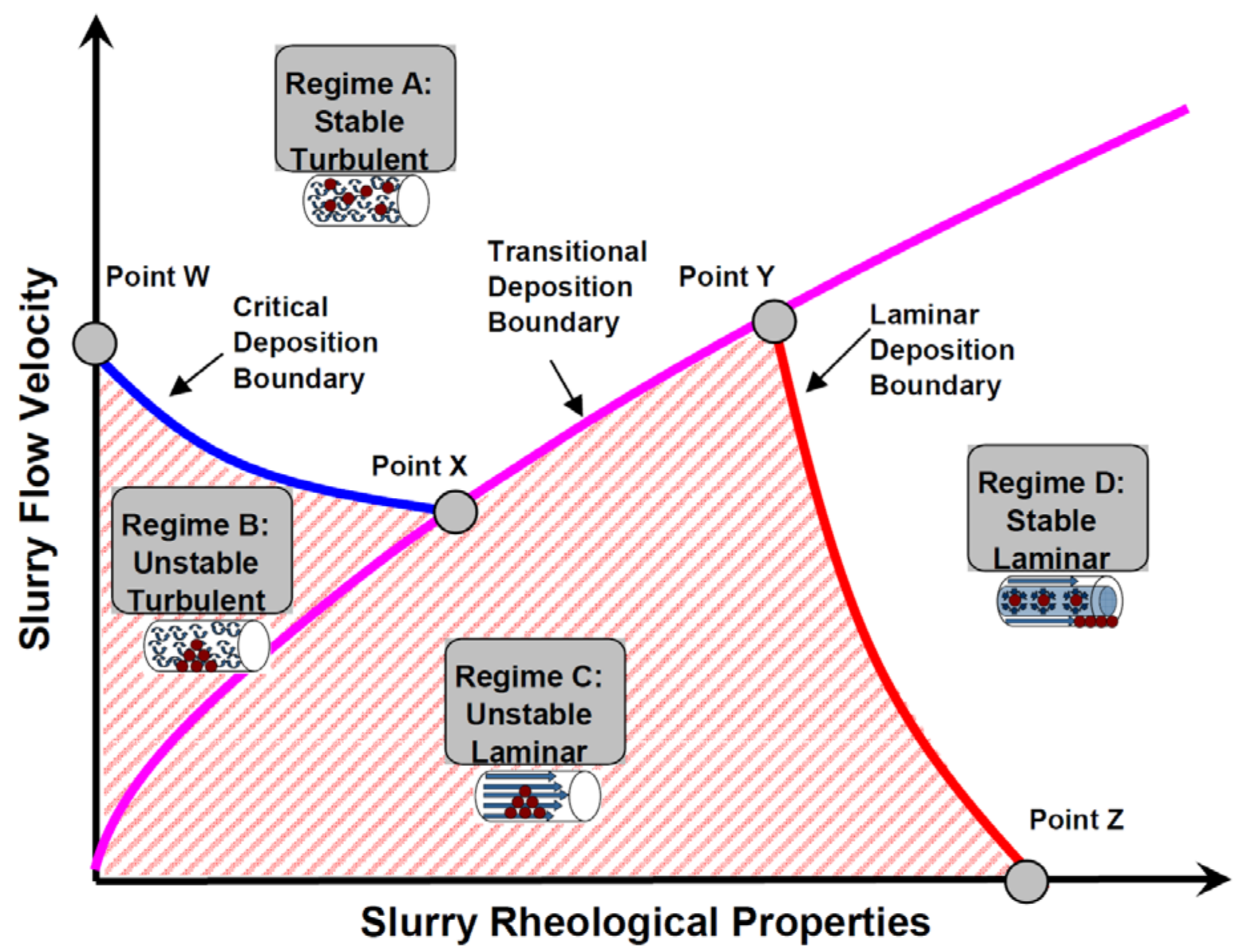

Figure 3.2. Graphical Illustration of a "Stability Map" 


\subsection{Third Party Review}

A third party review was conducted on the report WTP-RPT-175 Rev. A. The review found that "The report is thorough, complete and scientifically sound, with the experimental techniques being nicely justified for the range of materials examined." A bio-sketch of the reviewer and the complete review report can be found in Appendix E.

\subsection{Critical Deposition Boundary}

The Gillies and Shook (1991) model has been updated in an article authored by Gillies et al. (2000). In this article, Gillies et al. (2000) proposes that the principal independent variable should be the Archimedes Number. In this correlation, the dependent variable that is used to calculate the deposition velocity is the Froude number. The Archimedes Number can be defined as the ratio of gravitational forces on the particle, corrected for buoyancy, to viscous forces on the particle. Mathematically, this can be expressed as,

$$
A r=\frac{4}{3} \frac{g d^{3}(S-1) \rho_{f}^{2}}{\mu_{f}^{2}}
$$

$$
\text { where } \quad \begin{aligned}
g & =\text { gravitational acceleration }\left(\mathrm{m} / \mathrm{s}^{2}\right) \\
d & =\text { particle diameter }(\mathrm{m}) \\
S & =\text { ratio of the density of the coarse solids to the density of the slurry, } \\
& \rho_{\mathrm{s}} / \rho_{\mathrm{f}} \\
\rho_{f}= & \text { slurry density }\left(\mathrm{kg} / \mathrm{m}^{3}\right) \\
\mu_{f} & =\text { slurry dynamic viscosity }(\mathrm{Pa} \mathrm{s})
\end{aligned}
$$

The Froude Number can be defined as the ratio of inertial forces in the fluid flow to the gravitational forces the particle must overcome to stay suspended in the flow. Mathematically, this can be expressed as:

$$
F r=\frac{V_{c}}{\sqrt{g D(S-1)}}
$$

where $V_{c}$ is the deposition velocity $(\mathrm{m} / \mathrm{s})$, and $D$ is the pipe diameter $(\mathrm{m})$.

Shook et al. (2002) provide a relation between the Archimedes Number and the Froude Number.

$$
\begin{aligned}
540<A r \quad F r & =1.78 A r^{-0.019} \\
160<A r<540 F r & =1.19 A r^{0.045} \\
80<A r<160 F r & =0.197 A r^{0.4}
\end{aligned}
$$

This relationship allows the critical deposition velocity to be calculated over a range of particle and carrier-fluid properties in non-dimensional form. This equation has the benefit of not containing a slurry-concentration term included in similar deposition-velocity equations. This simplification allows increased engineering flexibility for a slight decrease in correlation accuracy. For example, Turian et al. (1987) presents a 37\% absolute average percent deviation for the Durand and Condolios (1952) equation, which does not include a concentration term. In comparison, the Oroskar and Turian (1981) equation, with a concentration term, has a $26 \%$ absolute average percent 
deviation. The Shook et al. (2002) correlations are expected to have performance similar to the Durand and Condolios (1952) equation.

Gillies and Shook (1991) also presented a carrier-fluid concept where a criterion for a homogeneous carrier "vehicle" is established: material can be considered effectively homogeneous if it can pass through a 200-mesh sieve (i.e. $74 \mu \mathrm{m}$ opening). Results from the report WTP-RPT-175 Rev. 0 (Poloski et al. 2009) show that particles smaller than $74 \mu \mathrm{m}$ can behave as heterogeneous solids and deposit in pipelines. Consequently, the homogeneous-fraction criterion is much more complex than previously anticipated. For simplicity, bulk fluid property data were used for density and viscosity inputs in this model rather than calculated carrier-fluid values.

A critical deposition boundary for both Newtonian and non-Newtonian systems is obtained in WTP-RPT-175 Rev. 0 (Poloski et al. 2009) by redefining the Archimedes Number used in the Shook et al. (2002) correlations (see Equations 3.3) with an apparent-viscosity term supplemented with an $A r<80$ correlation developed in the previous report. For Casson and Bingham-plastic fluids, the Archimedes Number with the apparent-viscosity modification is defined according to Equation (3.1):

$$
\begin{gathered}
\text { Casson Fluid } \rightarrow \quad A r=\frac{4}{3} \frac{g d^{3}(S-1) \rho_{f}^{2}}{\mu_{C}^{2}}\left(1-\xi^{\frac{1}{2}}\right)^{4}=A r_{\infty}\left(1-\xi^{\frac{1}{2}}\right)^{4} \\
\text { Bingham Plastic } \rightarrow \quad A r=\frac{4}{3} \frac{g d^{3}(S-1) \rho_{f}^{2}}{\mu_{B}^{2}}(1-\xi)^{2}=A r_{\infty}(1-\xi)^{2}
\end{gathered}
$$

This definition of the Archimedes Number can be substituted into the Shook et al. (2002) correlations to obtain a correlation for Casson and Bingham-plastic fluids as shown by Equations (3.5) and (3.6), respectively. These equations define the critical deposition boundary that separates the stable-turbulent flow regime from the unstableturbulent flow regime. For non-Newtonian slurries, the ratio of yield stress to wall shear stress, $\xi$, is calculated from the methods discussed in Appendix A of WTP-RPT-175 Rev. 0 (Poloski et al. 2009). The addition of this term accounts for the shear-thinning behavior of the non-Newtonian slurries. For Newtonian slurries, this ratio is zero, and the original Shook et al. (2002) correlations appear.

$$
\begin{gathered}
\text { Casson Fluid } \\
540<A r \rightarrow F r=1.78 A r_{\infty}{ }^{-0.019}\left(1-\xi^{\frac{1}{2}}\right)^{-0.076} \\
160<A r<540 \rightarrow F r=1.19 A r_{\infty}^{0.045}\left(1-\xi^{\frac{1}{2}}\right)^{0.18} \\
80<A r<160 \rightarrow F r=0.197 A r_{\infty}{ }^{0.4}\left(1-\xi^{\frac{1}{2}}\right)^{1.6} \\
A r<80 \rightarrow F r=0.59 A r_{\infty}{ }^{0.15}\left(1-\xi^{\frac{1}{2}}\right)^{0.6}
\end{gathered}
$$




\section{Bingham Plastic}

$$
\begin{gathered}
540<A r \rightarrow F r=1.78 A r_{\infty}{ }^{-0.019}(1-\xi)^{-0.038} \\
160<A r<540 \rightarrow F r=1.19 A r_{\infty}{ }^{0.045}(1-\xi)^{0.09} \\
80<A r<160 \rightarrow F r=0.197 A r_{\infty}{ }^{0.4}(1-\xi)^{0.8} \\
A r<80 \rightarrow F r=0.59 A r_{\infty}{ }^{0.15}(1-\xi)^{0.3}
\end{gathered}
$$

\subsection{Transitional Deposition Boundary}

The non-Newtonian deposition data in report WTP-RPT-175 Rev 0 (Poloski et al. 2009) show that deposition occurs as the transition velocity from turbulent-to-laminar flow is reached. These data support the statement of Shook et al. (2002) that "There have been many experimental investigations of non-Newtonian slurries in laminar and turbulent flow, and deposition is often observed as the laminar flow condition is approached." The transition velocities for both Casson and Bingham fluids define the transitional deposition boundary that separates the stableturbulent flow regime from the unstable-laminar flow regime. These equations for the transition Reynolds number, $R e_{t}$, used to calculate the transition velocity for both Casson and Bingham plastic fluids are shown below:

$$
\begin{gathered}
\text { Casson Fluid } \rightarrow \quad \operatorname{Re}_{t}=1050\left[1+\left(1+\frac{C a}{370}\right)^{0.4}\right] \\
\text { Bingham Plastic } \rightarrow \quad \operatorname{Re}_{t}=1050\left(1+\sqrt{1+\frac{H e}{4500}}\right)
\end{gathered}
$$

The Casson and Hedstrom numbers are defined as shown below:

$$
\begin{gathered}
\text { Casson Fluid } \rightarrow \quad C a=\frac{D^{2} \rho_{f} \tau_{C}}{\mu_{C}^{2}} \\
\text { Bingham Plastic } \rightarrow \quad H e=\frac{D^{2} \rho_{f} \tau_{B}}{\mu_{B}^{2}}
\end{gathered}
$$

where $H e=$ Hedstrom Number (dimensionless)

$\mathrm{Ca}=$ Casson Number (dimensionless)

$D \quad=$ pipe diameter $(\mathrm{m})$

$\rho_{f} \quad=$ fluid or slurry density $\left(\mathrm{kg} / \mathrm{m}^{3}\right)$

$\tau_{B} \quad=$ yield-stress fit to Bingham plastic model $(\mathrm{Pa})$

$\tau_{C}=$ yield-stress fit to the Casson fluid model (Pa)

$\mu_{B} \quad=$ Bingham-plastic infinite-shear viscosity (Pa॰s)

$\mu_{C}=$ Casson infinite-shear viscosity $(\mathrm{Pa} \bullet \mathrm{s})$ 


\subsubsection{Settling in Laminar Flow}

The significance of avoiding the transitional deposition boundary is supported in several other open-literature sources. In a study that examined deposition velocities in non-Newtonian fluids, Shah and Lord (1991) made the following conclusion:

In the present study, most of the critical depositional velocities correspond to the laminar or near-laminar flow conditions based on the critical value of 2,100 for the Dodge-Metzner (1959) generalized Reynolds number. In this definition of Reynolds number, power-law apparent viscosity is substituted for viscosity in the usual expression for pipe flow... Generalized Reynolds number values correspond to laminar or transitional flow conditions except for water and low concentrations of HPG [hydroxypropyl guar].

On the subject of deposition occurring in laminar non-Newtonian flows, Gillies et al. (2007) state the following:

The body of evidence suggesting that coarse-particle settling can occur during the laminar pipeline transport of mixtures of this type [non-Newtonian slurries with a mixture of fine and coarse particles] is overwhelming. Cooke (2002) and Thomas et al. (2004) provide excellent reviews of such cases where coarse-particle settling was observed in operating pipelines and laboratory pipeline loops. In many of these cases, static settling tests show that the mixture is stable - that is, no coarse-particle settling occurs. However, when the same mixture is transported by pipeline, coarse-particle settling is observed. Recently, Wilson et al. (2003) and Wilson and Horsley (2004) presented a concise and compelling analysis of the fall velocity of particles suspended in nonNewtonian fluids. Their analysis shows unequivocally that the same particle will have a greater fall velocity in a sheared medium than in an unsheared one. There should no longer be any debate about (i) the fact that coarse-particle settling can occur in laminar flows and (ii) the absolute irrelevance of static settling tests in determining the tendency of coarse particles to settle during laminar pipeline transport of non-Newtonian mixtures.

Interestingly, line plugging was observed in melter-feed transport tests in support of the Hanford Waste Vitrification Plant (HWVP; Gaskill et al. 1996). Glass frit in the size range of 80 - 200 mesh (i.e., 75 to $180 \mu \mathrm{m}$ ) was added to a neutralized current acid waste (NCAW) simulant to form the melter feed. The resulting melter feed was characterized as a Bingham plastic with a yield stress of $25 \mathrm{~Pa}$. A 10-mm glass particle should be suspended in this fluid according to typical yield-stability parameter tests. However, Gaskill et al. (1996) made the following observation:

As time progressed during the melter feed run, the flow rate would gradually decrease. There are two reasons for this decrease in flow rate. As the melter feed transferred to the melter, the level in the test vessel, HB-15 decreases. With the decreasing level in HB-15, more of the pressure drop across the pump is used to lift the melter feed out of the tank and, therefore, the pump discharge pressure decreases. The flow in the melter feed line decreases as a result of the decrease in pressure in the recycle loop. The second reason for the decreasing flow in the melter feed line is the build-up of material in the melter feed line, thus effectively reducing the flow area and flow rate. Visual evidence of this phenomenon was observed at the end of the nozzle where material was building up and would occasionally fall off or be knocked off. Build-up of solids was also observed in the 3-way valve during a visual inspection after the run when the valve was disassembled. It is a safe assumption that build-up occurred at other parts of the system, particularly where there is a changing cross-section, as in the 3-way valve or cross-flow strainer.

The piping system described above was a $3 / 8$-in. pipe with an inner diameter of 0.423 inches. Flow was generally in the 0.20 to 0.35 gallons per minute range. Reynolds numbers under such conditions are extremely low 
and indicate that the flow was laminar. Again, this substantiates the finding of this report that settling can occur with highly non-Newtonian slurries in laminar flow even when they appear to be non-settling when stagnant.

\subsubsection{Operational Data from Pipelines in Laminar Flow}

Cooke (2002) presents a summary of operational issues observed in the mineral-processing industry when pumping non-Newtonian particulate slurries through pipelines in the laminar-flow regime. The abstract of this paper is as follows:

It is often assumed that low operating velocities are not a problem for high density thickened tailings and paste mixtures as they are inherently stable and pipelines may be started and shutdown without fear of blockage. However, this is not necessarily the case and when an apparently nonsettling suspension is subjected to shear in laminar flow, the settling rate of the coarse particles is increased significantly. For commercial pipelines operating in laminar flow, there is no effective mechanism for re-suspending settled particles and it is possible that the pipeline may block.

This paper discusses experiences with operating laminar flow pipelines and reviews the current state of knowledge.

The WTP will process non-Newtonian slurries with a wide range of rheological properties. Operating pipelines at a single flow velocity will result in turbulent flow under with slurries with low or "thin" rheological properties and laminar flow with other high or "thick" rheological properties. Due to the necessity of the plant to function under both laminar and turbulent flow regimes, the operational information from the minerals industry on transport of particulate slurries in laminar flow is directly applicable to the WTP. A summary of the Cooke (2002) paper as well as others on the topic is presented in this section.

\subsubsection{Rugby Limestone Pipeline}

Cooke (2002) describes a limestone-slurry pipeline in Rugby, England which is $92 \mathrm{~km}$ (57 mi) in length and $250 \mathrm{~mm}(9.8 \mathrm{in})$ in diameter. The pipeline started operation in 1964 operating at a velocity of $1.12 \mathrm{~m} / \mathrm{s}(3.67 \mathrm{ft} / \mathrm{sec})$. This velocity is close to the estimated transition between laminar and turbulent flow. Over a 36-hour period the following observations were made:

- The pressure gradient increased from $0.106 \mathrm{kPa} / \mathrm{m}$ to $0.121 \mathrm{kPa} / \mathrm{m}$

- Slurry entered the pipeline at a $56.5 \%$ mass and discharged at $54.5 \%$ by mass

- Nearly $4 \%$ of the particles entering the pipeline were $150 \mu \mathrm{m}$ or larger but only trace amounts of such particles were exiting the pipeline

Attempts to clear the deposits with pipeline pigs failed as the pigs became stuck in the pipeline. Excessive pipe erosion was then observed in areas around the stuck pigs due to increased flow velocity. Since that time, additives (i.e. rheological modifiers) were added to the slurry to reduce the rheological properties of the slurry; it is now possible that the pipeline is operating in turbulent flow.

\subsubsection{Belovo-Novosibirsk Pipeline}

Cooke (2002) also describes a stabilized coal-water pipeline in Siberia which is $262 \mathrm{~km}$ (163 mi) in length and $530 \mathrm{~mm}$ (20.9 in) in diameter. The pipeline was forced to shut down during startup commissioning exercises due to a blockage. 
Slurry was pumped through a $1 \mathrm{~km}(0.6 \mathrm{mi})$ test loop prior to being sent to the main pipeline. The following test results were obtained from the slurry test loop:

- The pressure gradient increased with time when the system was operated at low shear rates $\left(0.5\right.$ to $\left.2.0 \mathrm{~s}^{-1}\right)$.

- At the maximum shear rates of 9.0 to $11.0 \mathrm{~s}^{-1}$, the pressure gradient was independent of time.

- A stationary deposit was observed on the pipe invert with a highly viscous material above the bed.

The same behavior was observed in the main pipeline causing the pump-station discharge pressure to rise with time and lead to a blockage. The pressure rise was attributed to unstable rheological properties of the slurry. However, Cooke (2002) suspects that the pressure increase was due to particle sedimentation. The blockage was ultimately cleared with a pipeline pig. Initial tests with the slurry were conducted in a $200-\mathrm{m}$ long, $200 \mathrm{~mm}$ recirculating pipe loop. No flow instabilities were observed in the pipe loop.

\subsubsection{Experimental Data on Particle Sedimentation in Laminar Flow}

\subsubsection{Couette Flow Experiments}

Cooke (2002) used a set of concentric cyclinders with the inner cyclinder rotating to produce laminar, Couette flow. A slurry of clay with sand particles between 45 and $212 \mu \mathrm{m}$, at $15 \%$ by mass, was placed in the annulus of the system. The initial clay slurry has rheological properties of $59 \mathrm{~Pa}$ Bingham Yield Stress and a Bingham plastic viscosity of $8.4 \mathrm{cP}$. The density of the slurry was $1.330 \mathrm{~g} / \mathrm{mL}$. Under these conditions the sand particles are fully suspended by the yield stress of the fluid when the slurry is quiescent.

The apparatus was rotated at shear rates of 37.3 and $74.6 \mathrm{~s}^{-1}$ for a period of 30 minutes. Samples were withdrawn at various heights in the system and the fraction of particles greater than $45 \mu \mathrm{m}$ was measured. The resulting plot, showing that the sand particles had settled to the bottom of the apparatus, is shown in Figure 3.3.

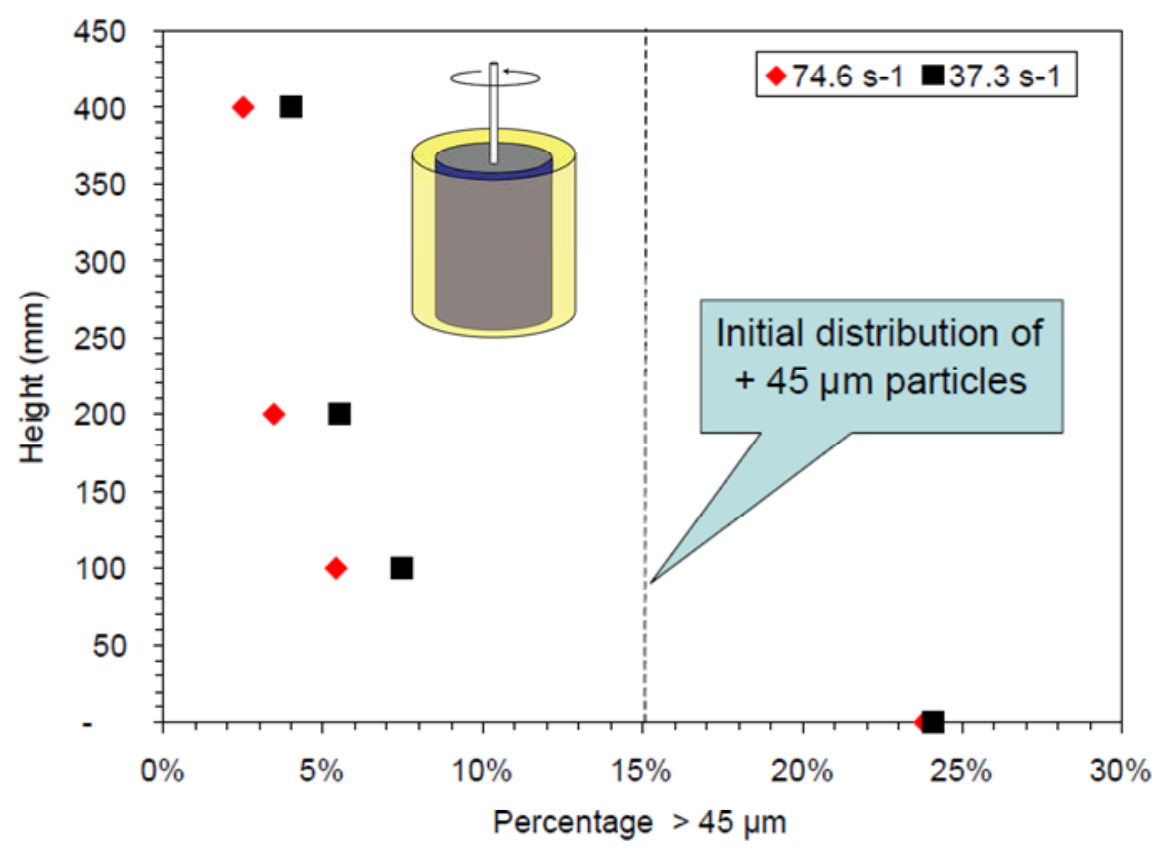

Figure 3.3. Laminar-Settling Test Data in Couette Flow; Source: Cook (2002) 


\subsubsection{Increasing Solids Content Experiments}

Ricks (2002) presents an overview of mineral-industry pipeline-transport design methods. In this overview, Ricks notes that both the deposition velocity and the transition velocity must be determined for slurry-transport applications. He states the following on this topic:

However, according to experience the slurry concentration has a significant role in the deposition phenomena. It has been observed that for conventional mineral concentrates the degree of heterogeneity or complexity of the slurry decreases as concentration increases. Therefore, the deposition velocity decreases with concentration up to the point where the viscosity (concentration) is sufficient to produce a homogeneous slurry. Thereafter, the deposition velocity and the transition velocity become nearly identical. To illustrate, refer to Figure 8 [Figure 3.4] showing the relationship between deposition and transition velocities for a selected concentrate slurry. A much more sophisticated relationship is used to determine this relationship.

Ricks (2002) goes on to warn of excessive pipe erosion occurring on the pipe invert when operation in slidingbed conditions occurs. This problem has been noted in industry (Miller and Schmidt 1987; Henday 1988, Brown and Heywood 1991) and other DOE sites (Poirier 2000). This increased wear on the pipe wall due to sliding bed should be accounted in the WTP piping design calculations.

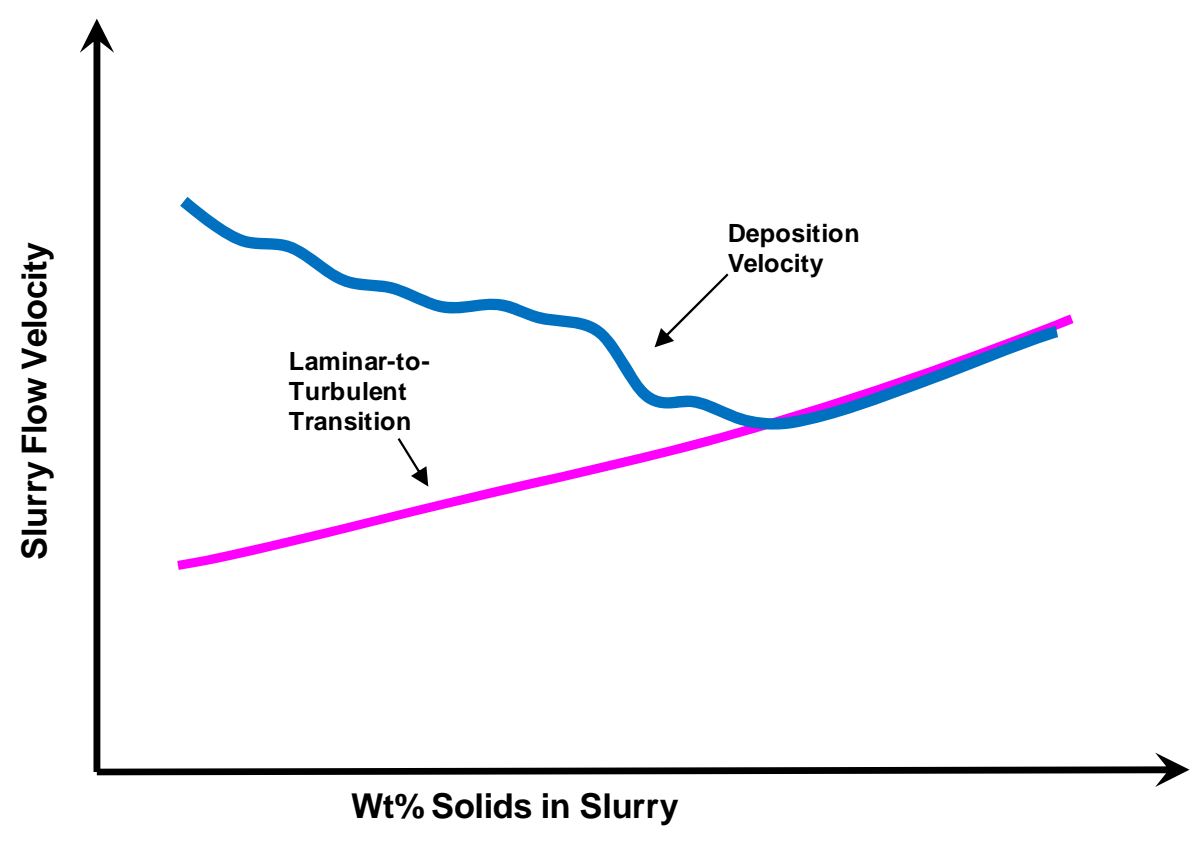

Figure 3.4. Relationship Between Deposition Velocity and Transition Velocity for an Example Slurry; Source: Ricks (2002)

\subsubsection{Sand-and-Clay Slurry Experiments}

Cooke (2002) presents experimental data from Song and Chiew (1997). In this experiment, a Bingham-plastic slurry with clay particles having a nominal size of $4.5 \mu \mathrm{m}$ was mixed with sand with a nominal size of $150 \mu \mathrm{m}$. The slurry was transported through a rectangular $180 \mathrm{~mm}$ wide by $100 \mathrm{~mm}$ high, transparent channel. When quiescent, 
the slurry was stable and no deposition was observed. As the flow velocity increased, a stationary bed of particles formed. At each velocity the height of the stationary bed was measured and plotted as shown in Figure 3.5. The maximum bed height was reached when the transition from laminar to turbulent flow was reached. Increasing the flow velocity while in turbulent flow resulted in a decrease in bed height. The process was then reversed; as flow velocity was decreased, the bed height increased while in turbulent flow. The maximum bed height again was reached at the transition from turbulent to laminar flow. Decreasing the velocity further while in laminar flow resulted in no change in stationary-bed height. This progression of test conditions is shown by the arrows in Figure 3.5. For example, the test started at point (a) with no deposition and the flow velocity at zero

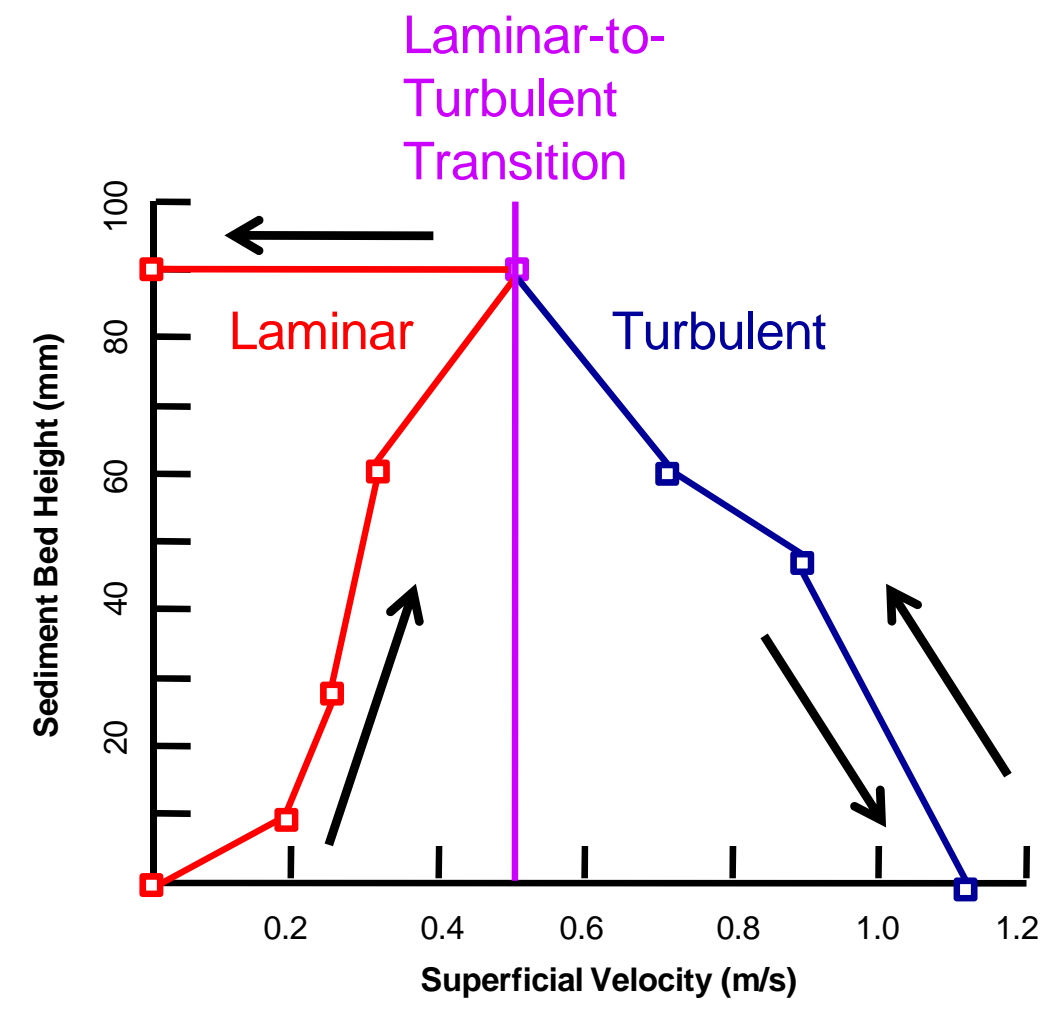

Figure 3.5. Sand-Clay Slurry Deposition Data in a Rectangular Pipeline; Arrows show the testing progression starting and ending with a superficial velocity of zero; Source: Song and Chiew (1997)

\subsubsection{Copper Tailings}

Deposition-velocity data from two pipelines with $150-\mathrm{mm}$ and 50-mm diameters transporting copper tailings $\left(\mathrm{d}_{50}=70 \mu \mathrm{m}\right.$ and $\left.\mathrm{d}_{90}=134 \mu \mathrm{m}\right)$ was presented by Cooke (2002) in Figure 3.6. At the lower solids concentration (i.e. points $1 \& 5$ ) deposition is observed in turbulent flow. As solids concentration increases, the slurry exhibits nonNewtonian behavior and the transition from laminar to turbulent flow occurs at higher velocities. Deposition is observed at points $2,3,4,6, \& 7$ which correspond to transitions from turbulent to laminar flow. Point 8 shows stable laminar flow occurring in the smaller-diameter pipe due to increased shear to extrude the settled particles through the pipe in the stable laminar flow regime. The author concludes that pipe tests with only $50 \mathrm{~mm}$ diameter would incorrectly find that operation at high solids concentrations is safe. 


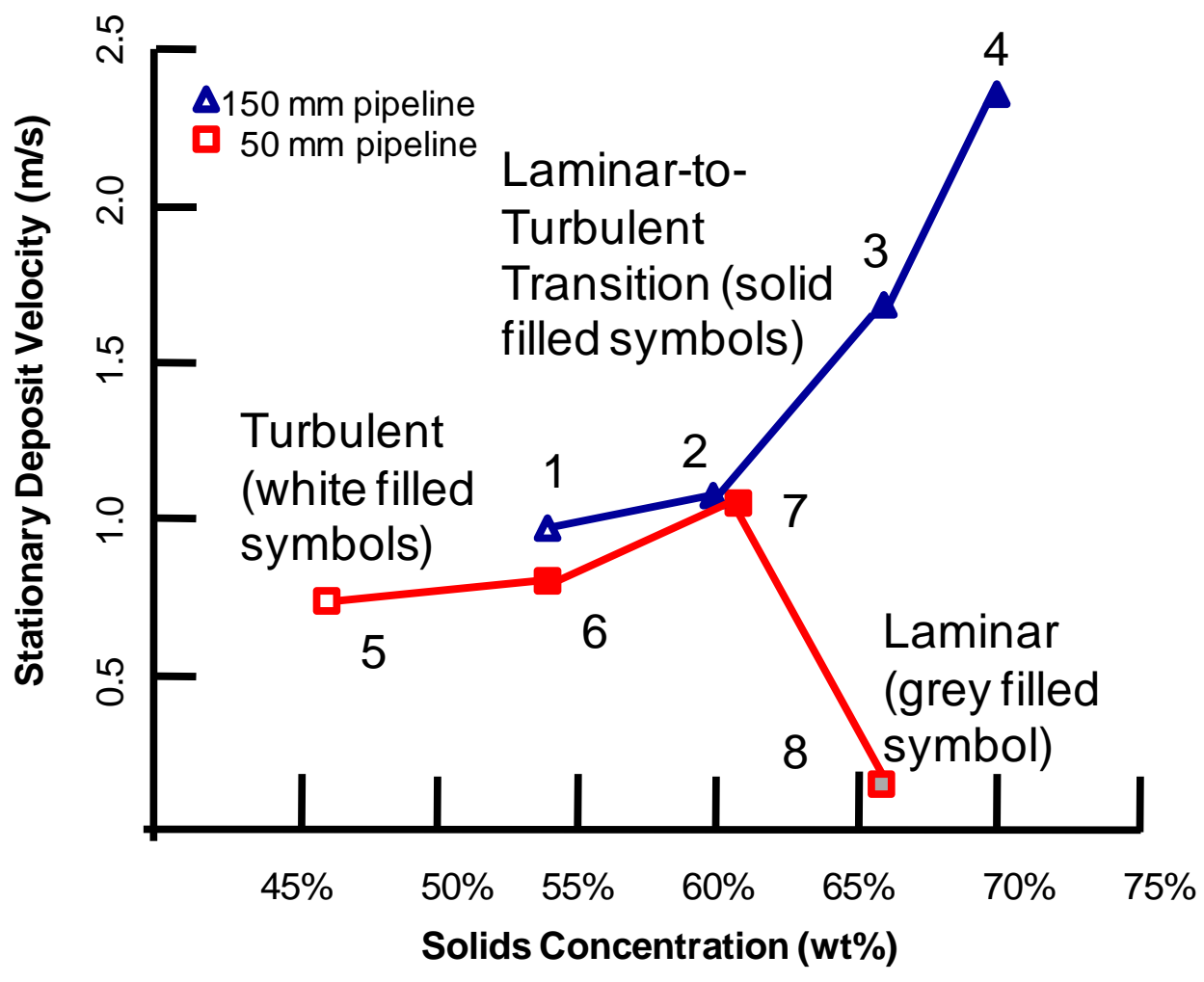

Figure 3.6. Copper-Tailings Deposition-Velocity Data; Source: Cooke (2002)

\subsection{Laminar-Deposition Boundary}

Gillies et al. (2007) recently published a paper on the topic of particle transport in laminar, non-Newtonian slurries. Industry standard was to use a "rule of thumb" of a $\sim 1.5$ - to $2-\mathrm{kPa} / \mathrm{m}$ pressure gradient threshold to transport solids in laminar flow. Gillies et al. (2007) established a new criterion that relates the ratio of the wall shear stress, $\tau_{\mathrm{w}}$, to the average surficial-particle shear stress. The average surficial-particle shear stress (Wilson et al. $2003,2004)$ and the ratio are defined by the equations below.

$$
\begin{gathered}
\tau_{p}=\frac{\left(\rho_{s}-\rho_{f}\right) g d}{6} \\
\alpha=\frac{\tau_{w}}{\tau_{p}} \rightarrow \xi=\frac{\tau_{0}}{\alpha \tau_{p}}
\end{gathered}
$$

Gillies et al. (2007) conclude that "a slurry's proclivity to experience laminar flow settling is greatly reduced when $\tau_{\mathrm{w}} / \tau_{\mathrm{p}}>60$ and nearly eliminated when $\tau_{\mathrm{w}} / \tau_{\mathrm{p}}>100 . "$

The laminar-flow velocities for these ratios can be obtained analytically for Casson and Bingham-plastic fluids as shown by the equations below. These equations define the laminar deposition boundary that separates the unstable laminar-flow regime from the stable laminar-flow regime. 


$$
\begin{gathered}
\text { Casson Fluid } \rightarrow \quad V=\left(\frac{D}{8}\right)\left(\frac{\alpha \tau_{p}}{\mu_{\infty}}\right)\left[1-\frac{16}{7} \sqrt{\frac{\tau_{C}}{\alpha \tau_{p}}}+\frac{4}{3} \frac{\tau_{C}}{\alpha \tau_{p}}-\frac{1}{21}\left(\frac{\tau_{C}}{\alpha \tau_{p}}\right)^{4}\right] \\
\text { Bingham Plastic } \rightarrow \quad V=\left(\frac{D}{8}\right)\left(\frac{\alpha \tau_{p}}{K}\right)\left[1-\frac{4}{3} \frac{\tau_{B}}{\alpha \tau_{p}}+\frac{1}{3}\left(\frac{\tau_{B}}{\alpha \tau_{p}}\right)^{4}\right]
\end{gathered}
$$




\subsection{Test Overview}

An experimental program was implemented to test the stability-map concepts in Section 3.0. Two types of simulant were tested. The first type of simulant was similar to the glass-bead simulants discussed in WTP-RPT-175 Rev. 0 (Poloski et al. 2009). The simulant consists of $150 \mu \mathrm{m}$ nominal particle size glass beads in a kaolin/water slurry. The initial simulant was prepared at a target yield stress of approximately $30 \mathrm{~Pa}$. The yield stress was then reduced, stepwise, via dilution or rheological modifiers ultimately to a level of $<1 \mathrm{~Pa}$. At each yield-stress step, deposition-velocity testing was performed. Testing over this yield-stress range bounds the expected rheological operating window of the WTP and allows the results to be compared to stability-map predictions for this system.

The second simulant was a precipitated-hydroxide that simulates HLW pretreated sludge from tank AZ-101. Testing was performed in a manner similar to that for the first simulant over a wide range of yield stresses; however, an additional test of net-positive suction-head required $\left(\mathrm{NPSH}_{\mathrm{R}}\right)$ was performed at each yield-stress condition. Unlike the previous simulant, the sizes and densities of the particles that can deposit in the piping are a result of the simulant-precipitation process; there is expected to be a complex mixture of particles of various sizes and densities that make it difficult to predict a stability map. The objective of the testing is to observe whether behavior consistent with the stability-map concept occurs in complex simulants with mixtures of different sizes and densities. Details of simulant physical and rheological properties can be found in Section 0 .

An experimental flow loop was constructed of approximately 100 feet of 3 -inch schedule 40 piping taken from the WTP excess yard (see Figure 4.1). Components of the flow loop included a four-baffled, 400-gallon mixing tank with a 25 -inch pitched-blade impeller; a Georgia Iron Works slurry pump, a 150-psig, 400-gallon pneumatic flush system, and a 1,000 gallon capture tank complete the flow loop system. The flow loop also has instrumentation for determining flow rate with inlet and outlet Micro Motion F-Series Coriolis meters. The pressure gradient and pump inlet and outlet pressures were measured with Rosemount 1151 differential pressure transducers. The particle-size chord-length distribution was measured with a Lasentec ${ }^{\mathrm{TM}}$ focused-beam reflectance-measurement (FBRM) sensor. Lastly, a cross-sectional pipe tomogram of slurry conductivity was measured using a P2000 electrical resistance tomography system manufactured by ITS. Further details of test apparatus can be found in WTP-RPT-175 Rev 0 (Poloski et al. 2009).

At the beginning of a test, the slurry flow velocity was set to nominally $8 \mathrm{ft} / \mathrm{sec}$. The flow was then incrementally decreased, and a pressure-gradient-versus-time signature was obtained at each flow condition. A rise in pressure gradient as the flow rate drops indicates that the pipe cross-sectional area begins to fill with sediment; this point is referred to as the "deposition velocity." This velocity typically corresponds to the point where a moving bed of particles begins to deposit on the bottom of a straight horizontal pipe during slurry-transport operations. This should not be confused with the laminar-to-turbulent transition velocity, which was referred to as the "transition velocity." Details of the test procedure can be found in Section 6.0. $\mathrm{NPSH}_{\mathrm{R}}$ testing using Non-Newtonian HLW simulant was also carried out under conditions and procedures specified by the Hydraulic Institute in the ANSI/HI 1.6-2000 manual, American National Standard for Centrifugal Pump Tests. 


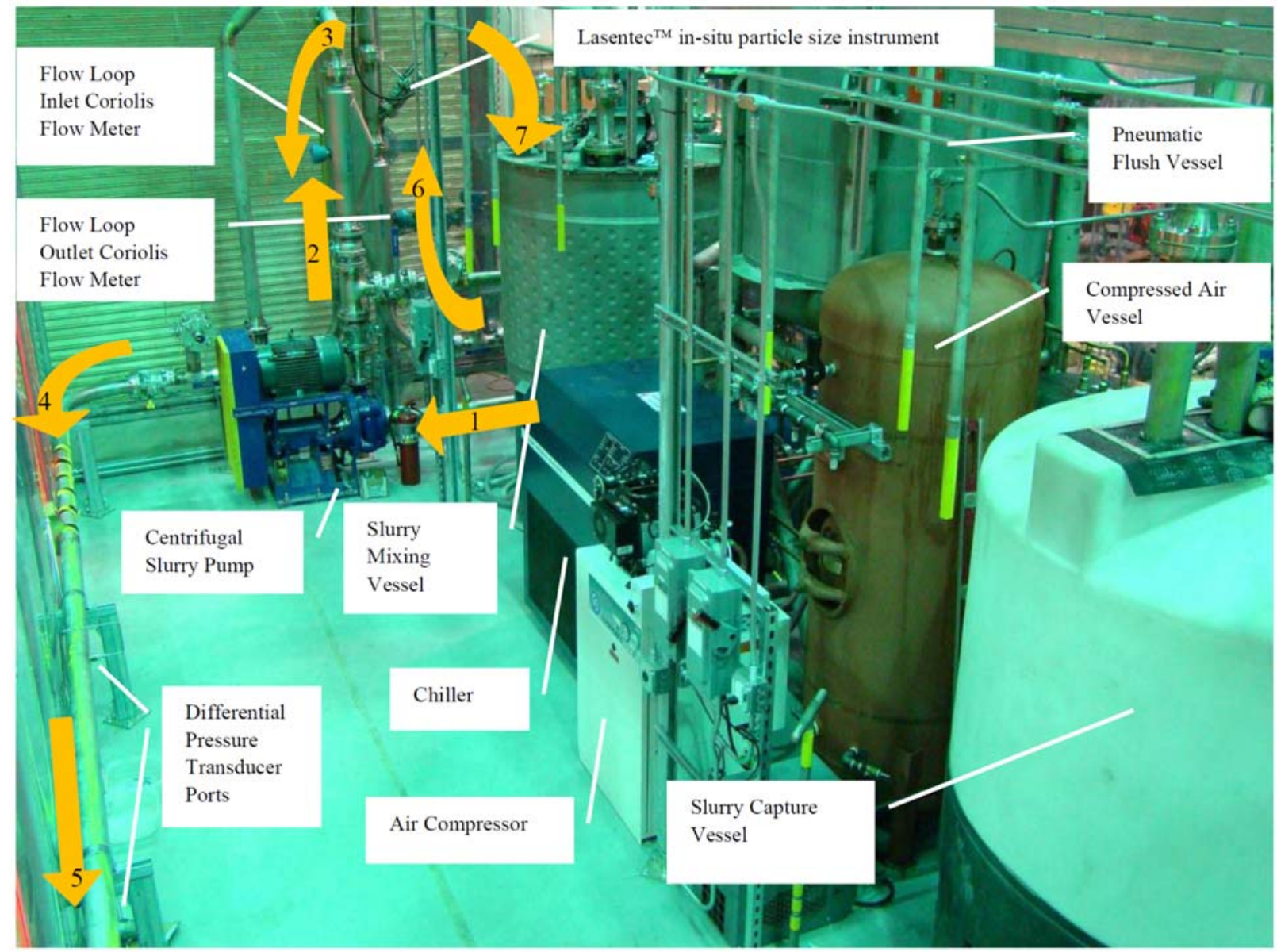

Figure 4.1. Photograph of Flow Loop System with Major Equipment Identified; Arrows and Numbers Indicate Flow Direction in Normal Operation 


\subsection{Test Materials}

The External Flowsheet Review Team (EFRT) expressed concern about the potential for pipe plugging in the Waste Treatment and Immobilization Plant (WTP). Plugging of pipes results when the turbulent and other lifting forces are no longer sufficient to fully maintain the suspension and prevent the particles from settling in the bottom of the pipe. Eventually, the bed thickens to form a stationary bed and the pressure gradient to maintain flow increases rapidly, potentially resulting in complete blockage of the pipe. Rheological properties of the suspending medium and physical properties of the solids determine the flow velocity at which settling begins; these properties include the viscosity and yield stress of the suspending medium and the density and size of the coarse particles. These physical and rheological properties for simulants tested in a pipe loop are described in this section of the report.

Transport velocities were determined for a series of two tests with both simple and complex simulants to further increase the confidence in the results presented in previous M-1 reports describing deposition velocities of nonNewtonian slurries in pipelines. A simple simulant consisting of kaolin clay with well-characterized coarse particles of a single density and a mono-disperse particle-size distribution were used in the first set of testing. A second set of testing used a complex simulant that was designed to mimic the complex mixture of particle sizes and densities expected to be processed in the Waste Treatment Plant (WTP) at Hanford. The complex simulant was the high-level waste (HLW) simulant used in previous WTP anti-foam agent (AFA) testing. This material was manufactured to match the chemical, rheological, and physical characteristics of pretreated HLW from Hanford waste tank AZ-101. Supernatant was decanted from two totes containing the complex simulant. Unfortunately, not enough supernatant was obtained to perform the dilutions needed to complete the test; therefore, additional supernatant was prepared that matches the chemical composition and $\mathrm{pH}$ of the decanted complex simulant supernatant.

\subsection{Simulant Composition}

A simple simulant consisting of soda-lime glass beads suspended in slurries of kaolin clay and water was used to test the technical approach. After testing this simulant, the HLW simulant was tested. Water was used to dilute the simple simulant while supernatant was used to dilute the complex simulant. Supernatant was chosen as the diluent for the complex simulant to avoid dissolution of high $\mathrm{pH}$, insoluble components in this simulant. A mixture of the supernatant from the vendor-produced HLW simulant and a manufactured supernatant was needed that would have sufficient volume to obtain the lower-yield-stress simulants. Tetrasodium pyrophosphate (TSPP) was added to the simple simulant to obtain yield stresses below $3 \mathrm{~Pa}$ without increasing the volume of simulant beyond the capacity of the pipe loop. TSPP is a dispersant for clay particles that has been shown to decrease the yield stress in kaolin-clay slurries (Litzenberger 2003).

\subsubsection{Simple Simulant}

Soda-lime glass beads were selected as the coarse-particle fraction in the simple simulant used for the initial testing. These glass beads have a nominal density of $2.5 \mathrm{~g} / \mathrm{cc}$. Beads with diameters of approximately $150 \mu \mathrm{m}$ were selected to provide coarse particles that would settle in the slurries with substantial yield strengths. Slurries of Feldspar EPK kaolin clay and water were used to adjust the rheology of the test simulant to obtain a yield stress ranging from 30 to $3 \mathrm{~Pa}$. The kaolin clay formed the fine-particle fraction of the test mixture. Water was added to the initial kaolin-clay and water slurry to decrease the yield stress of the suspending medium. TSPP was added to the low-yield-strength simulants to adjust the rheology from $3 \mathrm{~Pa}$ to $0.3 \mathrm{~Pa}$. Manufacturer and product information for each of the components is shown in Table 5.1. The purpose of this simulant is to test deposition velocity correlations at higher yield stresses with controlled particle size and density combinations. The simple simulant is not chemically representative of the actual materials being transported in the WTP. However, physical properties 
such as the particle size, density, and rheological properties of this simulant are representative of a subset of Hanford waste particles that will be transported in the WTP.

Table 5.1. Slurry Materials for Simple Simulant

\begin{tabular}{|c|c|c|}
\hline \multirow[b]{2}{*}{ Slurry Density $\left(\mathrm{g} / \mathrm{cm}^{3}\right)$} & \multicolumn{2}{|c|}{ Insoluble Particles } \\
\hline & $\begin{array}{l}\text { Coarse } \\
150 \mu \mathrm{m} \\
2.5 \mathrm{~g} / \mathrm{cm}^{3}\end{array}$ & $\begin{array}{l}\text { Fines } \\
1 \mu \mathrm{m} \\
2-3 \mathrm{~g} / \mathrm{cm}^{3}\end{array}$ \\
\hline $1.21-1.50$ & $\begin{array}{l}\text { Material: } \\
\text { Soda Lime Glass } \\
\text { Manufacturer: } \\
\text { Potters Industries Inc. } \\
\text { Product: } \\
\text { Spheriglass }{ }^{\circledR} \text { solid A glass spheres, Product } \\
\text { Grade } 2024\end{array}$ & $\begin{array}{l}\text { Material: } \\
\text { Kaolin Clay } \\
\text { Manufacturer: } \\
\text { Feldspar Corp. } \\
\text { Product: } \\
\text { EPK Kaolin }\end{array}$ \\
\hline
\end{tabular}

\subsubsection{Complex Simulant}

The complex simulant was prepared by Optima Chemical for AFA testing. This simulant is based on the chemical composition of AZ-101 Envelope D sludge as shown in Table 5.2. Target compositions for the solids in the complex simulant are also provided in Table 5.2. These targets are based on chemical analysis of a pretreatedHLW precipitated-hydroxide simulant prepared at the Savannah River National Laboratory (SRNL). The recipe for the complex simulant is provided in detail in the Westinghouse Savannah River Company technical report describing the development of this simulant (Eibling 2003). The solids are primarily oxides and hydroxides of aluminum, iron, silicon, and zirconium. The analyses of these simulants was normalized to the iron concentration to obtain similar solids contents. The complex simulant is chemically representative of the actual materials being transported in the WTP. In addition physical properties such as the particle size, density, and rheological properties of this simulant are representative of a subset of Hanford waste particles that will be transported in the WTP.

Table 5.2. Chemical Composition of the Complex Simulant Compared to Actual Tank Waste

\begin{tabular}{lllll}
\hline \multicolumn{5}{c}{ Concentration $(\mu \mathrm{g} / \mathrm{gram}$ solids) } \\
\cline { 2 - 5 } Analyte & $\begin{array}{l}\text { Washed \& Leached } \\
241-\mathrm{AZ}-101\end{array}$ & $\begin{array}{l}\text { SRNL Simulant } \\
(\text { Eibling 2003) }\end{array}$ & Optima Batch 1 & Optima Batch 2 \\
\hline $\mathrm{Ag}$ & 902 & $<208$ & $\mathrm{~nm}^{(\text {b) }}$ & $\mathrm{nm}^{(\text {b) }}$ \\
$\mathrm{Al}$ & 99,872 & 86,659 & 81,749 & 113,000 \\
$\mathrm{~B}$ & 91 & 3,573 & 314 & $<580$ \\
$\mathrm{Ba}$ & 1,510 & 1,657 & 1,484 & 1,612 \\
$\mathrm{C}_{2} \mathrm{O}_{4}$ & 518 & 186 & 633 & 325 \\
\hline
\end{tabular}


Table 5.2. (contd)

\begin{tabular}{|c|c|c|c|c|}
\hline \multirow[b]{2}{*}{ Analyte } & \multicolumn{4}{|c|}{ Concentration ( $\mu \mathrm{g} / \mathrm{gram}$ solids) } \\
\hline & $\begin{array}{l}\text { Washed \& Leached } \\
\text { 241-AZ-101 }\end{array}$ & $\begin{array}{l}\text { SRNL Simulant } \\
\text { (Eibling 2003) }\end{array}$ & Optima Batch 1 & Optima Batch 2 \\
\hline $\mathrm{Ca}$ & 7,505 & 8,884 & 9,018 & 710 \\
\hline $\mathrm{Cd}$ & 14,500 & 11,098 & 13,161 & 13,943 \\
\hline $\mathrm{Ce}$ & 5,240 & 3,444 & 2,453 & $<1,329$ \\
\hline $\mathrm{Cl}$ & 703 & 443 & 1,267 & 848 \\
\hline Co & 128 & 150 & 82 & $<135$ \\
\hline $\mathrm{Cr}$ & 2,284 & 2,344 & 2,750 & 2,328 \\
\hline $\mathrm{Cu}$ & 584 & 609 & 494 & 508 \\
\hline $\mathrm{F}$ & 390 & 172 & 284 & 310 \\
\hline $\mathrm{Fe}$ & $202,384^{(\mathrm{a})}$ & & & \\
\hline K & 2,000 & 2,840 & 4,038 & $<228,000$ \\
\hline $\mathrm{La}$ & 5,808 & 3,755 & 4,816 & 4,996 \\
\hline $\mathrm{Mg}$ & 1,540 & 1,554 & 2,543 & 1,278 \\
\hline $\mathrm{Mn}$ & 5,364 & 5,438 & 5,474 & 5,810 \\
\hline Mo & 66 & $<90$ & 138 & 218 \\
\hline $\mathrm{Na}$ & 54,545 & 41,630 & 61,020 & $<80,900$ \\
\hline $\mathrm{Nd}$ & 4,290 & 3,108 & 2,737 & $<2,048$ \\
\hline $\mathrm{Ni}$ & 9,992 & 9,970 & 9,497 & 9,470 \\
\hline $\mathrm{NO}_{2}$ & 7,268 & 4,623 & 6,745 & 3,971 \\
\hline $\mathrm{NO}_{3}$ & 2,178 & 48,686 & 90,723 & 58,643 \\
\hline $\mathrm{P}$ & 4,505 & 4,505 & 3,141 & 2,309 \\
\hline $\mathrm{Pb}$ & $\mathrm{nm}^{(\mathrm{b})}$ & $\mathrm{nm}^{(\mathrm{b})}$ & 1,690 & 1,496 \\
\hline $\mathrm{PO}_{4}$ & $<340$ & 627 & 311 & 427 \\
\hline $\mathrm{Rh}$ & 512 & 546 & $\mathrm{~nm}^{(\mathrm{b})}$ & $\mathrm{nm}^{(\mathrm{b})}$ \\
\hline $\mathrm{Ru}$ & 1,600 & 947 & $\mathrm{~nm}^{(\mathrm{b})}$ & $\mathrm{nm}^{(\mathrm{b})}$ \\
\hline S & $\mathrm{nm}^{(\mathrm{b})}$ & $\mathrm{nm}^{(\mathrm{b})}$ & 7,478 & $<4,750$ \\
\hline $\mathrm{Si}$ & 13,055 & 21,558 & 18,246 & 15,541 \\
\hline $\mathrm{Sn}$ & 3,600 & 1,554 & 3,619 & 4,648 \\
\hline $\mathrm{SO}_{4}$ & 2,410 & 1,997 & 6,491 & 2,699 \\
\hline $\mathrm{Sr}$ & $\mathrm{nm}^{(\mathrm{b})}$ & $\mathrm{nm}^{(\mathrm{b})}$ & 3,084 & 3,371 \\
\hline $\mathrm{Ti}$ & 178 & 341 & 302 & 257 \\
\hline $\mathrm{Zn}$ & 278 & 337 & 292 & 523 \\
\hline $\mathrm{Zr}$ & 65,050 & 60,420 & 27,863 & 106,615 \\
\hline
\end{tabular}

(a) Concentrations are normalized to iron as measured in the washed and leached actual waste sample from Tank 241-AZ-101. (b) These analytes were not measured. 
Supernatant composition from the Optima simulant was measured in the analytical laboratory at PNNL using Inductively Coupled Argon Plasma Optical Emission Spectrometry (ICP-OES) and Ion Chromatography (IC). Additional supernatant was made based on this analysis to provide sufficient diluent for the complex-simulant testing. The supernatant from the Optima simulant and the additional supernatant were combined prior to testing. Analysis of this combined supernatant was also performed at PNNL by the same methods used for the Optima simulant. The results of these analyses are provided in Table 5.3.

Table 5.3. Chemical Composition of the Complex-Simulant Supernatant

\begin{tabular}{llll}
\hline & Concentration $(\mu \mathrm{g} / \mathrm{ml})$ & & \\
\cline { 2 - 4 } Analyte & Optima Simulant & Additional Supernatant* & Combined Supernatant \\
\hline $\mathrm{B}$ & 70 & 70 & 64 \\
$\mathrm{CO}_{3}$ & $\mathrm{n} / \mathrm{m}$ & 5793 & 6150 \\
$\mathrm{C}_{2} \mathrm{O}_{4}$ & 89 & 0 & $\mathrm{n} / \mathrm{m}$ \\
$\mathrm{Cl}$ & 279 & 277 & 265 \\
$\mathrm{Cr}$ & 225 & 69 & 49 \\
$\mathrm{~F}$ & 53 & 53 & 50 \\
$\mathrm{~K}$ & 905 & 898 & 843 \\
$\mathrm{Mo}$ & 28 & 27 & 25 \\
$\mathrm{Na}$ & 13,150 & 13,070 & 12,750 \\
$\mathrm{NO}_{2}$ & 1430 & 1421 & 1340 \\
$\mathrm{NO}_{3}$ & 19,100 & 18,181 & 17,900 \\
$\mathrm{PO}_{4}$ & 40 & 39 & 37 \\
$\mathrm{SO}_{4}$ & 822 & 827 & 775 \\
$\mathrm{pH}^{*}$ & 12.2 & 12.2 & 12.0 \\
\hline
\end{tabular}

* Calculated concentrations based on the mass of the added chemicals and the volume of additional supernatant prepared.

A scanning electron microscope image of the coarse-particle component of the complex simulant (fastestsettling component) is shown in Figure 5.1. The largest particles are roughly spherical with diameters of approximately $80 \mu \mathrm{m}$. These particles are composed of aluminum hydroxide, probably in the form of gibbsite. Images were obtained by centrifuging a subsample of the complex simulant, sampling the bottom of the centrifuge cone, placing the sample on a carbon-backed microscope stud, carbon coating the sample, and measuring the sample with an Amray Model 1610T Scanning Electron Microscope [SEM] coupled with a x-ray fluorescence detector. Images of the slower-settling particles were also obtained by this method except the samples were taken from the top of the solids in the centrifuge cone. Figure 5.2 is an image of these slower-settling particles. Particles in this sample are primarily sodium, iron, and zirconium hydroxides or phosphates with diameters less than $10 \mu \mathrm{m}$. In these images, the submicron particles form a cake on the microscope stud. The micron-sized particles tend to sit in this cake. 


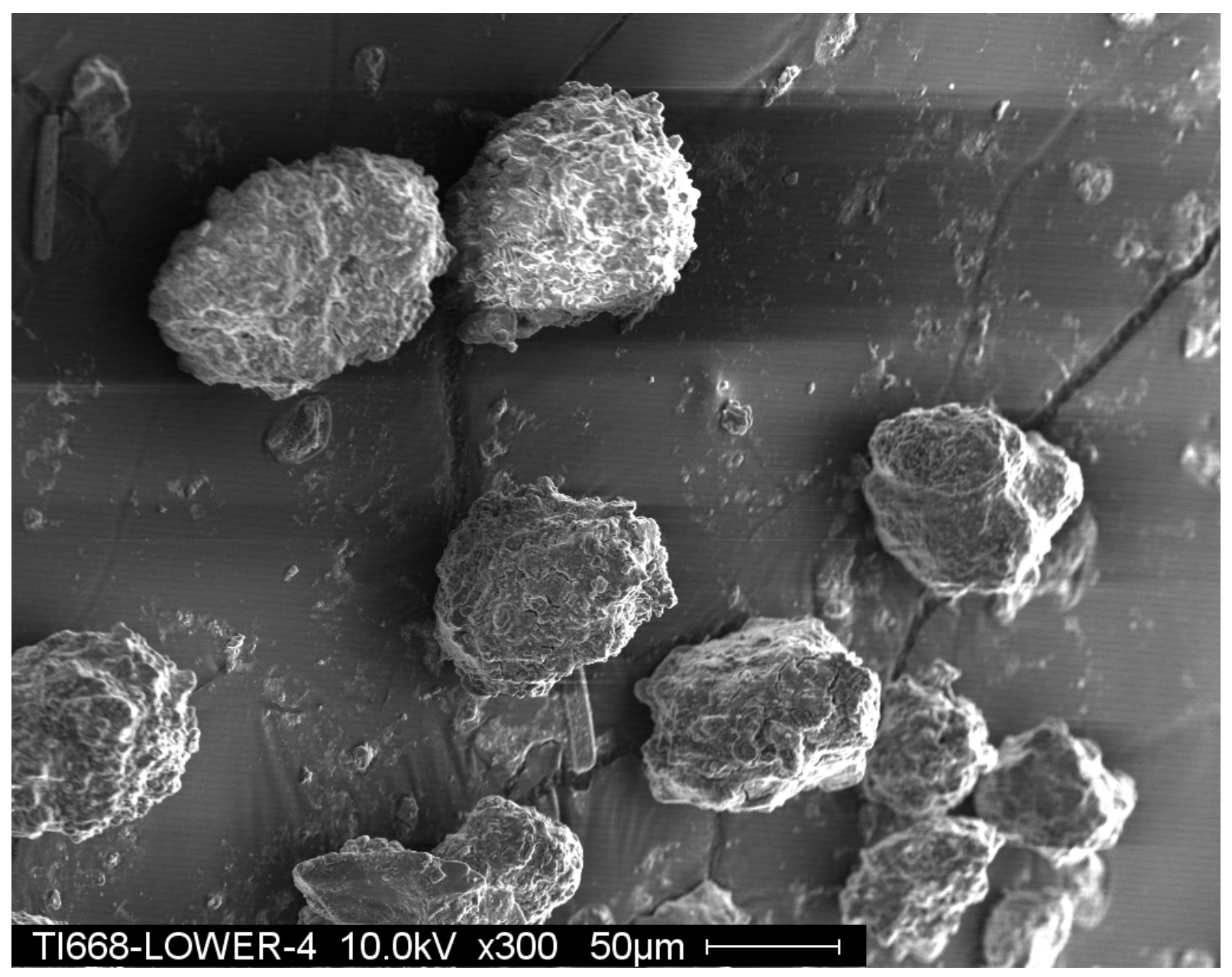

Figure 5.1. Micrograph of Fastest-Settling Particles in the Complex Simulant 


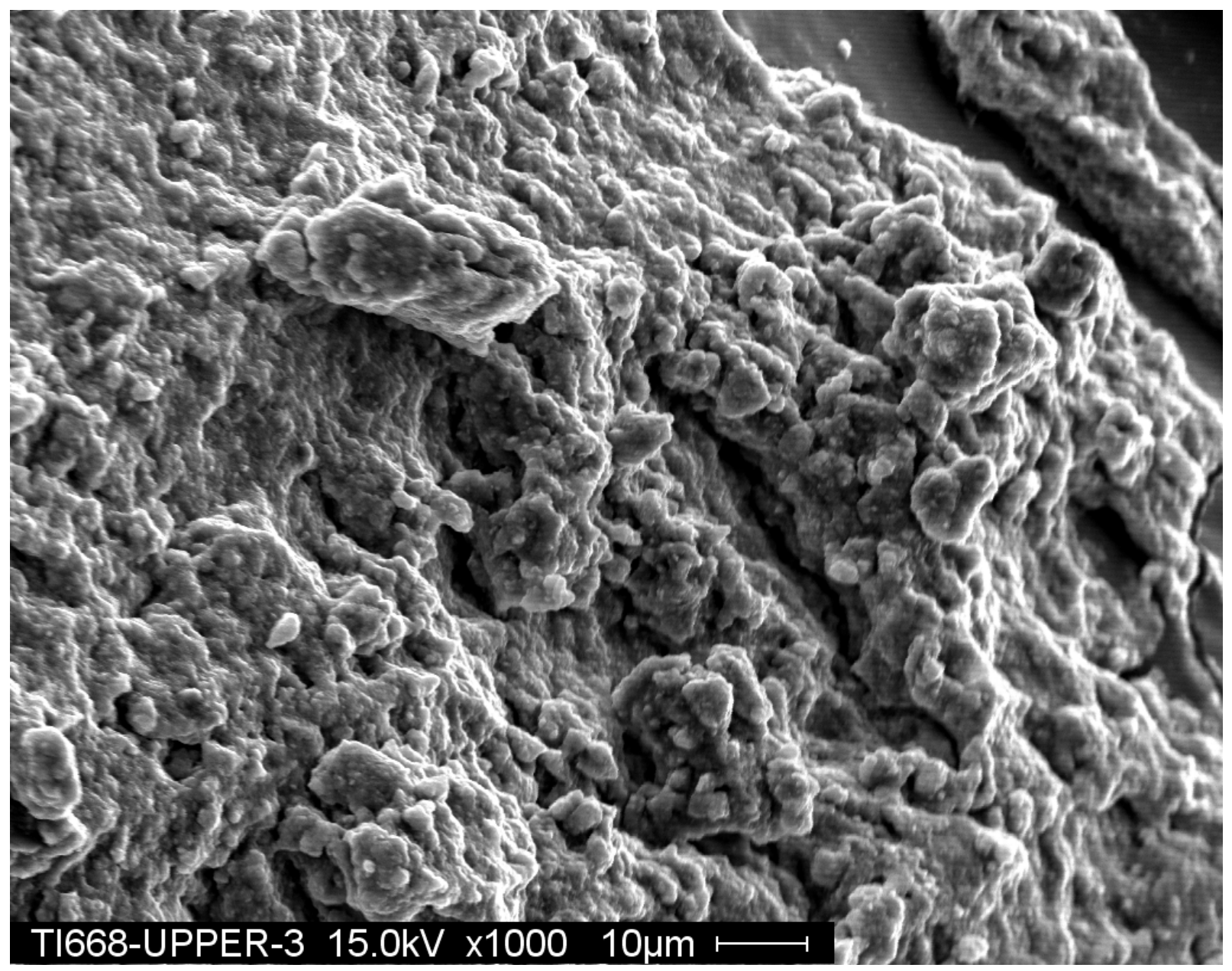

Figure 5.2. Micrograph of Slower-Settling Particles in the Complex Simulant

\subsection{Physical and Rheological Properties}

The physical and rheological properties of the resulting test slurries are reported in Tables 5.4 and 5.5 for the simple and complex simulants, respectively. Bulk and component densities; volume and mass fractions along with mass per unit volume of slurry of each component; total, dissolved, and undissolved solids, and the Casson model fit to the rheograms for each test are reported in these tables. Physical and rheological properties that are reported in these tables were measured on samples that were taken at the beginning of each test after the rheological properties of the simulant were adjusted. Particle-size distribution for the simulants is also reported in each table. This particle distribution includes the average and standard deviation of the reported percentiles averaged over all of the tests. 
Table 5.4. Properties of the Simple Simulant

\begin{tabular}{|c|c|c|c|c|c|c|c|c|c|c|c|}
\hline Test Instruction $\mathrm{Nu}$ & & 653 & 654 & 655 & 656 & 657 & 658 & 659 & 545 & 551 & 645 \\
\hline \multicolumn{12}{|c|}{ Mass per Unit Volume } \\
\hline Kaolin Clay & $\mathrm{g} / \mathrm{L}$ & 526 & 419 & 386 & 346 & 324 & 307 & 261 & 239 & 235 & 243 \\
\hline Glass Beads & $\mathrm{g} / \mathrm{L}$ & 237 & 189 & 174 & 156 & 146 & 138 & 117 & 108 & 106 & 109 \\
\hline Dissolved Solids & $\mathrm{g} / \mathrm{L}$ & 0 & 0 & 0 & 0 & 0 & 0 & 0 & 0 & 0 & 0 \\
\hline Water & $\mathrm{g} / \mathrm{L}$ & 732 & 767 & 786 & 819 & 833 & 828 & 857 & 873 & 875 & 862 \\
\hline \multicolumn{12}{|l|}{ Volume Fraction } \\
\hline Kaolin Clay & $\mathrm{vol} \%$ & $21 \%$ & $16 \%$ & $15 \%$ & $14 \%$ & $13 \%$ & $12 \%$ & $10 \%$ & $9 \%$ & $9 \%$ & $10 \%$ \\
\hline Glass Beads & vol $\%$ & $9 \%$ & $8 \%$ & $7 \%$ & $7 \%$ & $6 \%$ & $6 \%$ & $5 \%$ & $4 \%$ & $4 \%$ & $5 \%$ \\
\hline Dissolved Solids & vol $\%$ & $0 \%$ & $0 \%$ & $0 \%$ & $0 \%$ & $0 \%$ & $0 \%$ & $0 \%$ & $0 \%$ & $0 \%$ & $0 \%$ \\
\hline Water & vol $\%$ & $73 \%$ & $77 \%$ & $79 \%$ & $82 \%$ & $83 \%$ & $83 \%$ & $86 \%$ & $87 \%$ & $88 \%$ & $86 \%$ \\
\hline \multicolumn{12}{|l|}{ Mass Fraction } \\
\hline Kaolin Clay & $\operatorname{mass} \%$ & $34.5 \%$ & $29.9 \%$ & $28.1 \%$ & $25.7 \%$ & $24.4 \%$ & $23.6 \%$ & $20.7 \%$ & $19.2 \%$ & $19.0 \%$ & $19.6 \%$ \\
\hline Glass Beads & $\operatorname{mass} \%$ & $16.5 \%$ & $14.3 \%$ & $13.5 \%$ & $12.3 \%$ & $11.7 \%$ & $11.3 \%$ & $9.9 \%$ & $9.2 \%$ & $9.1 \%$ & $9.4 \%$ \\
\hline Dissolved Solids & $\operatorname{mass} \%$ & $0.0 \%$ & $0.0 \%$ & $0.0 \%$ & $0.0 \%$ & $0.0 \%$ & $0.0 \%$ & $0.0 \%$ & $0.0 \%$ & $0.0 \%$ & $0.0 \%$ \\
\hline Water & $\operatorname{mass} \%$ & $49.0 \%$ & $55.8 \%$ & $58.4 \%$ & $62.0 \%$ & $63.9 \%$ & $65.1 \%$ & $69.4 \%$ & $71.6 \%$ & $71.9 \%$ & $71.0 \%$ \\
\hline \multicolumn{12}{|l|}{ Component Density } \\
\hline Kaolin Clay & $\mathrm{kg} / \mathrm{L}$ & 2.50 & 2.50 & 2.50 & 2.50 & 2.50 & 2.50 & 2.50 & 2.50 & 2.50 & 2.50 \\
\hline Glass Beads & $\mathrm{kg} / \mathrm{L}$ & 2.50 & 2.50 & 2.50 & 2.50 & 2.50 & 2.50 & 2.50 & 2.50 & 2.50 & 2.50 \\
\hline Supernatant & $\mathrm{kg} / \mathrm{L}$ & 0.98 & 0.98 & 0.98 & 0.98 & 0.98 & 0.98 & 0.98 & 0.98 & 0.98 & 0.98 \\
\hline Bulk & $\mathrm{kg} / \mathrm{L}$ & 1.50 & 1.37 & 1.35 & 1.32 & 1.30 & 1.27 & 1.24 & 1.22 & 1.22 & 1.21 \\
\hline Total Solids & $\operatorname{mass} \%$ & $51.0 \%$ & $44.2 \%$ & $41.6 \%$ & $38.0 \%$ & $36.1 \%$ & $34.9 \%$ & $30.6 \%$ & $28.4 \%$ & $28.1 \%$ & $29.0 \%$ \\
\hline Undissolved Solids & mass $\%$ & $51.0 \%$ & $44.2 \%$ & $41.6 \%$ & $38.0 \%$ & $36.1 \%$ & $34.9 \%$ & $30.6 \%$ & $28.4 \%$ & $28.1 \%$ & $29.0 \%$ \\
\hline
\end{tabular}


Table 5.4. (contd)

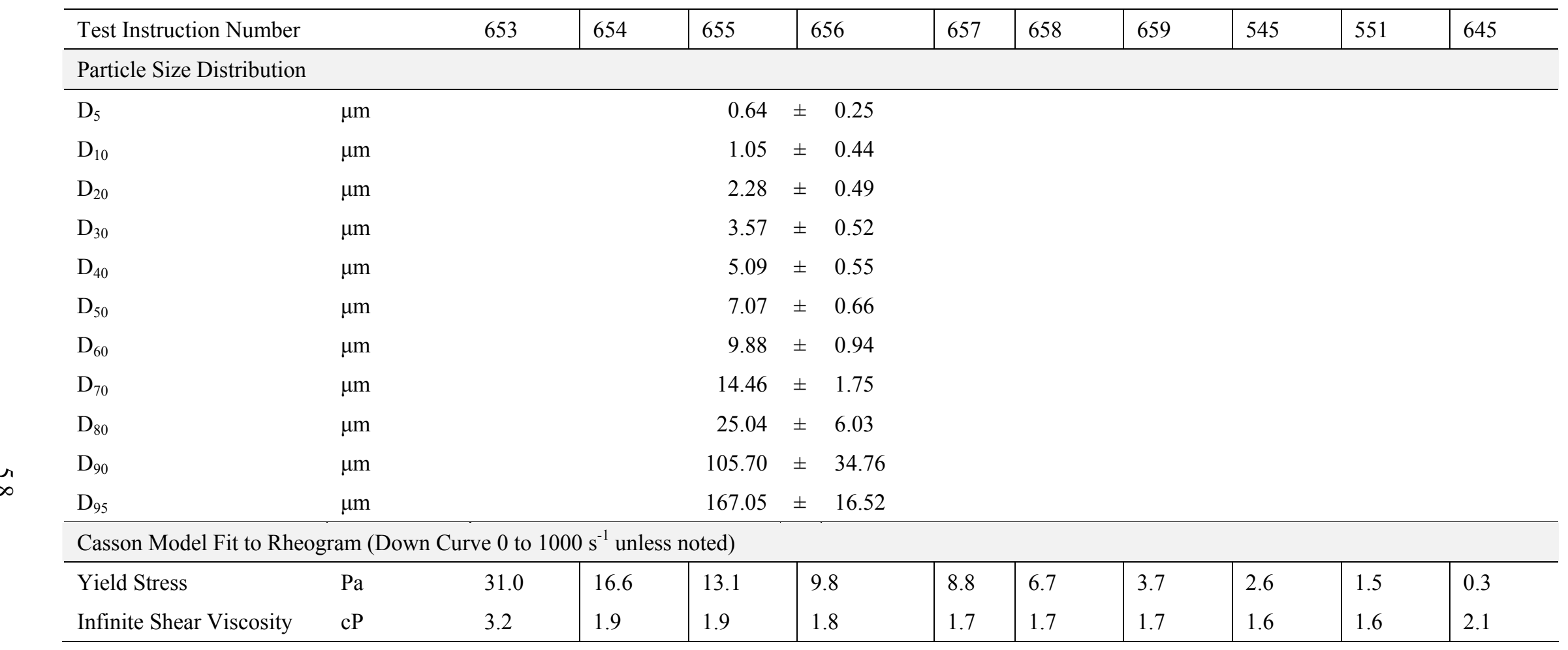


Table 5.5. Properties of the Complex Simulant

\begin{tabular}{|c|c|c|c|c|c|c|c|c|c|}
\hline Test Instruction Number & & 661 & 662 & 664 & 665 & 666 & \multicolumn{2}{|c|}{667} & 668 \\
\hline \multicolumn{10}{|l|}{ Mass per Unit Volume } \\
\hline Undissolved Solids & $\mathrm{g} / \mathrm{L}$ & 242 & 222 & 201 & 175 & 163 & \multicolumn{2}{|c|}{146} & 132 \\
\hline Dissolved Solids & $\mathrm{g} / \mathrm{L}$ & 40 & 40 & 40 & 38 & 39 & \multicolumn{2}{|c|}{39} & 39 \\
\hline Water & $\mathrm{g} / \mathrm{L}$ & 918 & 919 & 919 & 917 & 918 & \multicolumn{2}{|c|}{895} & 919 \\
\hline \multicolumn{10}{|l|}{ Mass Fraction } \\
\hline Undissolved Solids & $\operatorname{mass} \%$ & $20.1 \%$ & $18.8 \%$ & $17.3 \%$ & $15.5 \%$ & $14.6 \%$ & \multicolumn{2}{|c|}{$13.5 \%$} & $12.1 \%$ \\
\hline Dissolved Solids ( $\left.\mathrm{m}_{\mathrm{DS}} / \mathrm{m}_{\text {Slurry }}\right)$ & $\operatorname{mass} \%$ & $3.4 \%$ & $3.3 \%$ & $3.4 \%$ & $3.4 \%$ & $3.5 \%$ & \multicolumn{2}{|c|}{$3.6 \%$} & $3.6 \%$ \\
\hline Water & $\operatorname{mass} \%$ & $76.5 \%$ & $77.8 \%$ & $79.3 \%$ & $81.1 \%$ & $81.9 \%$ & \multicolumn{2}{|c|}{$82.9 \%$} & $84.3 \%$ \\
\hline \multicolumn{10}{|l|}{ Component Density } \\
\hline Supernatant & $\mathrm{kg} / \mathrm{L}$ & 1.03 & 1.03 & 1.03 & 1.03 & 1.03 & \multicolumn{2}{|c|}{1.03} & 1.03 \\
\hline Bulk & $\mathrm{kg} / \mathrm{L}$ & 1.20 & 1.18 & 1.16 & 1.13 & 1.12 & \multicolumn{2}{|c|}{1.08} & 1.09 \\
\hline Total Solids & $\operatorname{mass} \%$ & $23.5 \%$ & $22.2 \%$ & $20.7 \%$ & $18.9 \%$ & $18.1 \%$ & \multicolumn{2}{|c|}{$17.1 \%$} & $15.7 \%$ \\
\hline Dissolved Solids $\left(\mathrm{m}_{\mathrm{DS}} / \mathrm{m}_{\mathrm{Sup}}\right)$ & $\operatorname{mass} \%$ & $4.2 \%$ & $4.1 \%$ & $4.1 \%$ & $4.0 \%$ & $4.1 \%$ & \multicolumn{2}{|c|}{$4.1 \%$} & $4.1 \%$ \\
\hline \multicolumn{7}{|c|}{ Casson Flow Curve (Down Curve 0 to $1000 \mathrm{~s}^{-1}$ unless noted) } & \multicolumn{3}{|c|}{ w/o AFA w/AFA } \\
\hline Yield Stress & $\mathrm{Pa}$ & 28.0 & 18.6 & 12.8 & 7.5 & 5.1 & 2.6 & 3.1 & 0.9 \\
\hline Infinite Shear Viscosity & $\mathrm{cP}$ & 3.3 & 3.2 & 2.5 & 2.0 & 2.1 & 2.5 & 2.3 & 2.2 \\
\hline \multicolumn{10}{|l|}{ Particle-Size Distribution } \\
\hline $\mathrm{D}_{5}$ & $\mu \mathrm{m}$ & & & 0.35 & \pm & 0.42 & & & \\
\hline $\mathrm{D}_{10}$ & $\mu \mathrm{m}$ & & & 0.58 & \pm & 0.60 & & & \\
\hline $\mathrm{D}_{20}$ & $\mu \mathrm{m}$ & & & 0.95 & \pm & 1.02 & & & \\
\hline $\mathrm{D}_{30}$ & $\mu \mathrm{m}$ & & & 1.39 & \pm & 1.53 & & & \\
\hline $\mathrm{D}_{40}$ & $\mu \mathrm{m}$ & & & 2.19 & \pm & 2.12 & & & \\
\hline $\mathrm{D}_{50}$ & $\mu \mathrm{m}$ & & & 3.59 & \pm & 2.51 & & & \\
\hline $\mathrm{D}_{60}$ & $\mu \mathrm{m}$ & & & 5.44 & \pm & 3.08 & & & \\
\hline $\mathrm{D}_{70}$ & $\mu \mathrm{m}$ & & & 8.32 & \pm & 4.21 & & & \\
\hline $\mathrm{D}_{80}$ & $\mu \mathrm{m}$ & & & 14.64 & \pm & 7.39 & & & \\
\hline $\mathrm{D}_{90}$ & $\mu \mathrm{m}$ & & & 42.14 & \pm & 19.14 & & & \\
\hline $\mathrm{D}_{95}$ & $\mu \mathrm{m}$ & & & 72.41 & \pm & 17.86 & & & \\
\hline
\end{tabular}




\subsubsection{Density}

For each test, the bulk density of the slurry was measured in situ with Coriolis flow meters and on a subsample taken from the sampling port positioned downstream of the first Coriolis flow meter. Densities from these two measurement methods are compared in Table 5.6. Coriolis readings reported in Table 5.6 are the densities measured near the same time the sample was taken. Bulk densities of the subsamples were calculated from the mass of the sample measured in a $50 \mathrm{ml}$ pycnometer. The reported value is the average of duplicate measurements. Bulk densities provided in Tables 5.4 and 5.5 are measured densities from the subsamples.

Table 5.6. Properties of the Complex Simulant

\begin{tabular}{llll}
\hline \multirow{2}{*}{ Simulant } & Test Instruction & Density $(\mathrm{g} / \mathrm{ml})$ & \\
\cline { 3 - 4 } Number & Subsample & Coriolis Meter \\
\hline Simple (Clay) & 653 & 1.50 & 1.425 \\
& 654 & 1.37 & 1.352 \\
& 655 & 1.34 & 1.329 \\
656 & 1.32 & 1.300 \\
657 & 1.30 & 1.285 \\
Complex (HLW) & 658 & 1.27 & 1.258 \\
& 659 & 1.24 & 1.221 \\
& 545 & 1.22 & 1.205 \\
& 551 & 1.22 & 1.202 \\
& 645 & 1.21 & 1.202 \\
& 661 & 1.20 & 1.225 \\
& 662 & 1.18 & 1.206 \\
& 664 & 1.16 & 1.215 \\
& 665 & 1.13 & 1.253 \\
& 666 & 1.12 & 1.250 \\
667 & 1.08 & 1.170 \\
& 668 & 1.09 & 1.129 \\
\hline
\end{tabular}

Bulk density measurements obtained by both methods gave similar results for the simple simulant. Coriolismeter densities were about $0.02 \mathrm{~g} / \mathrm{ml}$ lower than those measured in the subsamples using a $50-\mathrm{ml}$ pycnometer. Because the Coriolis-meter densities are measured in situ, they are not susceptible to the subsampling errors associated with the measurements in the pycnometer. Obtaining accurate densities by the pycnometer method requires that the $50 \mathrm{ml}$ sample is representative of the bulk. Settling in the sample and the location at which the subsample is obtained may influence the densities. If the density sample is taken from the bottom of the subsample, higher solids content and more dense particles may be obtained, which will result in higher measured densities.

For the complex simulant, the bulk densities measured by the Coriolis meter and the pycnometer were similar for the first two tests and the last two tests. Densities measured by the Coriolis meter for the other tests were 
significantly higher than those measured by the pycnometer. The trend of the densities measured by the Coriolis meter in these tests also does not match the dilutions made. During these tests, entrainment of gas in the slurries was observed. During the final two tests, anti-foaming agent (AFA) was added to mitigate this entrainment. The addition of AFA to the simulant corresponds with better agreement in the bulk densities between the two methods. In test 667, densities measured by the Coriolis meter prior to the addition of AFA were approximately $1.27 \mathrm{~g} / \mathrm{ml}$ and decreased to the value reported in Table $5.6(1.170 \mathrm{~g} / \mathrm{ml})$ after the addition of AFA. Entrained gas is a known problem for Coriolis flow meters. Heywood and Mehta (1996) report that entrained air degraded meter performance to the point where measured and actual flow rates varied by 15\%. AZ-101 HLW simulant tests with AFA and glassbead/kaolin slurry tests appear not to have gas-retention issues.

Density of the supernatant obtained by centrifuging the samples was made using the pycnometer method described previously. The supernatant densities are averaged over all of the tests since the density of the supernatant did not change significantly throughout the tests. Impact of subsampling on the supernatant densities was minimal since the sample is homogeneous. Glass-bead and kaolin densities reported in Tables 4.3 are literature values provided by the vendor.

\subsubsection{Solids and Moisture Content}

Total-solids content and dissolved-solids content were measured on a subsample from each test. Both the totalsolids and dissolved-solids content were measured on a Mettler Toledo Halogen Moisture Analyzer Model HR83 according to PNNL technical procedure TPR-RPP-WTP-648. In this procedure a small sample $(\sim 5 \mathrm{~g})$ of supernatant (for dissolved solids) or slurry (for total solids) is heated in the moisture analyzer to $95^{\circ} \mathrm{C}$ and held at that temperature for 30 minutes to remove the free water, the temperature is then ramped up to $105^{\circ} \mathrm{C}$, and held at that final temperature till the mass decreases by less than 0.001 grams over 140 seconds. The mass of the dried sample divided by the mass of the initial sample is the total-solids content, for the slurry, and dissolved-solids content, for the supernatant. Calibration of both the temperature and mass readings in the moisture analyzer are checked on a regular basis (daily for the balance and weekly for the temperature calibration).

Dissolved-solids content was measured for the supernatant by centrifuging a fraction of the subsample. For the simple simulant, no dissolved solids were observed in the samples. This is consistent with the composition of the simulant, which is insoluble kaolin clay and glass beads suspended in water. The dissolved-solids content of the complex simulant did not vary significantly over the range of the tests. The average dissolved-solids content for the complex simulant is $4.1 \%$.

Undissolved-solids content is calculated from the dissolved solids and total solids content according to equation 5.1. Undissolved-solids content represents the fraction of insoluble solids in the slurry. The mass fraction of each component was calculated from the solids, dissolved-solids, and undissolved-solids contents. The mass fraction of the undissolved solids is equal to the undissolved-solids content, but the mass fraction of dissolved solids is dissolved-solids content multiplied by the mass ratio of supernatant to slurry. This value can also be calculated by subtracting the undissolved-solids content from the total solids content. The water content is unity minus the total solids contents. For the simple simulant, the mass and volume fractions of kaolin clay and glass beads in the simulant during the first test (test 653) were determined while preparing the test simulant. The total volume in the system was measured via level probes in the mixing vessel, and the mass of each component added to the simulant was measured. These data allow one to calculate the volume and mass fraction of these two types of insoluble particles in the flow-loop system. For the remaining tests of the simple simulant, the mass fraction of these components was calculated using this ratio.

$$
W t \% \text { Undissolved Solids }=\left(1-\frac{100-W t \% \text { Total Solids }}{100-W t \% \text { Dissolved Solids }}\right) \times 100
$$


Volume fractions of each component were calculated by multiplying the mass fraction of that component by the reciprocal of the ratio of the density of the component to the bulk density. Mass per unit volume was calculated by multiplying the mass fraction of that component by the bulk density. For the simple simulant, the masses per unit volume of the kaolin clay and the glass beads were calculated by multiplying the mass per unit volume of the total undissolved solids in the slurry by the ratio of the mass of the individual component (kaolin or glass) to the sum of the masses of the kaolin clay and the glass beads. The volume fractions of the kaolin clay and the glass beads were calculated by multiplying the volume fraction of the total undissolved solids in the slurry by the ratio of the volume of the individual component (kaolin or glass) to the sum of the volumes of the kaolin and glass. The mass fractions of the kaolin clay and the glass beads were calculated by multiplying the mass fraction of the undissolved solids in the slurry by the ratio of the mass of the kaolin or the glass to the mass of the total undissolved solids (kaolin + glass).

\subsubsection{Particle-Size Distribution}

Particle-size distribution of the each of the simulants was measured using laser-diffraction technology. A Malvern Mastersizer 2000 was used to measure the samples; proprietary software for that particle-size analyzer calculates the particle-size distribution from the light-scattering patterns using Mie scattering theory. Analysis was performed for particles with diameters between 0.02 and 1400 microns $(\mu \mathrm{m})$ to determine the particle-size distribution of the simulants.

Particle-size calibration standards were measured prior to measuring the distribution of these simulants. The results obtained during the measurement and the reported values are provided in Table 5.7 The mean particle size (50\% cumulative undersize) and the 10 and $90 \%$ cumulative undersize measured on the standard are within the uncertainty of the reported values. 
Table 5.7. Particle-Size Standard for the Malvern Mastersizer 2000 Analyzer

\begin{tabular}{llll}
\hline & \multicolumn{3}{l}{ Particle Diameter at the Cumulative Percent Undersize $(\mu \mathrm{m})$} \\
\cline { 2 - 4 } & 10 & 50 & 90 \\
\hline Certificate Value & 37.64 & 62.55 & 90.72 \\
Uncertainty $^{(\mathrm{a})}$ & 1.13 & 1.25 & 2.72 \\
Measured Value & 37.04 & 62.40 & 90.72 \\
Difference & 0.60 & 0.15 & 0.00 \\
\hline
\end{tabular}

(a) Based on upper and lower limit.

Small aliquots of the simulant samples $(<1 \mathrm{ml})$ were diluted in water in a variable-speed recirculator (Hydro G) prior to making the particle-size measurements. The total volume of the recirculator is $800 \mathrm{ml}$. Appropriate dilutions were determined by the amount of light passing through the diluted material (obscuration) as measured by the particle-size analyzer. Measurements were made at a pump rate of $3000 \mathrm{rpm}$.

All of the simulant samples were shaken prior to taking aliquots for measurement of particle-size distribution. Measurements were made on samples with no additional treatment and on samples that were sonicated. Sonication was performed at $50 \%$ and $75 \%$ of full power; particle-size distribution was also measured after sonication was completed. The results provided in Tables 5.4 and 5.5 are the distribution after sonication and are reported as an average and standard deviation of the percentiles for all tests for each simulant.

Real-time particle-size data were obtained in the pipe loop with a Mettler-Toledo Lasentec ${ }^{\mathrm{TM}}$ focused-beam reflectance-measurement (FBRM) system. Installation and operation of this system in the pipe loop is described in detail in the reference-case testing report (Poloski et al. 2009). Particle-size data from the Lasentec system are not provided in this report but are available upon request.

At the beginning of each test, a sample of the simulant was taken from the mixing tank and a flow curve was measured to determine what adjustment was needed to match the target rheology (Bingham yield stress). The rheology of the simulant was adjusted to approach the desired Bingham yield stress target by adding water to reduce the yield stress, or by either removing water via settle/decant or adding $\mathrm{MgSO}_{4}$ to increase the yield stress. On the order of 10 parts per million of $\mathrm{MgSO}_{4}$ were required to significantly raise the yield stress of the slurry. For this reason, the rheological properties sometimes do not follow the same trend as solids concentration. After the rheology was adjusted, another sample was drawn, and a flow curve was again measured. Rheology samples were taken at regular intervals (generally about every 4 hours) throughout the test.

\subsubsection{Rheology}

Flow curves were obtained on a TA Instruments AR2000 rheometer configured with a standard-size recessedend concentric-cylinder geometry with a $1 \mathrm{~mm}$ gap. The shear rate was ramped from 0 to $1000 \mathrm{~s}^{-1}$ over a 5 -minute period (Smith and Prindiville 2002). The shear rate was held at $1000 \mathrm{~s}^{-1}$ for 1 minute and then ramped down from 1000 to $0 \mathrm{~s}^{-1}$ over another 5 -minute period. The temperature of the sample was controlled at $25^{\circ} \mathrm{C}$. Bingham-plastic and Casson curve fits were obtained for the up and down ramp portions of each curve. For the lower-shear-strength materials, Taylor-vortex formation at higher rotational rates was observed; therefore, the rheograms were fit over a smaller shear-rate range. The range over which these rheograms were analyzed is indicated in the footnotes of 
Tables 5.4 and 5.5.

A description of the Bingham-plastic curve-fit model is provided in Appendix A of the reference-case testing report (Poloski et al. 2009). A brief description of the Casson model is provided in Appendix A of this report.

A silicon-oil Newtonian-viscosity standard was run at regular intervals (at least monthly) to verify that the instrument was working properly. The viscosity of these standards was always within $10 \%$ of the reported value. The yield-stress and viscosity values reported for each test in Tables 5.4 and 5.5 are the Casson yield stress and viscosity from each of the down-ramp portions of the flow curves measured on the rheology samples after the target yield stress was achieved. These rheograms with the Casson fit are provided in Appendix D. The rheograms of additional samples taken during the test are compared with the initial rheogram in Appendix D. The data for all of the curve fits can be obtained from the Laboratory Record Books (LRBs).

Table 5.8 provides a comparison of the Casson and Bingham-Plastic model fits for the rheograms reported in Tables 5.4 and 5.5. For these samples, the Casson model fits the rheograms much better than the Bingham-Plastic model. As the sample is diluted, the sample approaches the Bingham-Plastic model. At low yield stresses, the Bingham-Plastic model may provide an effective model for the materials tested. The Bingham-Plastic and Casson models are defined according to equations 5.2 and 5.3, respectively. The fit parameters in these equations are the yield stress and viscosity; the measured parameters are the shear stress and shear rate.

$$
\begin{gathered}
\tau=\tau_{B}+\mu_{B} \dot{\gamma} \\
\tau^{\frac{1}{2}}=\tau_{C}^{\frac{1}{2}}+\left(\mu_{C} \dot{\gamma}\right)^{\frac{1}{2}}
\end{gathered}
$$

$$
\text { where } \begin{aligned}
\tau & =\text { shear stress, } \\
\dot{\gamma} & =\text { shear rate, } \\
\tau_{B} & =\text { Bingham yield stress, } \\
\mu_{B} & =\text { Bingham-plastic viscosity, } \\
\tau_{C} & =\text { yield-stress fit to the Casson fluid model, and } \\
\mu_{C} & =\text { Casson infinite shear viscosity. }
\end{aligned}
$$

Standard error is used to determine the reasonableness of the curve fit. Standard errors for the Bingham-Plastic and Casson model fits are also provided in Table 5.8; the greater the standard error, the worse the model fits the data. Generally, a reasonable fit has a standard error of less than about 20. In the curve-fitting software used for this data, standard error is defined by Equation 5.4. In all but one condition, the standard error is significantly higher for the Bingham-Plastic model than was calculated for the Casson model.

$$
\frac{\left[\frac{\sum\left(x_{m}-x_{c}\right)^{2}}{n-2}\right]^{1 / 2}}{\text { Range }} \times 1000
$$

$$
\text { where } \begin{aligned}
x_{m} & =\text { measured value } \\
x_{c} & =\text { calculated value } \\
n & =\text { number of data points, and } \\
\text { Range } & =\text { difference between the minimum and maximum measured values. }
\end{aligned}
$$


Table 5.8. Comparison of Bingham and Casson Model Fits

\begin{tabular}{|c|c|c|c|c|c|c|c|}
\hline \multirow[b]{3}{*}{ Test Instruction } & \multirow[b]{3}{*}{ Sample } & \multicolumn{6}{|c|}{ Rheological Model Curve Fits } \\
\hline & & \multicolumn{3}{|c|}{ Bingham Plastic } & \multicolumn{3}{|l|}{ Casson } \\
\hline & & $\tau_{\mathrm{B}}(\mathrm{Pa})$ & $\mu_{\mathrm{B}}(\mathrm{mPa} \cdot \mathrm{s})$ & Standard Error & $\tau_{\mathrm{C}}(\mathrm{Pa})$ & $\mu_{\mathrm{C}}(\mathrm{mPa} \cdot \mathrm{s})$ & Standard Error \\
\hline TI-RPP-WTP-653 & M1-081112-0908 & 36.9 & 18.2 & 23.0 & 31.0 & 3.2 & 20.1 \\
\hline TI-RPP-WTP-654 & M1-081113-1123 & 19.8 & 10.9 & 24.1 & 16.6 & 1.9 & 7.4 \\
\hline TI-RPP-WTP-655 & M1-081114-0920 & 15.8 & 9.6 & 23.6 & 13.1 & 1.9 & 9.3 \\
\hline TI-RPP-WTP-656 & M1-081118-0800 & 12.1 & 8.3 & 24.5 & 9.8 & 1.8 & 8.9 \\
\hline TI-RPP-WTP-657 & M1-081119-1020 & 11.0 & 7.8 & 23.4 & 8.8 & 1.7 & 8.0 \\
\hline TI-RPP-WTP-658 & M1-081120-1110 & 8.5 & 7.0 & 20.8 & 6.7 & 1.7 & 5.9 \\
\hline TI-RPP-WTP-659 & M1-081121-0754 & 5.0 & 5.7 & 16.7 & 3.7 & 1.7 & 8.0 \\
\hline TI-RPP-WTP-545 & M1-081121-1435 & 3.7 & 5.0 & 15.3 & 2.6 & 1.6 & 10.3 \\
\hline TI-RPP-WTP-551 & M1-081124-0850 & 2.3 & 4.7 & 7.0 & 1.5 & 1.6 & 8.7 \\
\hline TI-RPP-WTP-645 & M1-081124-1230 & 0.7 & 3.9 & 18.0 & 0.3 & 2.1 & 6.9 \\
\hline TI-RPP-WTP-661 & M1-081209-1902 & 33.2 & 18.7 & 19.0 & 28.0 & 3.3 & 9.6 \\
\hline TI-RPP-WTP-662 & M1-081212-0840 & 22.7 & 15.5 & 28.2 & 18.6 & 3.2 & 15.1 \\
\hline TI-RPP-WTP-664 & M1-081215-0929 & 15.9 & 11.5 & 20.2 & 12.8 & 2.5 & 6.2 \\
\hline TI-RPP-WTP-665 & M1-081217-0814 & 9.6 & 8.1 & 23.1 & 7.5 & 2.0 & 8.0 \\
\hline TI-RPP-WTP-666 & M1-090106-1545 & 6.9 & 7.3 & 21.7 & 5.1 & 2.1 & 5.4 \\
\hline \multirow{2}{*}{ TI-RPP-WTP-667 } & M1-090108-0805 & 4.0 & 6.6 & 27.0 & 2.6 & 2.5 & 14.7 \\
\hline & M1-090109-0905* & 4.6 & 6.6 & 14.8 & 3.1 & 2.3 & 9.1 \\
\hline TI-RPP-WTP-668 & M1-090109-1923* & 1.5 & 5.2 & 14.5 & 0.9 & 2.2 & 12.7 \\
\hline
\end{tabular}

* - Anti-foaming agent (AFA) added to mitigate gas entrainment 
TI-RPP-WTP-668

TPR-RPP-WTP-569, Rev 0

Page 6.1 of 164

\subsection{Test Procedure}

Both deposition velocity and Net Positive Suction Head were assessed in a single test. These evaluations were performed on the AZ-101 HLW simulant exclusively. Testing was accomplished by operating the system according to the sequence of steps outlined below:

1. Load Simulant for Testing

The simulants with properties consistent with the information in Section 5.0 were loaded into the flow loop.

2. Homogenize Simulant

The mechanical agitator on the mixing vessel was started for solids homogenization. The mixing-vessel temperature-control system was set to the appropriate value, nominally $25^{\circ} \mathrm{C}$.

3. Take Samples and Measure Rheological Properties

A grab sample was taken from the mixing vessel, and a flow curve or rheogram was measured.

4. Start Pipe Flow

The flow-loop pumps were started with a target flow velocity of $8 \mathrm{ft} / \mathrm{sec}$. Coriolis meters on the flow loop were used to verify this reading.

5. Flow/Instrumentation Measurements

The state of the flow was assessed with multiple techniques. A list of these techniques and a description of the significance of the measurement data are shown in the steps below.

a. Superficial Flow Velocity $(V)$ versus pipeline pressure drop $(\Delta P)$ - A pressure drop over a known length of pipeline as a function of pipeline velocity is the primary measurement technique. These measurements were coupled with flow-rate data to ultimately provide a plot of flow rate and pressure drop versus time. An example of a typical slurry-transport plot is shown in Figure 6.1. When the system is stable, the pressure-versus-time signature is constant. The flow velocity versus time is always constant due to the feedback control system between the pump variable frequency drive and the flow loop inlet Coriolis meter. When deposition occurs, the pressure-versus-time signature becomes unstable and increases as a bed of sediment forms in the pipe. In this figure, as performed during testing, the velocity is decreased using a constant step size from a higher to a lower magnitude of superficial velocity. Whether the unstable pressure condition surpasses the previous pressure measurement depends on the selected velocity step and test duration.

b. Visual data - the transparent test section was observed visually and video was taken to assess the flow condition in the pipe at a particular flow rate.

c. Flow tomographs (spatial conductivity maps within the pipe cross-sectional area) were measured using the ERT system. This system was used for visualization purposes only. 
TI-RPP-WTP-668

TPR-RPP-WTP-569, Rev 0

Page 6.2 of 164
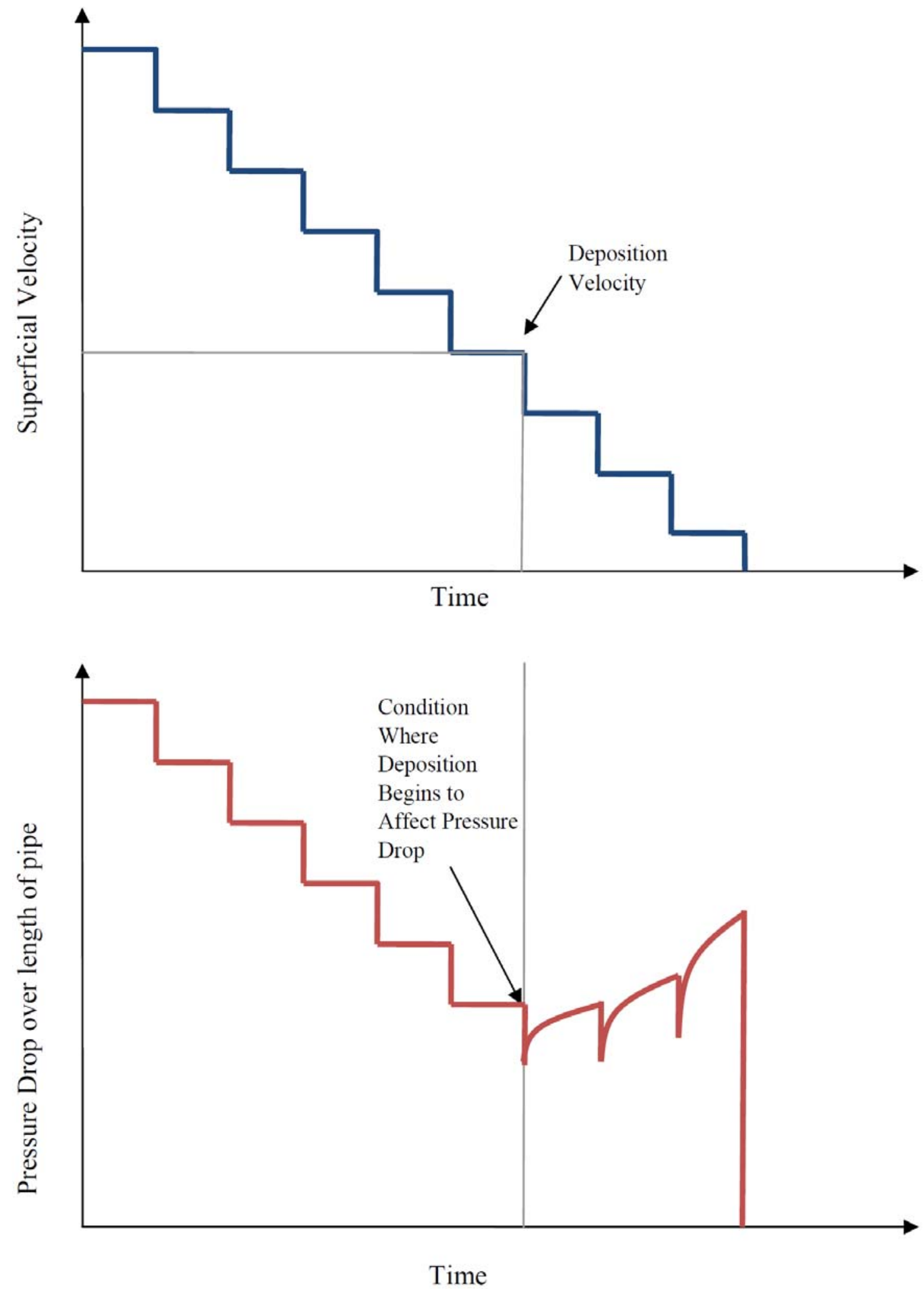

Figure 6.1. Example Data Showing Pressure Drop as a Function of Pipeline Superficial Velocity 
TI-RPP-WTP-668

TPR-RPP-WTP-569, Rev 0

Page 6.3 of 164

6. Attempt to reach a Steady-State Condition

A flow rate was held constant for a minimum of 20 minutes before a steady-state condition was determined. If the transient pressure signal indicated a trend after this 20 -minute period, the flow was held constant for additional time until a steady-state condition was declared by the cognizant scientist.

The temperature of the slurry was held constant during this testing via automatic temperature control on the jacketed mixing vessel. The temperature was maintained within $\pm 10^{\circ} \mathrm{C}$ of target temperature.

7. Decrease Flow rate

The flow rate was decreased in typically 0.5 or $1 \mathrm{ft} / \mathrm{sec}$ increments, and steps 6 and 7 were repeated until an unstable pressure signature with respect to time was observed.

8. Stop Flow

The pump was then stopped with the line partially filled with sediment.

9. Switch to NPSH Mode and perform pump $\mathrm{NPSH}_{\mathrm{R}}$ testing

The pump variable-frequency drive (VFD) was reconfigured to ignore feedback from the inlet coriolis meter and to provide a constant baseline electrical frequency of $60 \mathrm{~Hz}\left(\mathrm{NPSH}_{\mathrm{R}}\right.$-determination mode). A system description of the loop and its original equipment/configuration is provided in Section 5.0 of WTP-RPT-175 Rev. 0 (Poloski et al. 2009). Modifications performed to the loop and the detailed $\mathrm{NPSH}_{\mathrm{R}}$ procedure are detailed in Section 9.2. The pump $\mathrm{NPSH}_{\mathrm{R}}$ tests were carried out in a slightly different fashion than that outlined in ANSI/HI 1.6-2000 for the purpose of obtaining results with a greater degree of accuracy and information regarding the stability state. A "scanning" approach was first utilized to determine the approximate $\mathrm{NPSH}_{\mathrm{R}}$ and then the operating state about the approximate $\mathrm{NPSH}_{\mathrm{R}}$ was given detailed investigation. This test process was first applied to determine the pump $\mathrm{NPSH}_{\mathrm{R}}$ for water and yielded results that were in excellent agreement with the pump vendor's published data. Greater detail is provided in Section 9.2. 

TI-RPP-WTP-668

TPR-RPP-WTP-569, Rev 0

Page 7.1 of 164

\subsection{Deposition-Velocity Test Results and Discussion}

The waste simulants described in Section 5.0 were used in the test apparatus described in Section 1.0. Using the test procedure discussed in Section 6.0, deposition-velocity measurements were obtained for each condition.

\section{1 $150 \mu \mathrm{m}$ Glass Bead Results}

The pressure drop over a 224.75 -inch section of straight, horizontal, schedule 40,3-inch pipe was measured at multiple pipeline velocities as a function of time for the non-Newtonian slurries discussed in Section 5.0. These data are shown in Appendix A. Each plot is partitioned into "stable" and "unstable" regions. Stable regions denote regions where there is no evidence of the formation of a sediment bed. In these regions, when the superficial velocity of the fluid is held at a constant value, the resulting pressure-versus-time signal also remains constant. At the highest rheological property measured, 31 Pa Casson yield stress, evidence of rheopexy is observed. Rheopectic behavior can be seen when the pressure signature rises with time under high-shear conditions, i.e. high pipeline velocities. At lower pipeline velocities, about $3 \mathrm{ft} / \mathrm{sec}$ and below, the shear conditions are lower and the rheological properties are stable, resulting in a steady pressure signature with respect to time. Litzenberger (2003) has the following discussion on kaolin-clay rheopexy on page 35 of his Master's thesis:

Work performed by P. Larsen et al. (1994) reported rheopectic behaviour in kaolin clay suspensions at a concentration of $32 \%$ by volume. Rheopexy is observed when the viscosity increases with time at a constant shear rate. Like thixotropic behaviour when shear is removed the particles will rearrange to develop a structure similar to the one present prior to shear. They found that at low clay concentrations or if the shear rate was lower than a threshold value, the shear stress did not increase. Larsen proposed that an explanation of the phenomenon could be that "a considerable part of the flat clay particles overlapped each other in the suspensions, they were separated by the high shear rate, and therefore, more and thinner particles built stronger flocculant structure." The kaolin clay slurry initially exhibited a yield stress of $30 \mathrm{~Pa}$ but after being exposed to a high shear rate the yield stress increased to $300 \mathrm{~Pa}$.

Stable pressure signatures with respect to particle deposition were found at all velocities for tests with Casson yield stresses of both 31.0 and 16.6 Pa, see Figure A.1 and Figure A.2, respectively. At a yield stress of $13.1 \mathrm{~Pa}$ (see Figure A.3), particle deposition is observed to occur at velocities below $2 \mathrm{ft} / \mathrm{sec}$. As the slurry is diluted and the yield stress drops, the velocity where deposition occurs increases to a maximum of $5 \mathrm{ft} / \mathrm{sec}$ at a Casson yield stress of about $8 \mathrm{~Pa}$. Further dilution of the slurry and reduction in yield stress results in a decrease in the deposition velocity to a minimum of $3 \mathrm{ft} / \mathrm{sec}$ at a Casson yield stress of about $0.3 \mathrm{~Pa}$. A plot of these deposition results against a stability map for $150 \mu \mathrm{m}$ glass beads is shown in Figure 7.1. The experimental results clearly show the features of a laminar deposition boundary separating stable and unstable laminar-flow regions. The transitional deposition boundary is also clearly seen, as increasing pressure signatures were observed along the laminar-to-turbulent deposition boundary. 
TI-RPP-WTP-668

TPR-RPP-WTP-569, Rev 0

Page 7.2 of 164

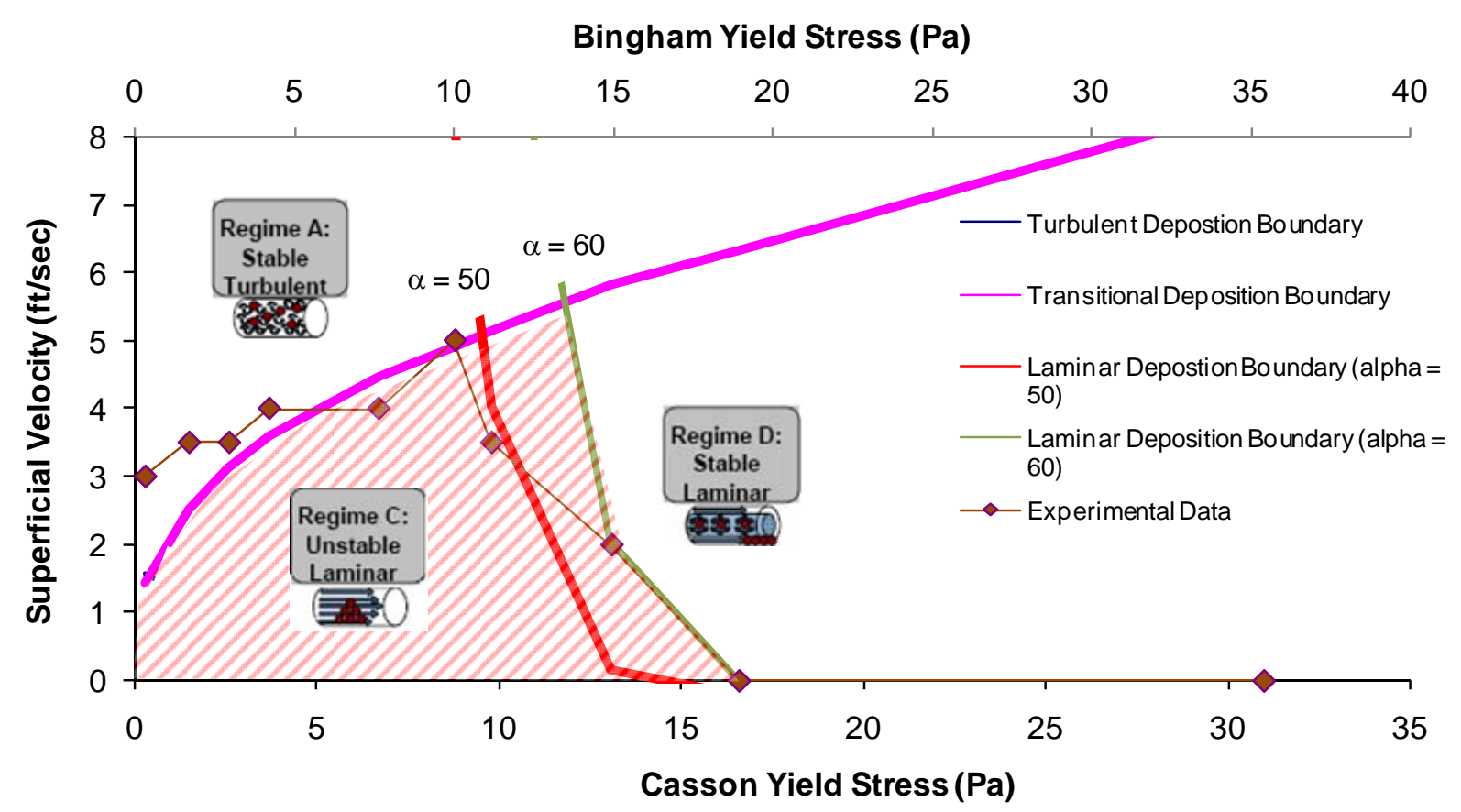

Figure 7.1. Stability Map for 150 mm Glass Beads and Corresponding Measured Deposition Velocity

Electrical resistance tomograms for each fluid rheological property at several test velocities are complied in Table 7.1. These images were post-processed with sensitivity conjugate gradients (SCG) methods to provide increased resolution and image complexity over the standard linear back-projection (LBP) image-reconstruction algorithm. The images generally show concentration gradients developing at the lower superficial velocities that are consistent with either moving-bed or stationary-bed flow regimes. 
TI-RPP-WTP-668

TPR-RPP-WTP-569, Rev 0

Page 7.3 of 164

Table 7.1. Electrical-Resistance Tomograms (ERT) of Slurries of 150- $\mu \mathrm{m}$ Glass Beads and Kaolin at Different Casson Yield Stresses. These images are considered "For Information Only."

\begin{tabular}{|c|c|c|c|c|c|c|c|c|c|c|}
\hline $\begin{array}{l}\text { Yield } \\
\text { Stress } \rightarrow \\
\text { Velocity } \downarrow\end{array}$ & $0.3 \mathrm{~Pa}$ & $1.5 \mathrm{~Pa}$ & $2.6 \mathrm{~Pa}$ & 3.7 $\mathrm{Pa}$ & 6.7 $\mathrm{Pa}$ & $8.8 \mathrm{~Pa}$ & $9.8 \mathrm{~Pa}$ & $113.1 \mathrm{~Pa}$ & $16.6 \mathrm{~Pa}$ & $31.0 \mathrm{~Pa}$ \\
\hline $10 \mathrm{ft} / \mathrm{sec}$ & & & & & & & & & & \\
\hline $9.5 \mathrm{ft} / \mathrm{sec}$ & $*$ & $*$ & $*$ & $*$ & $*$ & $*$ & $*$ & $*$ & $*$ & \\
\hline $9.0 \mathrm{ft} / \mathrm{sec}$ & $*$ & $*$ & $*$ & $*$ & $*$ & $*$ & $*$ & $*$ & $*$ & \\
\hline $8.5 \mathrm{ft} / \mathrm{sec}$ & $*$ & $*$ & $*$ & $*$ & $*$ & $*$ & $*$ & $*$ & * & \\
\hline $8.0 \mathrm{ft} / \mathrm{sec}$ & $*$ & $*$ & $*$ & $*$ & & & & & & \\
\hline $7.5 \mathrm{ft} / \mathrm{sec}$ & $*$ & $*$ & $*$ & $*$ & & & & & & \\
\hline $7.0 \mathrm{ft} / \mathrm{sec}$ & $*$ & $*$ & $*$ & $*$ & & & & & & \\
\hline $6.5 \mathrm{ft} / \mathrm{sec}$ & $*$ & $*$ & $*$ & $*$ & & & & & & \\
\hline $6.0 \mathrm{ft} / \mathrm{sec}$ & $*$ & $*$ & $*$ & $*$ & & & & & & \\
\hline $5.5 \mathrm{ft} / \mathrm{sec}$ & $*$ & $*$ & $*$ & & & & & & & \\
\hline
\end{tabular}


TI-RPP-WTP-668

TPR-RPP-WTP-569, Rev 0

Page 7.4 of 164

Table 7.1. (contd)

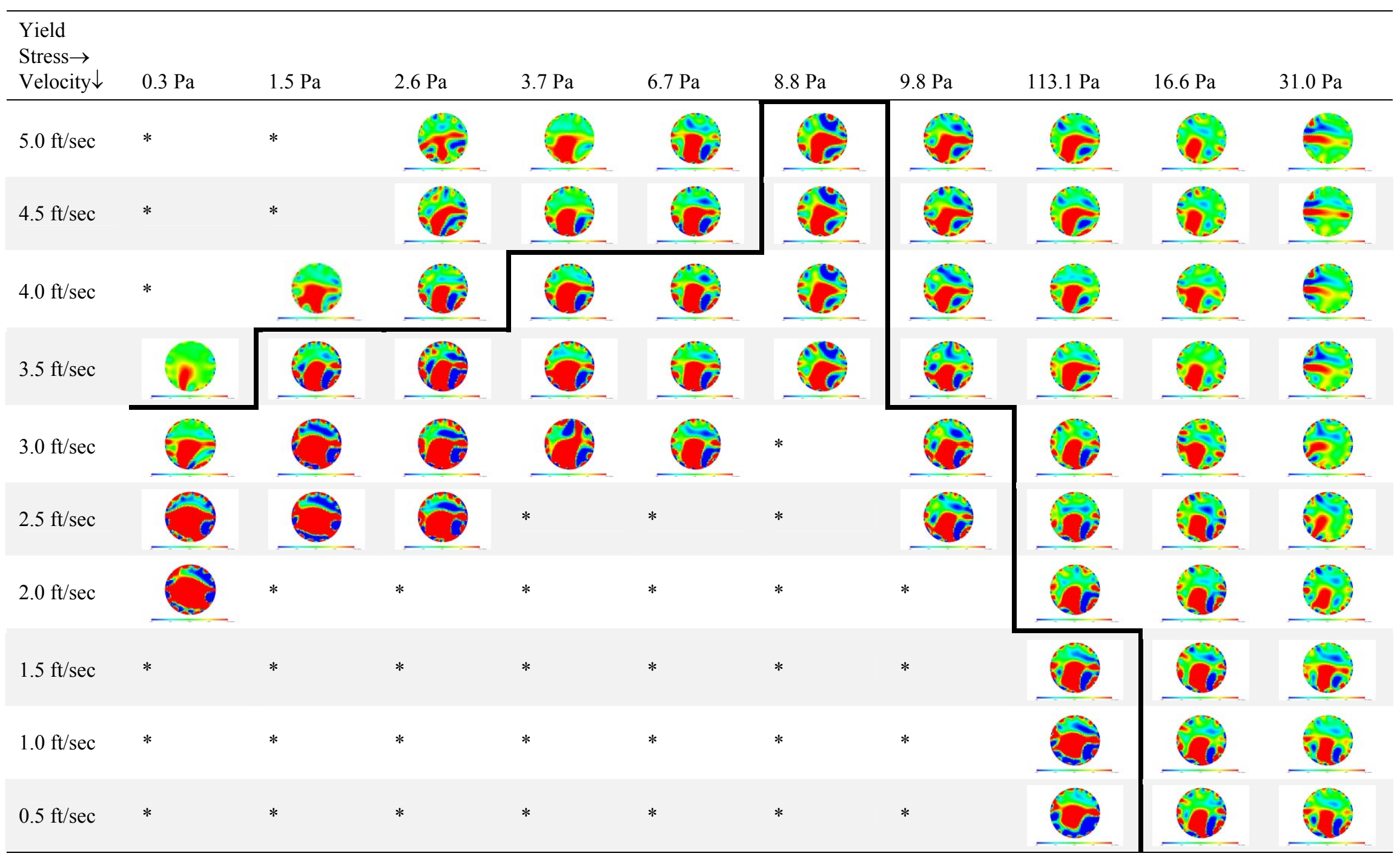

* - Velocity not tested; Heavy border denotes the boundary between stable and unstable pressure signatures. 
TI-RPP-WTP-668

TPR-RPP-WTP-569, Rev 0

Page 7.5 of 164 
TI-RPP-WTP-668

TPR-RPP-WTP-569, Rev 0

Page 7.6 of 164

\subsection{HLW Simulant Results}

The pressure drop over a 224.75-inch section of straight, horizontal, schedule 40,3-inch pipe was measured at multiple pipeline velocities as a function of time for the non-Newtonian slurries discussed in Section 5.0. These data are shown in Appendix B. Each plot is partitioned into "stable" and "unstable" regions. Stable regions denote regions where there is no evidence of the formation of a sediment bed. In these regions, when the superficial velocity of the fluid is held at a constant value, the resulting pressure-versus-time signal is also constant. At the highest rheological property measured, $27 \mathrm{~Pa}$ Casson yield stress, stable laminar flow is observed. A moving bed of particles was observed to form at a flow rate of $5 \mathrm{ft} / \mathrm{sec}$. A stationary bed of particles was not observed until the slurry was diluted to a yield stress of $7.5 \mathrm{~Pa}$ and the pipe superficial velocity was at $2.5 \mathrm{ft} / \mathrm{sec}$. An increasing pressure signature was observed at a slurry yield stress of $5 \mathrm{~Pa}$ and a superficial velocity of $4 \mathrm{ft} / \mathrm{sec}$. As the slurry was diluted to lower yield stress, the velocity where the unstable pressure signatures began followed the laminar-toturbulent transition velocity. A maximum in the velocity where a stationary bed was observed occurred at a yield stress of $3.1 \mathrm{~Pa}$ and a velocity of $4 \mathrm{ft} / \mathrm{sec}$.

These data have been plotted on Figure 7.2 and both the visual and pressure data show features of a stability map for the slurry. For example, a laminar-deposition boundary is observed with the formation of a stationary bed and unstable pressure signature at increasing superficial velocities as the yield stress is decreased in the 10 to $5 \mathrm{~Pa}$ yield-stress range. The stationary-bed and unstable pressure-signature velocities then decrease as the yield stress is further decreased in the 5 to $0.5 \mathrm{~Pa}$ range. Over this yield stress region the deposition velocities appear to follow the transition velocity from laminar to turbulent flow, thus forming the transitional-deposition boundary.

An ultrasonic transducer was installed against the outside of the bottom pipe. The transducer was located just downstream of the first differential pressure transducer port on the $15.75 \mathrm{ft}$ straight section of pipe. The transducer was operated in a "pulse echo" mode. This technique sends an ultrasonic pulse through the pipe wall and into the slurry. The system then records the echo from the pulse back to the transducer. If the echo signal is steady with respect to time, the material is stationary. However, if the echo signal modulates with time, the medium is in motion. The point on the echo signal where the modulation begins signifies an interface between stationary and moving fluid. If the speed of sound in the slurry is known, the distance from the transducer to the moving interface can be calculated. This system was installed for the final three complex-simulant tests. A more complete description of this technology can be found in Appendix C. The full NQA-1 pedigree of the system has not been completed; these results are considered "for information only." The results are interesting (see Figure 7.3) and show indication of a thin stationary bed of material depositing at velocities in the 4 to $8 \mathrm{ft} / \mathrm{sec}$ range. Below $4 \mathrm{ft} / \mathrm{sec}$, the height of the stationary bed begins to increase dramatically. This is the range of velocities where increasing pressure signatures were observed on the differential-pressure transducers.

In previous testing with glass bead/water systems (Poloski et al 2009), it was observed that the beads form a stationary bed that starts at the front of the loop and migrates to the discharge of the loop. We postulate that the presence of a stationary bed can increase the fluid velocity to the point that particles can be transported in that section of pipe. When the fluid enters a pipe region further downstream where no stationary bed exists, the crosssectional area of the pipe increases and the fluid velocity drops below the deposition velocity. Particles are then deposited in the region. In this manner, a stationary-bed "front" migrates from the beginning of the loop to the end. Since the ultrasonic transducer is located near the start of the flow loop, larger stationary beds are expected in this area and can explain the relatively large stationary-bed thickness values in a 3" pipe (77.9 mm ID). 
TI-RPP-WTP-668

TPR-RPP-WTP-569, Rev 0

Page 7.7 of 164

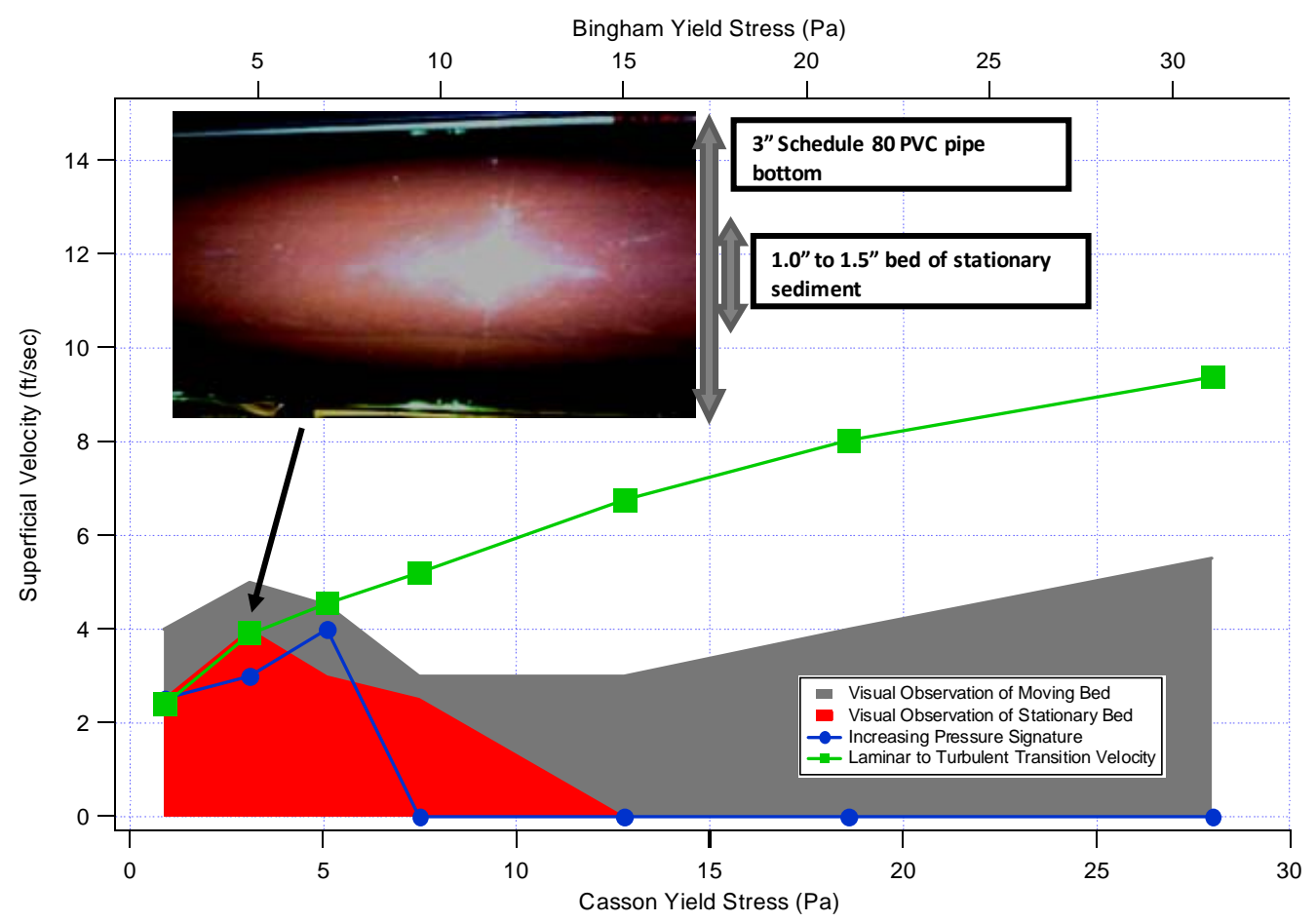

Figure 7.2. Stability Map for Simulant of AZ-101 HLW Pretreated Sludge With Deposition Velocities Determined by Pressure Signatures and Visual Observation in Transparent Pipe Section

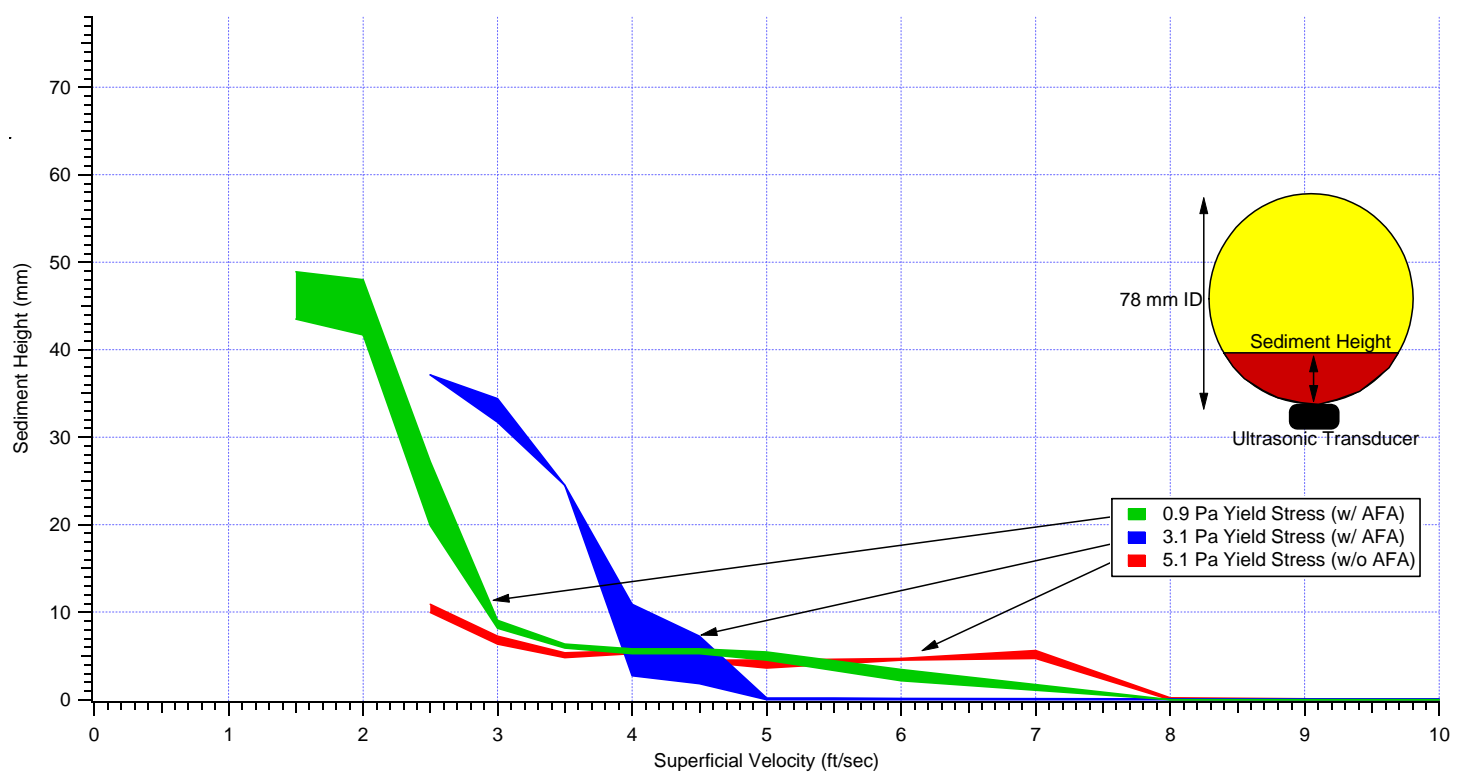

Figure 7.3. Thickness of Stationary Bed of Particles in Pipeline With Simulant of AZ-101 HLW Pretreated Sludge at Different Yield Stresses As Measured by Ultrasonic Pulse-Echo Technique; These data are considered "For Information Only." 
TI-RPP-WTP-668

TPR-RPP-WTP-569, Rev 0

Page 7.8 of 164

Electrical-resistance tomograms for each fluid rheological property at several test velocities are compiled in Table 7.2. These images were post-processed with the sensitivity conjugate gradients (SCG) method to provide increased resolution and image complexity over the standard linear back-projection (LBP) image-reconstruction algorithm. The images generally show concentration gradients developing at the lower superficial velocities that are consistent with either moving-bed or stationary-bed flow regimes.

Table 7.2. Electrical-Resistance Tomograms (ERT) of Simulant of AZ-101 Pretreated HLW Slurries at Different Casson Yield Stresses. These images are considered "For Information Only."

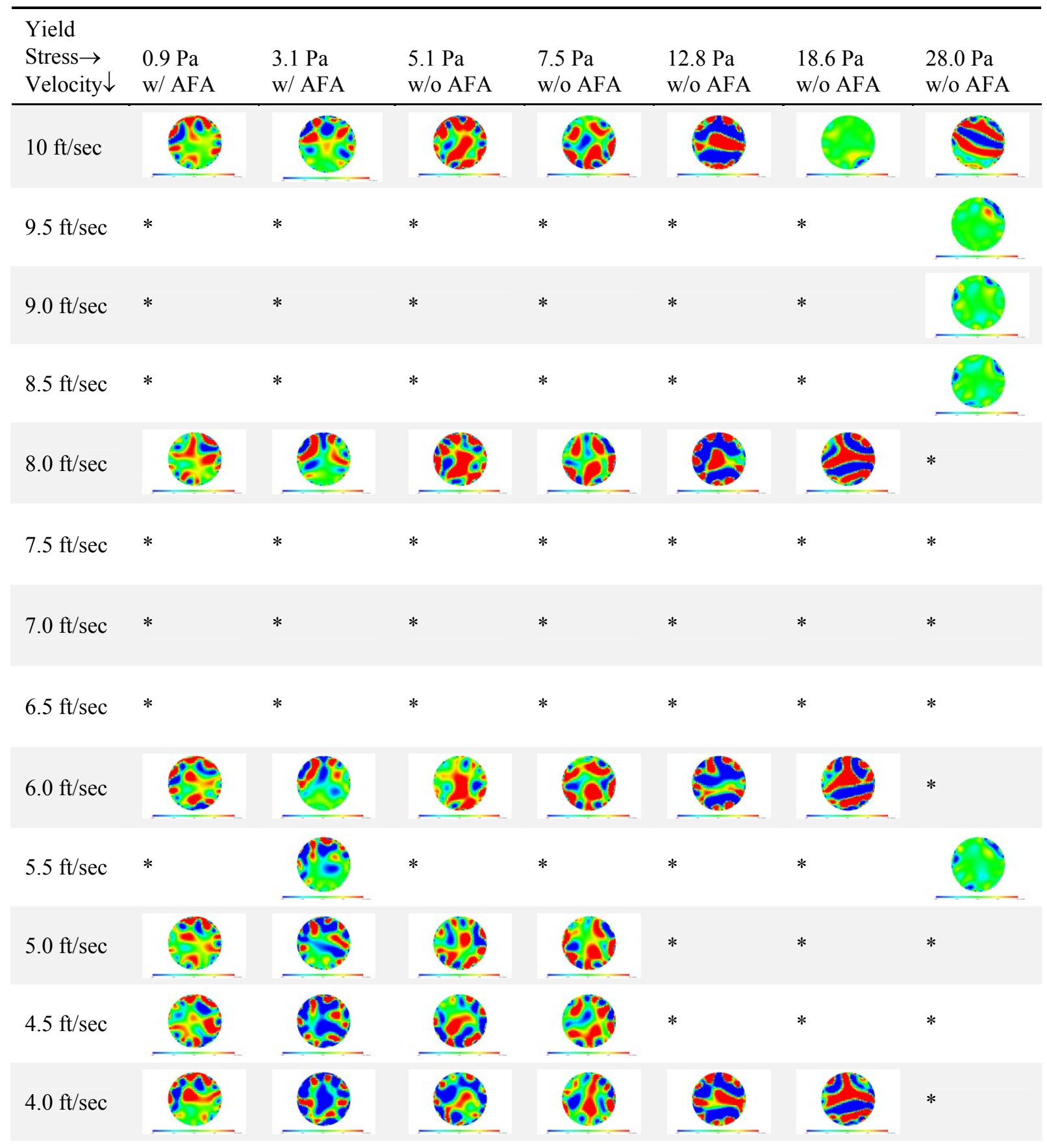


TI-RPP-WTP-668

TPR-RPP-WTP-569, Rev 0

Page 7.9 of 164

Table 7.2. (contd)

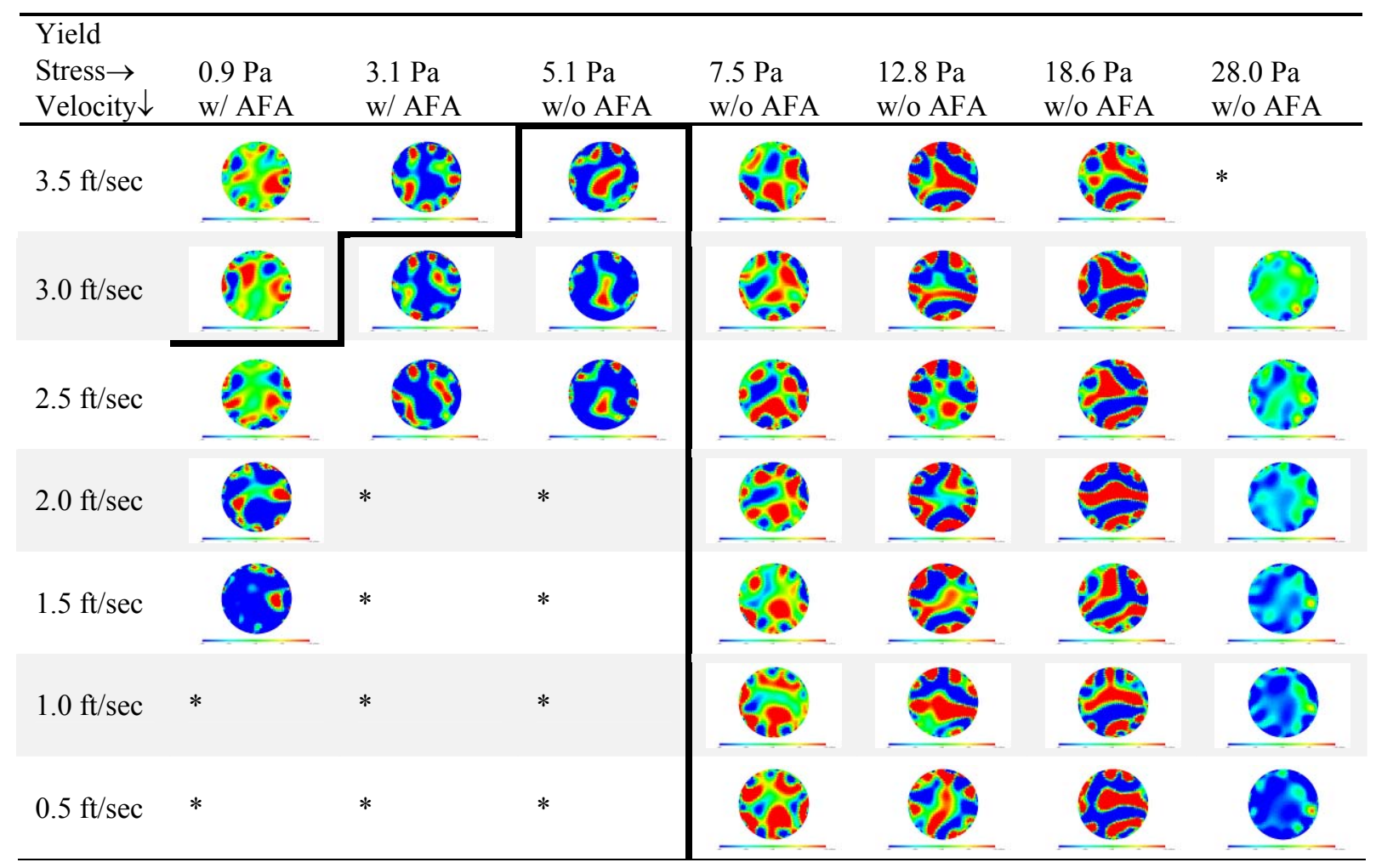

* - Velocity not tested

Heavy border denotes the boundary between stable and unstable pressure signatures

\subsection{M-1 Deposition Velocity Summary}

A summary of all of the M-1 deposition velocity data is shown in Figure 7.4. The data considered include experimental results from Poloski et al. (2009; WTP-RPT-175 Rev 0) and this report. Features from a stability map are clearly seen in this plot. A maximum is observed under Newtonian conditions, when the Casson number is zero. This maximum corresponds to Point $\mathrm{W}$ on a stability map. The deposition Reynolds number dramatically drops to a minimum that corresponds to Point $\mathrm{X}$. The majority of the data then follows the transition Reynolds number to a second maximum corresponding to Point $Y$. When stable laminar flow is achieved, the deposition Reynolds number drops to zero which corresponds to Point $Z$. In the case of the $10 \mu \mathrm{m}$ glass beads, the stable laminar flow regime begins immediately and the only maximum observed is under Newtonian conditions (Point W). Due to the presence of two maximum values for deposition in pipelines, a design philosophy that considers both conditions is appropriate. Also note that segregation of particles by size and density was observed in these experiments. The coarse particles including $10 \mu \mathrm{m}$ stainless steel, $50 \mu \mathrm{m}$ alumina, $100 \mu \mathrm{m}$ stainless steel, $100 \mu \mathrm{m}$ stainless steel, and $150 \mu \mathrm{m}$ glass beads separated from the kaolin particles into a bed at the bottom of pipe. Some fraction of the AZ$101 \mathrm{HLW}$ simulant particles also separated from the bulk material into a bed at the bottom of the pipe. The point at which stable laminar flow is attained depends on the physical properties of these segregated particles, which includes the size and density of the particles in the bed. 
TI-RPP-WTP-668

TPR-RPP-WTP-569, Rev 0

Page 7.10 of 164

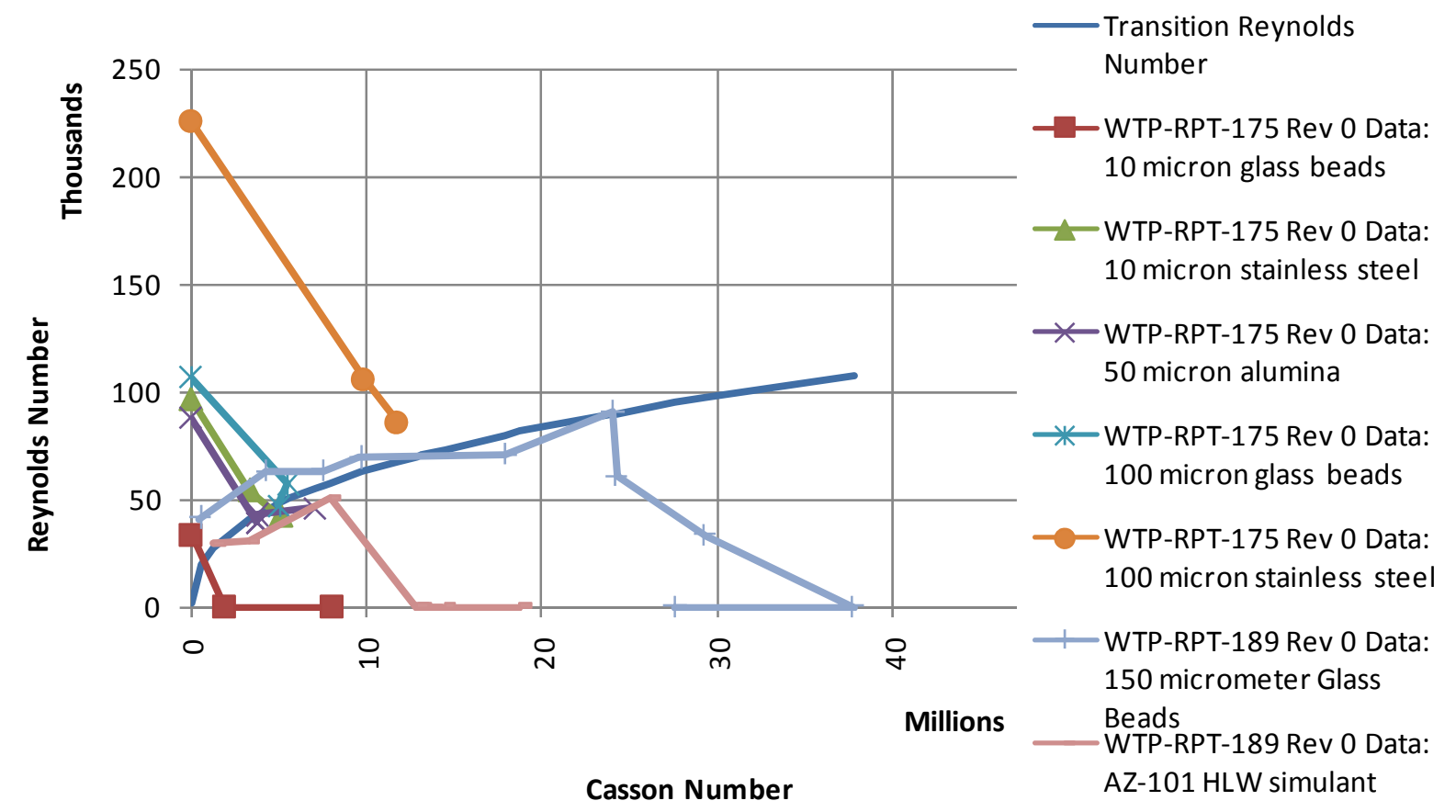

Figure 7.4. Plot of Reynolds Number at Deposition for all Experimental Data from the M-1 Project; Reynolds Number at the Laminar to Turbulent Transition is also Plotted. 


\subsection{Impacts to WTP Design}

This section contains an analysis of the particle size and density distributions (PSDD) on Hanford waste that can be used as inputs to the recommended M-1 design correlations. Recommended M-1 design correlation results from these PSDD inputs are then presented at the end of this section. The results reveal that sedimentation in pipelines for non-Newtonian slurries in laminar flow at the current design velocities can be expected.

\subsection{Particle Size and Density Data}

This section contains a summary of significant particle size and density data applicable to the WTP. These data can be used as inputs to mixing and transport calculations that support the WTP design. Waste will be fed to the WTP by the Hanford waste-feed delivery (WFD) system. High-level waste (HLW) feed includes insoluble solids consisting primarily of oxides and hydroxides of metals that were used to fabricate and reprocess nuclear fuels. These solid particles range in size and density from small, dense primary particles to large, low-density, diffuse flocs or soft agglomerates and large, relatively dense, cemented aggregates and stable agglomerates (collectively termed hard agglomerates). Figure 8.1 depicts these different particles.

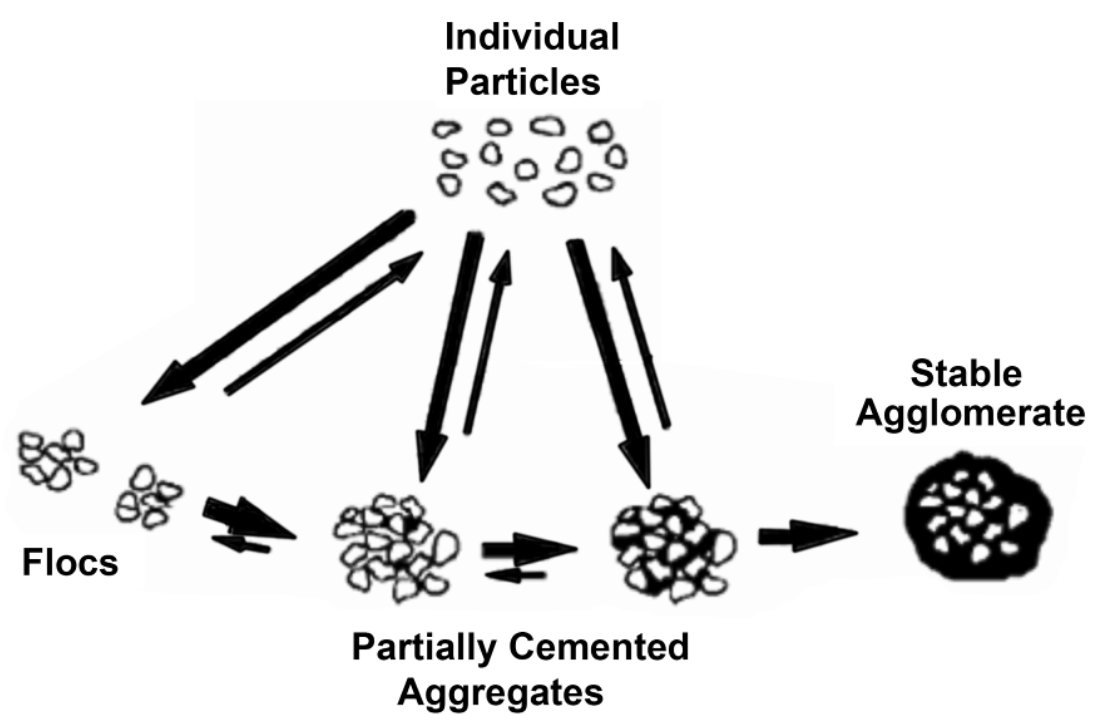

Figure 8.1. Solid Particles and Soft and Hard Agglomerates, From Ilievski, D. and E.T. White. (1994)

The individual particle size in a waste stream may vary by five orders of magnitude and is affected by the constituents present; as stated in Jewett et al. (2002),

...the smallest particles are many oxides and hydroxides, including $\mathrm{ZrO}_{2}$ and $\mathrm{FeOOH}$, whose diameters are in the 3 to $6 \mathrm{~nm}$ range. Other particles such as boehmite $(\mathrm{AlOOH})$ and apatite are in the 0.1 to $1 \mu \mathrm{m}$ size range. These submicron primary particles found in many HLW tanks form agglomerates typically 1 to $10 \mu \mathrm{m}$ in size, but can reach $100 \mu \mathrm{m}$ or more (Herting 1997, Bunker et al. 1995). Some of the largest primary particles are gibbsite $\left(\mathrm{Al}(\mathrm{OH})_{3}\right)$ and uranium phosphate, which can exceed $20 \mu \mathrm{m}$ in size.

Thus, the individual primary particles vary in density as well as size, and it follows that the agglomerates formed therefore also vary in density. Many studies have been conducted to determine the particle size and constituents of the undissolved solids in the Hanford waste. However, the available information relating the particle size and the constituents, i.e., the density, is limited. Consequently, relating measured particle-size distributions 
(PSDs) to solid-phase compounds and generating expected particle-size and density distributions (PSDDs) is very significant to the design of waste retrieval and processing facilities for the Hanford site.

Wells et al. (2007; WTP-RPT-153 Rev 0) have developed representative particle-size and density distributions (PSDDs) of Hanford-waste insoluble solids based on the new approach that relates measured particle-size distributions (PSDs) to solid-phase compounds. This work was achieved through extensive review of available Hanford waste PSDs and solid-phase compound data. Composite PSDs representing the waste in up to 19 Hanford waste tanks were developed, and the insoluble solid-phase compounds for the 177 Hanford waste tanks, their relative fractions, crystal densities, and particle size and shape were developed.

With such a large combination of particle sizes and particle densities, a Monte Carlo simulation approach was used to model the PSDDs. Further detail was added by including an agglomeration of these compounds where the agglomerate density was modeled with a fractal-dimension relation. The Monte Carlo simulations were constrained to hold the following relationships: 1) the composite PSDs are reproduced, 2) the mass fractions of the solid-phase compounds are reproduced, 3 ) the expected in situ bulk-solids density is qualitatively reproduced, and 4) a representative fraction of the sludge volume comprising agglomerates is qualitatively reproduced to typical Hanfordwaste values.

Wells et al. (2007) developed and evaluated four PSDDs. These four PSDD scenarios correspond to permutations where the master PSD was sonicated or not-sonicated before being analyzed and whether or not agglomerates existed in the PSD samples. The four PSDD modeling approaches considered include:

- Case 1: Upper-Bound Sonicated PSD Case

- Primary particles and hard agglomerates are assigned crystal density.

- Case 2: Lower-Bound Sonicated PSD Case

- Primary particles are assigned crystal density.

- Density of hard agglomerates is assigned via fractal relation.

- Case 3: Upper-Bound Minimal-Disturbance PSD Case

- Primary particles and soft and hard agglomerates are assigned crystal density.

- Case 4: Lower-Bound Minimal-Disturbance PSD Case

- Primary particles are assigned crystal density.

- Density of soft and hard agglomerates is assigned via fractal relation.

The PSDs for Cases $3 \& 4$ are larger than those for Cases $1 \& 2$ due to sonication of the samples. Cases $3 \& 4$ will then be more conservative and will be considered further. The actual PSDD tables are presented by Wells et al. (2007) as Table 5.2.7 and 5.2.8 for Case 3 and Table 5.2.9 and 5.2.10 for Case 4 in his report. Graphical versions of the PSDDs for these two cases have been extracted from Wells et al. (2007) and are shown in Figure 8.2. These figures show that the combination of bigger and more dense particles (bottom center of each figure) is eliminated due to fractal aggregation density effects in the Case 4 PSDD. Since particle density is a significant parameter in pipeline transport and mixing, Case 3 is significantly more conservative than Case 4 . 

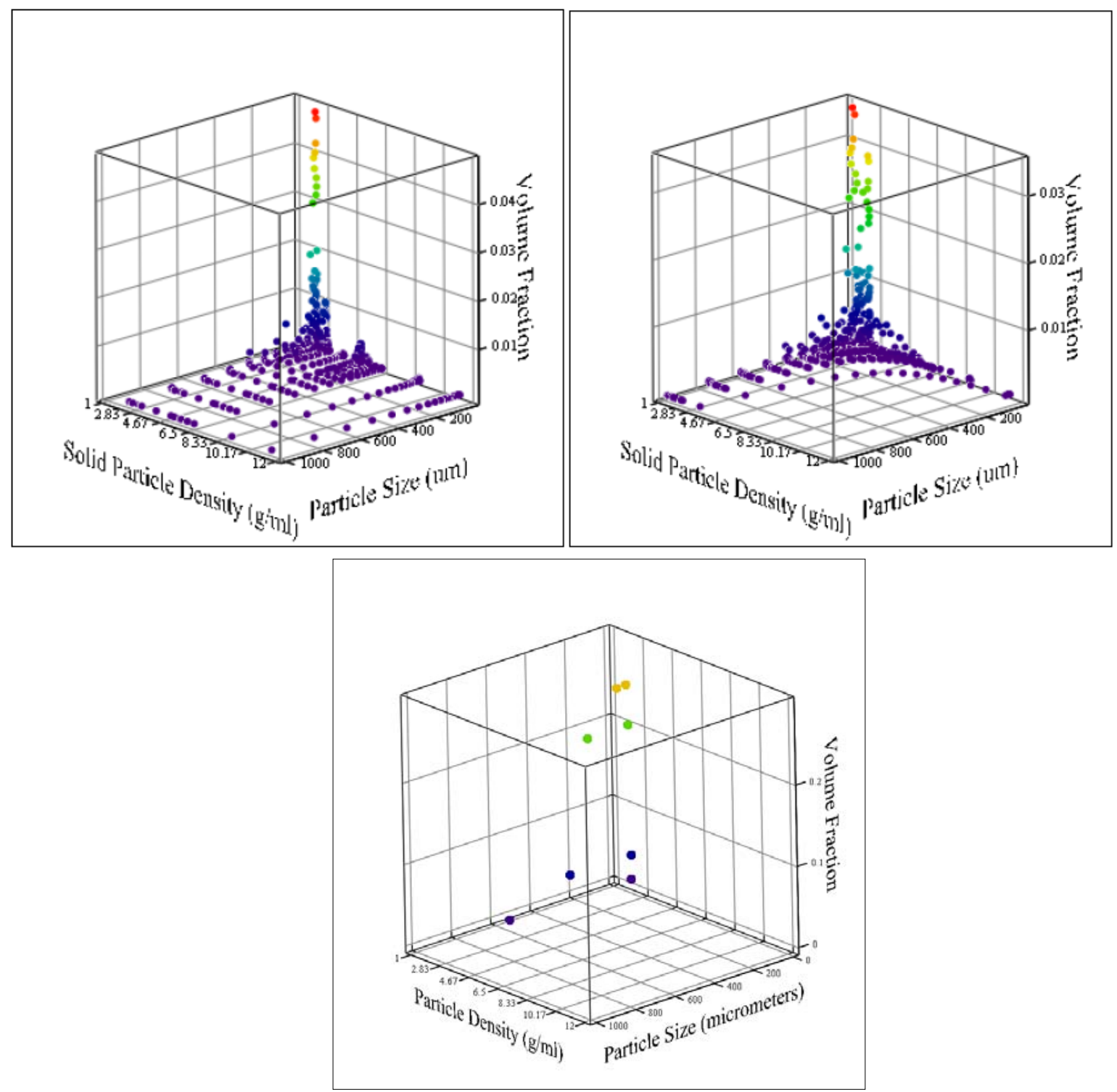

Figure 8.2. Wells et al. (2007; WTP-RPT-153 Rev. 0) Case 3 (Top-Left), Case 4 (Top-Right) and Jewett et al. (2002; RPP-9805; Bottom) Particle Size and Density Distributions

Jewett et al. (2002; RPP-9805) also present a composite PSD based on a statistical evaluation of PSDs from seven Hanford tanks (see Table 8.1). Information was presented on the density of the solid compounds in the tanks from thermodynamic analysis of the tank-waste chemistry using Gibbs-free-energy minimization techniques. Ultimately, an alternative assessment of the particle density was presented based on assuming that the particles exist exclusively as large flocs or aggregates of small particles. In this case, the density of the interstitial liquid is averaged with all the solids compounds. Jewett et al. (2002) report the average of these aggregate densities over ten Hanford tanks to be $2.18 \mathrm{~g} / \mathrm{cc}$. Since particle density is a significant parameter in pipeline transport and mixing, this scenario with extremely low particle densities, referred to as the RPP-9805 PSDD, is not conservative. The RPP9805 PSDD is compared graphically to the WTP-RPT-153 Case 3 and 4 PSDDs in Figure 8.2. 
Table 8.1. Composite Particle-Size Distribution Under Minimal-Disturbance Conditions From Seven Hanford Waste Tanks As Reported by Jewett et al. (2002; RPP-9805)

\begin{tabular}{|l|r|r|r|r|r|r|r|}
\hline Percentile & $\mathbf{1 . 0} \%$ & $5.0 \%$ & $\mathbf{2 5 . 0 \%}$ & $\mathbf{5 0 . 0 \%}$ & $\mathbf{7 5 . 0} \%$ & $\mathbf{9 5 . 0} \%$ & $\mathbf{9 9 . 0} \%$ \\
\hline Mean & 0.7 & 1.2 & 3.7 & 7.5 & 31 & 140 & 210 \\
\hline Std Dev & 0.4 & 0.6 & 1.8 & 4.2 & 38 & 94 & 145 \\
\hline $95 \%$ UL & 1 & 1.6 & 5 & 11 & 58 & 210 & 310 \\
\hline $95 / 95$ TL & 2 & 3.1 & 10 & 22 & 160 & 460 & 700 \\
\hline
\end{tabular}

\subsection{EFRT Issue M-12 Physical and Rheological Property Data}

Recently, several Hanford tank-waste samples have been composited and tested with a series of caustic and oxidative leaching tests. These tests were designed to support the EFRT M-12 issue, titled "undemonstrated leaching process". Eight composites were produced and extensive characterization of these samples occurred prior to and after caustic leach testing. The sources of the data presented in this section are WTP-RPT-166 Rev. 0 for Groups 1 \& 2, WTP-RPT-167 Rev. 0 for Groups 3 \& 4, WTP-RPT-157 Rev. 0 for Groups 5 \& 6, WTP-RPT-169 Rev. 0 for Group 7, and WTP-RPT-170 Rev. 0 for Group 8. Particle-size distribution measurements before and after leaching are shown in Table 8.2.These results generally indicate that the particle-size distribution shifts to the right (particle size increases) after leaching is complete. One hypothesis is that the small particles are dissolved or consumed during leaching leaving a higher population of larger particles in the HLW pretreated sludge. Rheological measurements including Bingham-Plastic curve fits at various solids concentrations are shown in Table 8.3. These results show that extreme variation in the rheological properties, most importantly yield stress, can be expected during waste-processing operations. Lastly, X-ray diffraction results from the various composites are shown in Table 8.4. These results show that the composition of the process stream changes from lower-density species (primarily aluminum species) prior to leaching, to higher-density species (composed primarily of heavy metals).

The change in properties before and after leaching can be seen specifically in the Group 5 analysis where the dominant species prior to leaching is Boehmite, while after leaching the dominant species becomes Clarkite, a uranium mineral. The PSD results show a dramatic increase after leaching and the rheological properties vary from a relatively low yield stress of $2 \mathrm{~Pa}$ to a high of over $90 \mathrm{~Pa}$. The PSDD for the unleached and leached Group 5 samples from the M-12 project are shown graphically in Figure 8.3. The plot clearly shows the shift toward larger, higherdensity, particles after leaching has occurred. 
Table 8.2. Unsonicated PSD Data From WTP M-12 Actual-Waste Samples. When duplicate samples were run, the average value is reported.

\begin{tabular}{|c|c|c|c|c|c|c|c|c|c|c|c|c|c|c|c|c|}
\hline \multirow{2}{*}{$\begin{array}{c}\text { PSD data (micrometer) } \\
\qquad d_{1} \\
\end{array}$} & \multicolumn{2}{|c|}{$\begin{array}{c}\text { Group 1 } \\
\mathrm{BiPO}_{4} \text { Sludge } \\
\text { caustic- } \\
\text { unleached leached }\end{array}$} & \multicolumn{2}{|c|}{$\begin{array}{r}\text { Group 2 } \\
\mathrm{BiPO}_{4} \text { Saltcake } \\
\text { caustic- } \\
\text { unleached leached }\end{array}$} & \multicolumn{2}{|c|}{$\begin{array}{c}\text { Group 3 } \\
\text { PUREX Cladding } \\
\text { Waste Sludge } \\
\text { leached \& } \\
\text { unleached washed }\end{array}$} & \multirow{2}{*}{\multicolumn{2}{|c|}{$\begin{array}{c}\text { Group 4 } \\
\text { REDOX Cladding } \\
\text { Waste Sludge } \\
\begin{array}{lr} \\
\text { leached \& } \\
\text { unleached } & \text { washed } \\
0.4 & \mathrm{n} / \mathrm{a}\end{array}\end{array}$}} & \multicolumn{2}{|c|}{$\begin{array}{c}\text { Group 5 } \\
\text { REDOX Sludge (R) } \\
\text { caustic- } \\
\text { unleached leached }\end{array}$} & \multicolumn{2}{|c|}{$\begin{array}{c}\text { Group } 6 \\
\\
\text { S- Saltcake (S) } \\
\text { caustic \& } \\
\text { oxidative- } \\
\text { unleached leached }\end{array}$} & \multicolumn{2}{|c|}{$\begin{array}{c}\text { Group 7 } \\
\text { TBP Sludge } \\
\text { caustic- } \\
\text { leached \& } \\
\text { unleached washed }\end{array}$} & \multicolumn{2}{|c|}{$\begin{array}{c}\text { Group 8 } \\
\text { FeCN Wastes } \\
\text { caustic- } \\
\text { leached \& } \\
\text { unleached washed }\end{array}$} \\
\hline & 0.4 & I 0.6 & 0.4 & 0.3 & 0.4 & I 0.3 & & & 0.4 & I $\quad 0.4$ & 0.4 & I $\quad 0.4$ & 0.4 & I 0.4 & 0.4 & I 0.5 \\
\hline$d_{5}$ & 0.7 & 3.0 & 0.6 & 0.5 & 0.6 & 0.4 & 0.8 & $\mathrm{n} / \mathrm{a}$ & 0.8 & 0.6 & 0.6 & 0.6 & 0.6 & 0.5 & 1.1 & 2.2 \\
\hline$d_{10}$ & 1.0 & 8.3 & 0.8 & 0.6 & 1.1 & 0.5 & 1.7 & $\mathrm{n} / \mathrm{a}$ & 1.4 & 1.1 & 0.8 & 1.0 & 1.1 & 0.6 & 2.4 & 3.3 \\
\hline$d_{20}$ & 1.6 & 17.7 & 1.3 & 0.8 & 2.0 & 0.8 & 3.7 & $\mathrm{n} / \mathrm{a}$ & 3.1 & 2.6 & 1.3 & 2.4 & 3.5 & 0.9 & 3.9 & 4.7 \\
\hline$d_{25}$ & 1.9 & 20.6 & 1.6 & 1.0 & 2.5 & 1.0 & 4.7 & $n / a$ & 3.8 & 3.7 & 1.5 & 3.3 & 4.4 & 1.0 & 4.5 & 5.3 \\
\hline$d_{30}$ & 2.3 & 23.4 & 1.9 & 1.1 & 3.1 & 1.2 & 5.5 & $n / a$ & 4.5 & 5.0 & 1.8 & 4.2 & 5.2 & 1.2 & 5.2 & 6.0 \\
\hline$d_{40}$ & 3.3 & 29.0 & 2.5 & 1.5 & 4.3 & 1.7 & 7.1 & $n / a$ & 5.9 & 7.8 & 2.6 & 6.1 & 7.1 & 1.5 & 6.6 & 7.7 \\
\hline$d_{50}$ & 4.8 & 35.6 & 3.3 & 1.9 & 5.5 & 2.4 & 8.8 & $\mathrm{n} / \mathrm{a}$ & 7.3 & 10.7 & 3.7 & 8.2 & 12.3 & 2.1 & 8.4 & 10.2 \\
\hline$d_{60}$ & 6.7 & 44.1 & 4.3 & 2.6 & 6.9 & 10.5 & 10.8 & $\mathrm{n} / \mathrm{a}$ & 8.8 & 14.0 & 5.2 & 10.9 & 27.7 & 3.2 & 11.1 & 15.0 \\
\hline$d_{70}$ & 9.4 & 56.6 & 5.5 & 3.7 & 8.5 & \begin{tabular}{|l|l|} 
& 19.4 \\
\end{tabular} & 13.6 & $\mathrm{n} / \mathrm{a}$ & 10.6 & 18.3 & 7.5 & 14.7 & 37.6 & 5.7 & 33.3 & 23.6 \\
\hline$d_{75}$ & 11.2 & 65.2 & 6.4 & 4.5 & 9.5 & \begin{tabular}{|l|l|}
23.3 \\
\end{tabular} & 15.5 & $n / a$ & 11.7 & 21.2 & 9.2 & 17.7 & 43.4 & 7.5 & 46.4 & 28.9 \\
\hline$d_{80}$ & 13.5 & 75.8 & 7.3 & 5.5 & 10.6 & 28.3 & 18.7 & $n / a$ & 13.0 & 24.9 & 12.4 & 22.3 & 50.3 & 19.8 & 56.7 & 35.1 \\
\hline$d_{90}$ & 22.1 & \begin{tabular}{|l|l}
104.8 \\
\end{tabular} & 10.4 & 8.4 & 13.6 & 59.7 & 34.7 & $n / a$ & 16.8 & 41.5 & 34.6 & 55.9 & 71.5 & 77.6 & 82.8 & 53.9 \\
\hline$d_{95}$ & 34.5 & 127.6 & 13.1 & 11.0 & 16.2 & 91.6 & 47.0 & $n / a$ & 20.6 & 76.0 & 44.3 & 81.7 & 94.2 & 138.0 & 109.6 & 71.4 \\
\hline$d_{99}$ & 69.6 & 163.6 & 18.3 & 15.6 & 20.2 & 127.3 & 81.0 & $n / a$ & 43.7 & 121.3 & 59.3 & 113.3 & 167.7 & 208.1 & 265.1 & 101.6 \\
\hline
\end{tabular}

Table 8.3. Rheological Data From WTP M-12 Actual-Waste Samples

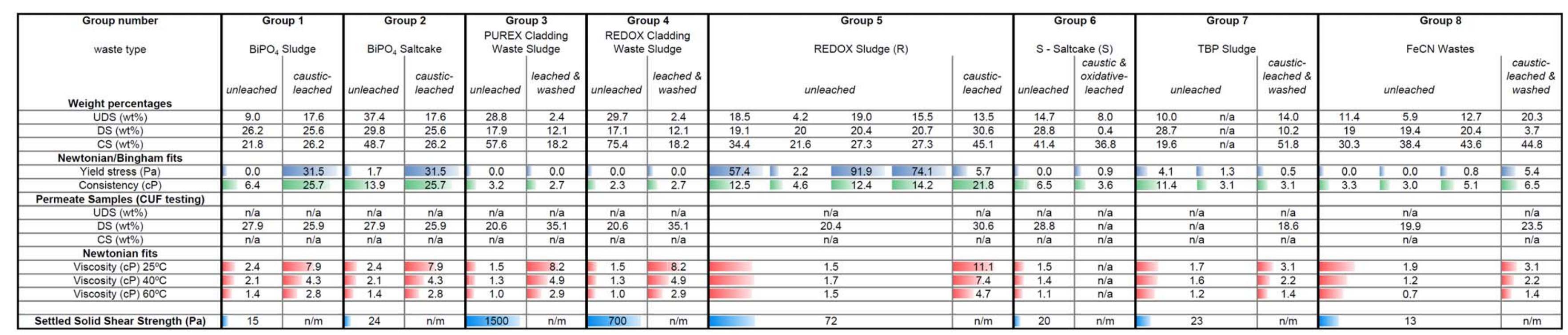



Table 8.4. XRD Data Showing Observed Crystalline Compounds in WTP M-12 Actual-Waste Samples

\begin{tabular}{|c|c|c|c|c|c|c|c|c|c|c|c|c|c|c|c|c|c|c|c|}
\hline $\begin{array}{l}\text { Crystalline Phase } \\
\text { Sodium Aluminum Iron Oxide }\end{array}$ & $\begin{array}{l}\text { Chemical Structure } \\
\text { Fee9.5015 }\end{array}$ & Density & unleached & $\begin{array}{l}\text { upi } 1 \\
\text { sludge }\end{array}$ & unleached & 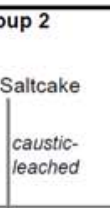 & $\begin{array}{l}\text { Gro } \\
\text { PUREX } \\
\text { Waste }\end{array}$ & 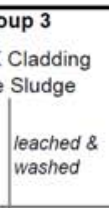 & $\begin{array}{r}\text { Gr } \\
\text { REDor } \\
\text { Waste } \\
\text { unleached }\end{array}$ & 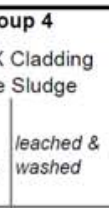 & Unleached & Sludge $(R)$ & \begin{tabular}{|c|} 
Grol \\
s. Satto \\
unleached
\end{tabular} & 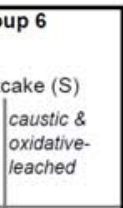 & & 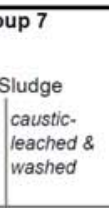 & $\begin{array}{c}\text { FeCN } \\
\text { unfeached } \\
\text { observed }\end{array}$ & $\begin{array}{l}\text { Wastes } \\
\text { caustic. } \\
\text { leached \& } \\
\text { washed } \\
\text { observed }\end{array}$ & \begin{tabular}{|l} 
Density S \\
Jade 6.03 ICDD-ICSD (PDF \# 40.0024 )
\end{tabular} \\
\hline $\begin{array}{l}\text { Sodium phosphate } \\
\text { Sodium oxide cyanide }\end{array}$ & & $\frac{1.6}{1.9}$ & & & & & & & & & & & $4.3 \%$ & & & & observed & observed & 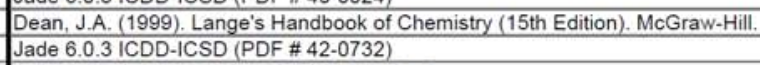 \\
\hline $\begin{array}{l}\text { Dormanite } \\
\text { Nickel hyrogen phosphate hydrate }\end{array}$ & 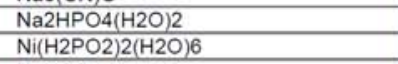 & 2.00 & & & observed & & & & & 0.2 & $0.2 \%$ & & & & & & & & 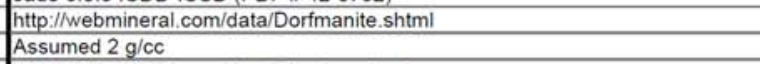 \\
\hline 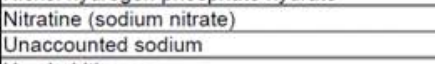 & & & observed & & & & $0.5 \%$ & & & & $20.4 \%$ & 9.89 & $11.0 \%$ & $17.0 \%$ & & & & & 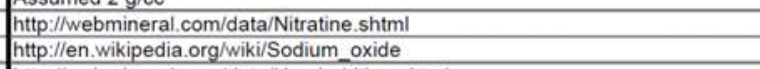 \\
\hline $\begin{array}{l}\text { Humboldtine } \\
\text { Zeolite A (prototypic) }\end{array}$ & 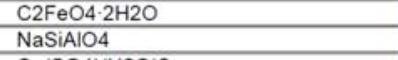 & & & & & & & & & & $3.9 \%$ & $14.60^{\circ}$ & & & $\begin{array}{l}\text { observed } \\
\text { observed }\end{array}$ & & ב- & & 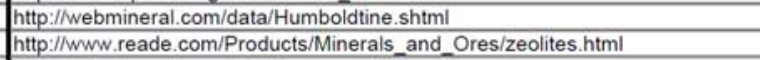 \\
\hline $\begin{array}{l}\text { Calcium sutate } \\
\text { Sodium auluminum silicate hydrate }\end{array}$ & 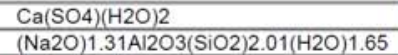 & $\frac{2.3}{2.3}$ & observed & & & & & & & & & & & & & & & & 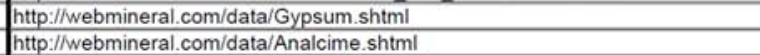 \\
\hline $\begin{array}{l}\text { Nabaphite } \\
\text { Nybroxycancrinte }\end{array}$ & 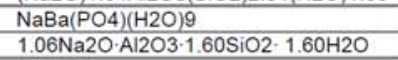 & & & & & & & & & & & & & & & observed & & observed & 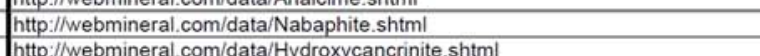 \\
\hline $\begin{array}{l}\text { Gibstite } \\
\text { Sobstalate }\end{array}$ & & $\frac{23}{23}$ & & & observed & & $92.1 \%$ & & & & $6.3 \%$ & & $\begin{array}{ll}43.8 \% \\
157 \%\end{array}$ & $5.3 \%$ & fobserved & & observed & 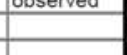 & 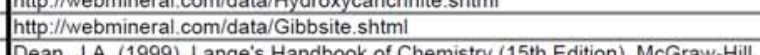 \\
\hline 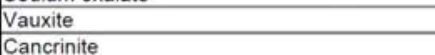 & 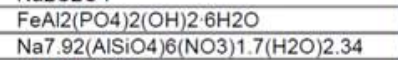 & $\frac{2.4}{2.4}$ & observed & & Fheorved & Therened & $5.5 \%$ & & & & $20 \%$ & & $7106 \mathrm{~g}$ & $1910 \%$ & & & & & 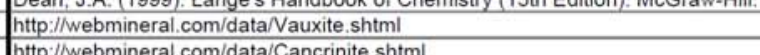 \\
\hline $\begin{array}{l}\text { Ammonium aluminum hydrogen phosphate } \\
\text { Calcium nitate }\end{array}$ & 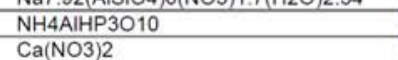 & $\frac{24}{2.4}$ & observed & & o ooserved & josservec & & & & & 2.006 & & & & & observed & observed & observed & 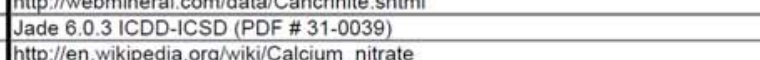 \\
\hline $\begin{array}{l}\text { Sodium pyrophosphhate } \\
\text { Sirconium hydrogen hosphate hydrate }\end{array}$ & 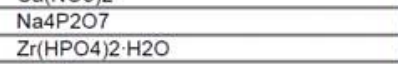 & $\frac{2.5}{2.5}$ & $\begin{array}{l}\text { observed } \\
\text { observed }\end{array}$ & & & & & & & & & & & & & 然served & 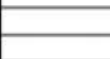 & & 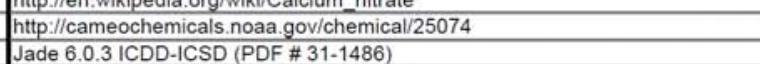 \\
\hline $\begin{array}{l}\text { Berlinite } \\
\text { Silicon oxide }\end{array}$ & AP104 & $\frac{2.6}{2.6}$ & lobserved & observed & & & & & & & & & $1.0 \%$ & $3.9 \%$ & & & & & 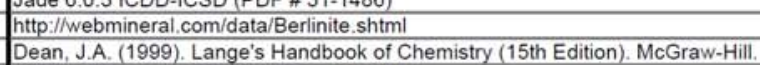 \\
\hline $\begin{array}{l}\text { Bassanite(a) } \\
\text { CCaclium arbonate }\end{array}$ & 0.00 .5 & $\frac{2.7}{2.7}$ & & & & & & & & & & 5.50 & & $4.7 \%$ & & & observed & observed & 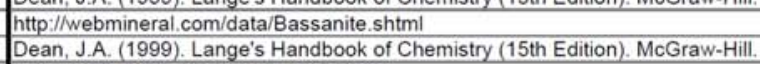 \\
\hline 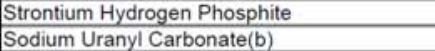 & $\frac{\mathrm{Sr}\left(\mathrm{H} 2 \mathrm{PO} \mathrm{O}_{3}\right)}{\mathrm{Na} / \mathrm{CO} / 3}$ & $\frac{2.8}{2.8}$ & & & & & & & & & & & & & & & $\begin{array}{l}\text { observed } \\
\text { observed }\end{array}$ & $\begin{array}{l}\text { observed } \\
\text { observed }\end{array}$ & 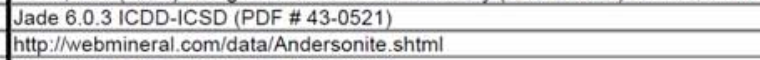 \\
\hline $\begin{array}{l}\text { Urany y hrogogen phosphate actone } \\
\text { Cacicium suffate }\end{array}$ & $\begin{array}{l}\text { C3HHO-UO2HPO4 } \\
\text { CaSO4 }\end{array}$ & 2.8. & pobserved & & & & & & & & & & & & & & & & 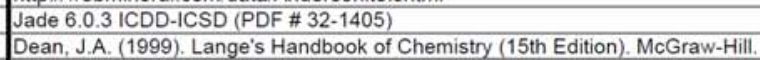 \\
\hline $\begin{array}{l}\text { Strotinum manganess oxide hydrate } \\
\text { toohmite }\end{array}$ & 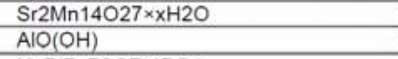 & $\begin{array}{l}3.0 . \\
3.0 \\
\end{array}$ & lobserved & observed & & & & & & & $63.8 \%$ & $\begin{aligned} 14.89 \\
18.30^{\circ} \\
\end{aligned}$ & $7.6 \%$ & $14.8 \%$ & & & & & 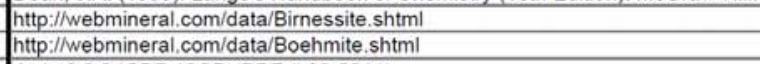 \\
\hline $\begin{array}{l}\text { Sodium lon Phosshate } \\
\text { Shromium hydroxide }\end{array}$ & 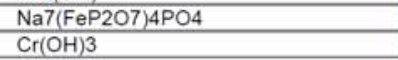 & $\begin{array}{ll}3.0 \\
3.0\end{array}$ & & & & & & & & & $0.4 \%$ & & & & observed & & & & $\begin{array}{l}\text { Jade 6.0.3 ICDD-ICSD (PDF \# 39-0011) } \\
\text { Sititated }\end{array}$ \\
\hline 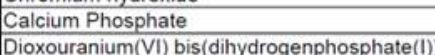 & 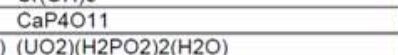 & $\frac{3.1}{3.1}$ & & & & & & & & & & & & & & & observed & observed & 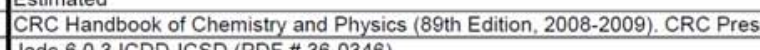 \\
\hline Threadgolditite & 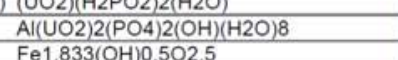 & $\frac{3.1}{3.4}$ & & & & Cobserved & & & & & & & & & observed & & & & 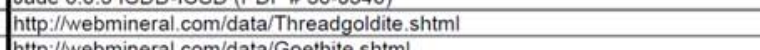 \\
\hline 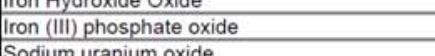 & 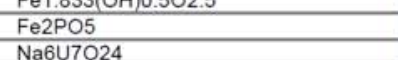 & & Tobserved & & & & & & & & $1.0 \%$ & & $0.0 \%$ & & observed & hereved & Fberented & Anserved & 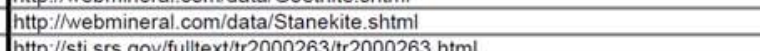 \\
\hline epidocrocite & 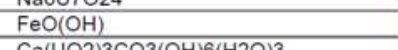 & 4.0 & 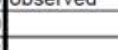 & & & & & & & & & & & & observed & & - & & 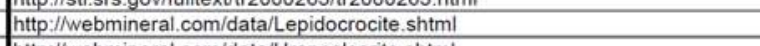 \\
\hline 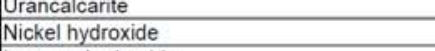 & 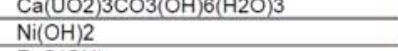 & $\begin{array}{l}4.0 . \\
4.1 \\
-1\end{array}$ & & & observed & & & & & & & 0.99 & $0.1 \%$ & & & & & & 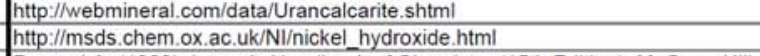 \\
\hline $\begin{array}{l}\text { llinon oxy-hydroxide } \\
\text { liron hydroxide }\end{array}$ & $\begin{array}{lll}\mathrm{FeOOOOH} \\
\mathrm{Fe}(\mathrm{OH}) 3^{3}\end{array}$ & 4.22 & & & & & & & & & & & $1.7 \%$ & $5.4 \%$ & & & & & 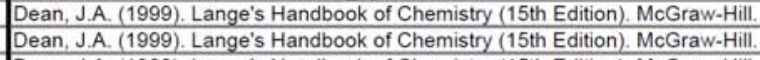 \\
\hline $\begin{array}{l}\text { Strontium oxide } \\
\text { Manganese dioxide }\end{array}$ & $\begin{array}{ll}\mathrm{SrO}^{\mathrm{MnO} 2} \\
\mathrm{MnO2}\end{array}$ & 5.7. & & & & & & & & & $\begin{array}{l}0.1 \% \% \\
0.4 \%\end{array}$ & & $0.0 \% \%$ & $23.4 \%$ & & & & & 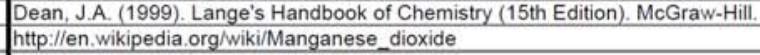 \\
\hline $\begin{array}{l}\text { Becauerellte } \\
\text { Chromium oxide } \\
\end{array}$ & & 5.2 & & & & & & & & & Cact & 0.79 & $6.8 \%$ & $5.6 \%$ & & observed & & & 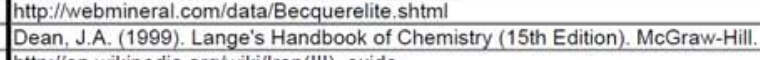 \\
\hline Hematte & & $\frac{5.2}{5.3}$ & thenondt & & & & $1.8 \%$ & & & & & & & & & & observed & obserened & 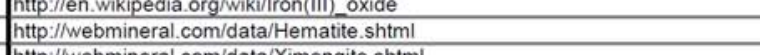 \\
\hline $\begin{array}{l}\text { Istumun nhosphate } \\
\text { linc oxide }\end{array}$ & & & posented & & & & & & & & & & $0.1 \%$ & & & & & & 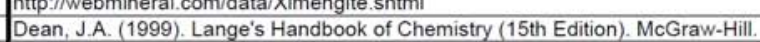 \\
\hline Clarkente & $\frac{\mathrm{Na}(\mathrm{UO} 2) \mathrm{O}(\mathrm{OH})}{\mathrm{CaBi2}}$ & 6.3. & Tohserved & & & observed & $0.1 \%$ & & & & & 22.60 & & $1.0 \%$ & & observed & & & hitpl//webmineral.com/data/Clarkeite.shtml \\
\hline Jannium Dioxide & 002 & 87 & & & & observed & & & & & & & & & & & & & 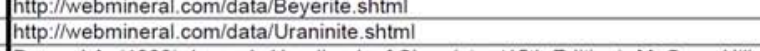 \\
\hline ismuth oxide & $8 \mathrm{Bi} 203$ & $\begin{array}{l}8.7 \\
\text { sun }\end{array}$ & n/a & $\mathrm{n} / \mathrm{a}$ & n/a & n/a & $\begin{array}{l}100.0 \% \\
\end{array}$ & n/a & $0.0 \%$ & $n / a$ & $100.0 \%$ & $100.0 \%$ & $100.0 \%$ & $100.0 \%$ & nla & n/a & & n/a & 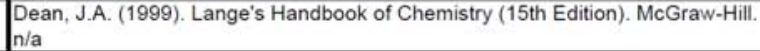 \\
\hline
\end{tabular}




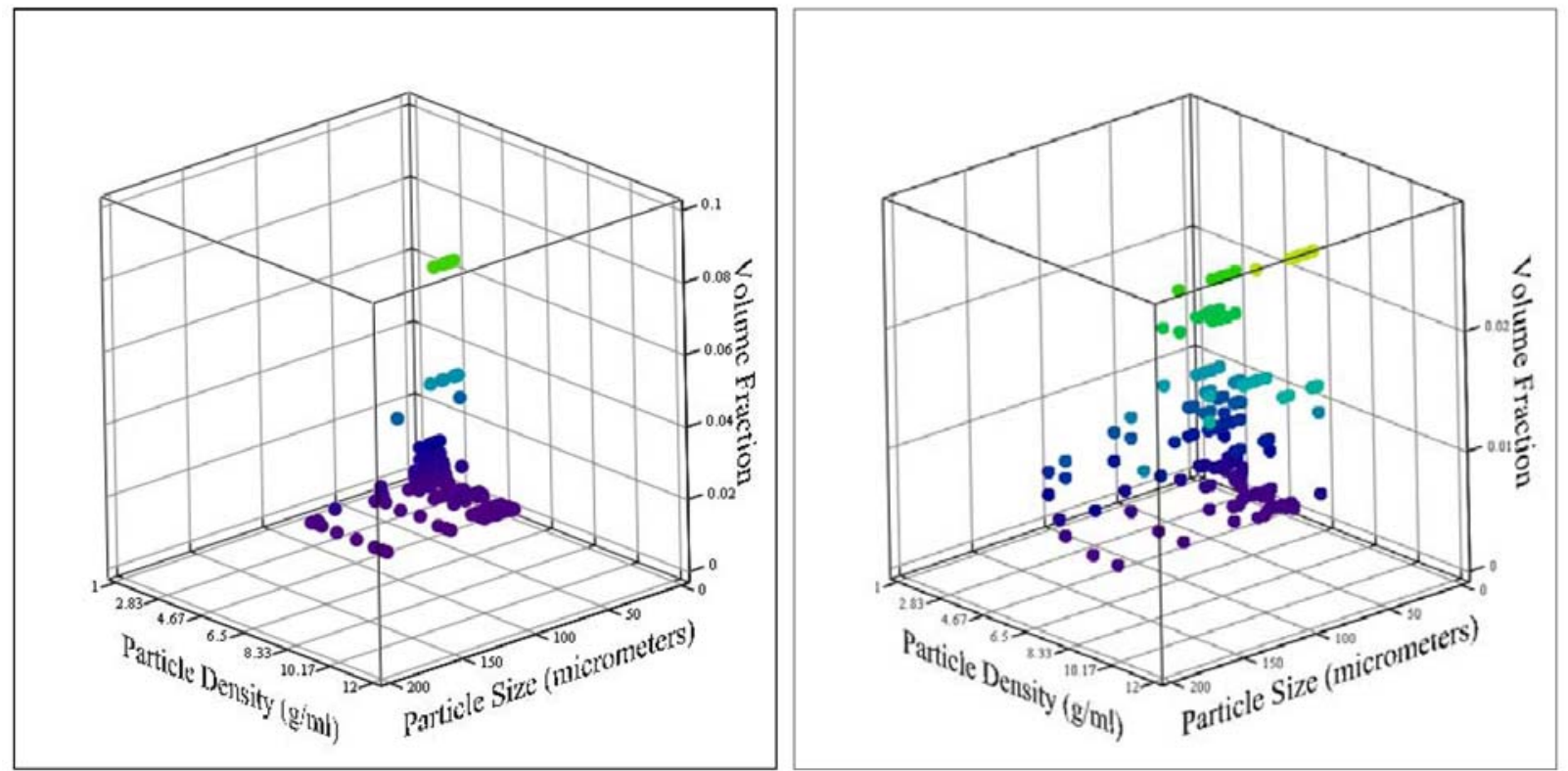

Figure 8.3. M-12 PSDD From Unleached (Left) and Leached (Right) Group 5 Composite With Data From Fiskum et al. (2008; WTP-RPT-157 Rev. 0 )

\subsection{Minimum Design Velocity for non-Newtonian Pipeline Transport Systems in the Waste Treatment Plant}

A recommended minimum transport velocity can be determined by considering both maxima on the stability map, Point $\mathrm{W}$ for Newtonian fluids, and Point $\mathrm{Y}$ for non-Newtonian fluids. The greater of these values should be used as it represents the greatest lower bound on transport velocity which can be considered the "minimum transport velocity" for the WTP. If a variety of Point W velocities are considered for a complex simulant with distributions of particle size and density, the fraction of the slurry particles that are in stable and unstable flow at each condition can be calculated (see Figure 8.4). 


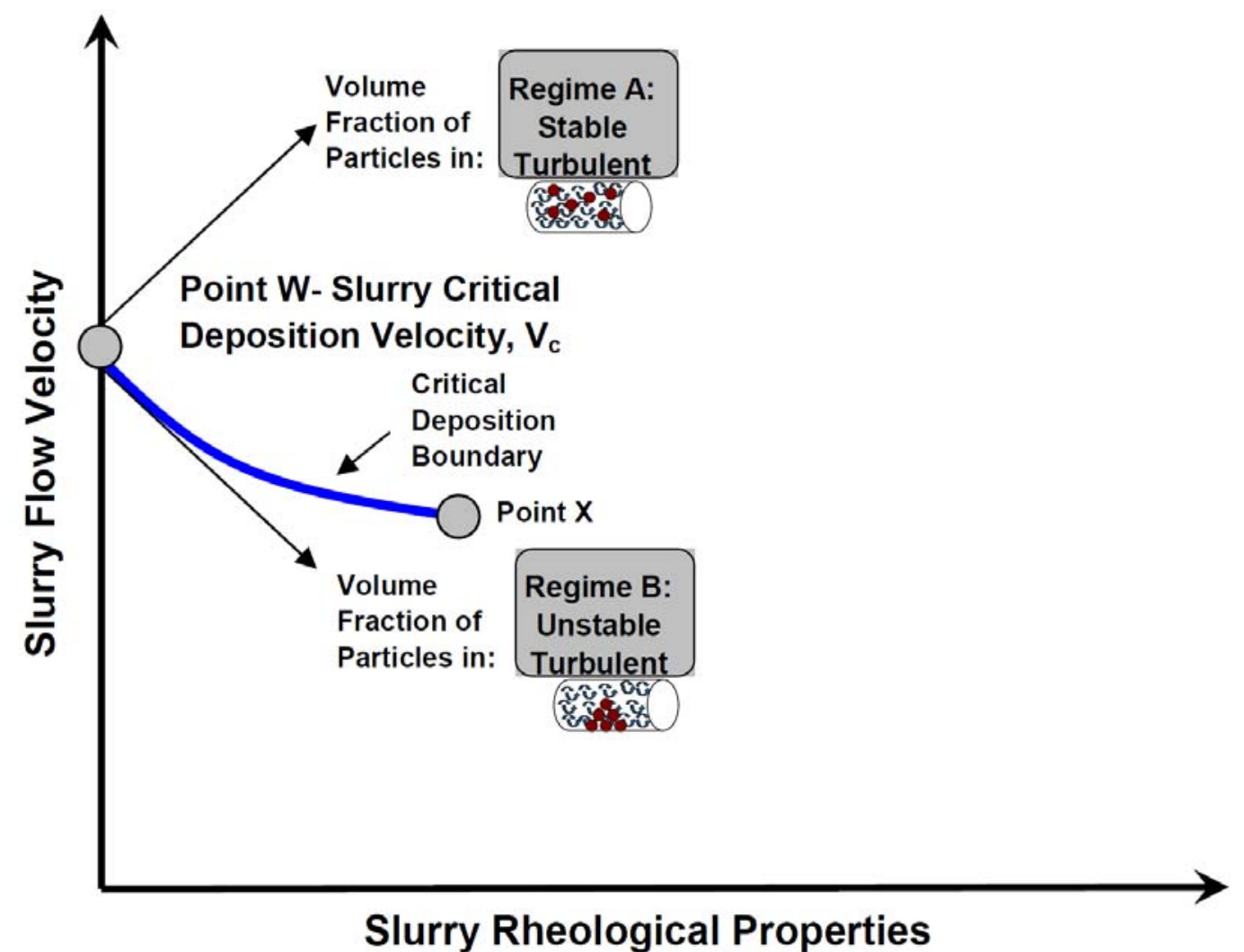

Figure 8.4. Schematic Showing a Design Approach for Newtonian Slurries of Setting a Maximum Velocity at which Turbulent Deposition Can Occur and Determining the Volume Fraction of Slurry Particles in Unstable Turbulent Flow

When this calculation is performed using the PSDDs presented in this section, Figure 8.5 is obtained. The Group 5 initial characterization and WTP-RPT-153 Case 4 PSDDs predict similar behavior and the lowest deposition velocities. The WTP-RPT-153 Case 3 PSDD predicts an increased amount of deposition with a tail at the higher velocities that is attributed to large or dense particles. The RPP-9805 PSDD predicts a higher level of deposition at the lower velocities but does not have a tail indicating deposition at the higher velocities. The M-12 Group 5 PSDD follows the RPP-9805 behavior at lower velocities but has a tail indicating 3 to $1 \%$ of the slurry particles will deposit at higher velocities. Again, this tail is attributed to the presence of large or dense particles in the PSDD, e.g. on the order of $100-\mu \mathrm{m}$ Clarkeite $\left(\mathrm{Na}\left[\left(\mathrm{UO}_{2}\right) \mathrm{O}(\mathrm{OH})\right]\left(\mathrm{H}_{2} \mathrm{O}\right)_{0-1} ; \rho_{s}=6.39 \mathrm{~g} / \mathrm{ml}\right)$ particles. When the pipe diameter is increased from 3 " to 4 " the curves shift to the right proportional to $\mathrm{D}^{1 / 2}$; this represents an approximately $15 \%$ increase in deposition velocity with the increased pipe diameter.

A similar calculation can be performed with respect to Point $Y$ on a stability map. In this case, one determines the fraction of particles that are either in stable-laminar or unstable-laminar flow when the slurry transitions from turbulent to laminar flow. This is shown graphically in Figure 8.6. 

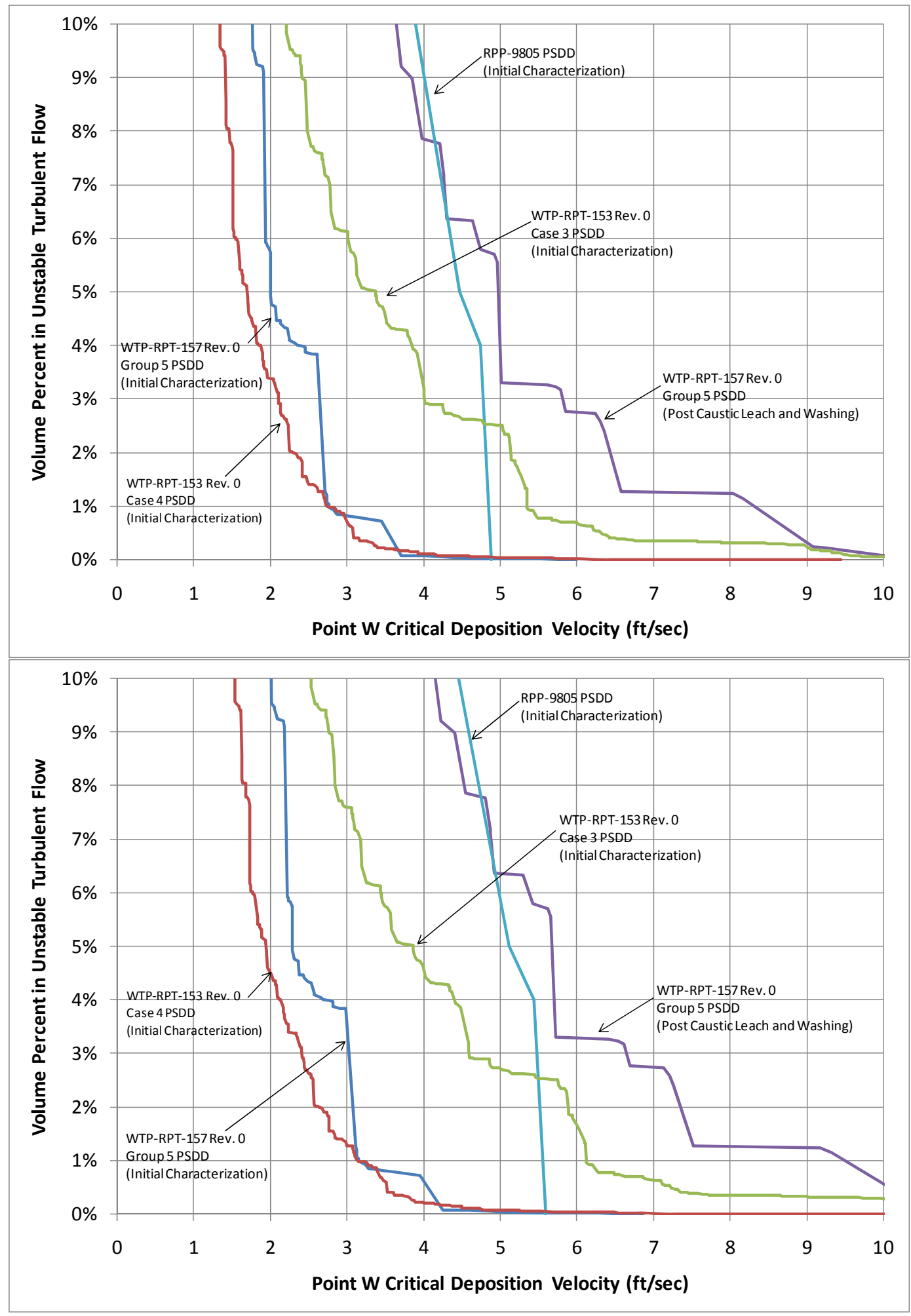

Figure 8.5. Fraction of Slurry Particles in Unstable Turbulent Flow in 3” Pipe (Top) and 4” Pipe (Bottom) at Various Velocities and PSDDs 


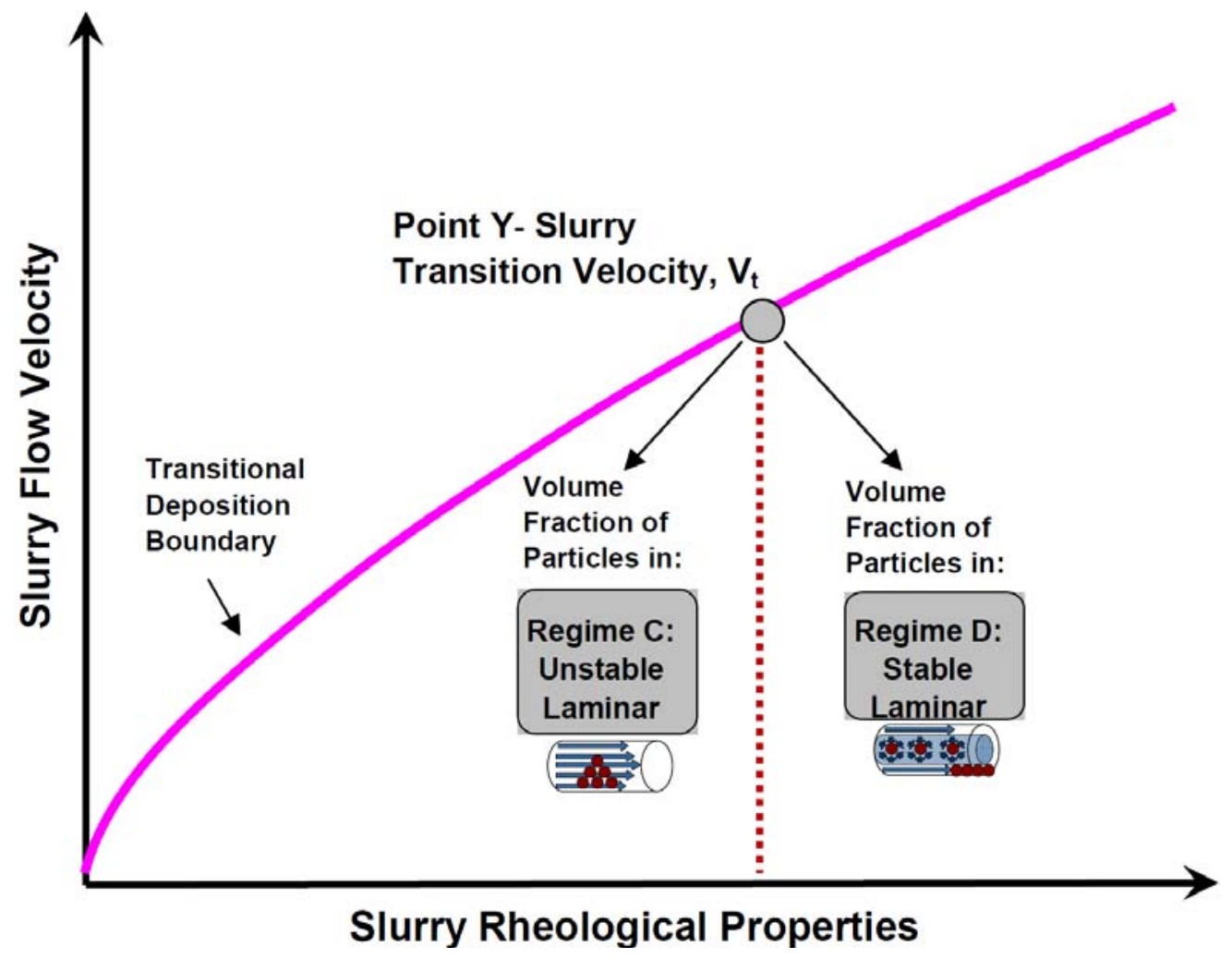

Figure 8.6. Schematic Showing a Design Approach for Non-Newtonian Slurries of Setting a Maximum Velocity at which Turbulent Flow Can Occur and Determining the Volume Fraction of Slurry Particles in Unstable Laminar Flow

As explained in Section 3.4, Gillies et al. (2007) established a criterion for stable laminar flow that relates the ratio of the wall shear stress, $\tau_{\mathrm{w}}$, to the average surficial particle shear stress, $\tau_{\mathrm{p}}$. The surficial-particle shear stress is defined in Equation 8.1.

$$
\tau_{p}=\frac{\left(\rho_{s}-\rho_{f}\right) g d}{6}
$$

Gillies et al. (2007) state that "a slurry's proclivity to experience laminar flow settling is greatly reduced when $\tau_{\mathrm{w}} / \tau_{\mathrm{p}}>60$ and nearly eliminated when $\tau_{\mathrm{w}} / \tau_{\mathrm{p}}>100$." If the ratio is taken to be at the low end of the range at 60 , the stability criterion shown in Equation 8.2 can be established.

$$
\alpha=\frac{\tau_{w, t}}{\tau_{p}} \geq 60
$$

The shear stress at the wall for a Bingham plastic fluid in laminar flow at the transition velocity can be calculated as shown in Equation 8.3 (Shook et al. 2002).

$$
\tau_{w, t}=\frac{8 K V_{t}}{D}+\frac{4 \tau_{B}}{3}
$$


Through the use of Equations 8.1 to 8.3, particle size and density characteristics can be used to predict whether a particle is likely to be in stable or unstable laminar-flow regimes in fluids with different rheological properties. When this methodology is applied to the PSDDs presented in this section, Figure 8.7 is obtained. Unlike the turbulent deposition calculation (Point W), for laminar deposition (Point Y) the RPP-9805 PSDD predicts the largest fraction of deposition. This is due to the increased dependence on size of the particles rather than density for these laminar stability calculations. In this case, the larger particle sizes assumed by the RPP-9805 PSDD dominate the lower particle-density assumption. When the pipe diameter is increased from 3 " to 4 " the curves shift to the right proportional to D. However, this effect is counteracted by a decrease in laminar to turbulent transition velocity with increasing pipe diameter. The net effect is only a slight increase in deposition velocity with increasing pipe diameter.

From the Point $\mathrm{W}$ and Point $\mathrm{Y}$ calculations shown in Figure 8.5 and Figure 8.7, respectively, the following set of conclusions can be drawn with respect to establishing a minimum transport velocity for the WTP:

- A significant fraction of particles is predicted to settle to a stationary bed in the 4-6 ft/sec range under both Newtonian and non-Newtonian conditions

- The settled particles will be predominately of high density or high particle size

- A transport velocity of approximately $10 \mathrm{ft} / \mathrm{sec}$ will maintain turbulent flow in a 3" pipe at the upper end of the rheological operating window (30 Pa Bingham plastic yield stress, $30 \mathrm{cP}$ consistency). If this is not achievable a minimum velocity of $6 \mathrm{ft} / \mathrm{sec}$ or greater is recommended for operation under laminar conditions.

- During slurry transfers in the WTP, a sediment bed is expected to slowly develop over time and must be aggressively flushed to mitigate potential line plugging. Sediment beds are expected to develop faster in largerdiameter pipes. Development of a basis for an aggressive flushing frequency should be supported by further testing.

- Flushing at $10 \mathrm{ft} / \mathrm{sec}$ or greater should be sufficient to remove the sediment beds. However, re-suspension of particles from a stationary bed involves different mechanics from deposition. The design basis value for the minimum flush velocity to remove a stationary bed should be supported by further testing.

- Flushing should be performed in the same direction as normal process flow: from the source tank to the destination tank. Back-flushing pipes to source tanks should not be permitted as particles will accumulate in vessels and pipes.

- The flush-system design should be reviewed to assure that all process lines in the WTP meet the conditions listed above. 

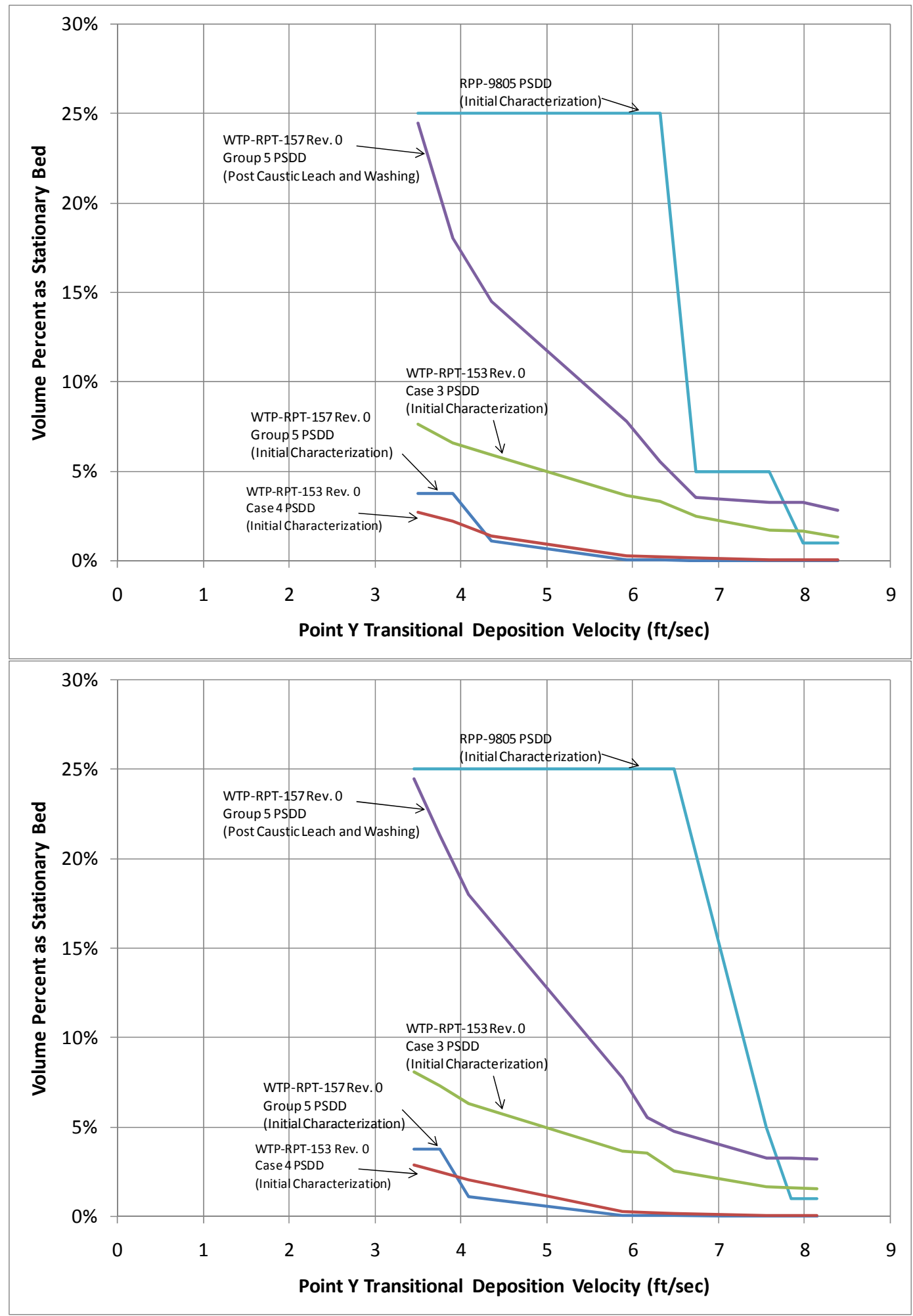

Figure 8.7. Fraction of Slurry Particles in Unstable Laminar Flow in 3” Pipe (Top) and 4” Pipe (Bottom) at Various Velocities and PSDDs 


\subsection{Net Positive Suction Head (NPSH) Testing}

Cavitation, the vaporization of liquid within a pump intake, will both reduce pump performance and damage the pump. In a centrifugal pump, as liquid passes through the suction intake, through the impeller eye, and over the impeller vanes the velocity increases and the pressure drops (See Figure 9.1, below). If the local static pressure on the liquid inside the pump reaches the vapor pressure of the liquid being pumped, the liquid will form vapor bubbles and cavitation will occur.

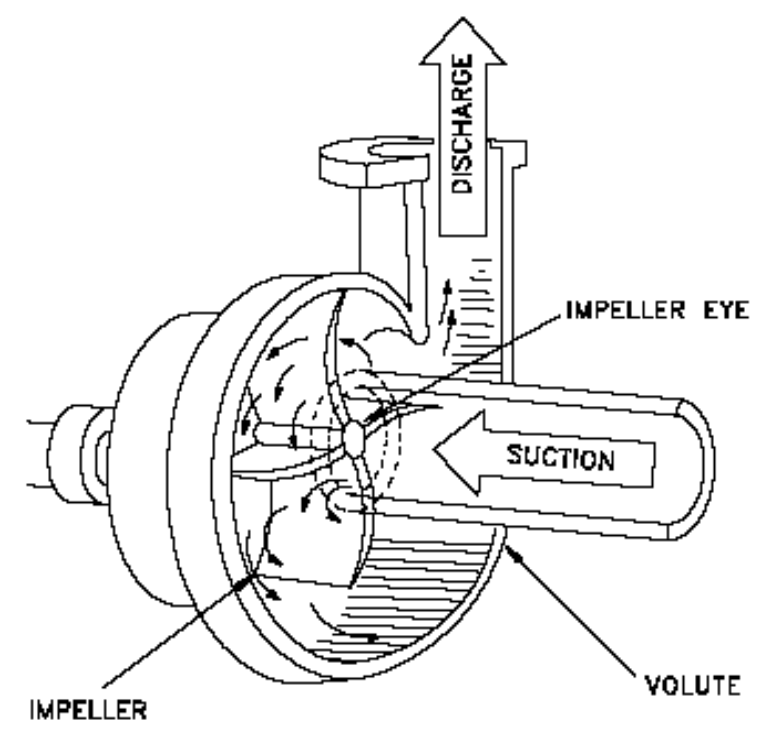

Figure 9.1. Principal Components of a Centrifugal Pump

The Net Positive Suction Head (NPSH) is the head required at the pump inlet to prevent cavitation; algebraically, the NPSH available $\left(\mathrm{NPSH}_{\mathrm{A}}\right)$ to a pump is the difference between the total absolute suction head at the pump suction inlet (referred to datum) minus the absolute vapor pressure of the liquid pumped (measured in head units) (ANSI/HI 1.6-2000):

$$
\mathrm{NPSH}_{\mathrm{A}}=\mathrm{h}_{\mathrm{s}(\mathrm{a})}-\mathrm{h}_{\mathrm{vp}(\mathrm{a})}
$$

Substituting terms for atmospheric-pressure head $\left(\mathrm{h}_{\mathrm{atm}}\right)$, gauge head $\left(\mathrm{h}_{\mathrm{g}}=\mathrm{p}_{\mathrm{i}} / \rho \mathrm{g}\right)$, and velocity head $\left(\mathrm{h}_{\mathrm{v}}=\mathrm{V}^{2} / 2 \mathrm{~g}\right)$ gives equation 9.2:

$$
\mathrm{NPSH}_{\mathrm{A}}=\mathrm{h}_{\mathrm{atm}}+\mathrm{h}_{\mathrm{g}}+\mathrm{h}_{\mathrm{v}}-\mathrm{h}_{\mathrm{vp}(\mathrm{a})}=\mathrm{h}_{\mathrm{atm}}+\mathrm{p}_{\mathrm{i}} / \rho \mathrm{g}+\mathrm{V}_{\mathrm{i}}^{2} / 2 \mathrm{~g}-\mathrm{h}_{\mathrm{vp}(\mathrm{a})}
$$

where $\mathrm{p}_{\mathrm{i}}$ is the pressure at the pump inlet, $\rho$ is the liquid density, $\mathrm{g}$ is gravitational acceleration, and $\mathrm{V}_{\mathrm{i}}$ is fluid velocity at the pump inlet.

The NPSH required by the pump to operate without cavitation $\left(\mathrm{NPSH}_{\mathrm{R}}\right)$ is a function of the pump design and is the positive absolute head required at the pump suction to overcome internal pressure drop in the pump while maintaining the pumped liquid above its vapor pressure. The formal definition for $\mathrm{NPSH}_{\mathrm{R}}$ is given by the Hydraulic Institute as total absolute suction head determined at the first-stage impeller datum minus the absolute vapor pressure of the liquid, in head of liquid pumped, required to prevent more than $3 \%$ loss in total head from the first stage of the pump at a specific rate of flow (ANSI/HI 1.6-2000). The $\mathrm{NPSH}_{\mathrm{R}}$ is determined by applying a standardized test procedure to the pump/liquid system of interest; pump manufacturers supply $\mathrm{NPSH}_{\mathrm{R}}$ data obtained with water in their performance data packages, but for critical service with other fluids the $\mathrm{NPSH}_{\mathrm{R}}$ must be 
determined by carrying out a test procedure with the liquid of interest. Temperature of the pumped fluid must be evaluated since the vapor pressure is exponentially dependent on temperature.

Reduction of pump performance can also occur when air is entrained into the pump inlet. When this occurs, the measurements discussed in this section still apply but the resulting $\mathrm{NSPH}_{R}$ value is termed "apparent $\mathrm{NSPH}_{\mathrm{R}}$ " since the reduction in performance is due to gas bubbles than liquid vapor forming due to cavitation.

\section{1 $\mathrm{NPSH}_{\mathrm{R}}$ Test Objectives}

Test objectives and the test matrix for $\mathrm{NPSH}_{\mathrm{R}}$ testing using a Non-Newtonian HLW simulant were defined in Test Plan TP-RPP-WTP-493 Rev 1. The Test Plan stated that $\mathrm{NPSH}_{\mathrm{R}}$ test methods employed will be consistent with those specified by the Hydraulic Institute in the ANSI/HI 1.6-2000 manual, American National Standard for Centrifugal Pump Tests and the resulting data at different rheological properties contrasted \& compared to the pump manufacturer's data. The test matrix is shown below (Table 9.1).

Table 9.1. Test Matrix from TP-RPP-WTP-493 Rev 1

\begin{tabular}{lllll}
\hline $\begin{array}{l}\text { Test } \\
\text { Number }\end{array}$ & Target Bingham Yield Stress $(\mathrm{Pa})$ & $\begin{array}{l}\text { Target Bingham } \\
\text { consistency }(\mathrm{cP}) ; \\
\text { Record Value }\end{array}$ & $\begin{array}{l}\text { Deposition } \\
\text { Velocity } \\
\text { Testing? }\end{array}$ & NPSH Testing? \\
\hline 1 & 27 (if achievable) & varies & Yes & Yes \\
2 & 18 (if achievable) & varies & Yes & Yes \\
3 & 12 & varies & Yes & Yes \\
4 & 9 & varies & Yes & Yes \\
5 & 6 & varies & Yes & Yes \\
6 & 3 & varies & Yes & Yes \\
7 & $<1$ (nearly Newtonian) & varies & Yes & Yes \\
\hline
\end{tabular}

\section{2 $\mathrm{NPSH}_{\mathrm{R}}$ Test Equipment \& Procedures}

$\mathrm{NPSH}_{\mathrm{R}}$ testing using Non-Newtonian HLW simulant was carried out under conditions and procedures specified by the Hydraulic Institute in the ANSI/HI 1.6-2000 manual, American National Standard for Centrifugal Pump Tests.

The $\mathrm{NPSH}_{\mathrm{R}}$ tests were performed on the test loop shown in Figure 5.1 of WTP-RPT-175 Rev. 0 (Poloski et al. 2009) with the following modifications:

A flanged side outlet was welded to the bottom of the mixing tank and a full-flow ball valve (V-30) attached; the ball valve outlet was connected by flex hose to a spool piece inserted below valve V-9 (V-9 was blanked off). A weld-o-let port was inserted 5 inches upstream of the pump inlet (28 inches downstream of the nearest flow disturbance, the equivalent of 9 pipe diameters) and the port plumbed with 1/4-in Swagelok tubing to a Rosemount 1151 differential-pressure transducer (identified as DPT 2, Figure 5.1 of WTP-RPT-175 Rev. 0). A straight spool piece was inserted at the pump outlet in place of the "T" fitting and three attached valves (V-10, V-11, and V-29) with a weld-o-let port inserted 28 inches above the pump mounting flange; the port was plumbed with $1 / 4-$ in Swagelok tubing to a second Rosemount 1151 differential-pressure transducer (identified as DPT 3, Figure 5.1 of 
WTP-RPT-175 Rev. 0). The weld-o-let port above Coriolis meter CM-1 was valved \& plumbed with 1/4-in Swagelok tubing to serve as a sampling port.

The differential pressure transducers named DPT 2 and DPT 3 measured the suction and discharge pressures on the pump respectively. Fluid motive power is provided by a Georgia Iron Works $15 \mathrm{HP}, 1800 \mathrm{rpm}$ slurry pump controlled by a variable-frequency drive (VFD). Flow, density and temperature were measured at the pump outlet using CM-1, a Micro-Motion F-Series Coriolis meter described in Section 5.0 of WTP-RPT-175 Rev. 0 (Poloski et al. 2009).

The pump $\mathrm{NPSH}_{\mathrm{R}}$ tests were carried out with pump speed and suction head held constant, with flow controlled by an outlet valve (V-13, Figure 5.1) to establish the baseline performance curve, and controlled by an intake valve (V-30, described above) to collect NPSH performance data. After flow was stabilized with the pump VFD setting at $60 \mathrm{~Hz}$ and with the inlet valve fully open, eight baseline performance-curve points were developed by progressively opening the outlet valve from a closed (deadhead) position through six intermediate indexed positions to a fullyopen position and collecting data on suction and discharge pressures, flow rate, and liquid density and temperature at all 8 positions. Then, with the outlet valve fully open ( $\max$ flow rate), the inlet valve was progressively closed while a set of data points was collected over an approximate $6 \%$ drop in dynamic head from the baseline condition. The $6 \%$ value was chosen to facilitate interpolation of the $3 \%$ total head loss criterion per ANSI/HI 1.6-2000. The outlet valve was then progressively set at index angles of $37^{\circ}, 46^{\circ}, 55^{\circ}, 60^{\circ}, 65^{\circ}$, and $72^{\circ}$ while data point sets were collected at each outlet-valve index-angle setting by throttling the inlet valve to achieve the $6 \%$ drop in dynamic head from the baseline condition. A sample of the HLW simulant was collected both before and after each NPSH test and rheologically evaluated for Bingham and Casson-fluid yield stress and infinite-shear viscosity.

The data collected for the 3.1 Pa HLW simulant test is shown in Figure 9.2 (below), with data-point-series labels for Point 1 representing outlet-valve index angle of $0^{\circ}$ (fully open), Point 2 representing outlet-valve index angle of $37^{\circ}$, and continuing to Point 6 with an outlet-valve index angle of $72^{\circ}$. The point of $3 \%$ dynamic-head drop-off from baseline is reported as the $\mathrm{NPSH}_{\mathrm{R}}$ point for the corresponding flow rate. 


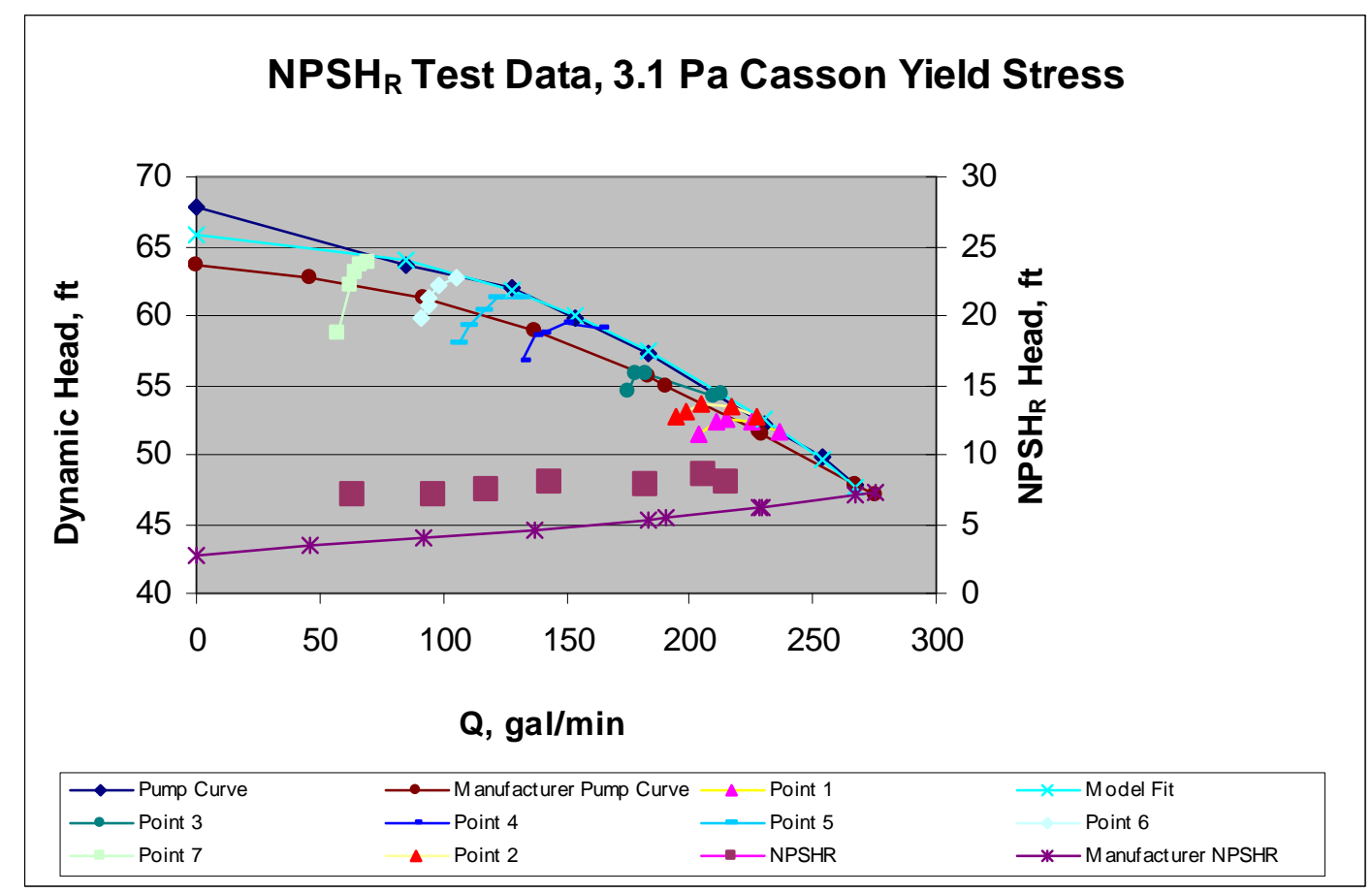

Figure 9.2. NPSH $_{R}$ Testing Data for Casson-Fluid Yield Stress of Approximately 3.1 Pa. the Manufacturer's Pump-Performance Curve and $\mathrm{NPSH}_{\mathrm{R}}$ Curves Are Shown, as well as $\mathrm{NPSH}_{\mathrm{R}}$ Data Points Collected. Head is Calculated on a Head-of-Slurry Basis

\section{3 $\mathrm{NPSH}_{\mathrm{R}}$ Test Results \& Discussion}

An $\mathrm{NPSH}_{\mathrm{R}}$ test series was performed using HLW simulants with Casson-fluid yield stresses of 28.0, 18.6, 12.8, 7.5, 5.1, 3.1, 2.6 and $0.9 \mathrm{~Pa}$, as well as with process water for comparison to the factory pump data. During testing of the 2.6 Pa Casson-fluid yield-stress case, it was observed that baseline performance-curve characteristics (unrestricted inlet flow) were changing with time, as well as mixing-tank level. This was found to be the result of air entrainment from mixing-tank impeller motion; an Anti-Foaming Agent (Dow-Corning QZ-3183A) was added at $350 \mathrm{ppm}$ concentration and mixer rpm reduced. The 3.1 Pa and 0.9 $\mathrm{Pa} \mathrm{NPSH}_{\mathrm{R}}$ simulant tests (performed with the Anti-Foaming Agent) and the process-water test are the only tests presented here as complete $\mathrm{NPSH}_{\mathrm{R}}$ results, due to uncertainties as a consequence of the air entrainment problem in the earlier tests. The 3.1 Pa test results are shown in Figure 9.3 and the 0.9 Pa test results are shown in Figure 9.4; process-water results are given in Figure 9.5. Results for the 28.0 Pa through 2.6 Pa tests with air entrainment are shown in Figure 9.6. Since the simulant was progressively diluted with supernate to produce the lower-yield-stress test cases, it was not possible to repeat the higher-yield-strength $\mathrm{NPSH}_{\mathrm{R}}$ tests. The 3.1 Pa test was carried out using the 2.6 Pa simulant; the addition of the AFA increased the Casson-fluid yield strength slightly to $3.1 \mathrm{~Pa}$

The $\mathrm{NPSH}_{\mathrm{R}}$ curves for $3.1 \mathrm{~Pa}$ and $0.9 \mathrm{~Pa}$ HLW simulant and for process water show greater deviation from manufacturer's values at lower flow rates (below $\sim 100 \mathrm{gpm}$ ); this is likely an artifact of cavitation induced at the edge of the inlet valve (full-flow ball type) and is seen to be the greatest for the water test. These HLW simulant curves each show an increase of 2.5-3.0 ft of head over manufacturer's data across the curve.

The $\mathrm{NPSH}_{\mathrm{R}}$ curves (with air entrainment) for the 28.0 Pa through 2.1 Pa tests also show the increased deviation from manufacturer's values at flow rates below $\sim 100 \mathrm{gpm}$ as for the $3.1 \mathrm{~Pa}, 0.9 \mathrm{~Pa}$, and process-water plots, but have much greater overall deviation from manufacturer's values at the points closest to the manufacturer's curve ( 110-140gpm): approximately $8 \mathrm{ft}$ of head increase for the $28.0 \mathrm{~Pa}$ simulant, increasing to over $18 \mathrm{ft}$ of head 
increase for the 5.1 Pa simulant. Greatest deviations from manufacturer's values (at higher flow rates) range from just under $9 \mathrm{ft}$ head increase for the 2.6 Pa simulant to $19 \mathrm{ft}$ head increase for the 5.1 Pa simulant. Since the lower Casson-fluid yield-stress simulants tested showed deviations of 2.5-3.0 ft of head over manufacturer's values, it can be seen that the much higher deviations of the earlier tests with higher yield-stress simulants point to increasing air entrainment as the simulant yield stress decreased. Like the $3.1 \mathrm{~Pa}, 0.9 \mathrm{~Pa}$ and process-water tests, the effect of inletvalve cavitation seems evident-and much more pronounced-below approximately $100 \mathrm{gpm}$.

A summary of the deviation from the manufacturers $\mathrm{NPSH}_{\mathrm{R}}$ data is shown in Table 9.2. The results show that when operating without AFA, the slurry retains gas that results in a significant increase in apparent $\mathrm{NPSH}_{\mathrm{R}}$ in the range of 2 to 3 times that reflected by the manufacturer data with water. At an approximate Casson-fluid yield stress of $3 \mathrm{~Pa}$, runs were conducted with and without AFA; the addition of the AFA reduced the apparent $\mathrm{NPSH}_{\mathrm{R}}$ increase by a factor of approximately three. The remaining slurry tests showed a positive deviation from the manufacturer data of approximately 1.5 times. A final run was conducted with water and no AFA and showed a negative deviation of $7 \%$ from the manufacturer data with water. Test results indicate significant increases in $\mathrm{NPSH}_{\mathrm{R}}$, on the order of 1.5 times, can be expected when air is not retained in the slurry. When air is retained in the slurry the apparent NPSHR increases by a factor of 2-3 times that reflected in manufacturer data for water. Therefore, additional engineering margins over accepted industrial practice should be added for $\mathrm{NPSH}_{\mathrm{R}}$ design specifications in the WTP.

$\mathrm{NPSH}_{\mathrm{R}}$ 3.1 Pa Casson Fluid Yield Stress

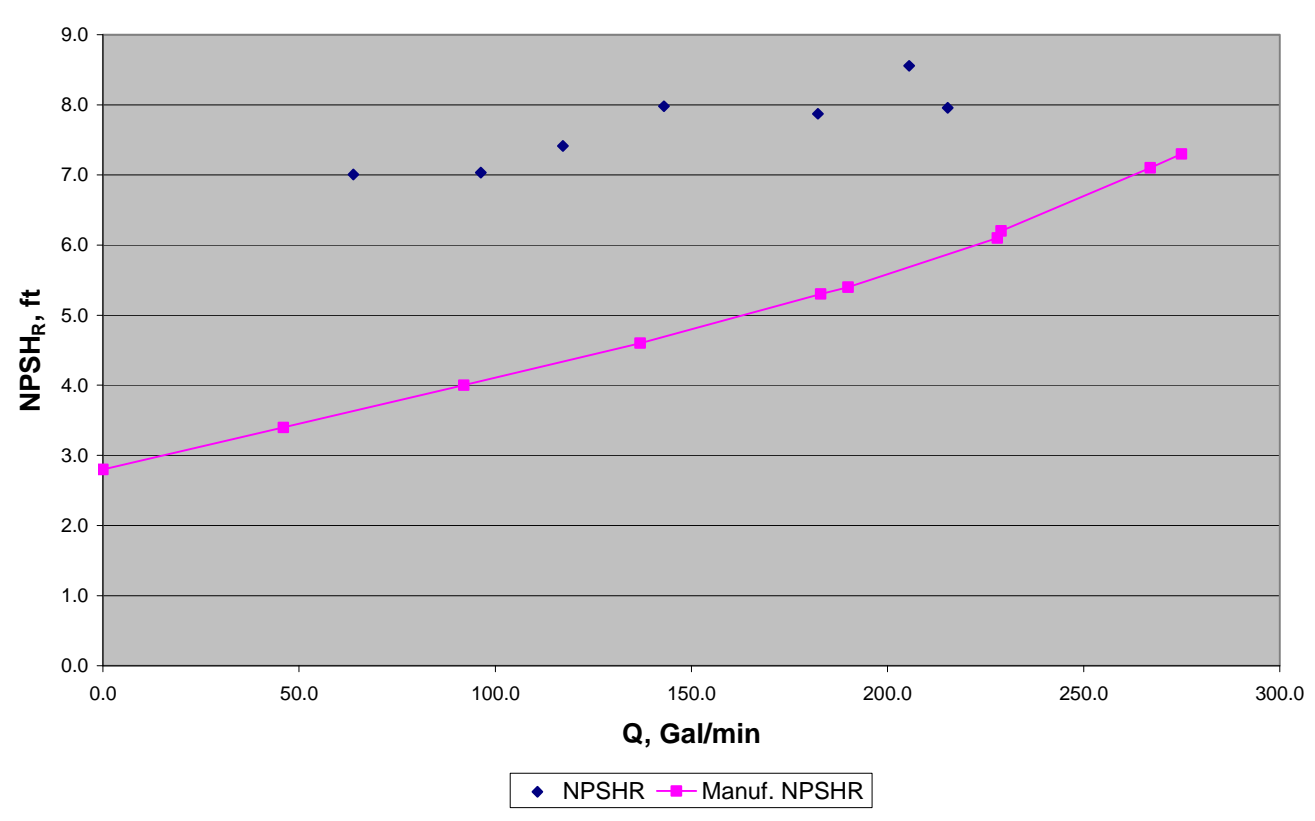

Figure 9.3. $\mathrm{NPSH}_{\mathrm{R}}$ Data for Casson-Fluid Yield Stress of Approximately 3.1 Pa; $\mathrm{T}$ Approximately $25^{\circ} \mathrm{C}$. This test was conducted on 1/9/09. Head is calculated on a head-of-slurry basis. 


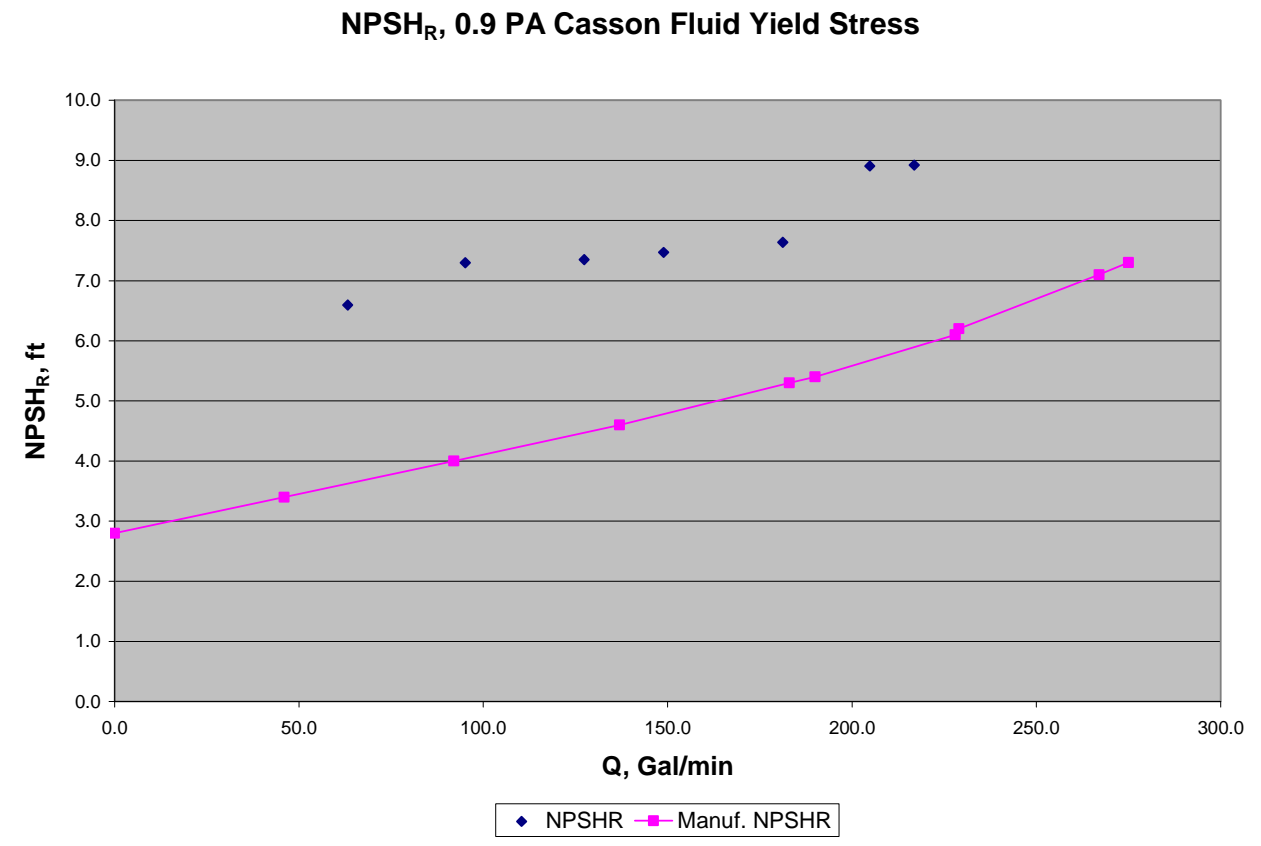

Figure 9.4. $\mathrm{NPSH}_{\mathrm{R}}$ Data for Casson-Fluid Yield Stress of Approximately 0.9 Pa; $\mathrm{T}$ Approximately $24^{\circ} \mathrm{C}$. This test was conducted on 1/10/09. Head is calculated on a head-of-slurry basis.

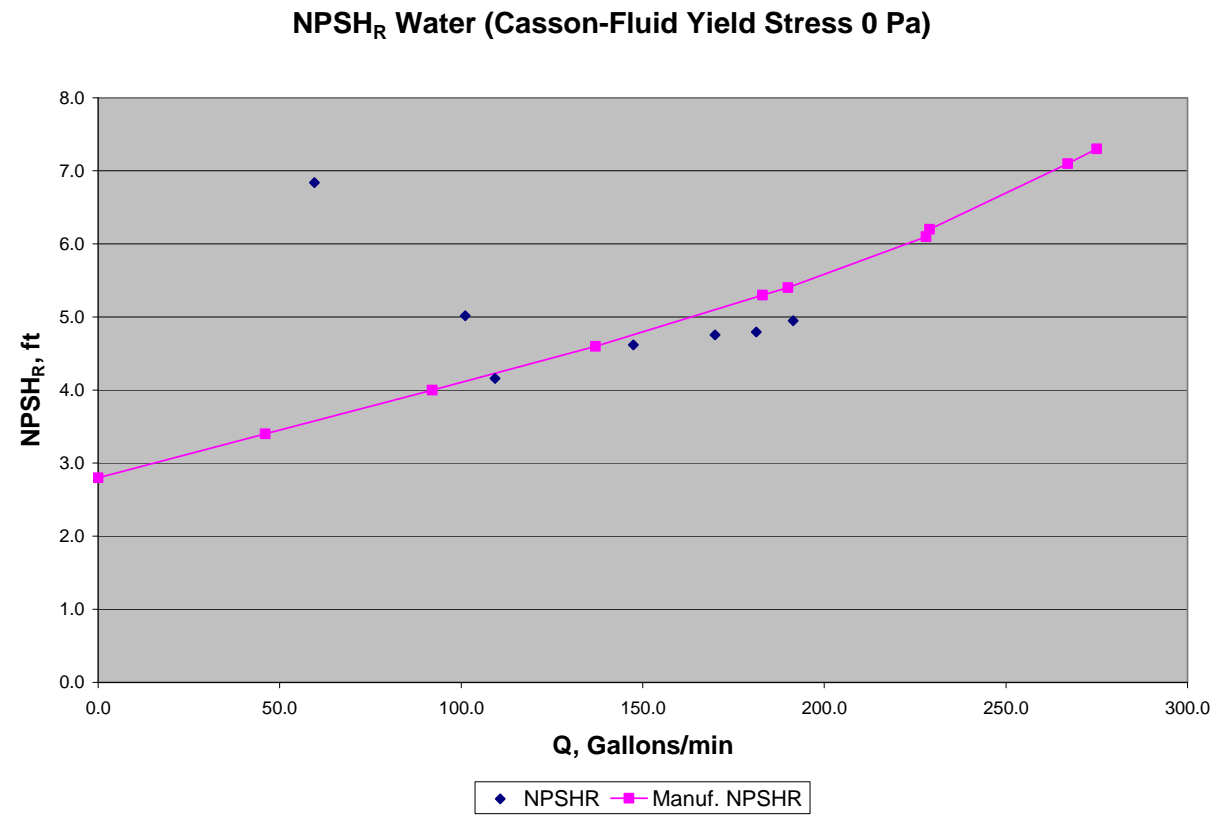

Figure 9.5. $\mathrm{NPSH}_{\mathrm{R}}$ Data for Process Water (Casson-Fluid Yield Stress $0 \mathrm{~Pa}$ ); $\mathrm{T}$ Approximately $19^{\circ}-23^{\circ} \mathrm{C}$. This test was conducted on 1/19/09. Head is calculated on a head-of-water basis. 
$\mathrm{NPSH}_{\mathrm{R}}$, 28.0 Pa - 2.6 Pa Casson Fluid Yield Stress

(Entrained Air)

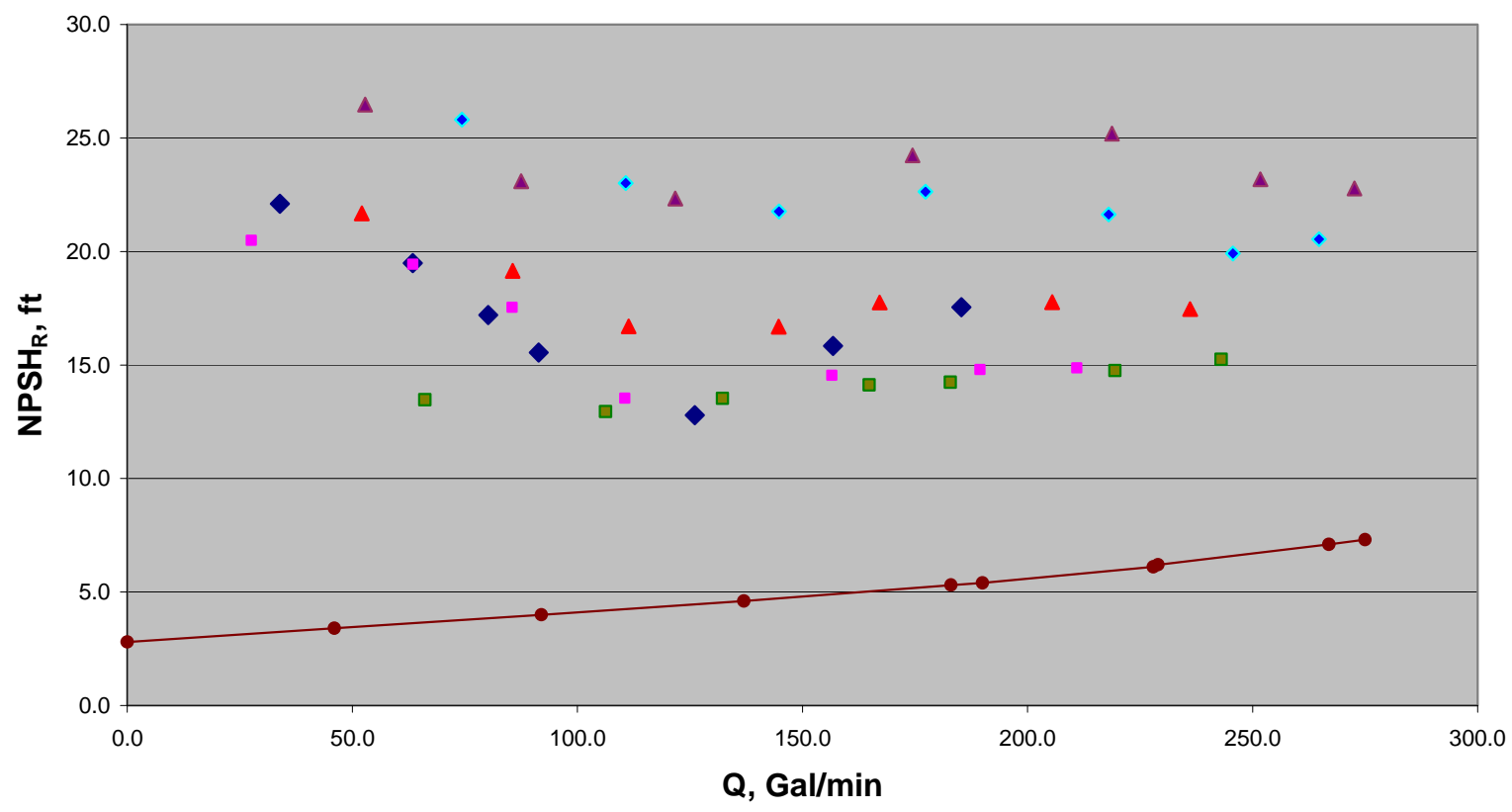

$28.0 \mathrm{~Pa} \| 18.6 \mathrm{~Pa} \Delta 12.8 \mathrm{~Pa} \bullet 7.5 \mathrm{~Pa} \Delta 5.1 \mathrm{~Pa} \backsim 2.6 \mathrm{~Pa} \rightarrow$ Manuf. NPSH

Figure 9.6. Apparent $\mathrm{NPSH}_{\mathrm{R}}$ Data for HLW Simulant (With Entrained Air) at Casson-Fluid Yield-Stress Range of 28.0 Pa to 2.6 Pa; All tests conducted at a $60 \mathrm{~Hz}$ VFD Setting. These tests were conducted from 12/10/08 to 1/6/09. Head is calculated on a head-of-slurry basis.

Table 9.2. Summary of Apparent $\mathrm{NPSH}_{\mathrm{R}}$ Data Under Various Conditions When Compared to the Pump Manufacturer Data for Water. Head is calculated on a head-of-slurry basis; water head calculated on head-of-water basis.

\begin{tabular}{llll}
\hline $\begin{array}{l}\text { Casson Yield } \\
\text { Stress }(\mathrm{Pa})\end{array}$ & $\begin{array}{l}\text { Bingham Yield } \\
\text { Stress }(\mathrm{Pa})\end{array}$ & AFA added? & $\begin{array}{l}\text { Average \% increase from manufacturers } \\
\mathrm{NPSH}_{\mathrm{R}} \text { data for water }(>130 \mathrm{gal} / \mathrm{min})\end{array}$ \\
\hline 28.0 & 33.2 & No & $210 \pm 20 \%$ \\
18.6 & 22.7 & No & $170 \pm 23 \%$ \\
12.8 & 15.9 & No & $220 \pm 39 \%$ \\
7.5 & 9.6 & No & $270 \pm 77 \%$ \\
5.1 & 6.9 & No & $290 \pm 69 \%$ \\
2.6 & 4.0 & No & $170 \pm 27 \%$ \\
3.1 & 4.6 & Yes & $51 \pm 15 \%$ \\
0.9 & 1.5 & Yes & $52 \pm 6 \%$ \\
0 (water) & 0 (water) & No & $-7 \pm 3 \%$ \\
\hline
\end{tabular}





\subsection{Conclusions}

Deposition velocity test results for both simulants show similar behavior of deposition occurring along the laminar to turbulent transition velocity. Since the transition velocity increases with yield stress, the deposition velocity also increases to a point where the yield stress produces a pressure gradient that is large enough to push the particles through the pipe in a stable laminar flow regime. This results in a maximum deposition velocity that typically occurs under moderate levels of yield stress in the range of 5 to $15 \mathrm{~Pa}$.

The AZ-101 HLW pretreated simulant had a susceptibility to retain air from the agitation system. The retained air resulted in a substantial increase in apparent $\mathrm{NPSH}_{\mathrm{R}}$. Addition of anti-foam agent (AFA) for the final two tests decreased amount of entrained air and reduced the $\mathrm{NPSH}_{R}$. However, even with the AFA added, the AZ-101 HLW pretreated simulant still showed a significant increase over the values provided by the manufacturer for water. Control tests with tap water confirmed the manufacturers published $\mathrm{NPSH}_{\mathrm{R}}$ data for this pump.

Based on the results and subsequent analysis presented in this report, the following conclusions can be made with respect to the test results discussed in this report:

- Experimental results substantiate literature claims of a stable laminar-flow regime for non-Newtonian fluids.

Gillies et al. (2007) recently published a paper on the topic of particle transport in laminar, non-Newtonian slurries. Industry standard was to use a "rule of thumb" of a $\sim 1.5$ - to $2-\mathrm{kPa} / \mathrm{m}$ pressure-gradient threshold to transport solids in laminar flow. A new criterion was established that relates the ratio of the wall shear stress, $\tau_{\mathrm{w}}$, to the average surficial-particle shear stress, $\tau_{\mathrm{p}}$. Gillies et al. (2007) conclude that "a slurry's proclivity to experience laminar flow settling is greatly reduced when $\tau_{\mathrm{w}} / \tau_{\mathrm{p}}>60$ and nearly eliminated when $\tau_{\mathrm{w}} / \tau_{\mathrm{p}}>100$." This behavior was observed in both simulants with a dramatic rise in deposition velocity as yield stress was decreased from $30 \mathrm{~Pa}$ to moderate values of yield stress in the 5 to $15 \mathrm{~Pa}$ range.

- Experimental results substantiate literature claims of particle deposition occurring near the laminar-to-turbulent transition for non-Newtonian fluids.

Cooke (2002) states the following on the topic of sedimentation in non-Newtonian laminar flows:

It is often assumed that low operating velocities are not a problem for high density thickened tailings and paste mixtures as they are inherently stable and pipelines may be started and shutdown without fear of blockage. However, this is not necessarily the case and when an apparently nonsettling suspension is subjected to shear in laminar flow, the settling rate of the coarse particles is increased significantly. For commercial pipelines operating in laminar flow, there is no effective mechanism for re-suspending settled particles and it is possible that the pipeline may block.

This statement is confirmed for both simulants by the experimental findings of the previous M-1 effort, WTPRPT-175 Rev. 0 as well as those presented in this report. Non-Newtonian simulants repeatedly settled at velocities near the predicted laminar-to-turbulent transition. This typically occurred at yield stresses in the range of 1 to $15 \mathrm{~Pa}$. As the yield stress was reduced, the deposition velocity was observed to decrease with the laminar-to-turbulent transition velocity.

- A rheological condition exists in which the deposition velocity reaches a maximum; this should be considered in the design of non-Newtonian pipelines. 
The increasing deposition velocity during the transition from stable-laminar to unstable-laminar flow coupled with the decreasing deposition velocity when yield stress drops further and reduces the laminar-to-turbulent transition velocity results in a maximum predicted deposition velocity for non-Newtonian slurries. This is referred to as point $Y$ on the stability maps presented in WTP-RPT-175 Rev 0. Experimental results for the deposition of both simulants tested in this report indicate that this peak occurs at moderate levels of yield stress in the range of 5 to $15 \mathrm{~Pa}$. A robust pipeline design should consider design correlations for Newtonian and nonNewtonian transport. An assessment was performed using this design philosophy on several particle-size and density distributions proposed for the WTP. A summary of the assessment findings follows:

- Within the WTP, a significant fraction of particles is predicted to settle to a stationary bed in the 4-6 ft/sec range under both Newtonian and non-Newtonian conditions

- The settled particles will be predominately of high density or large particle size

- A transport velocity of approximately $10 \mathrm{ft} / \mathrm{sec}$ will maintain turbulent flow in a 3 " pipe at the upper end of the rheological operating window (maximum of $30 \mathrm{~Pa}$ Bingham-plastic yield stress and $30 \mathrm{cP}$ consistency). If this is not achievable, a minimum velocity of $6 \mathrm{ft} / \mathrm{sec}$ or greater is recommended for operation under laminar conditions.

- During slurry transfers in the WTP, it is expected that a sediment bed will gradually develop that must be aggressively/periodically flushed to mitigate potential line plugging. Sediment beds are expected to develop faster in larger-diameter pipes. Development of a basis for an aggressive flushing frequency should be supported by further testing.

- The presence of a sliding bed on the pipe bottom is expected to result in increased wear and erosion of the pipe invert (bottom). This problem has been noted in industry (Ricks 2002; Miller and Schmidt 1987; Henday 1988, Brown and Heywood 1991) and other DOE sites (Poirier 2000). This increased wear on the pipe wall due to sliding bed should be accounted in the WTP piping design calculations.

- Flushing at $10 \mathrm{ft} / \mathrm{sec}$ or more should be sufficient to remove the sediment beds. However, re-suspension of particles from a stationary bed involves different mechanics from deposition. The design-basis value for the minimum flush velocity to remove a stationary bed should be supported by further testing.

- Flushing should be performed in the same direction as normal process flow: from the source tank to the destination tank. Back-flushing pipes to source tanks should not be permitted because particles will accumulate in vessels and pipes.

- Flush-system design should be reviewed to assure that all process lines in the WTP meet the conditions listed above.

- Net Positive Suction Head required $\left(\mathrm{NPSH}_{\mathrm{R}}\right)$ is significantly higher for non-Newtonian slurries than that for water.

Test results indicate significant increases in $\mathrm{NPSH}_{\mathrm{R}}$, on the order of 1.5-2 times that for water, can be expected for slurry flows when air is not retained in the slurry. When air is retained in the slurry, the apparent NPSHR increases by a factor of 2-3 times that specified for water. Additionally, pump manufacturers typically report "slurry" pump performance capability with the discharge side wide open and using water as the test fluid. As such, additional engineering margins over accepted industrial practice should be added for $\mathrm{NPSH}_{\mathrm{R}}$ design specifications in the WTP. 


\subsection{References}

10 CFR 830. “Nuclear Safety Management.” Code of Federal Regulations, U.S. Department of Energy.

ANSI/HI 1.6-2000, American National Standards for Centrifugal Pump Tests , Hydraulic Institute, Parsippany, NJ www.pumps.org.

Bechtel National, Inc. (BNI). 2007. Evaluation of Waste Slurry Critical Velocity and Line Flush Capabilities in WTP Process Piping. 24590-WTP-TSP-RT-07-005, Rev. 0, BNI, Richland, Washington.

Brown NP, Heywood NI (Editors). 1991. Slurry Handling: Design of solid-liquid systems. Springer.

Bunker BC, PJ Bruinsma, GL Gruff, CR Hymas, XS Li, JR Phillips, DR Rector, PA Smith, L Song, JM Tingey and Y Wang. 1995. Colloidal Studies for Solid/Liquid Separation. TWRSPP-95-045, Pacific Northwest Laboratory, Richland, Washington.

Churchill SW. 1977. "Friction Factor Spans All Fluid-Flow Regimes.” Chemical Engineering 84(24):91-92.

Cooke R. 2002. "Laminar flow settling: the potential for unexpected problems." BHRG 15th International Conference on Slurry Handling and Pipeline Transport, Hydrotransport 15; Banff, 121-133.

DOE Order 414.1C. 2005. “Quality Assurance.” U.S. Department of Energy, Washington, D.C.

Dodge DW and AB Metzner. 1959. "Turbulent Flow of Non-Newtonian Systems." AIChE Journal 5:189-204.

Durand R and E Condolios. 1952. In Compte Rendu de Deuxiemes Journees de l'Hydraulique, Societe Hydrotechnique de France, Paris pp. 29-55.

Edwards MK, JM Billing, DL Blanchard, Jr, EC Buck, AJ Casella, AM Casella, JV Crum, RC Daniel, KE Draper, SK Fiskum, LK Jagoda, ED Jenson, AE Kozelisky, PJ MacFarlan, RA Peterson, RW Shimskey, LA Snow, and RG Swoboda. 2009. Characterization, Leaching, and Filtration Testing for Tributyl Phosphate (TBP, Group 7) Actual Waste Sample Composites. PNNL-18119, WTP-RPT-169 Rev. 0, Pacific Northwest National Laboratory, Richland, WA.

Eibling RE, RF Schumacher, EK Hansen, December 2003, Development of Simulants to Support Mixing Tests for High Level Waste and Low Activity Waste, WSRC-TR-2003-00220 Rev 0, SRT-RPP-2003-00098 Rev. 0

Ferraris C, F de Larrard, and N Martys. 2001. "Fresh Concrete Rheology - Recent Developments." In: Materials Science of Concrete VI, S Mindess and J Skalny, Editors, American Ceramic Society, Westerville, Ohio.

Fiskum SK, EC Buck, RC Daniel, KE Draper, MK Edwards, TL Hubler, LK Jagoda, ED Jenson, GJ Lumetta, BK McNamara, RA Peterson, and SI Sinkov. 2008. Characterization and Leach Testing for REDOX Sludge and SSaltcake Actual Waste Sample Composites. PNNL-17368, WTP-RPT-157 Rev. 0, Pacific Northwest National Laboratory, Richland, WA.

Fiskum SK, JM Billing, JV Crum, RC Daniel, MK Edwards, RW Shimskey, RA Peterson, PJ MacFarlan, EC Buck, KE Draper, and AE Kozelisky. 2009. Characterization and Filtration Testing of Group 8 Ferrocyanide Tank Waste Sludge Actual Hanford Tank Waste in Support of the Waste Treatment and Immobilization Plant. PNNL-18120, WTP-RPT-170 Rev. 0 , Pacific Northwest National Laboratory, Richland, WA. 
Gaskill JR, Larson DE, Abrigo GP, Daume JT and Graves RE. 1996. Hanford Waste Vitrification Plant full-scale feed preparation testing with water and process simulant slurries. PNNL_11011, Pacific Northwest National Laboratory, Richland, Washington.

Gillies RG, and CA Shook. 1991. "A Deposition Velocity Correlation for Water Slurries." Canadian Journal of Chemical Engineering 69(5):1225-1228.

Gillies RG, J Schaan, RJ Sumner, MJ McKibben, and CA Shook. 2000. "Deposition Velocities for Newtonian Slurries in Turbulent Flow." Canadian Journal of Chemical Engineering 78(4):704-708.

Gillies RG, R Sun, RS Sanders, and J Schaan. 2007. "Lowered Expectations: The Impact of Yield Stress on Sand Transport in Laminar, Non-Newtonian Flows." Journal of the South African Institute of Mining and Metallurgy 107(6):351-357.

Henday, G. 1988. A comparison of commercial pipe materials intended for the hydraulic transport of solids. Research Report 2988, BHRA, The Fluid Engineering Centre, Cranfield UK

Herting DL 1997. Results of Dilution Studies with Waste from Tank 241-AN-105. HNF-SD-WM-DTR 46 Rev. 0, Numatec Hanford Corporation, Richland, Washington.

Heywood NI and KB Mehta. 1996. "The performance of Commercially-Available Coriolis Mass Flowmeters Applied to Industrial Slurries.” Proc. Hydrotransport 13, BHR Group, Cranfield, U.K., 719-747.

Ilievski D and ET White. 1994. "Agglomeration During Precipitation: Agglomeration Mechanism Identification for $\mathrm{Al}(\mathrm{OH})_{3}$ Crystals in Stirred Caustic Aluminate Solutions.” Chemical Engineering Science 49(19): 3227-3239.

Jewett JR, DA Reynolds, SD Estey, L Jensen, NW Kirch, and Y Onishi. 2002. Values of Particle Size, Particle Density, and Slurry Viscosity to Use in Waste Feed Delivery Transfer System Analysis. RPP-9805, Rev. 1, Numatec Hanford Corporation, CH2M HILL Hanford Group, Inc., Richland, Washington.

Larsen P, Z Wang and W Xiang. 1994. "Rheological properties of sediment suspensions and their implications." Journal of Hydraulic Research 32, 495-516.

Litzenberger CG, May 2003, Rheological Study of Kaolin Clay Slurries, M.Sc. Thesis, University of Saskatchewan, Saskatoon, Canada.

Lumetta GJ, EC Buck, RC Daniel, KE Draper, MK Edwards, SK Fiskum, RT Hallen, LK Jagoda, ED Jenson, AE Kozelisky, PJ MacFarlan, RA Peterson, RW Shimskey, SI Sinkov, and LA Snow. 2009. Characterization, Leaching, and Filtration Testing for Bismuth Phosphate Sludge (Group 1) and Bismuth Phosphate Saltcake (Group 2) Actual Waste Sample Composites. PNNL-17992, WTP-RPT-166 Rev. 0, Pacific Northwest National Laboratory, Richland, WA.

Miller JE, Schmidt F. 1987. Slurry Erosion: Uses, Applications, and Test Methods: a Symposium. ASTM Committee G-2 on Erosion and Wear. ASTM International

Oroskar AR, and RM Turian. 1980. "The Critical Velocity in Pipeline Flow of Slurries." AIChE Journal 26(4):550558.

Poloski AP, BE Wells, JM Tingey, LA Mahoney, MN Hall, SL Thomson, GL Smith, ME Johnson, JE Meacham, MA Knight, MJ Thien, JJ Davis and Y Onishi. 2007. Estimate of Hanford Waste Rheology and Settling Behavior. PNNL-16857, WTP-RPT-154, Rev. 0, Pacific Northwest National Laboratory, Richland, Washington. 
Poloski AP, HE Adkins, Jr, MJ Minette, J Abrefah, AM Casella, RE Hohimer, F Nigl, JJ Toth, JM Tingey, and ST Yokuda. 2009. Deposition Velocities of Newtonian and Non-Newtonian Slurries in Pipelines. PNNL-17639, WTPRPT-175, Rev. 0, Pacific Northwest National Laboratory, Richland, WA.

Poirier MR. 2000. Minimum Velocity Required to Transport Solid Particles from the 2H-Evaporator to the Tank Farm. WSRC-TR-2000-00263. Westinghouse Savannah River Company Aiken, SC 29808

Ricks BL "Slurry Pipeline Transportation" in: AL.Mular, DN.Halbe, DJ.Barratt (editors). 2002. Mineral Processing Plant Design, Practice and Control: Proceedings Society for Mining, Metallurgy and Exploration, Littleton, Colorado.

Shook CA, RG Gillies and RS Sanders. 2002. Pipeline Hydrotransport with Applications in the Oil-Sand Industry. SRC Publication No. 11508-1E02, Saskatchewan Research Council, Saskatoon, Canada.

Smith GL and K Prindiville. 2002. Guidelines for Performing Chemical, Physical, and Rheological Properties Measurements. 24590-WTP-GPG-RTD-001 Rev 0, Bechtel National, Inc., Richland, WA.

Snow LA, EC Buck, AJ Casella, JV Crum, RC Daniel, KE Draper, MK Edwards, SK Fiskum, LK Jagoda, ED Jenson, AE Kozelisky, PJ MacFarlan, RA Peterson, and RG Swoboda. 2009. Characterization and Leach Testing for PUREX Cladding Waste Sludge (Group 3) and REDOX Cladding Waste Sludge (Group 4) Actual Waste Sample Composite. PNNL-18054, WTP-RPT-167 Rev. 0, Pacific Northwest National Laboratory, Richland, WA.

Song T, and Y-M Chiew. 1997, "Settling Characteristics of Sediments in Moving Bingham Fluid." J of Hyd. Eng., 123:9, September, ASCE

Turian RM, FL Hsu and TW Ma. 1987. "Estimation of the Critical Velocity in Pipeline Flow of Slurries." Powder Technology 51(1):35-47.

Wells BE, MA Knight, EC Buck, RC Daniel, SK Cooley, LA Mahoney, PA Meyer, AP Poloski, JM Tingey, WS Callaway III, GA Cooke, ME Johnson, MG Thien, DJ Washenfelder, JJ Davis, MN Hall, G Smith, SL Thomson, and Y Onishi. 2007. Estimate of Hanford Waste Insoluble Solid Particle Size and Density Distribution. PNWD3824, WTP-RPT-153, Rev. 0, Battelle - Pacific Northwest Division, Richland, Washington.

Wilson KC, RR Horsley, T Kealy, JA Reizes and M Horsley. 2003 "Direct prediction of fall velocities in nonNewtonian materials." Int. J. Miner. Process. 71:17-30.

Wilson KC and RR Horsley. 2004. "Calculating fall velocities in non-Newtonian (and Newtonian) fluids: a new view." Proc. 16th Int. Conf. Hydraulic Transport of Solids: Hydrotransport 16, Santiago, Chile. BHR Group, Cranfield, UK, pp. 37-46. 



\section{Appendix A}

Velocity, Pressure, and Time Signatures for $150 \mu \mathrm{m}$ glass bead and kaolin clay simulant 



\section{Appendix A}

\section{Velocity, Pressure, and Time Signatures for $150 \mu \mathrm{m}$ glass bead and kaolin clay simulant}

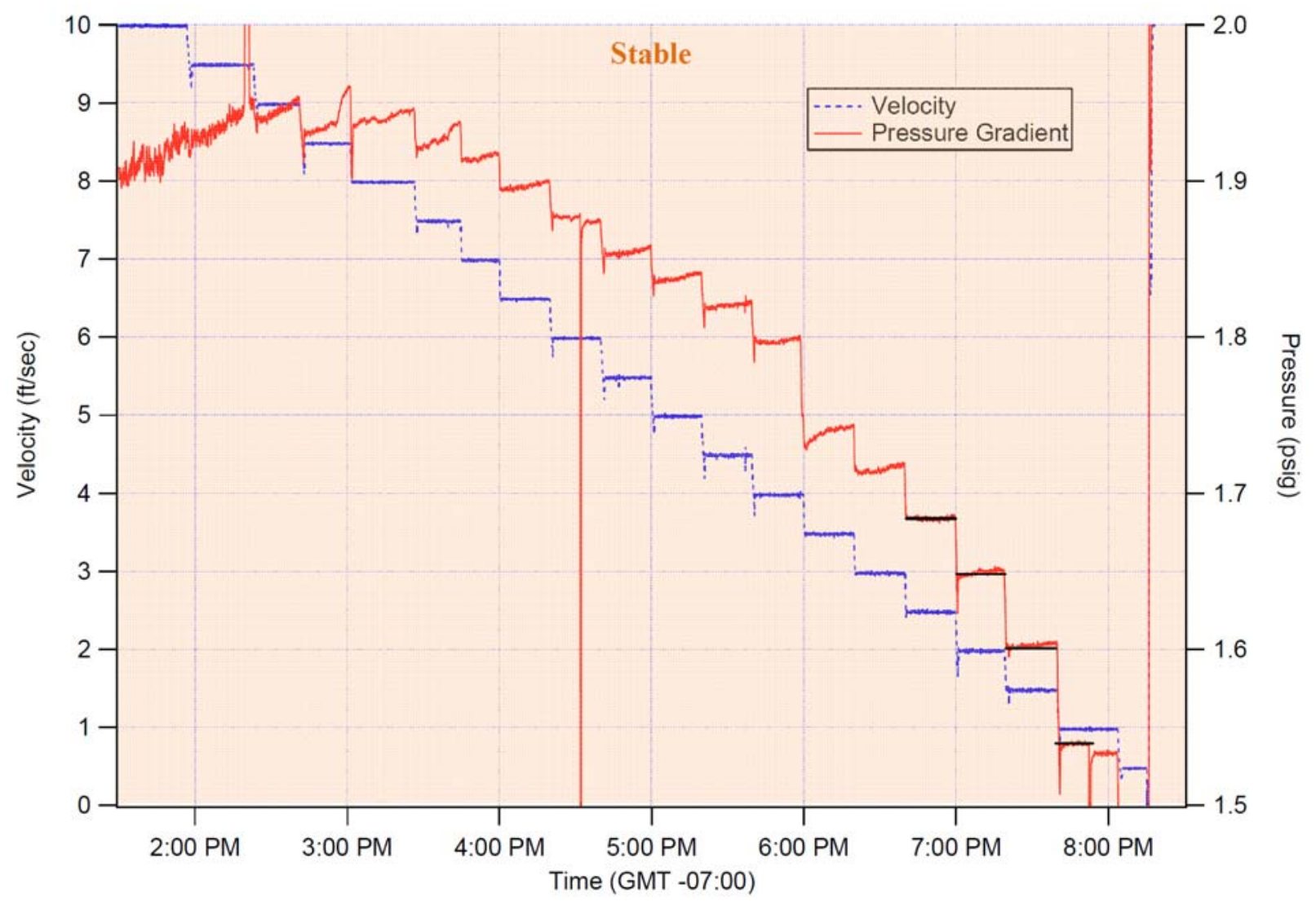

Figure A.1. Pressure-Gradient Data for Casson-Fluid Yield Stress of Approximately 31.0 Pa and InfiniteShear Viscosity of $3.2 \mathrm{cP}$. This test was conducted on 11/12/08. Note the increasing pressure as a function of time at high velocities were due to the rheopexy (thickens as shearing continues) of kaolin clay slurries at higher concentrations. Since no dramatic increase in pressure is observed at low velocities this slurry is considered to be stable in a 3 " pipe. 


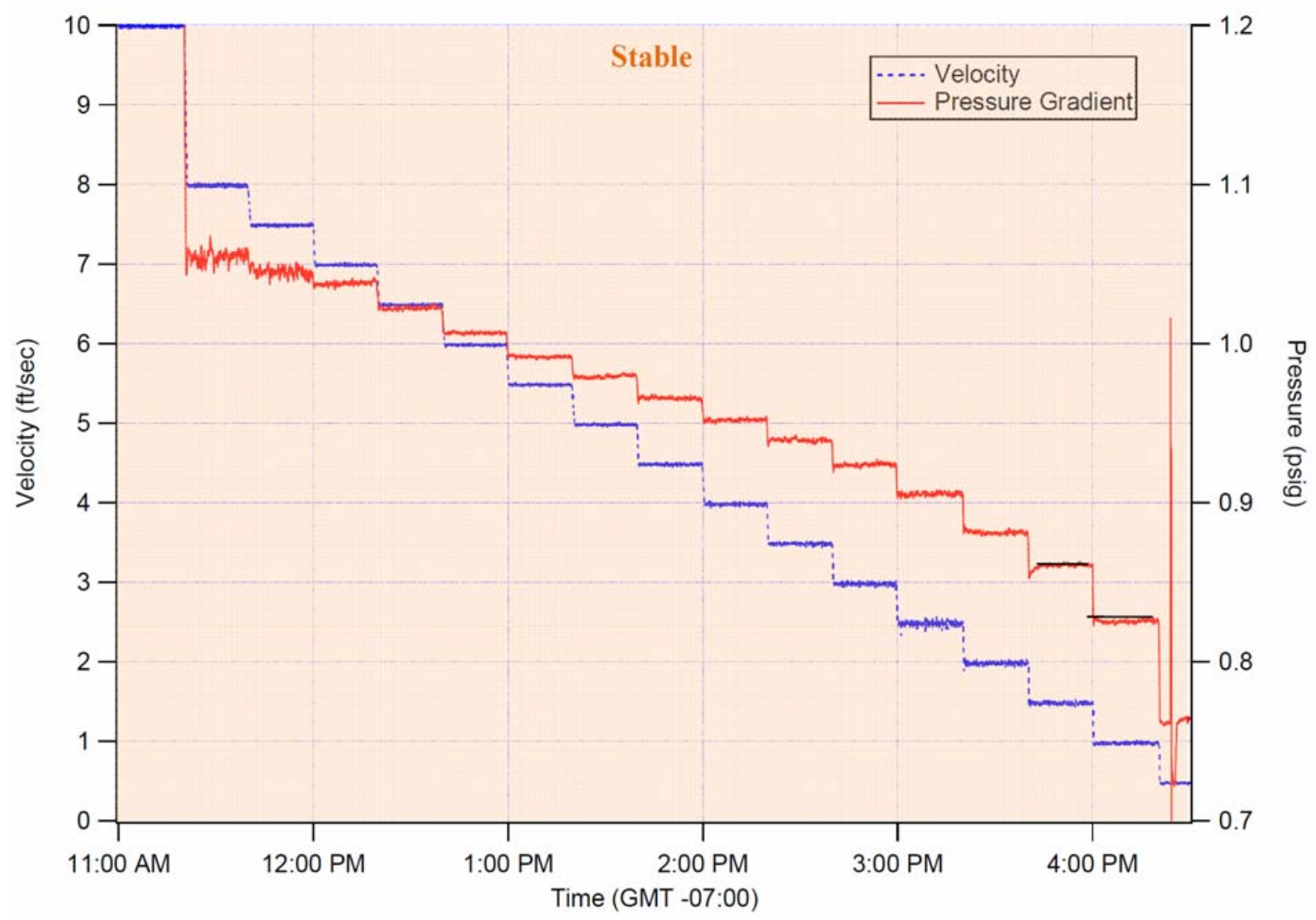

Figure A.2. Pressure-Gradient Data for Casson-Fluid Yield Stress of Approximately 16.6 Pa and InfiniteShear Viscosity of $1.9 \mathrm{cP}$. This test was conducted on 11/13/08. The absence of the rheopexy observed in the 11/12/08 tests is due to the lower concentration of kaolin clay used in this test. Since no dramatic increase in pressure is observed at low velocities this slurry is considered to be stable in a 3 " pipe. 


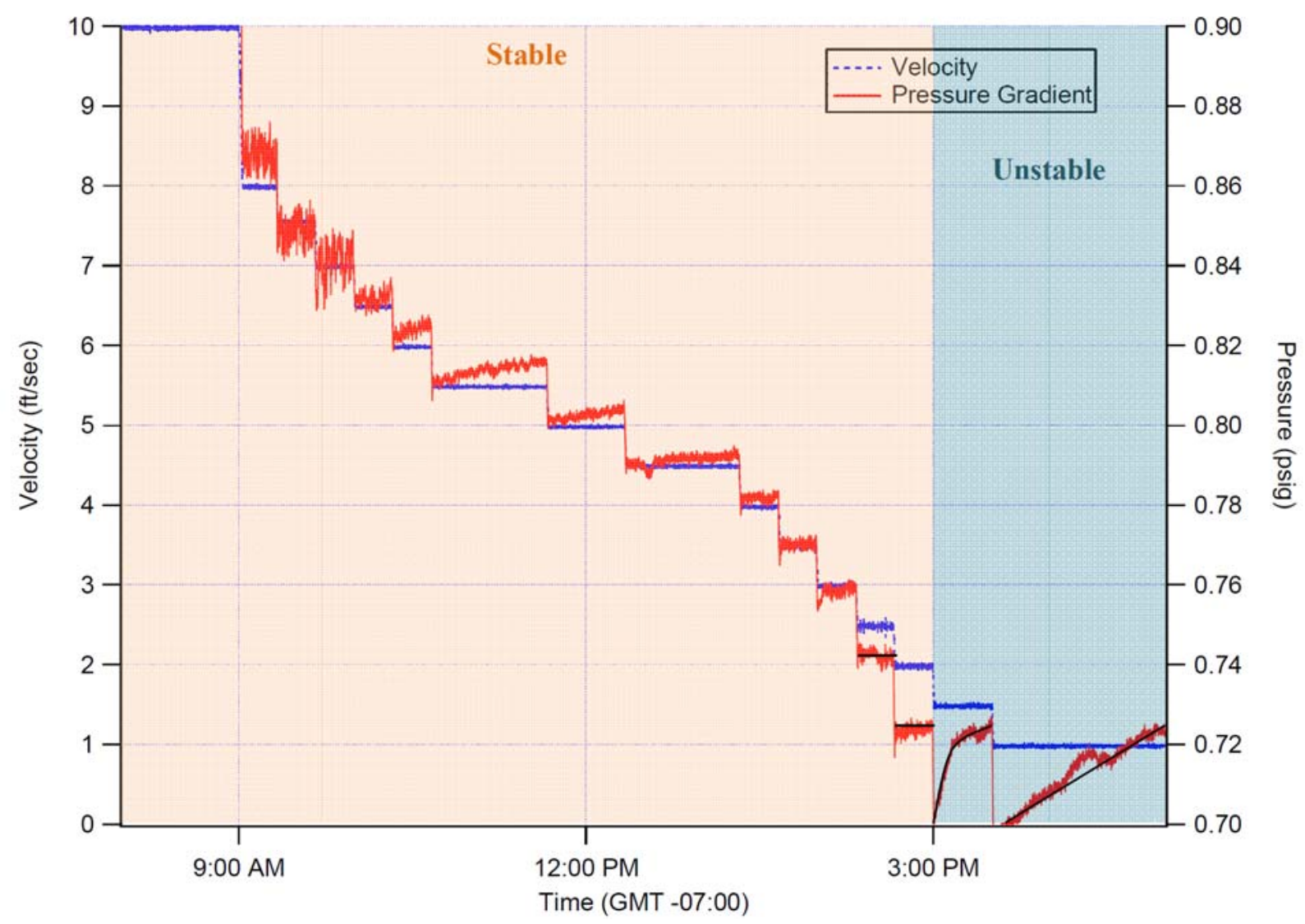

Figure A.3. Pressure-Gradient Data for Casson-Fluid Yield Stress of Approximately 13.1 Pa and InfiniteShear Viscosity of $1.9 \mathrm{cP}$. This test was conducted on $11 / 14 / 08$. Note the increase in pressure with time while running at 6 to $5 \mathrm{ft} / \mathrm{sec}$. This is likely due to slurry entering the differentialpressure ports and creating a plug. The drop in pressure at a velocity of $4.5 \mathrm{ft}$ sec is from the pressure-port lines being purged with rinse water. The pressure signal is then stable until 1.5 $\mathrm{ft} / \mathrm{sec}$ where an increase in pressure with time is observed. This slurry is considered to be unstable in a 3 ” pipe below $2 \mathrm{ft} / \mathrm{sec}$. 


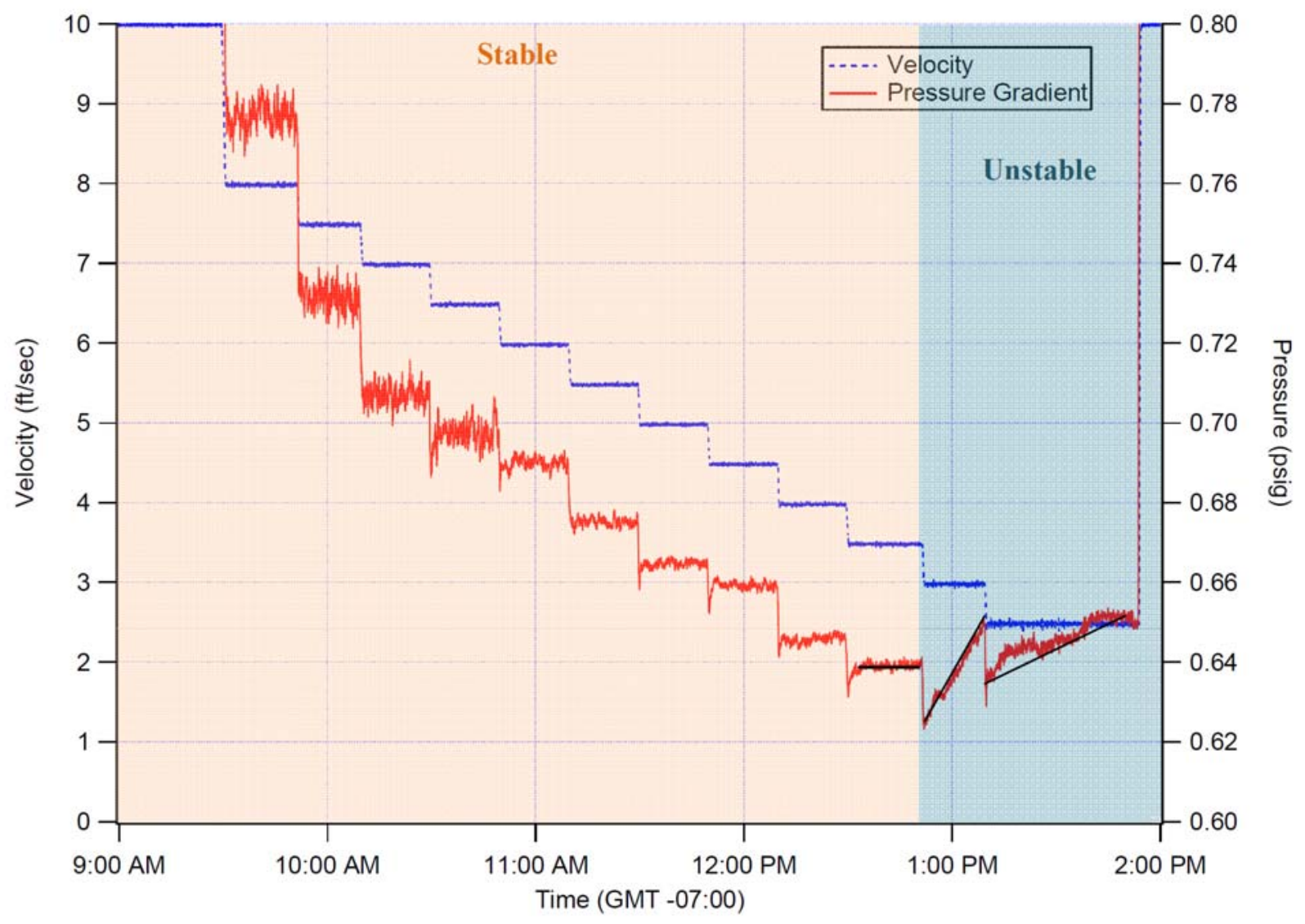

Figure A.4. Pressure-Gradient Data for Casson-Fluid Yield Stress of Approximately 9.8 Pa and InfiniteShear Viscosity of $1.8 \mathrm{cP}$. This test was conducted on 11/18/08. The pressure signal is stable until $3.0 \mathrm{ft} / \mathrm{sec}$ where an increase in pressure with time is observed. This slurry is considered to be unstable in a 3 " pipe below $3.5 \mathrm{ft} / \mathrm{sec}$. 


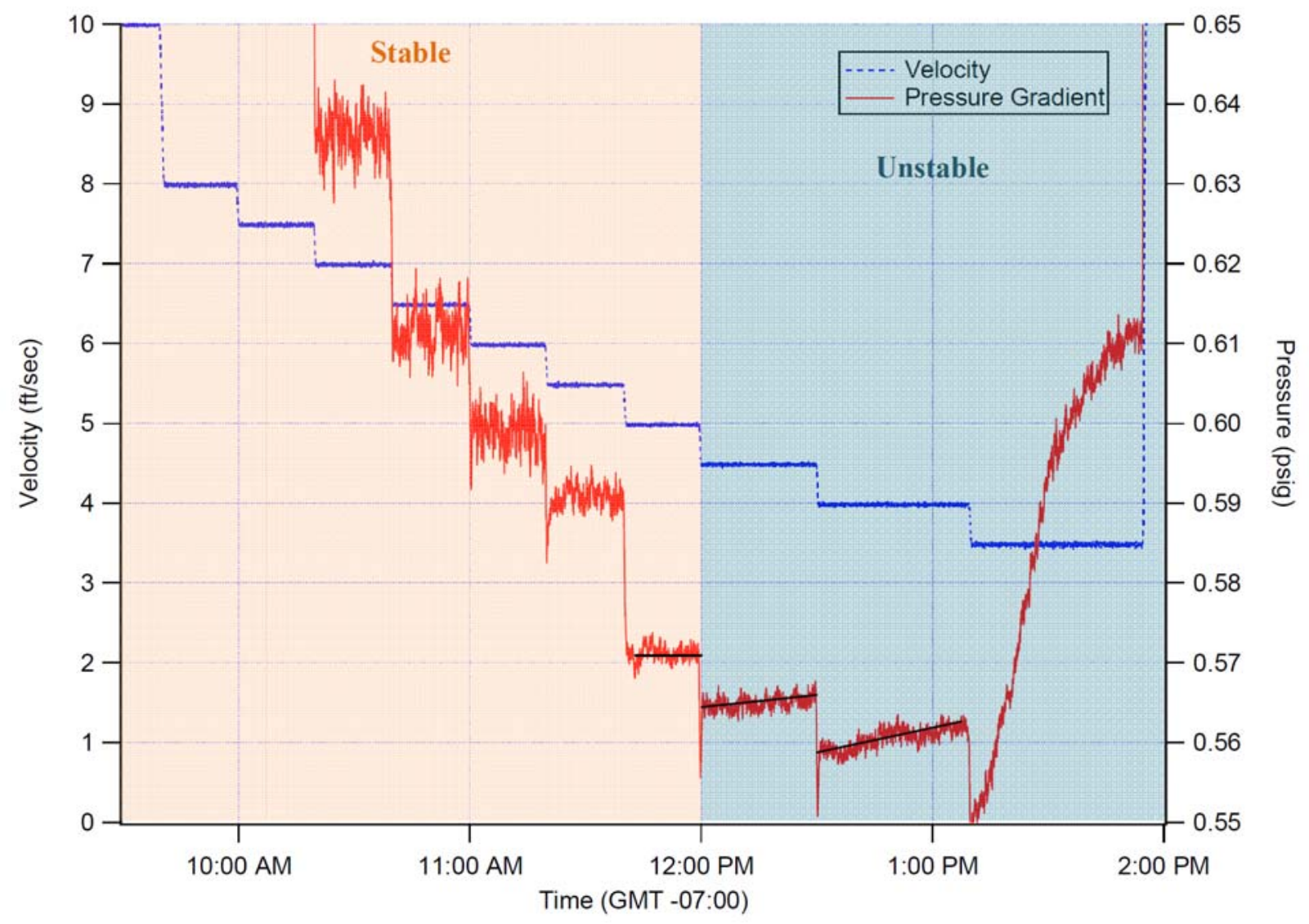

Figure A.5. Pressure-Gradient Data for Casson-Fluid Yield Stress of Approximately 8.8 Pa and InfiniteShear Viscosity of $1.7 \mathrm{cP}$. This test was conducted on 11/19/08. The pressure signal is stable until 4.5 to $4.0 \mathrm{ft} / \mathrm{sec}$ where an increase in pressure with time is observed. Due to the slow increase in pressure observed at $4.5 \mathrm{ft} / \mathrm{sec}$, this slurry is considered to be unstable in a 3 ” pipe below 5.0 ft/sec. 


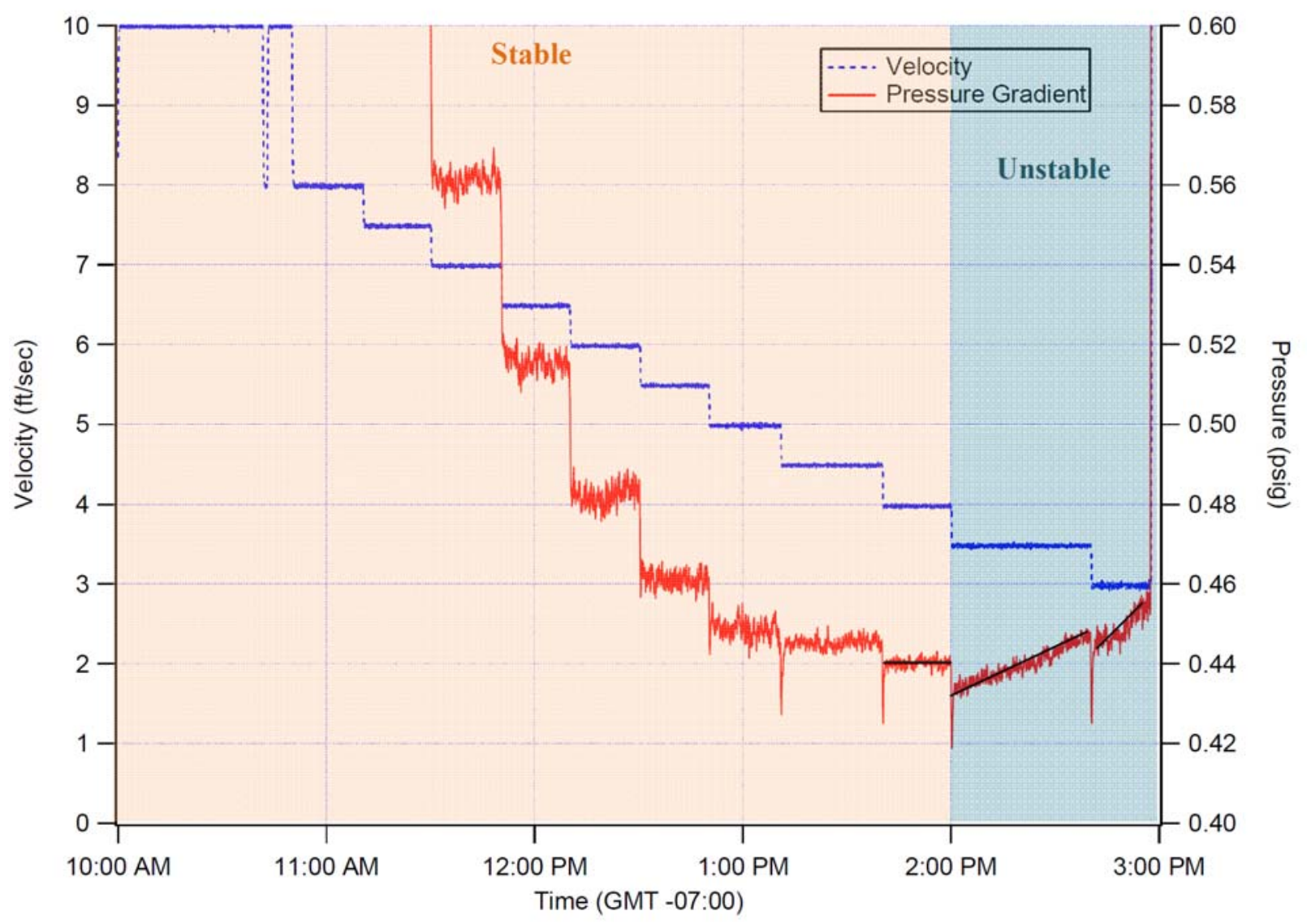

Figure A.6. Pressure-Gradient Data for Casson-Fluid Yield Stress of Approximately 6.7 Pa and InfiniteShear Viscosity of $1.7 \mathrm{cP}$. This test was conducted on 11/20/08. The pressure signal is stable until $3.5 \mathrm{ft} / \mathrm{sec}$ where an increase in pressure with time is observed. This slurry is considered to be unstable in a 3" pipe below $4.0 \mathrm{ft} / \mathrm{sec}$. 


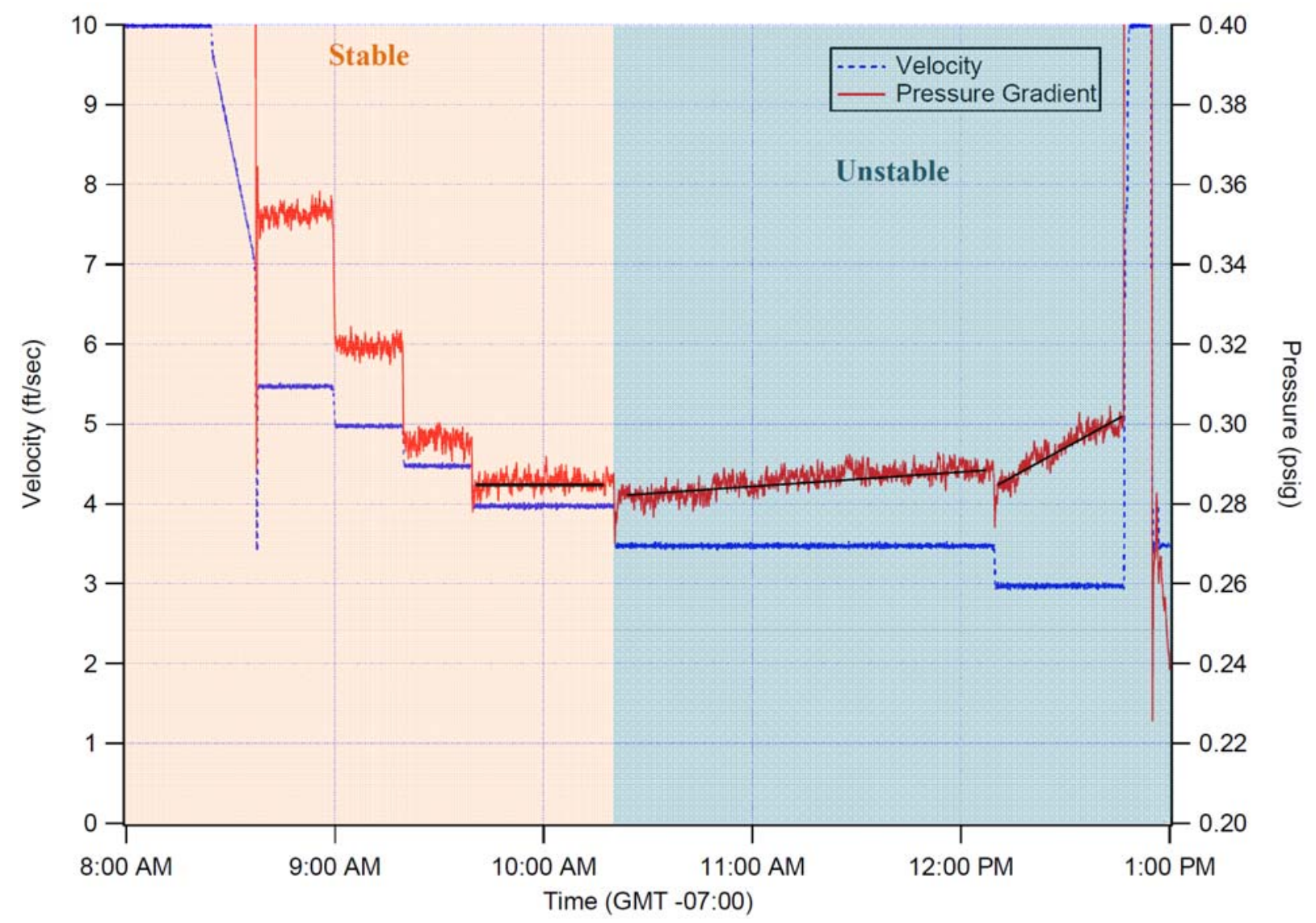

Figure A.7. Pressure-Gradient Data for Casson-Fluid Yield Stress of Approximately 3.7 Pa and InfiniteShear Viscosity of $1.7 \mathrm{cP}$. This test was conducted on 11/21/08. The pressure signal is stable until $3.5 \mathrm{ft} / \mathrm{sec}$ where an increase in pressure with time is observed. This slurry is considered to be unstable in a 3 " pipe below $4.0 \mathrm{ft} / \mathrm{sec}$. 


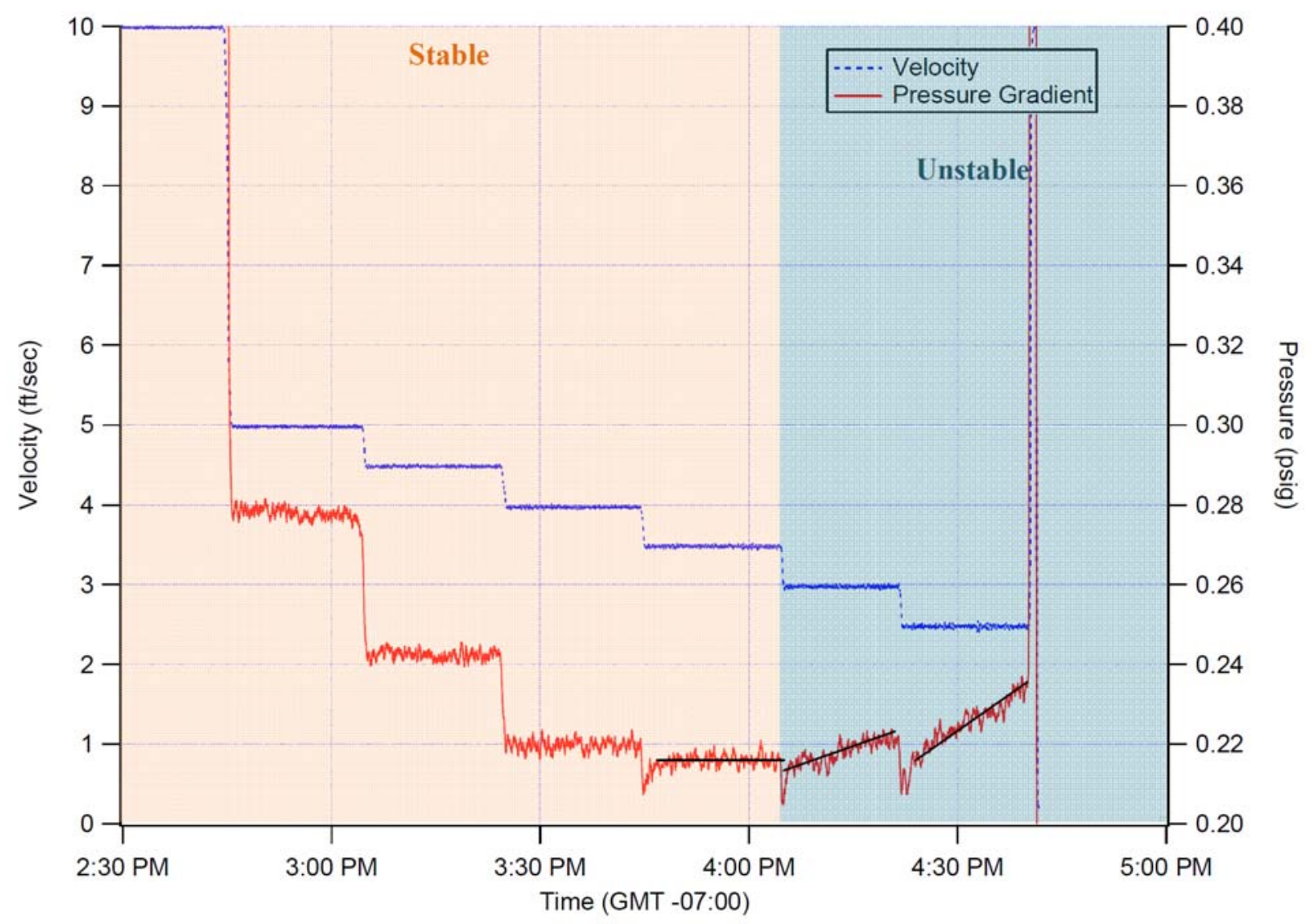

Figure A.8. Pressure-Gradient Data for Casson-Fluid Yield Stress of Approximately 2.6 Pa and InfiniteShear Viscosity of $1.6 \mathrm{cP}$. This test was conducted on $11 / 21 / 08$. The pressure signal is stable until $3.0 \mathrm{ft} / \mathrm{sec}$ where an increase in pressure with time is observed. This slurry is considered to be unstable in a 3" pipe below $3.5 \mathrm{ft} / \mathrm{sec}$. 


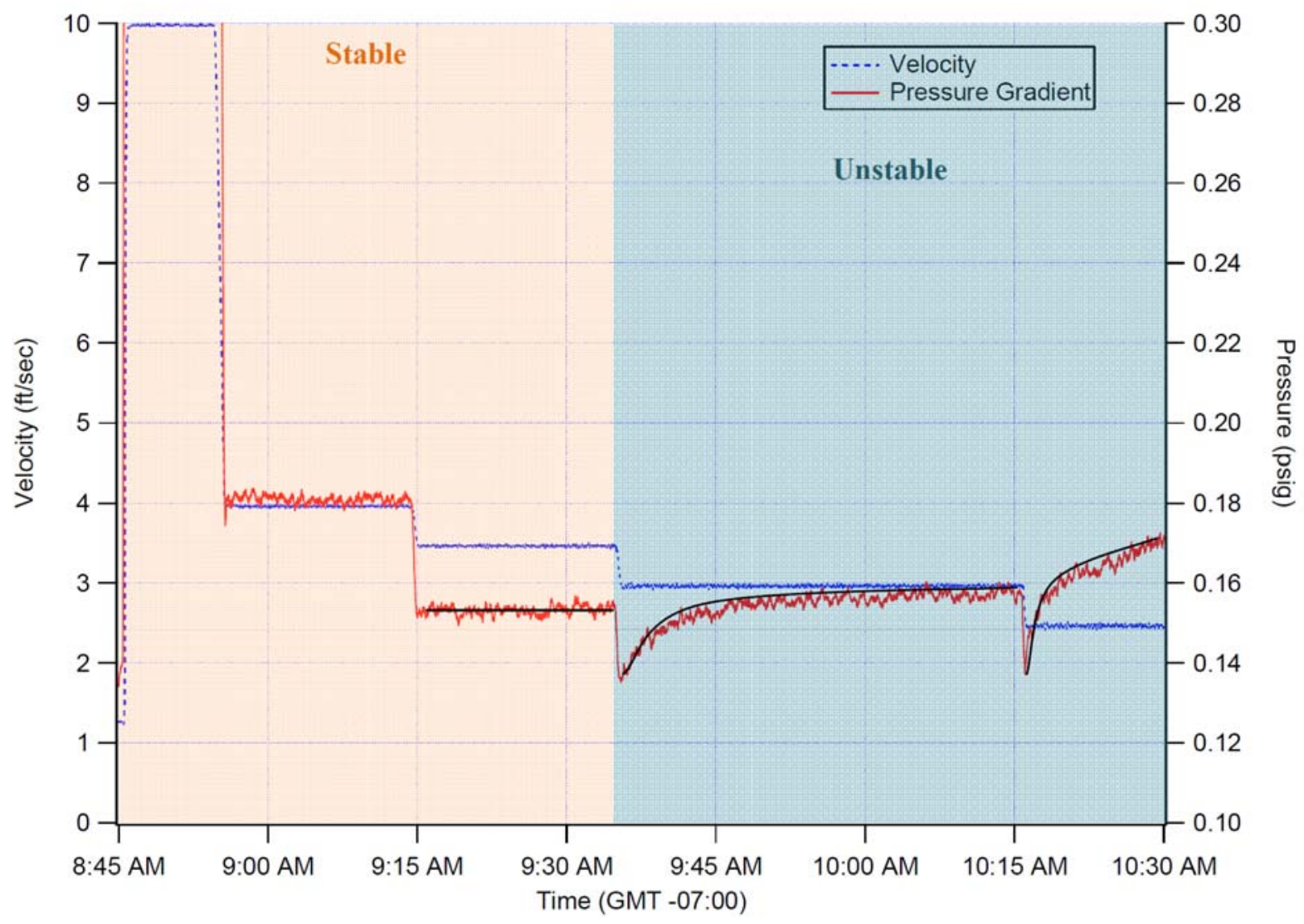

Figure A.9. Pressure-Gradient Data for Casson-Fluid Yield Stress of Approximately 1.5 Pa and InfiniteShear Viscosity of $1.6 \mathrm{cP}$. This test was conducted on 11/24/08. The pressure signal is stable until $3.0 \mathrm{ft} / \mathrm{sec}$ where an increase in pressure with time is observed. This slurry is considered to be unstable in a 3" pipe below $3.5 \mathrm{ft} / \mathrm{sec}$. 


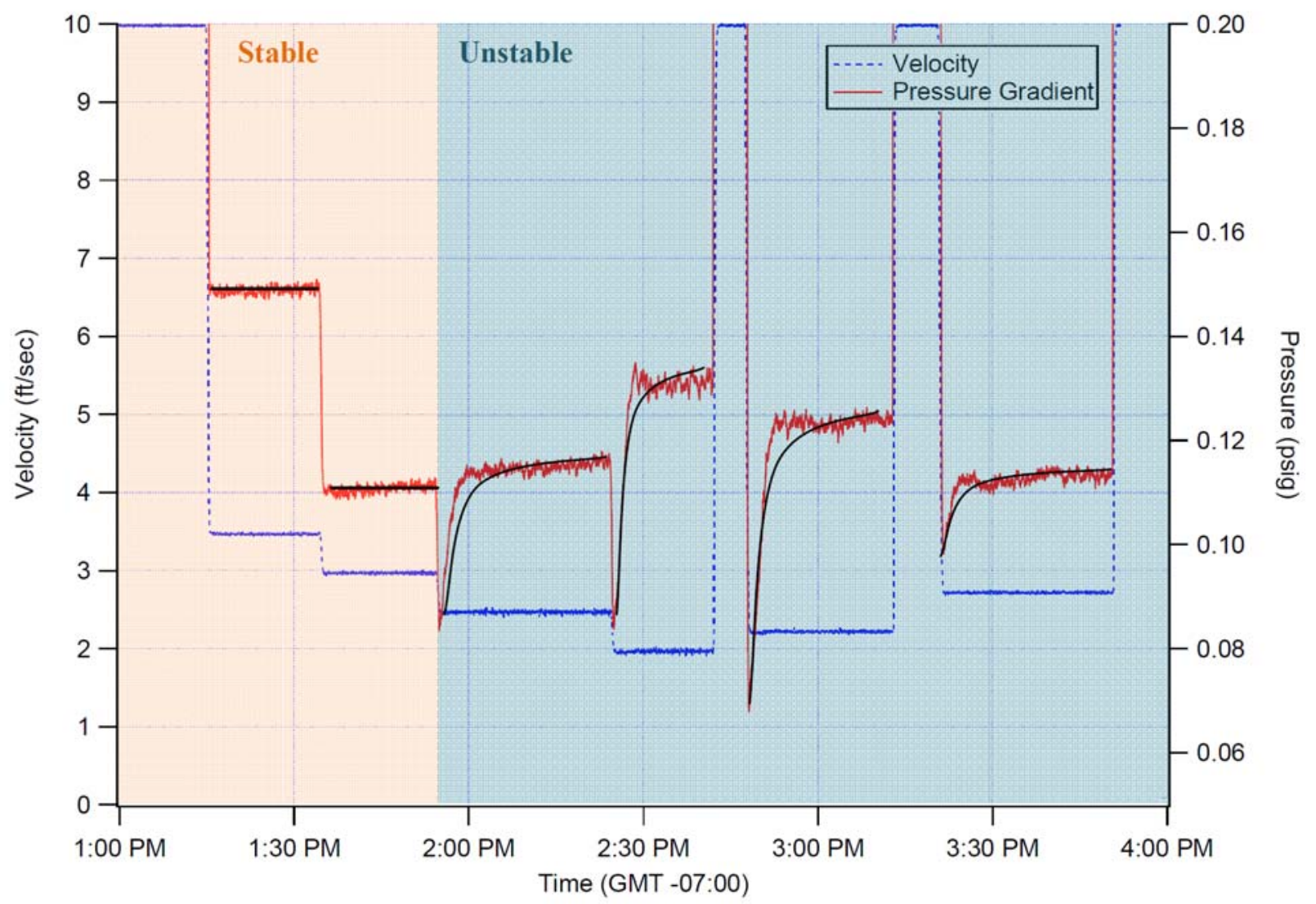

Figure A.10. Pressure-Gradient Data for Casson-Fluid Yield Stress of Approximately 0.3 Pa and InfiniteShear Viscosity of $2.1 \mathrm{cP}$. This test was conducted on 11/24/08. The pressure signal is stable until $2.5 \mathrm{ft} / \mathrm{sec}$ where an increase in pressure with time is observed. This slurry is considered to be unstable in a 3" pipe below $3.0 \mathrm{ft} / \mathrm{sec}$. 


\section{Appendix B}

Velocity, Pressure, and Time Signatures for AZ-101 pretreated HLW simulant 



\section{Appendix B}

\section{Velocity, Pressure, and Time Signatures for AZ-101 pretreated HLW simulant}

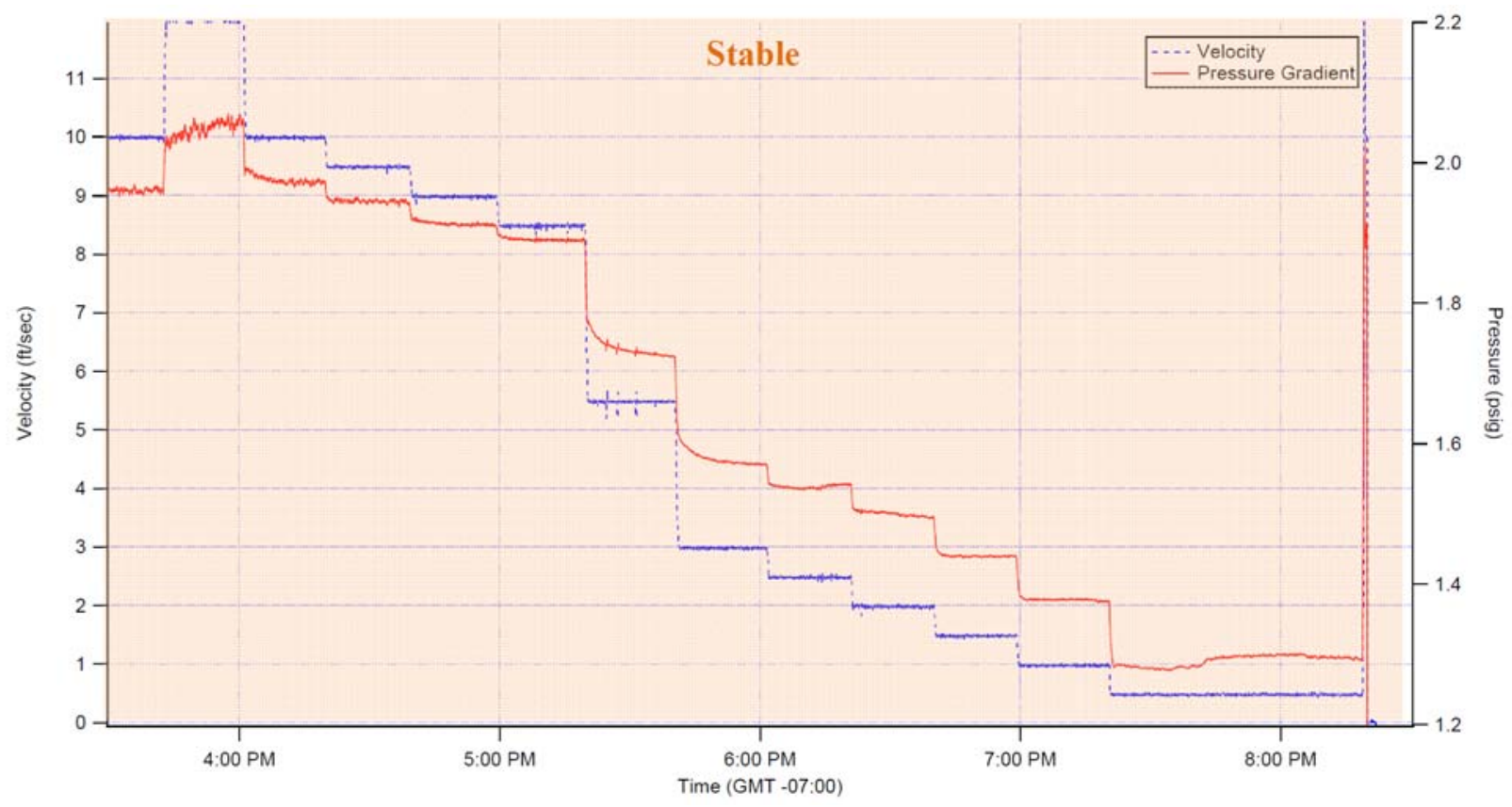

Figure B.1. Pressure-Gradient Data for Casson-Fluid Yield Stress of Approximately 28.0 Pa and InfiniteShear Viscosity of $3.3 \mathrm{cP}$. This test was conducted on 12/9/08. Since no dramatic increase in pressure is observed at low velocities this slurry is considered to be stable in a 3" pipe. 


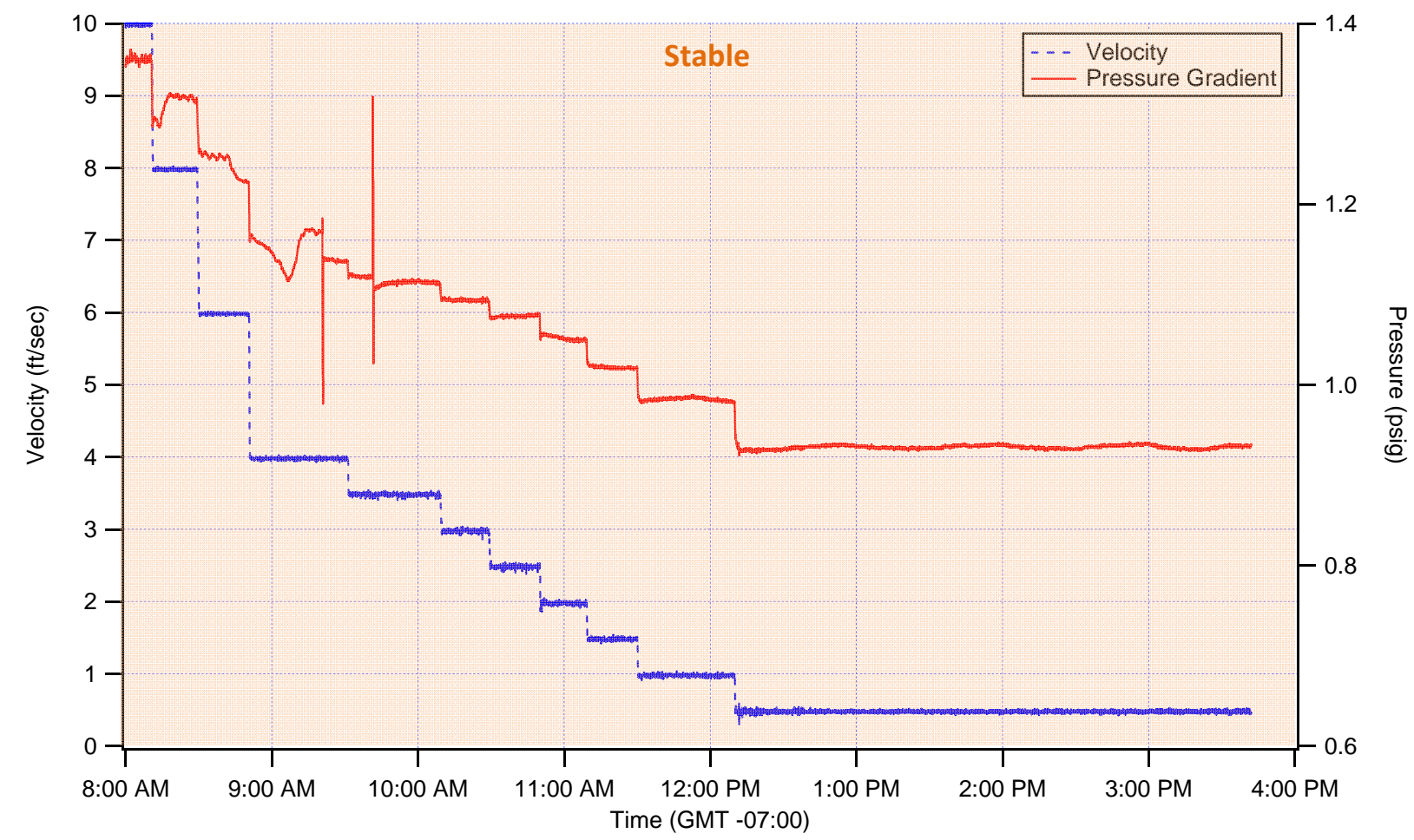

Figure B.2. Pressure-Gradient Data for Casson-Fluid Yield Stress of Approximately 18.6 Pa and InfiniteShear Viscosity of $3.2 \mathrm{cP}$. This test was conducted on 12/11/08. Since no dramatic increase in pressure is observed at low velocities this slurry is considered to be stable in a 3" pipe.

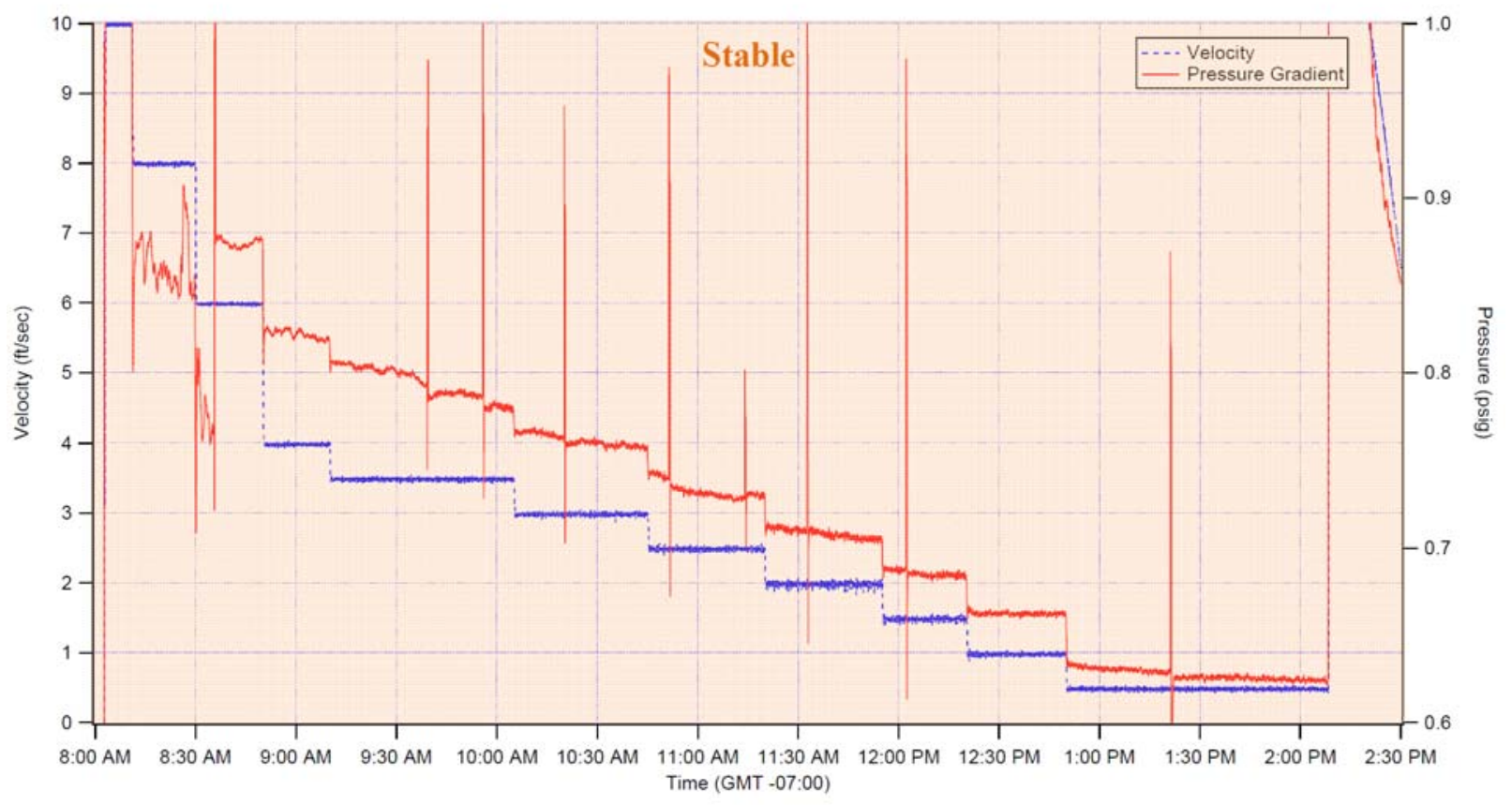

Figure B.3. Pressure-Gradient Data for Casson-Fluid Yield Stress of Approximately 12.8 Pa and InfiniteShear Viscosity of $2.5 \mathrm{cP}$. This test was conducted on 12/15/08. Since no dramatic increase in pressure is observed at low velocities this slurry is considered to be stable in a 3" pipe. 


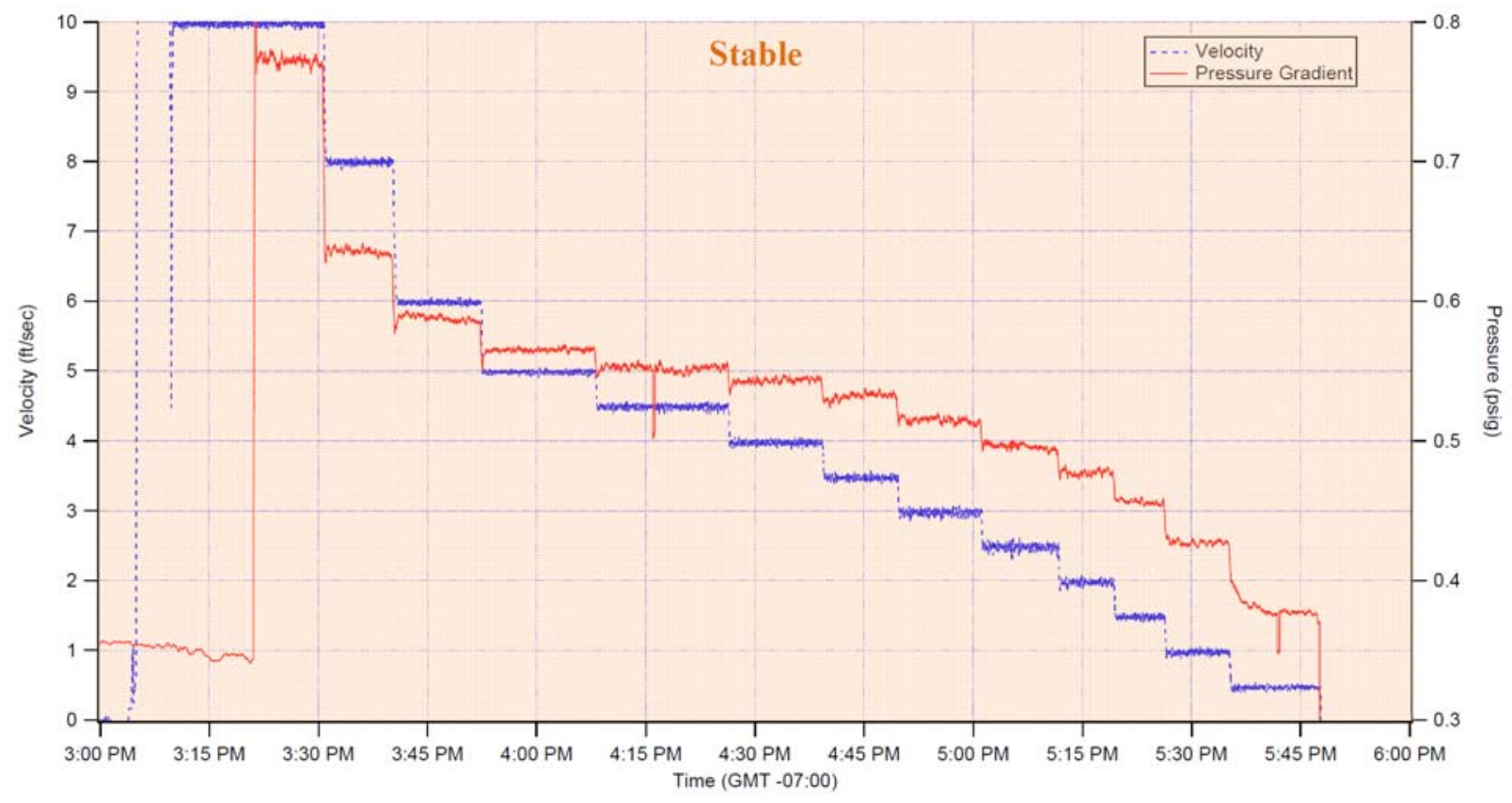

Figure B.4. Pressure-Gradient Data for Casson-Fluid Yield Stress of Approximately 7.5 Pa and InfiniteShear Viscosity of $2.0 \mathrm{cP}$. This test was conducted on $1 / 5 / 09$. Since no dramatic increase in pressure is observed at low velocities this slurry is considered to be stable in a 3 ” pipe.

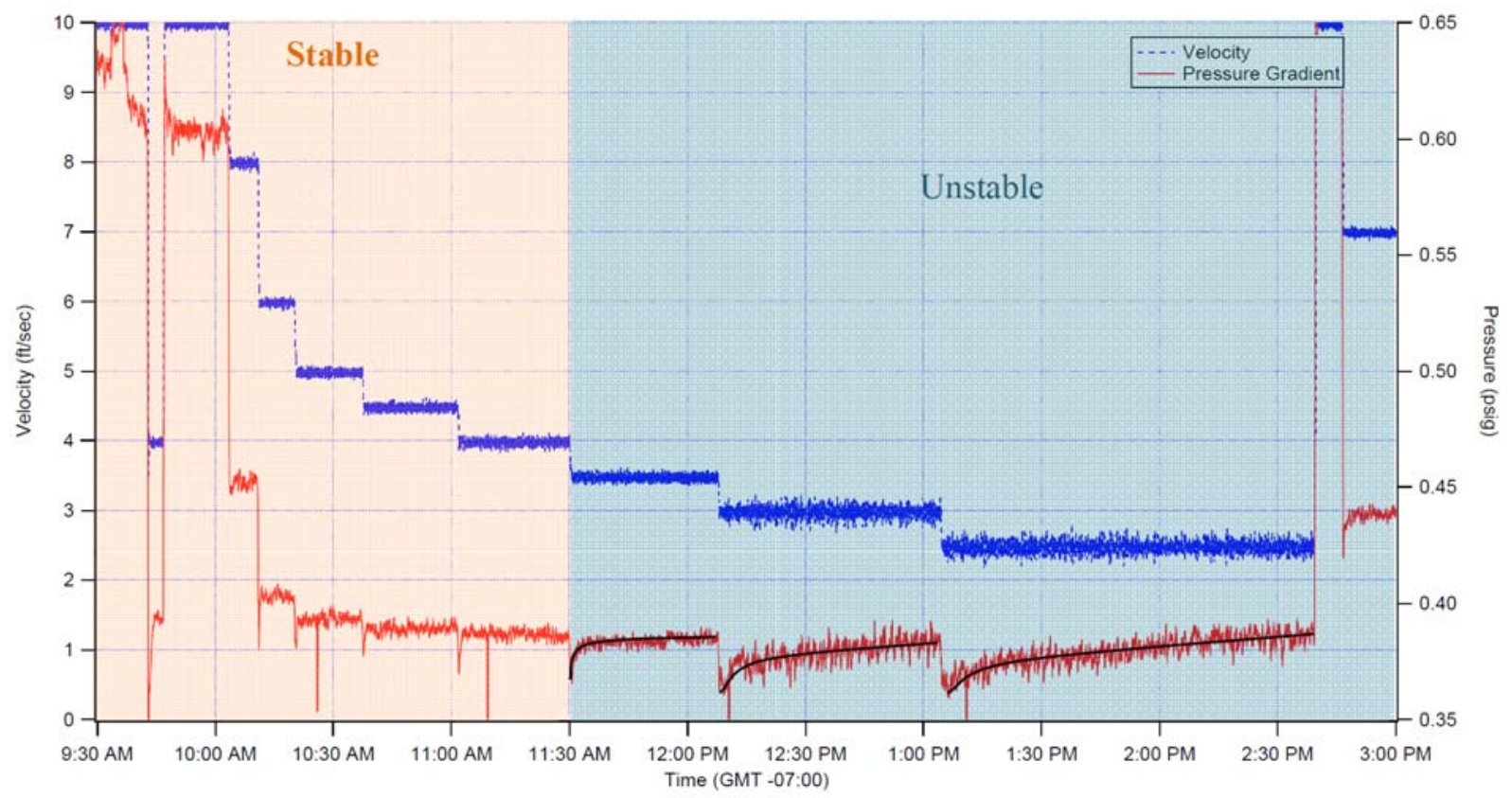

Figure B.5. Pressure-Gradient Data for Casson-Fluid Yield Stress of Approximately 5.1 Pa and InfiniteShear Viscosity of $2.1 \mathrm{cP}$. This test was conducted on $1 / 6 / 09$. The pressure signal is stable until $3.5 \mathrm{ft} / \mathrm{sec}$ where an increase in pressure with time is observed. This slurry is considered to be unstable in a 3" pipe below $4.0 \mathrm{ft} / \mathrm{sec}$. 


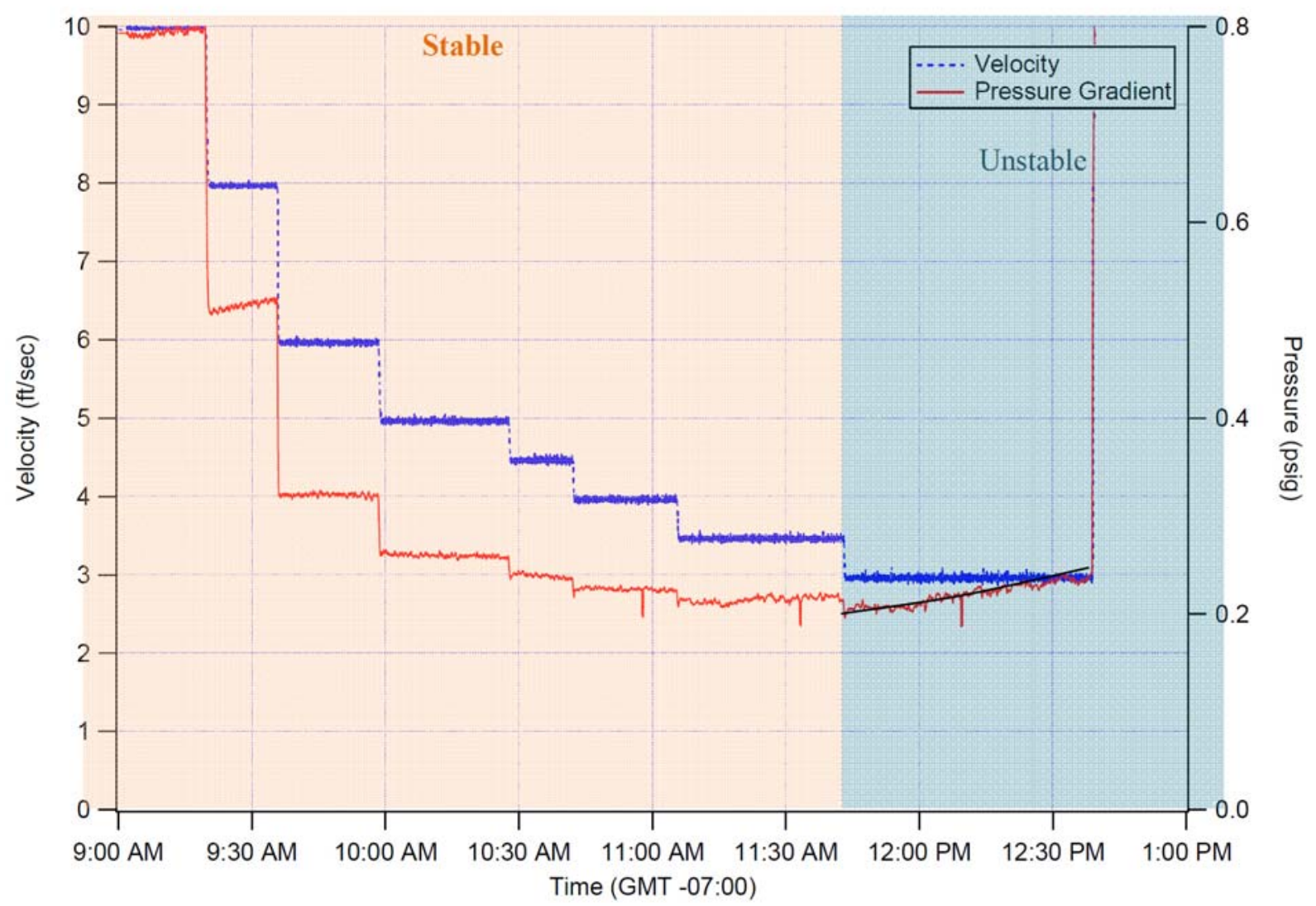

Figure B.6. Pressure-Gradient Data for Casson-Fluid Yield Stress of Approximately 2.6 Pa and InfiniteShear Viscosity of $2.5 \mathrm{cP}$. This test was conducted on 1/8/09 prior to AFA addition. The pressure signal is stable until $3.0 \mathrm{ft} / \mathrm{sec}$ where an increase in pressure with time is observed. This slurry is considered to be unstable in a 3" pipe below $3.5 \mathrm{ft} / \mathrm{sec}$. 


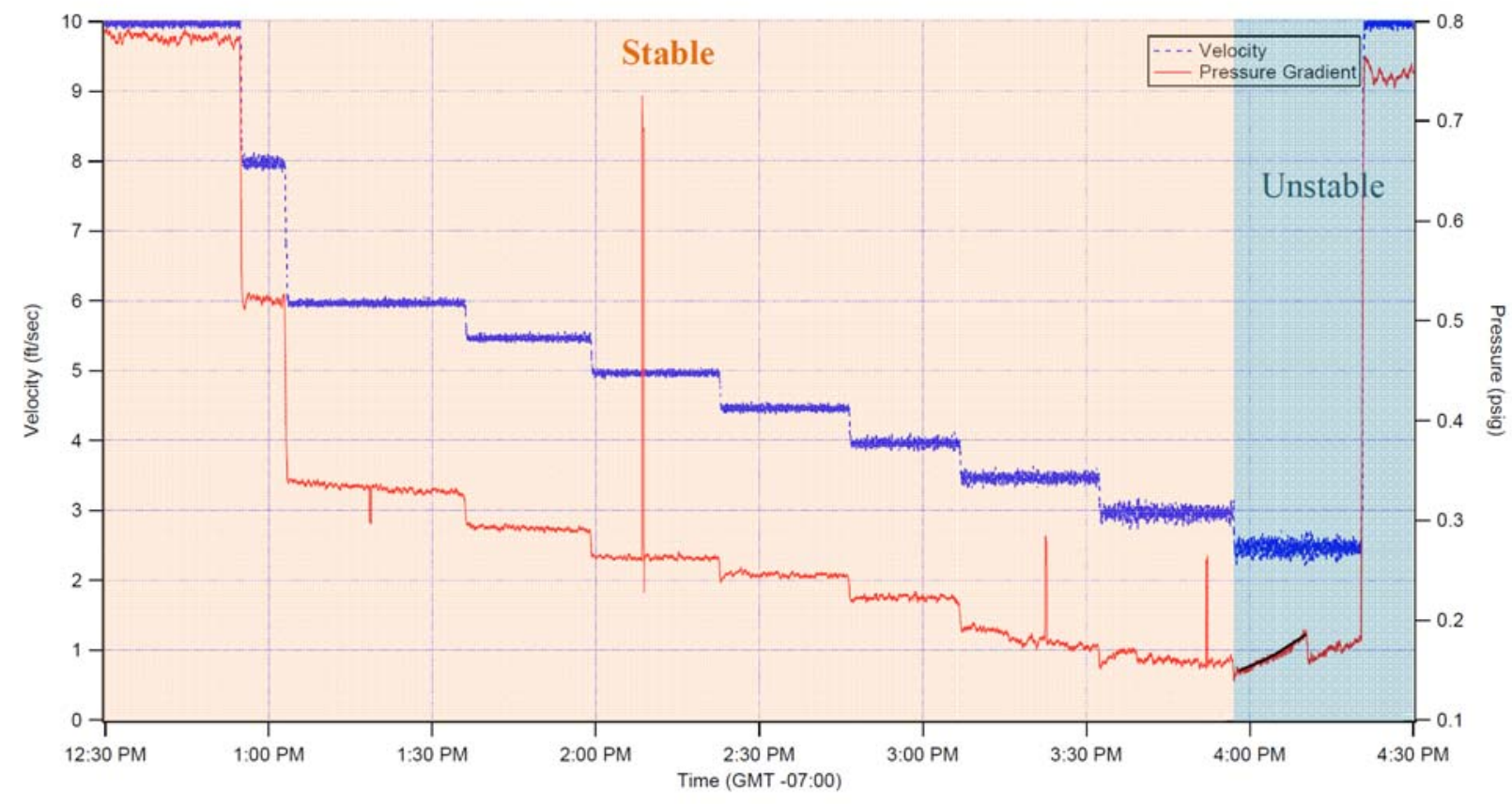

Figure B.7. Pressure-Gradient Data for Casson-Fluid Yield Stress of Approximately 3.1 Pa and InfiniteShear Viscosity of $2.3 \mathrm{cP}$. This test was conducted on 1/9/09 after AFA addition. The pressure signal is stable until $2.5 \mathrm{ft} / \mathrm{sec}$ where an increase in pressure with time is observed. This slurry is considered to be unstable in a 3" pipe below $3.0 \mathrm{ft} / \mathrm{sec}$.

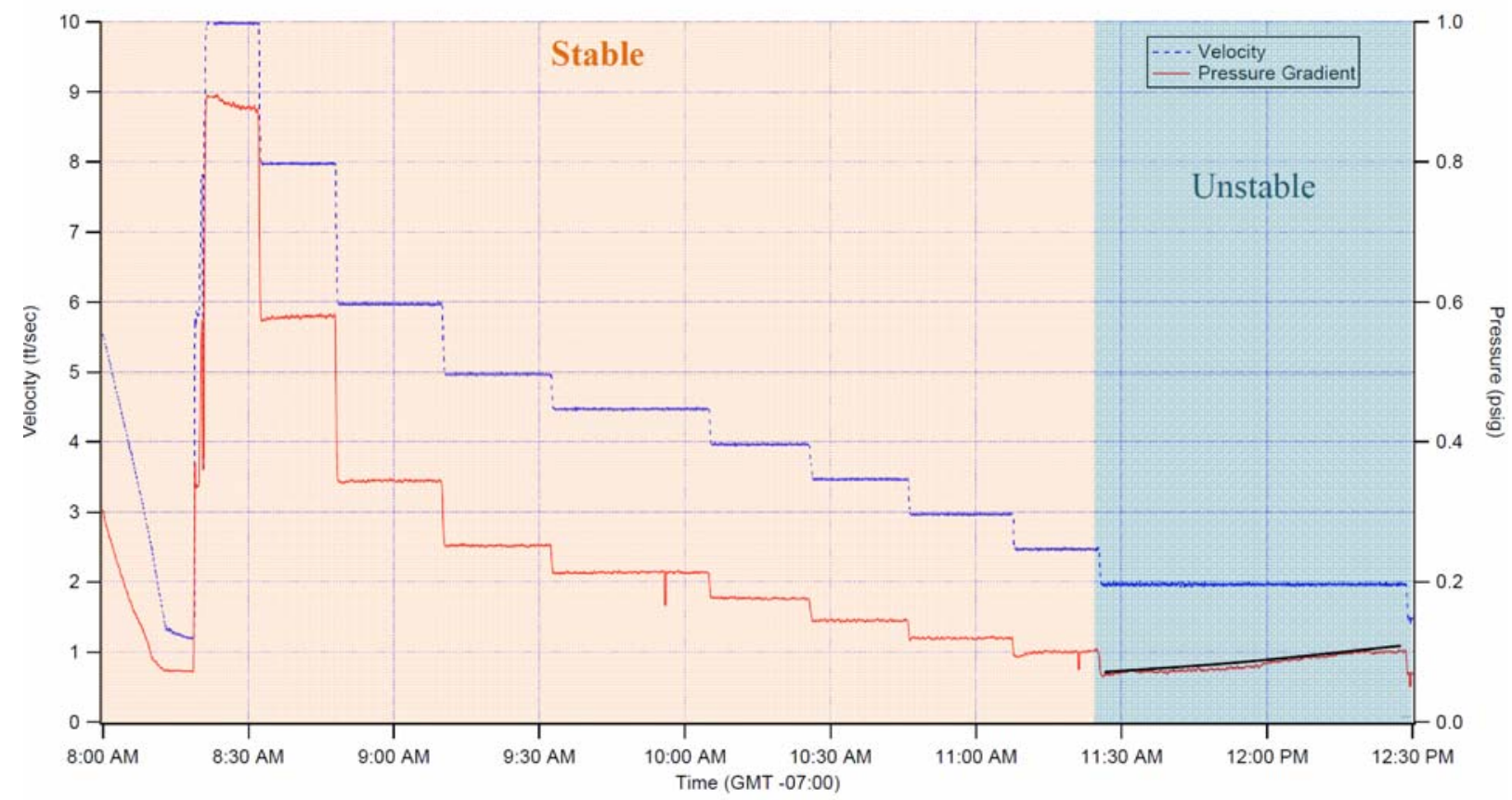

Figure B.8. Pressure-Gradient Data for Casson-Fluid Yield Stress of Approximately 0.9 Pa and InfiniteShear Viscosity of $2.2 \mathrm{cP}$. This test was conducted on $1 / 10 / 09$. The pressure signal is stable until $2.0 \mathrm{ft} / \mathrm{sec}$ where an increase in pressure with time is observed. This slurry is considered to be unstable in a 3" pipe below $2.5 \mathrm{ft} / \mathrm{sec}$. 

Appendix C

Technical Information on PulseEcho Ultrasonic Sensors 



\section{Appendix C}

\section{Technical Information on PulseEcho Ultrasonic Sensors}

\section{C.1 Introduction}

In support of RPP-WTP M1: Plugging-in-Piping step-down and ramp-down testing, the PulseEcho system was utilized to perform non-invasive, real-time ultrasonic detection and measurement of sediment in piping. The PulseEcho system was used in concert with visual observations made via an acrylic pipe section and the M1 Electrical Resistance Tomography (ERT) system. It is important to note that the monitoring points along the M1 flow loop for these three data-collection methods were significantly separated by distance along the M1 flow loop.

\section{C.2 Ultrasonic PulseEcho System Concept of Operation}

Conventional ultrasonic measurements have been used for decades to perform thickness measurements, concentration measurements, liquid-level measurements, physical-interface detection and more. The principal measurement methodology for level- and interface-detection and measurement is the conventional single- transducer pulse-echo measurement technique. This technique relies on obtaining ultrasonic echoes (signal returns) that result from reflections from physical interfaces (e.g. a solid-liquid interface) that arise due to differences in acoustic impedance. An acoustic interface can be formed by any two adjacent materials of dissimilar acoustic impedance, an acoustic property related to a material's density and speed-of-sound value. For the detection

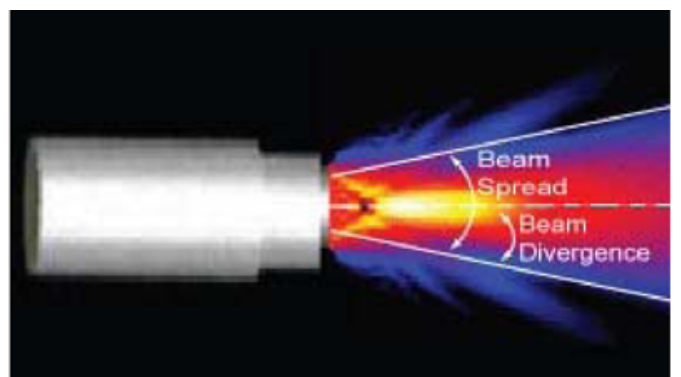

Figure C.1. Ultrasonic Transducer Emitting a Conical Sound Field. (Courtesy of the Center for Nondestructive Evaluation at Iowa State University) and measurement of solids sediment in a pipe, interfaces would ideally be represented by: the interface between the inner pipe wall and the slurry and the interface between the settled solids and the supernate or settled solids-slurry interface. While the resulting comprehensive echo pattern can appear complex, simple modeling is used to reconcile the measured echoes with the multiple physical interfaces.

Challenges with using the conventional pulse-echo measurement technique arise when physical interfaces are sufficiently uneven (i.e. not normal to the sound field of the transducer) and when acoustic impedances of physical interfaces are not sufficiently different to produce a return echo. These are inherent challenges when ultrasonically monitoring the formation of solids in a pipe or vessel under dynamic conditions. In dynamic-testing regimes, particle settling and lift-off rates vary rapidly, particles settle in a manner that results in an uneven sediment layer that is very seldom normal to the ultrasonic sound field, and the sedimentslurry interface is usually represented by a concentration gradient rather than a well-defined solids-slurry boundary. This behavior is commonly encountered when studying sandy ocean bottoms, for instance.

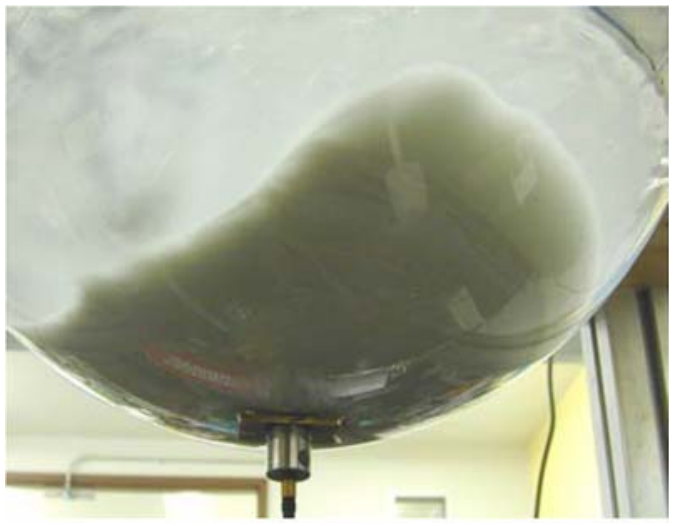

Figure C.2. PulseEcho Ultrasonic Transducer Monitoring the Thickness of an Uneven Sediment Bed 
The PulseEcho system was developed at PNNL to address the challenges faced by conventional pulse-echo measurement methods during sediment detection and monitoring. The PulseEcho system utilizes the single-transducer pulse-echo measurement mode; however, the system does not require signal returns in the form of echo patterns to detect and measure interfaces. Rather than relying on echo returns to detect interfaces, the PulseEcho system relies on obtaining ultrasonic backscatter from an ensemble of solid particles. Settled, motionless particles result in non-modulated backscattered signal returns while dynamic, moving particles result in backscattered signal returns that are modulated in phase, amplitude and frequency. Using a variance algorithm and a user-defined variance threshold, the transition time between the non-modulated and modulated portions of the backscattered signals in time is defined. The simple detection of settled solids can be accomplished using this information alone; however, in combination with empiricallyderived a priori knowledge of speed-of-sound for the solids being monitored, the thickness of the settled solids can also be quantified in real time.

For fully mobilized particles in a pipe or other containment, the entire ultrasonicbackscatter signal will be highly modulated in phase, amplitude and frequency up to the pipe or container wall signal; this fully modulated signal indicates that all solids are mobilized and will register as zero sediment depth in the PulseEcho system's user readout. The onset of solids settling will be detected by the ultrasonic transducer and will be evidenced by a fluctuation between zero and a small sedimentdepth value in the user readout. As solids continue to settle and increase in thickness, the transition point in time between non-modulated and modulated backscatter will continue to increase. This time value is continuously correlated with the user-defined speed-of-sound value to provide real-time values of sediment depth. The PulseEcho software automates the

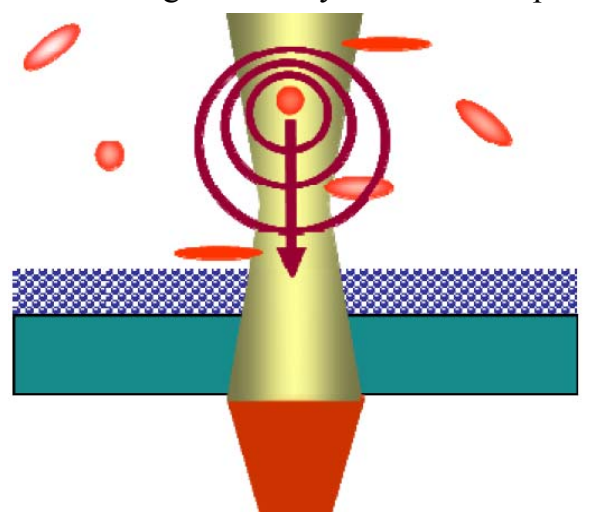

Figure C.3. Concept of Detection of Ultrasonic Backscatter From Solid Particles

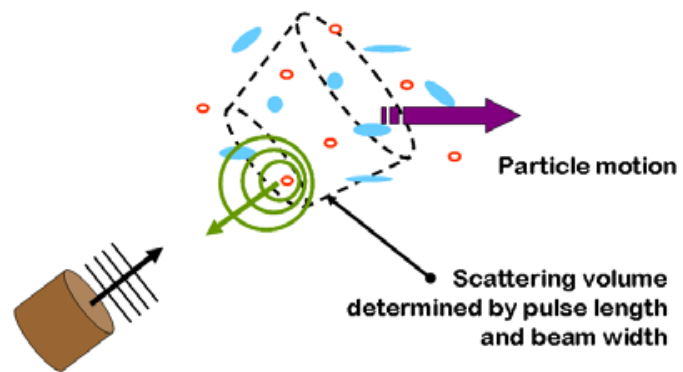

Figure C.4. Concept of Ultrasonic Measurement of Particle Motion

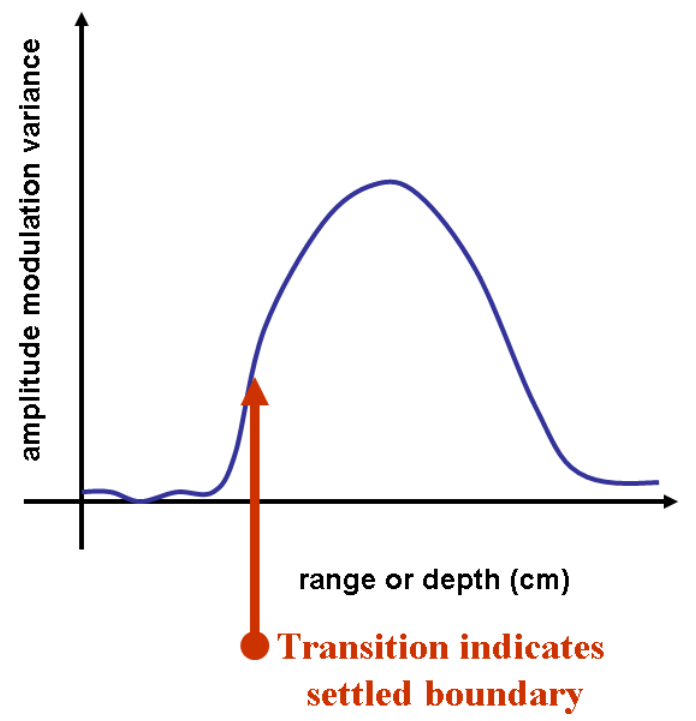

Figure C.5. Illustration of Pulse Echo Variance Algorithm

measurement process for an operator, providing a numerical read-out at a rate of up to 10 per second and a graph of these data points (sediment depth vs. time) for simple visual data assimilation. 


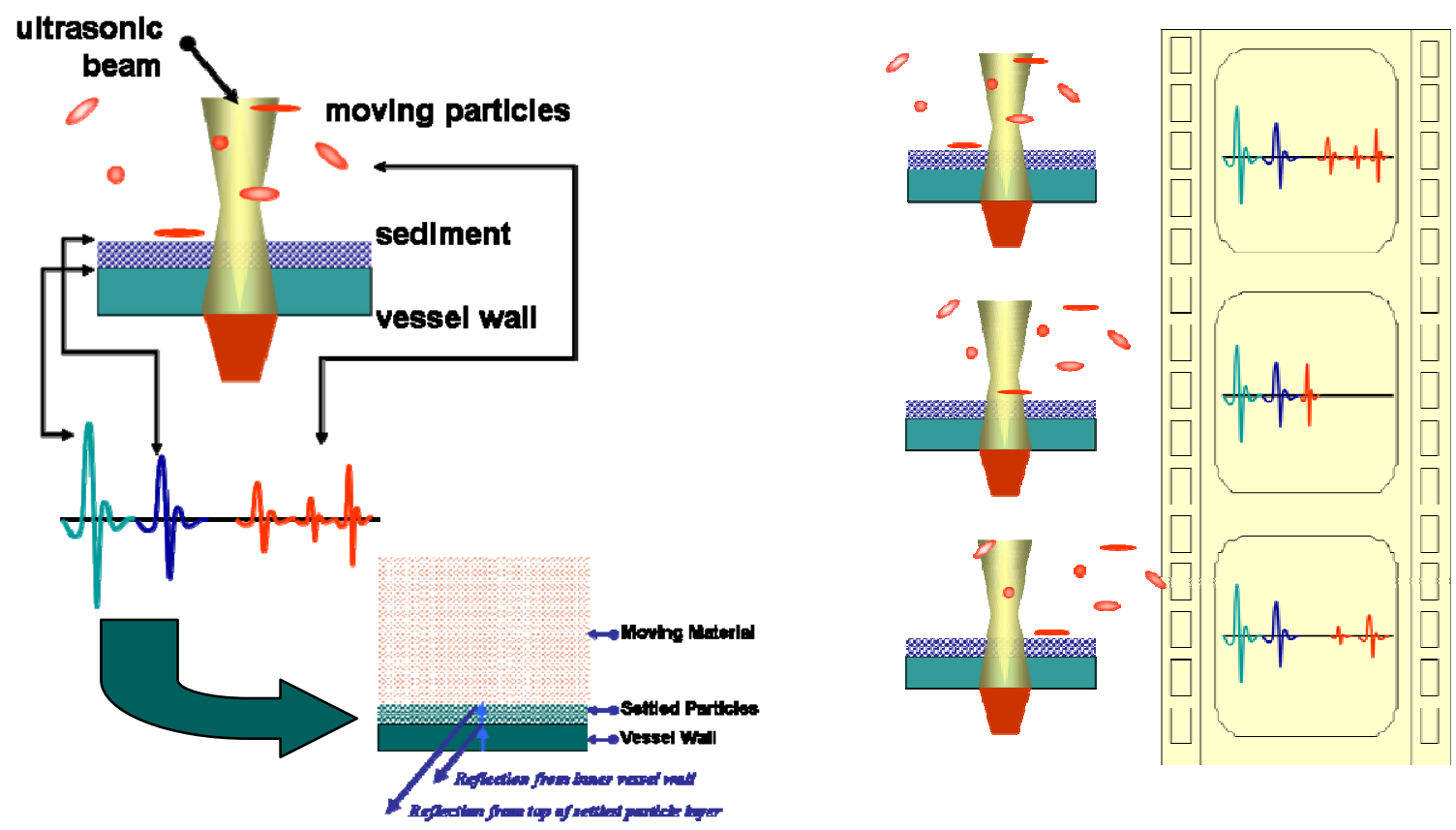

Figure C.6. Illustration of Pulse Echo Measurement and Signal-Processing Concepts

The pulse echo system is composed of one or more ultrasonic transducers (to monitor one or more locations), an ultrasonic pulser/receiver unit and an analog-to-digital (A/D) card that is located inside a workstation or expansion chassis that is interfaced with a workstation or laptop computer. The transducers(s) are coupled to the bottom of a pipe or other containment vessel and excited by the pulser to transmit ultrasonic energy into the vessel. The ultrasonic backscatter is then received by the same ultrasonic transducer, conditioned with the receiver portion of the pulser/receiver unit, and output to the A/D card for conversion prior to being analyzed via the PulseEcho algorithm. The PulseEcho software automates the measurement process for an operator, providing a numerical read-out at a rate of up to 10 per second and a graph of these data points (sediment depth vs. time) for simple data assimilation. The data is saved to a file on the workstation or laptop computer along with a configuration file.

The transition point between settled, motionless particles (non-modulated backscattered signal returns) and dynamic, moving particles (backscattered signal returns that are modulated in phase, amplitude and frequency) is easily observed on an oscilloscope in an amplitude-vs.-time display. An experienced user can use the raw backscatter data as observed on the oscilloscope to verify the PulseEcho system measurements. 


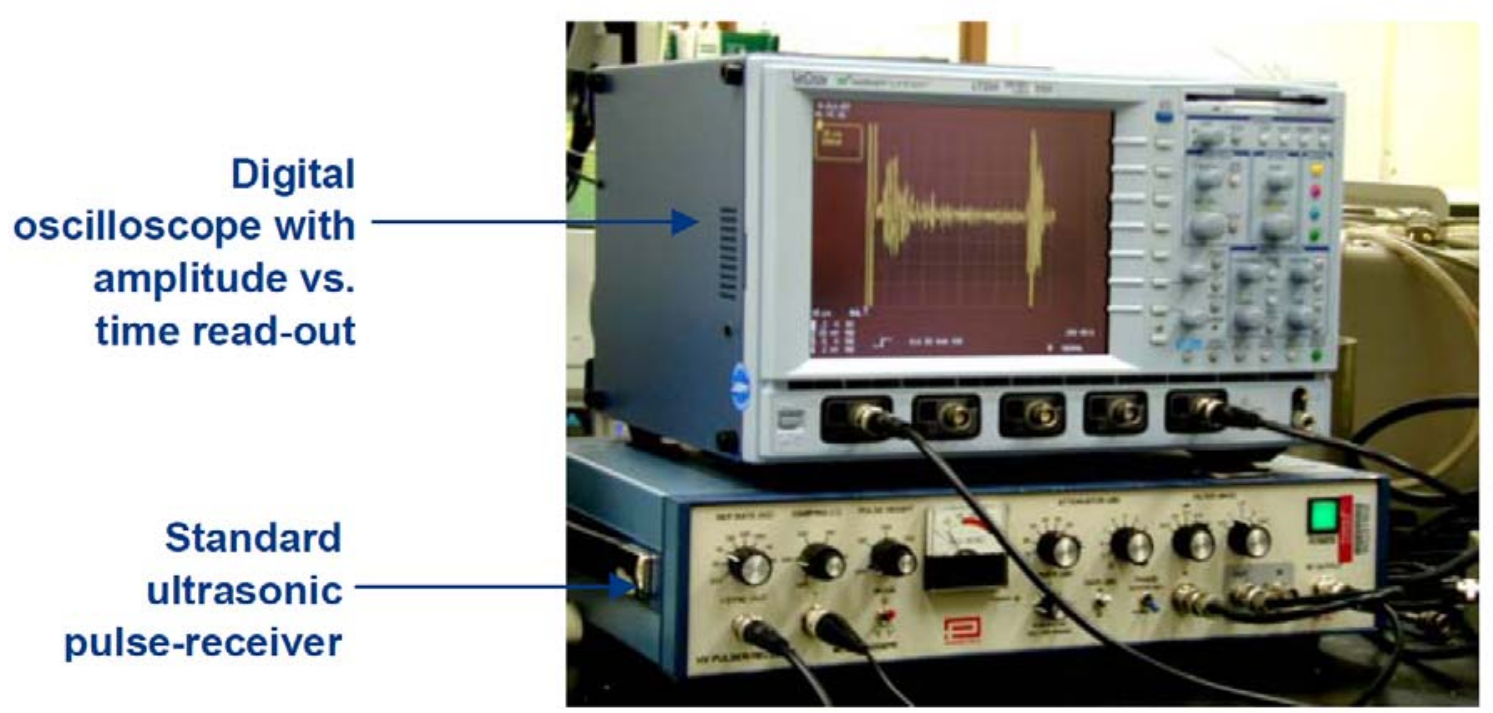

Figure C.7. Components of the PulseEcho Monitoring System 
Appendix D

Rheograms 



\section{Appendix D}

\section{Rheograms}

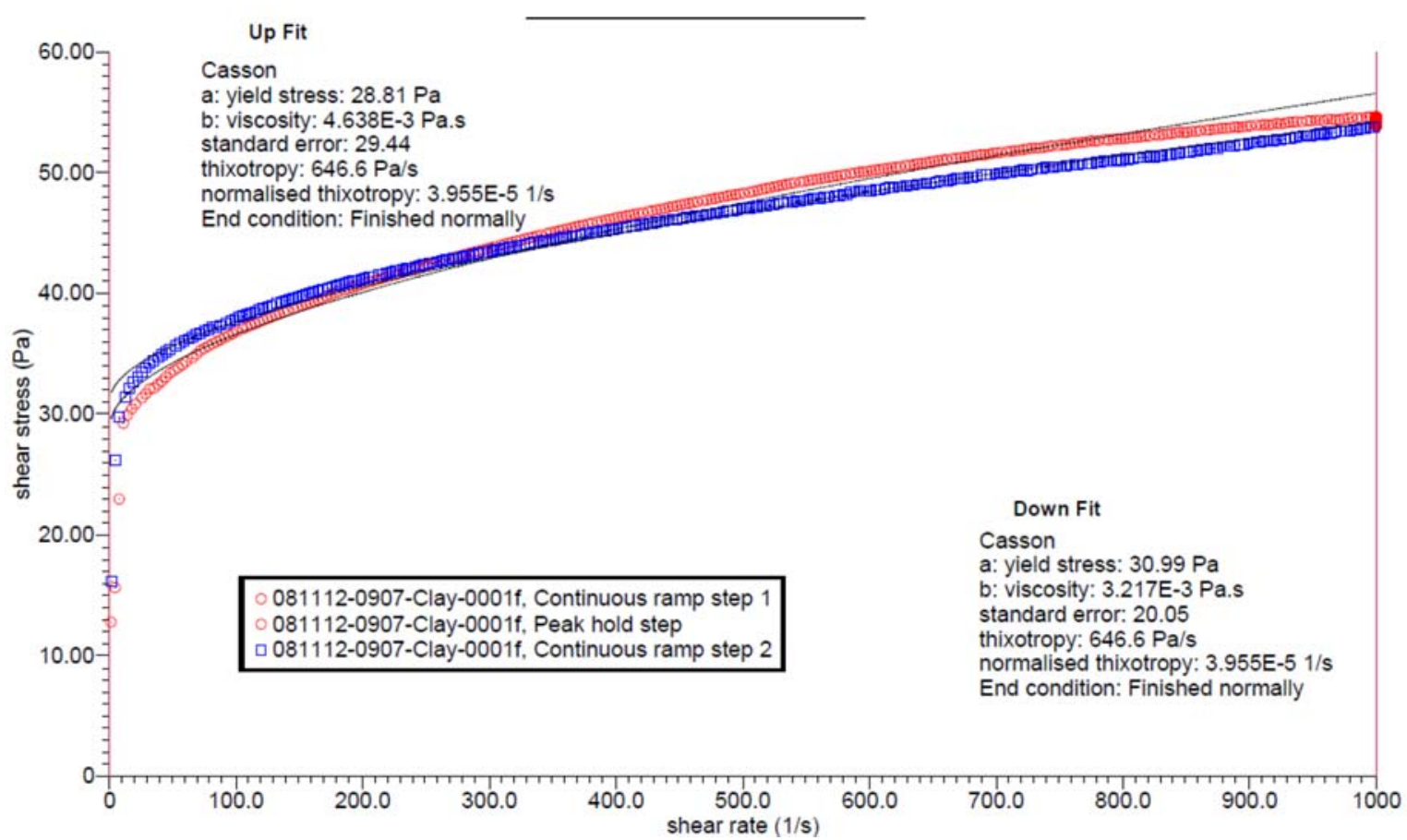

Figure D.1. Rheogram of Physical and Rheological Sample for TI-RPP-WTP-653

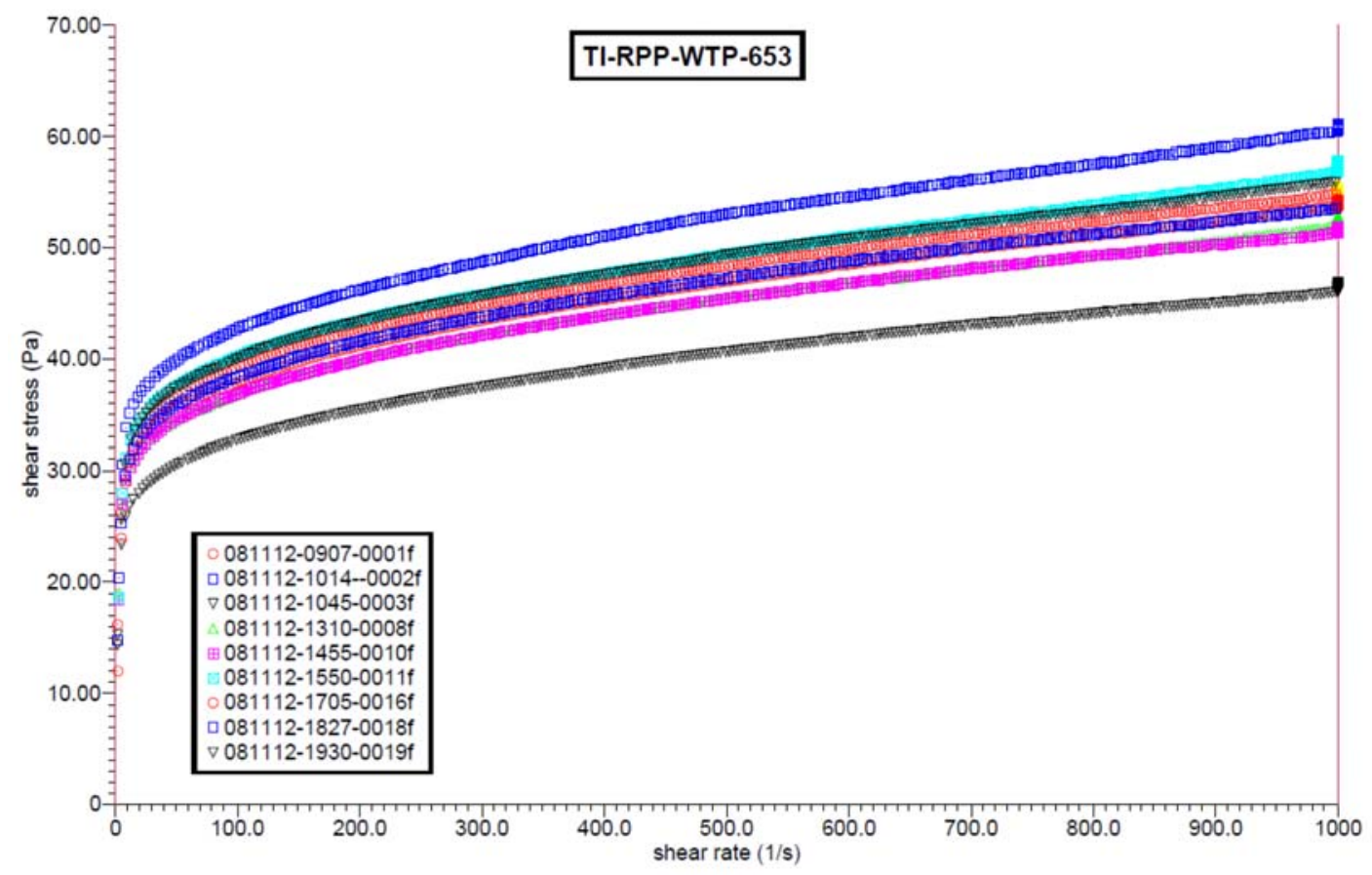

Figure D.2. Rheograms for All Samples Taken During TI-RPP-WTP-653 (Down Curves Only) 


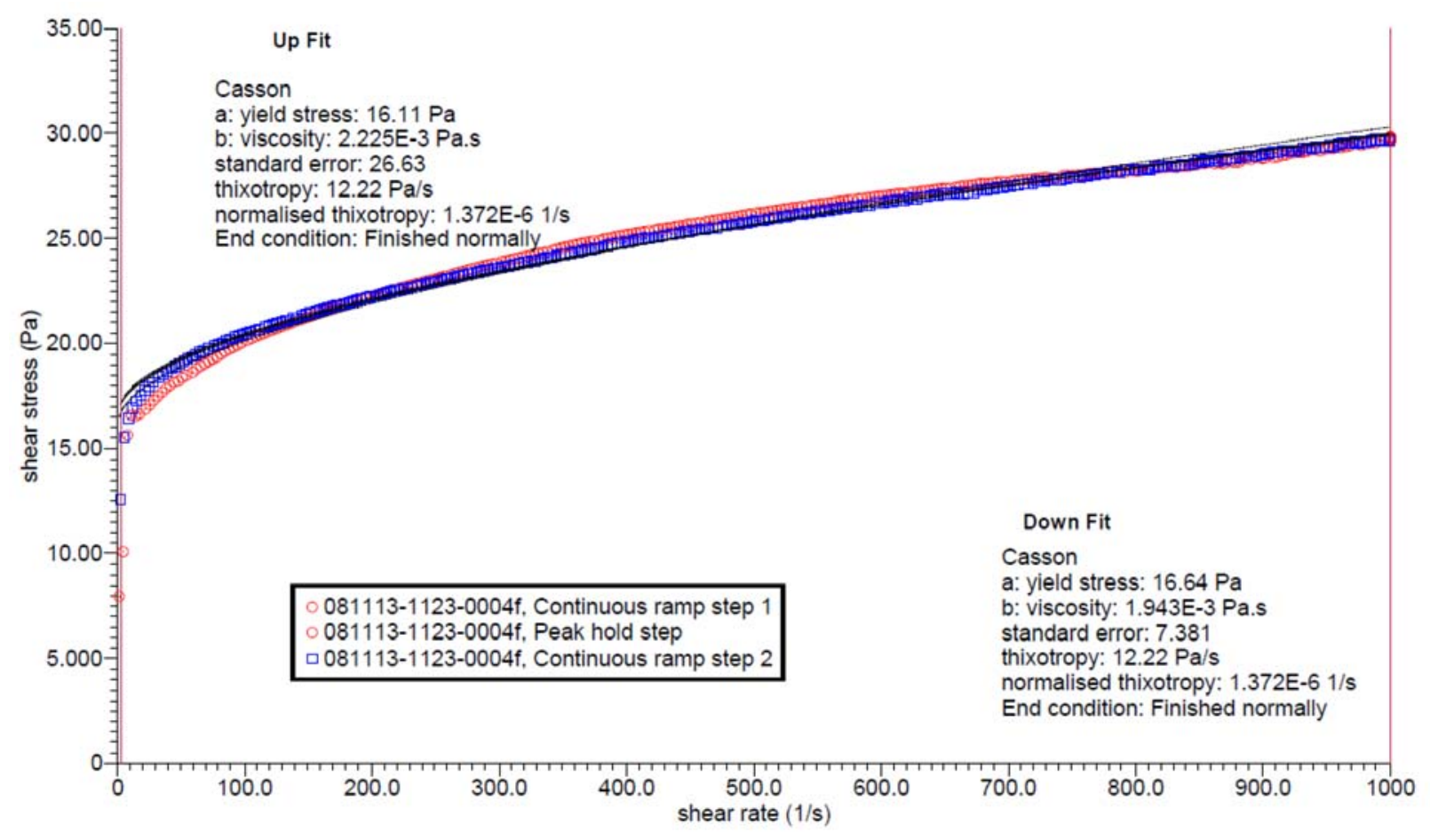

Figure D.3. Rheogram of Physical and Rheological Sample for TI-RPP-WTP-654

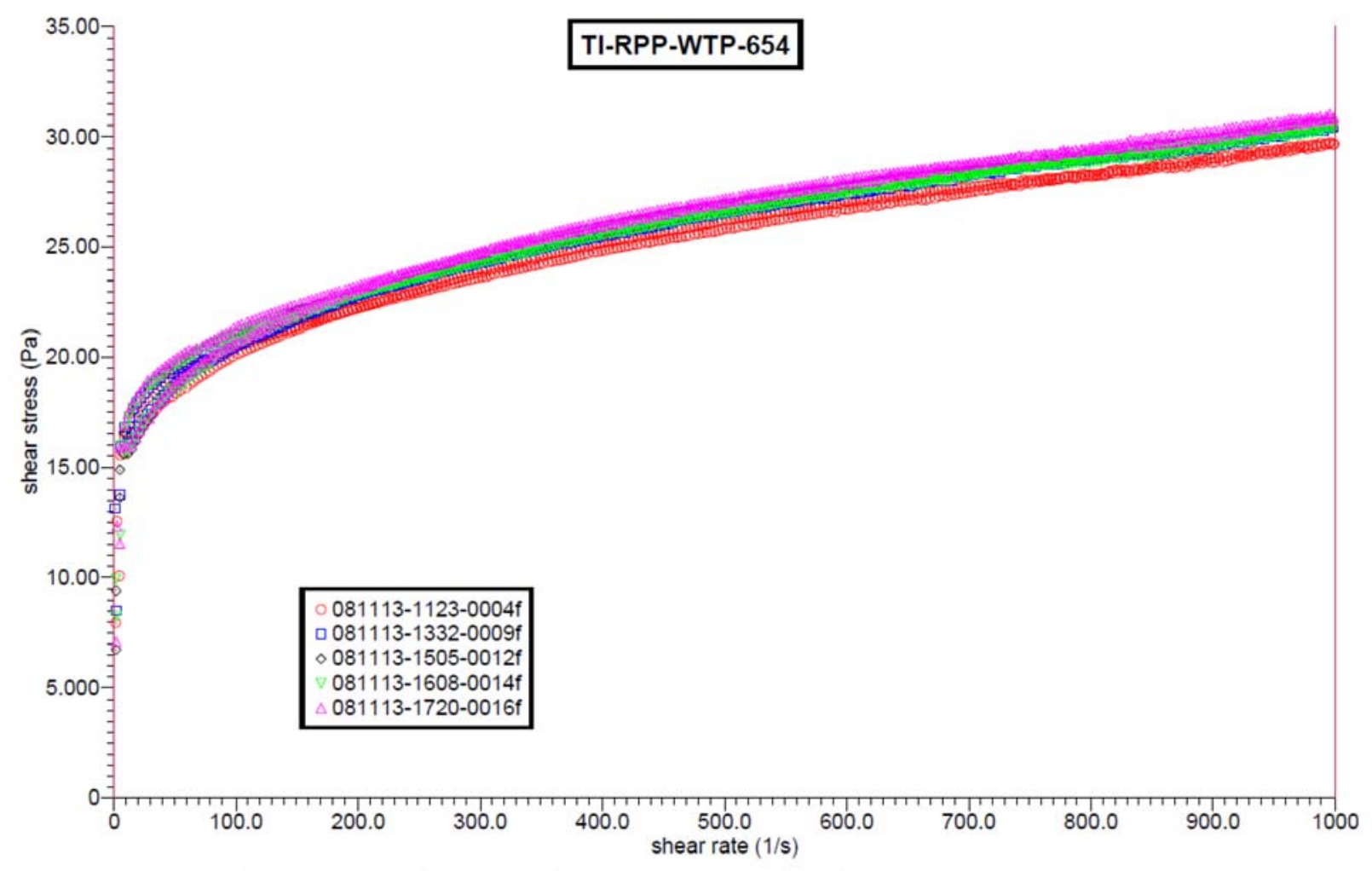

Figure D.4. Rheograms for All Samples Taken During TI-RPP-WTP-654 


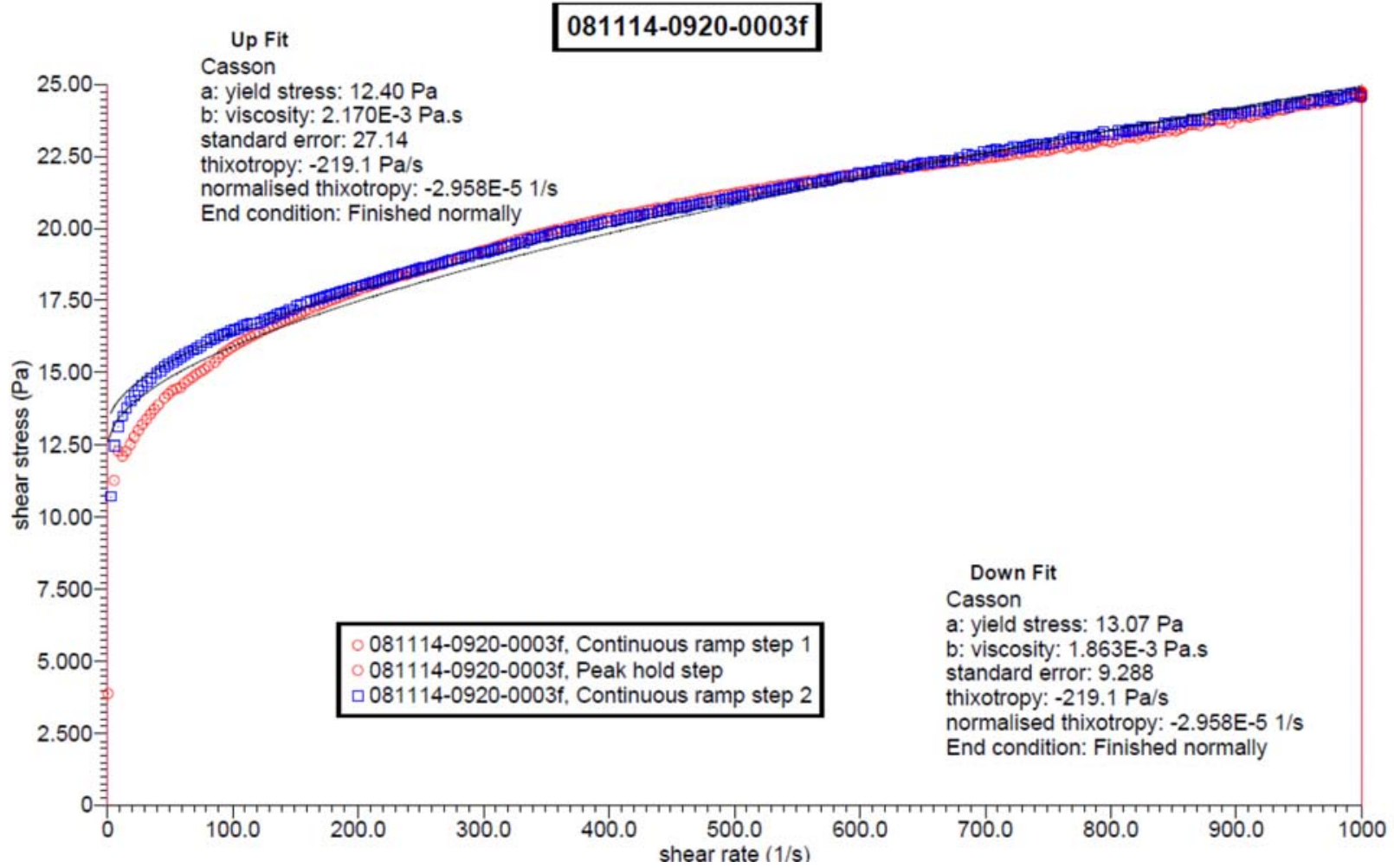

Figure D.5. Rheogram of Physical and Rheological Sample for TI-RPP-WTP-655

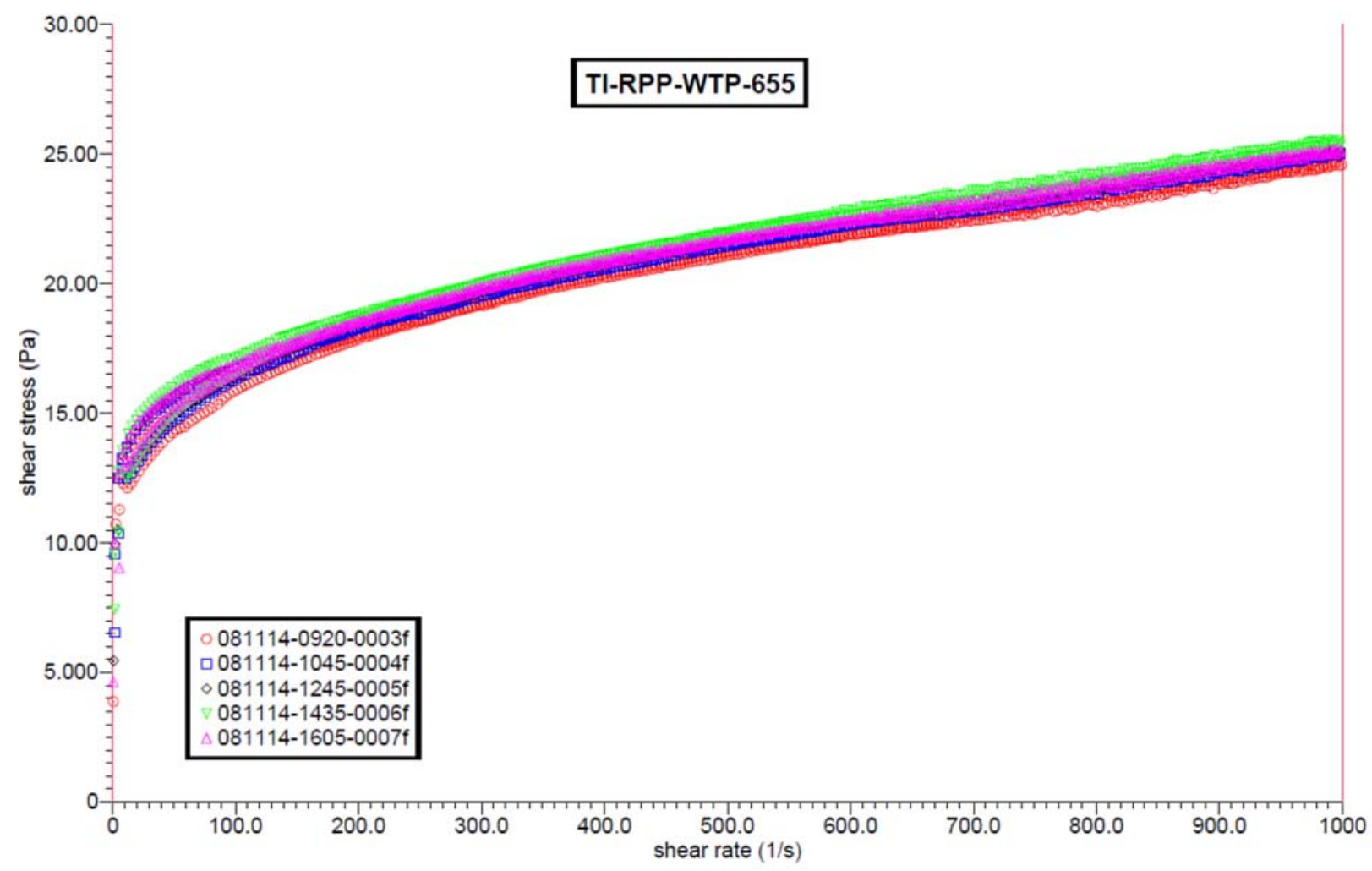

Figure D.6. Rheograms for All Samples Taken During TI-RPP-WTP-655 


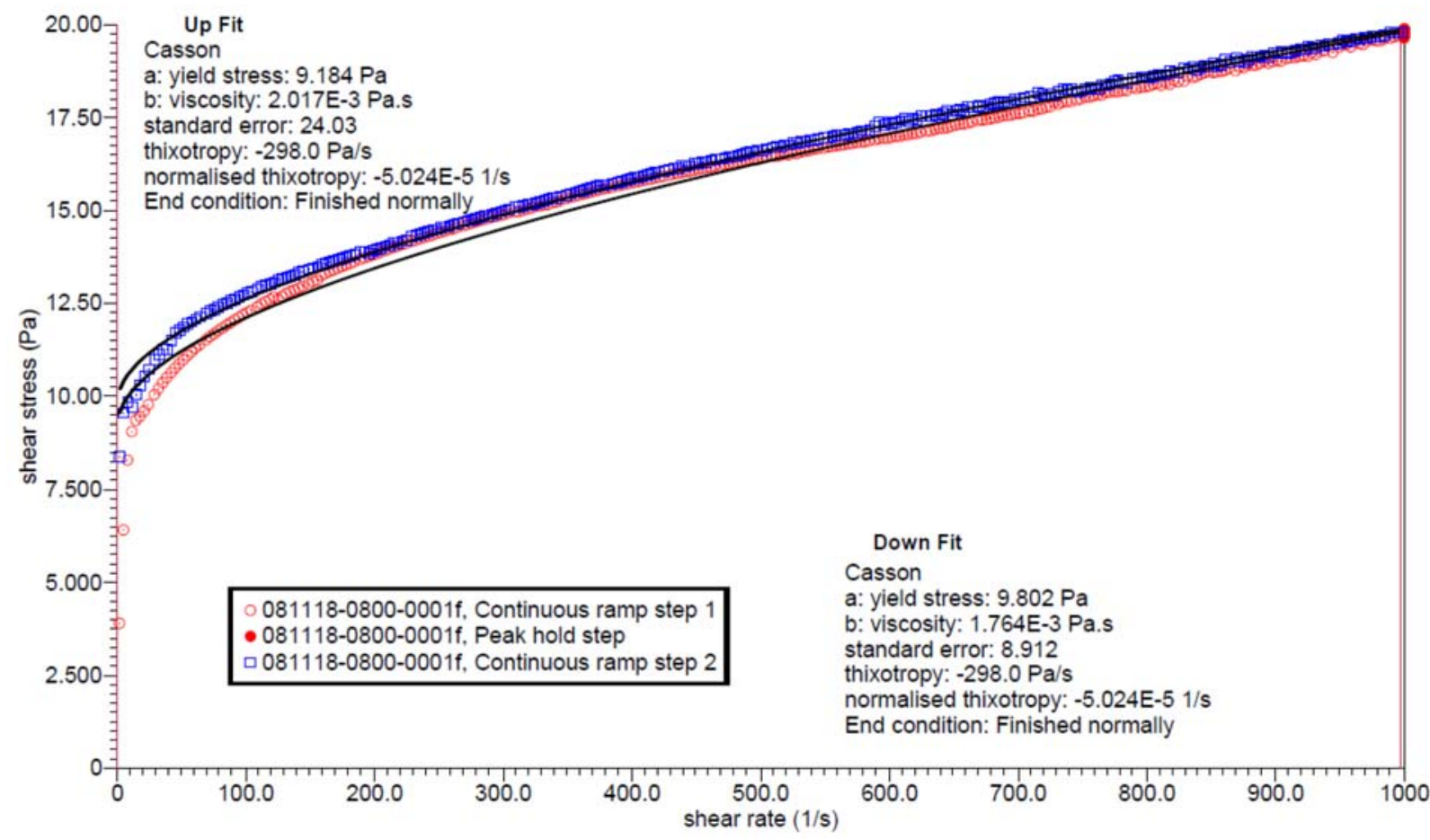

Figure D.7. Rheogram of Physical and Rheological Sample for TI-RPP-WTP-656

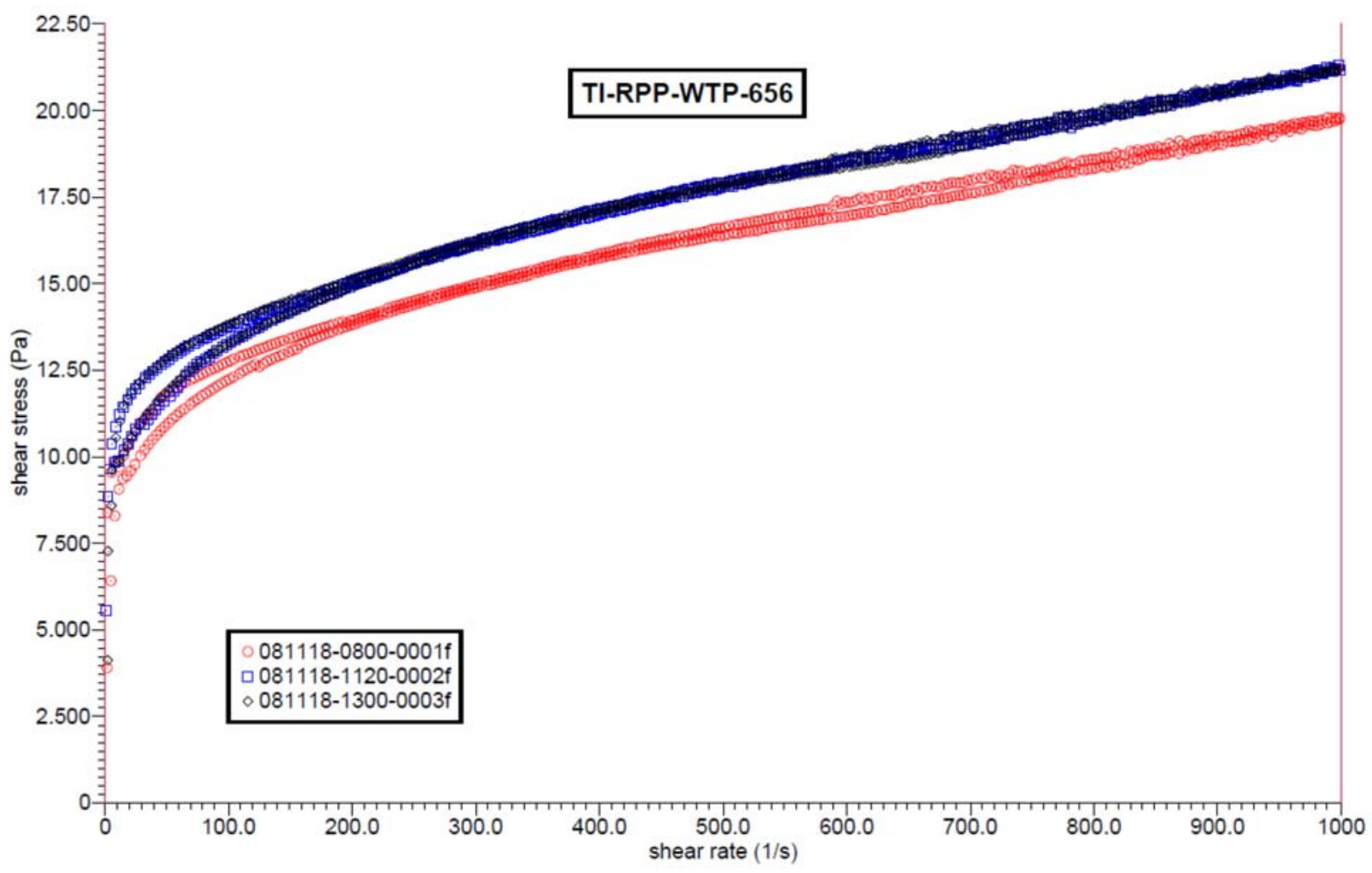

Figure D.8. Rheograms for All Samples Taken During TI-RPP-WTP-656 


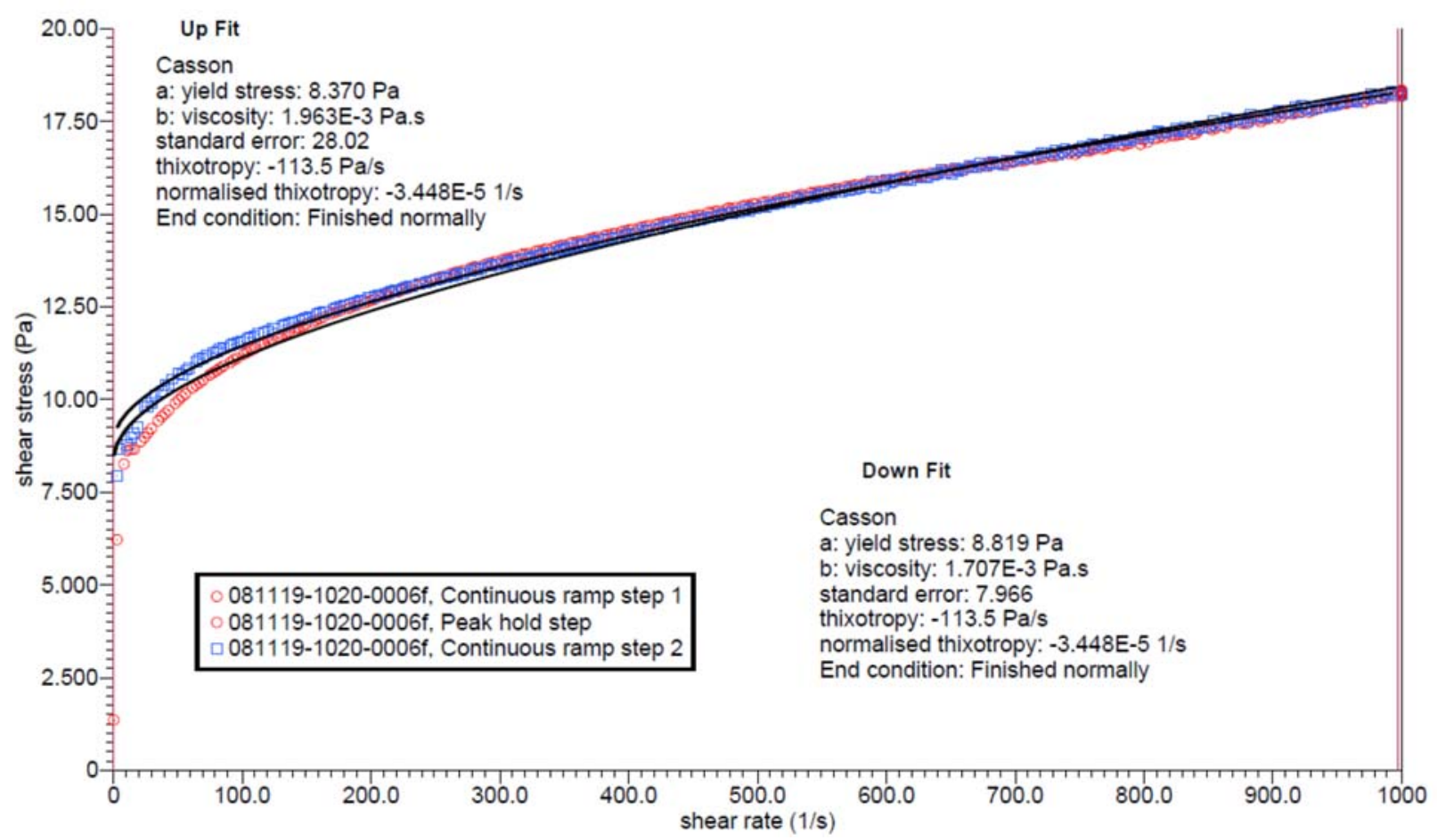

Figure D.9. Rheogram of Physical and Rheological Sample for TI-RPP-WTP-657

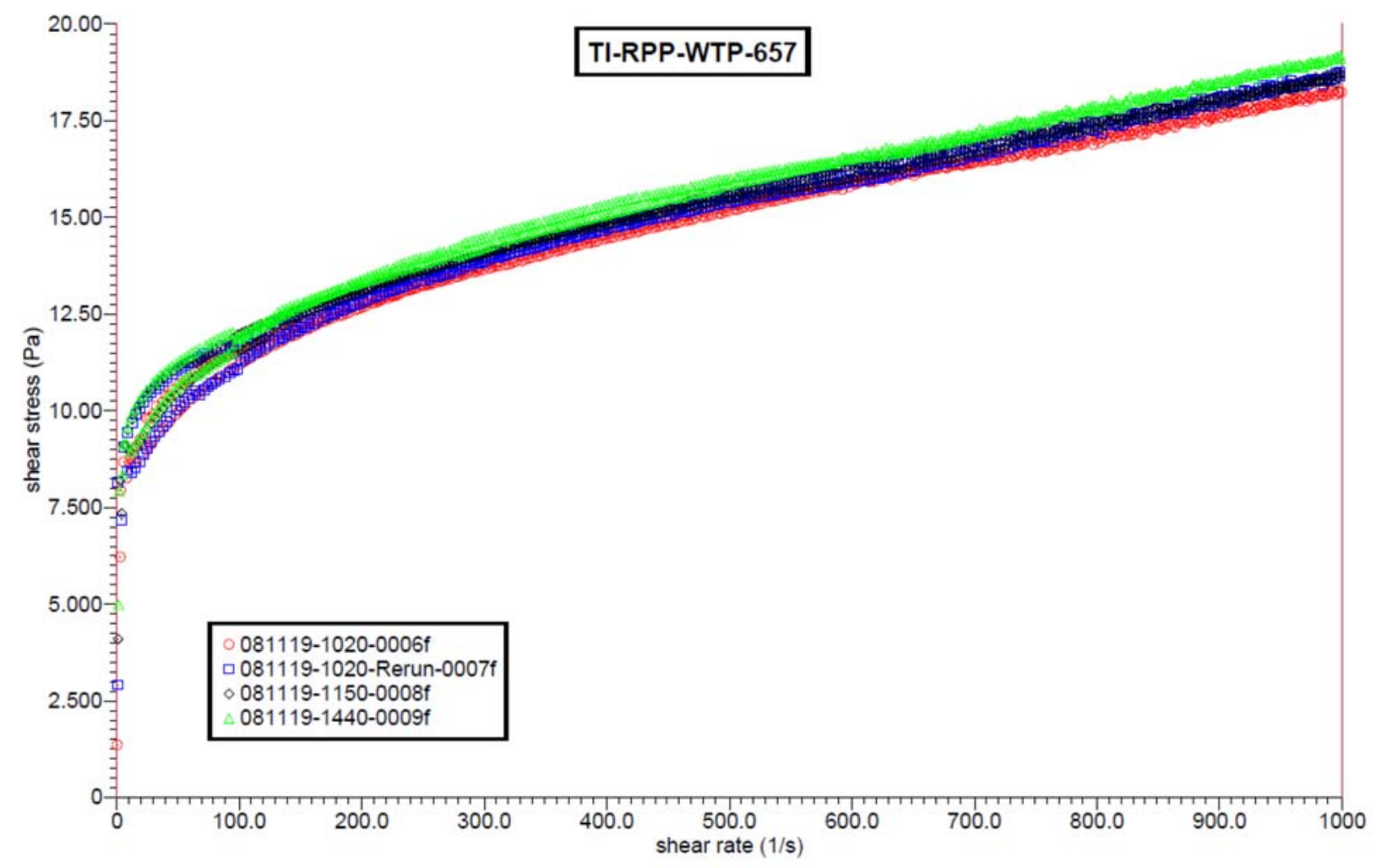

Figure D.10. Rheograms for All Samples Taken During TI-RPP-WTP-657 


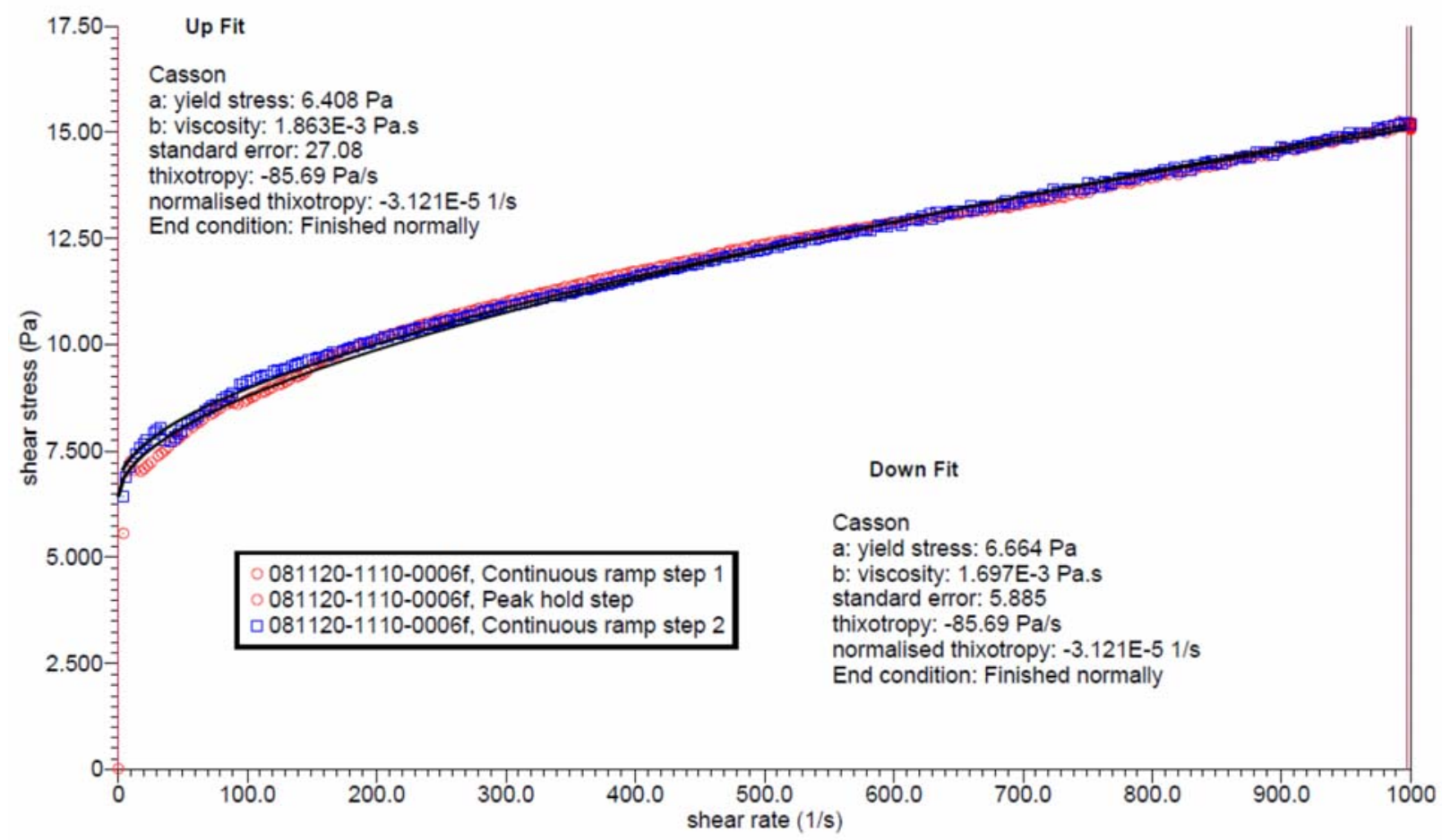

Figure D.11. Rheogram of Physical and Rheological Sample for TI-RPP-WTP-658

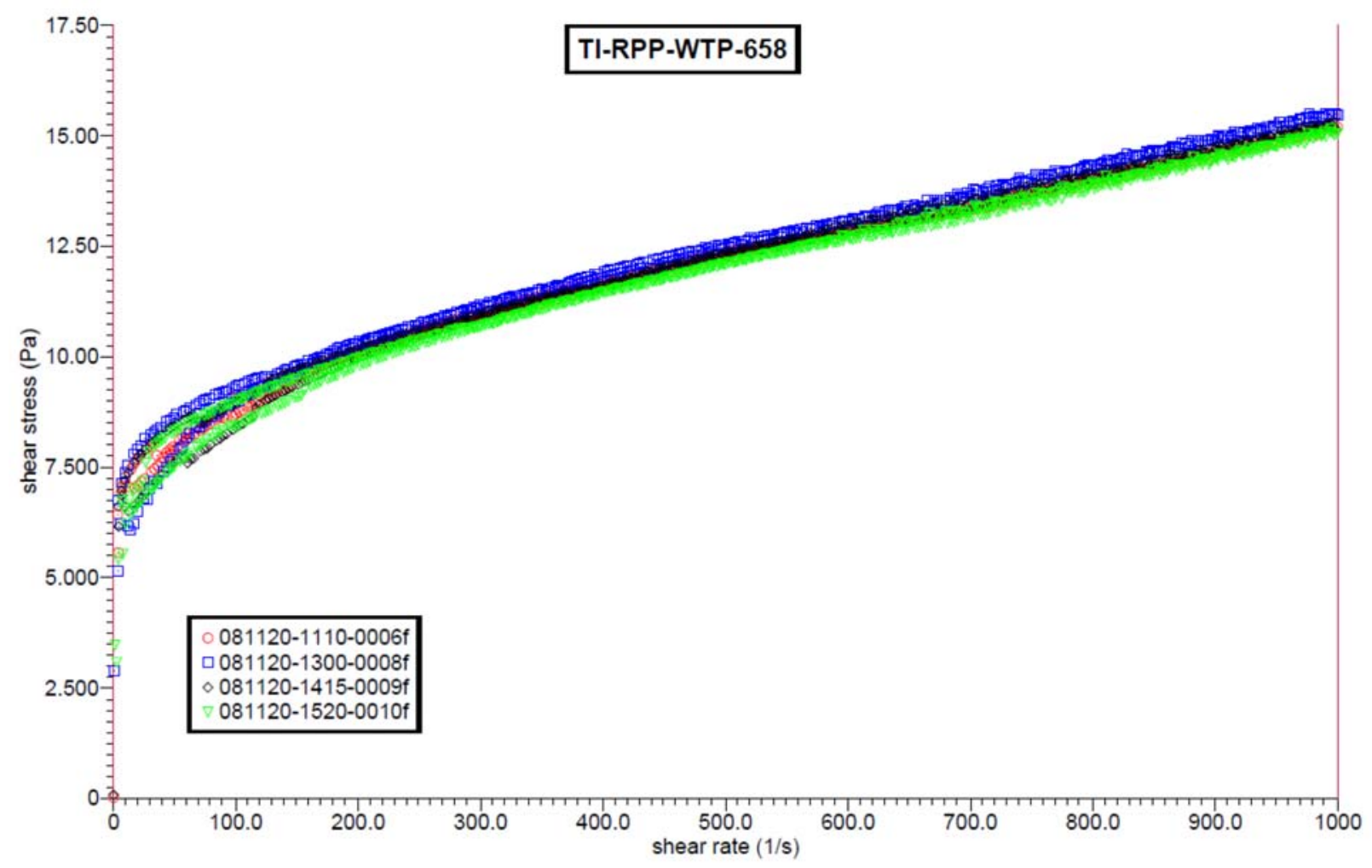

Figure D.12. Rheograms for All Samples Taken During TI-RPP-WTP-658 


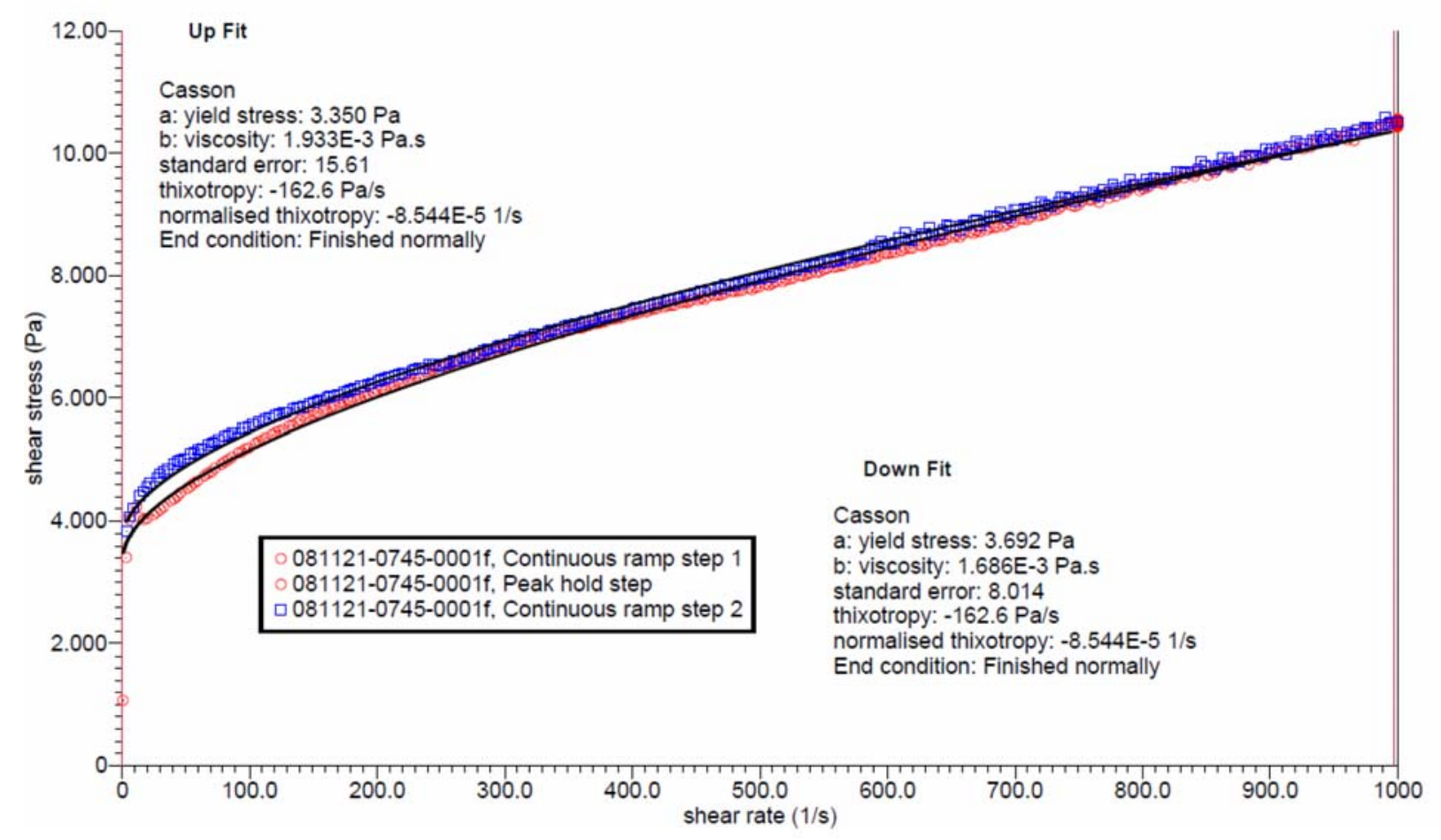

Figure D.13. Rheogram of Physical and Rheological Sample for TI-RPP-WTP-659

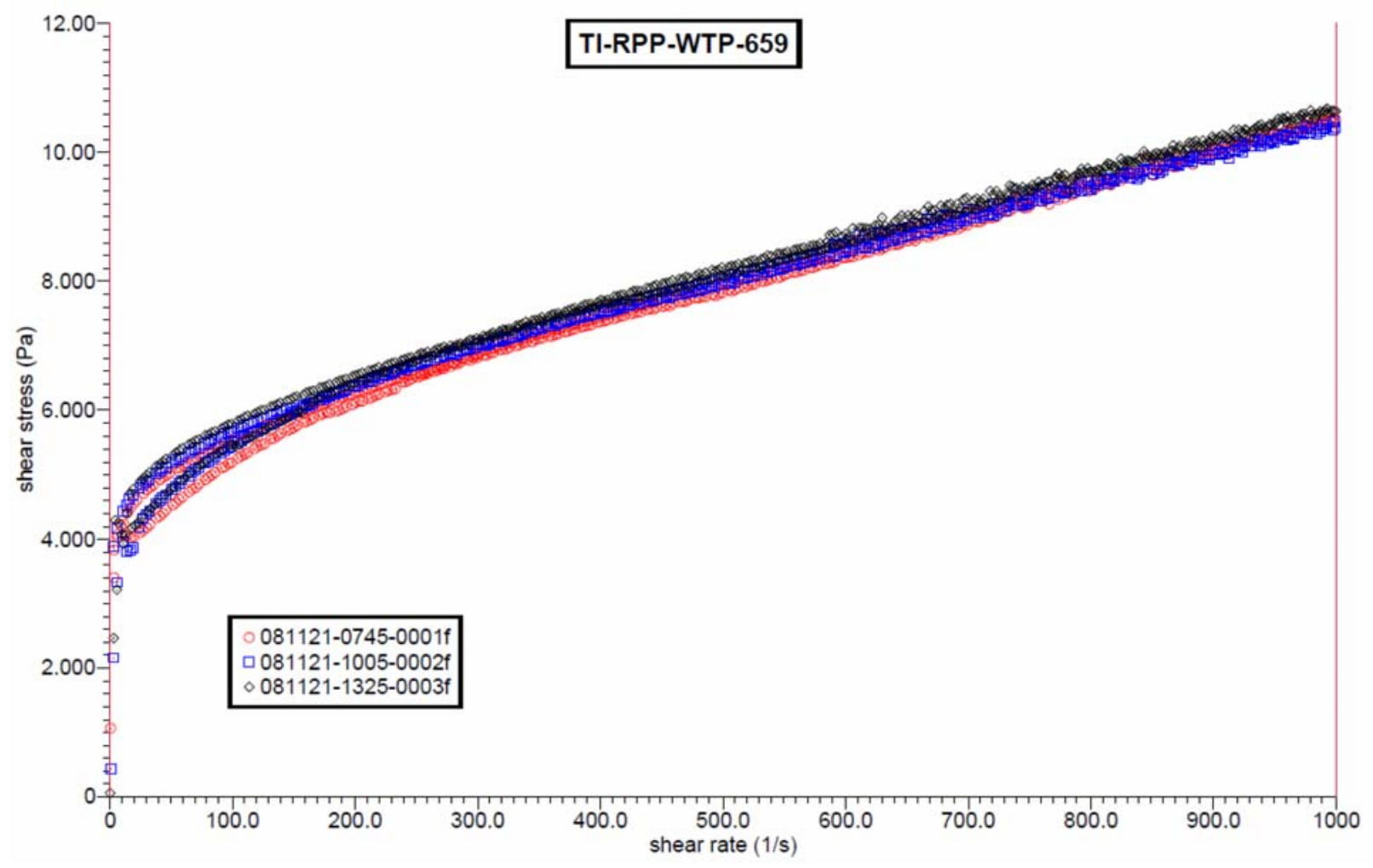

Figure D.14. Rheograms for All Samples Taken During TI-RPP-WTP-659 


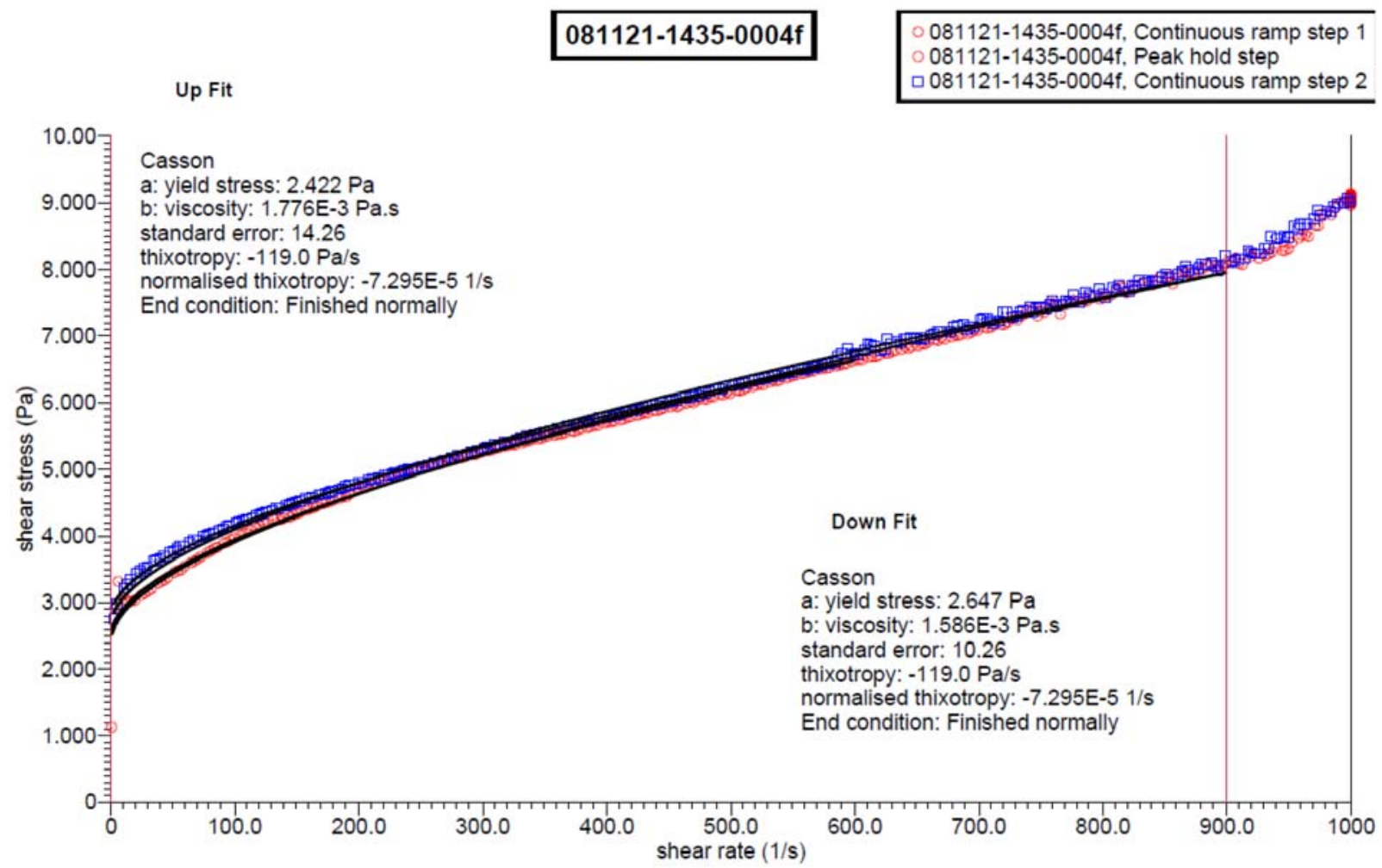

Figure D.15. Rheogram of Physical and Rheological Sample for TI-RPP-WTP-545

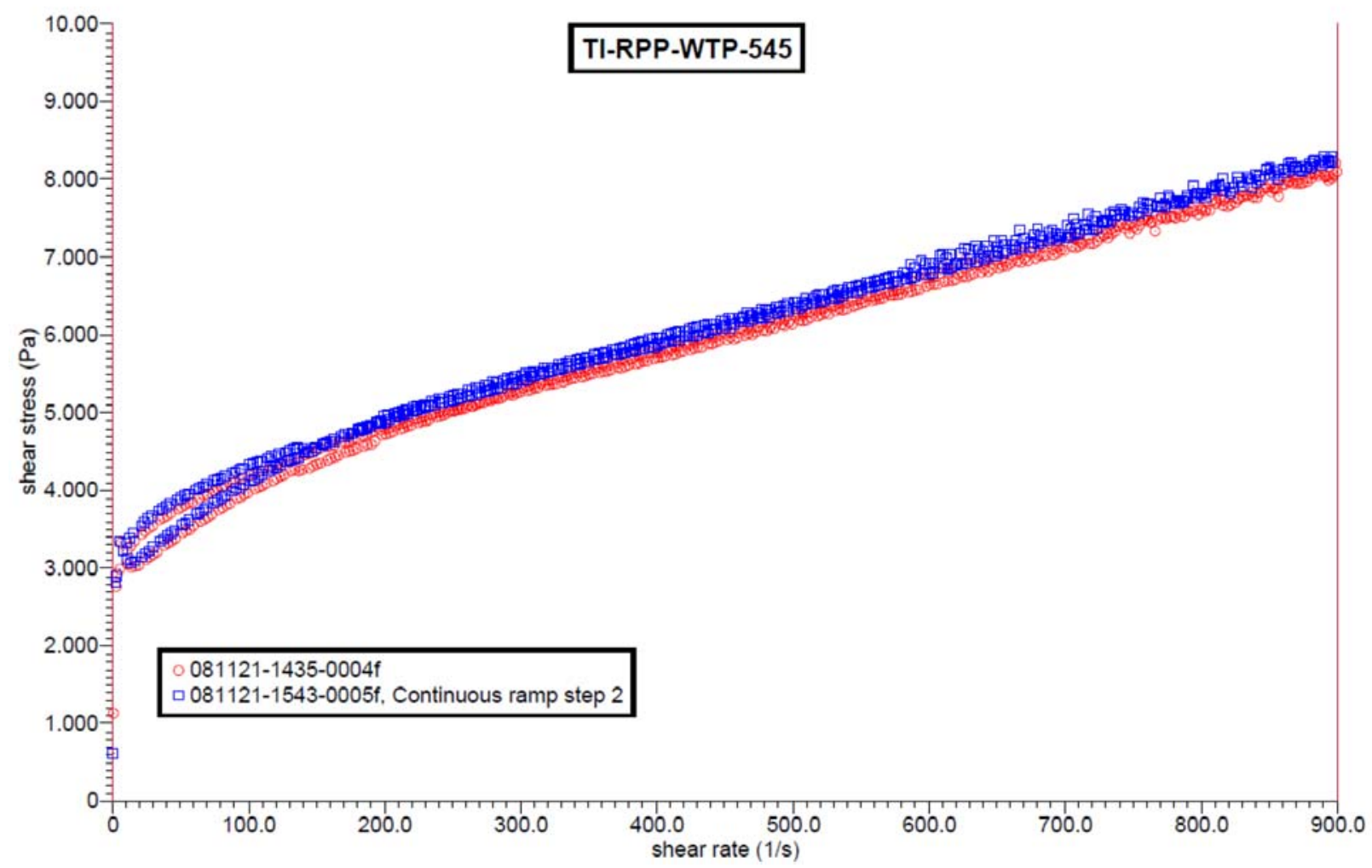

Figure D.16. Rheograms for All Samples Taken During TI-RPP-WTP-545 


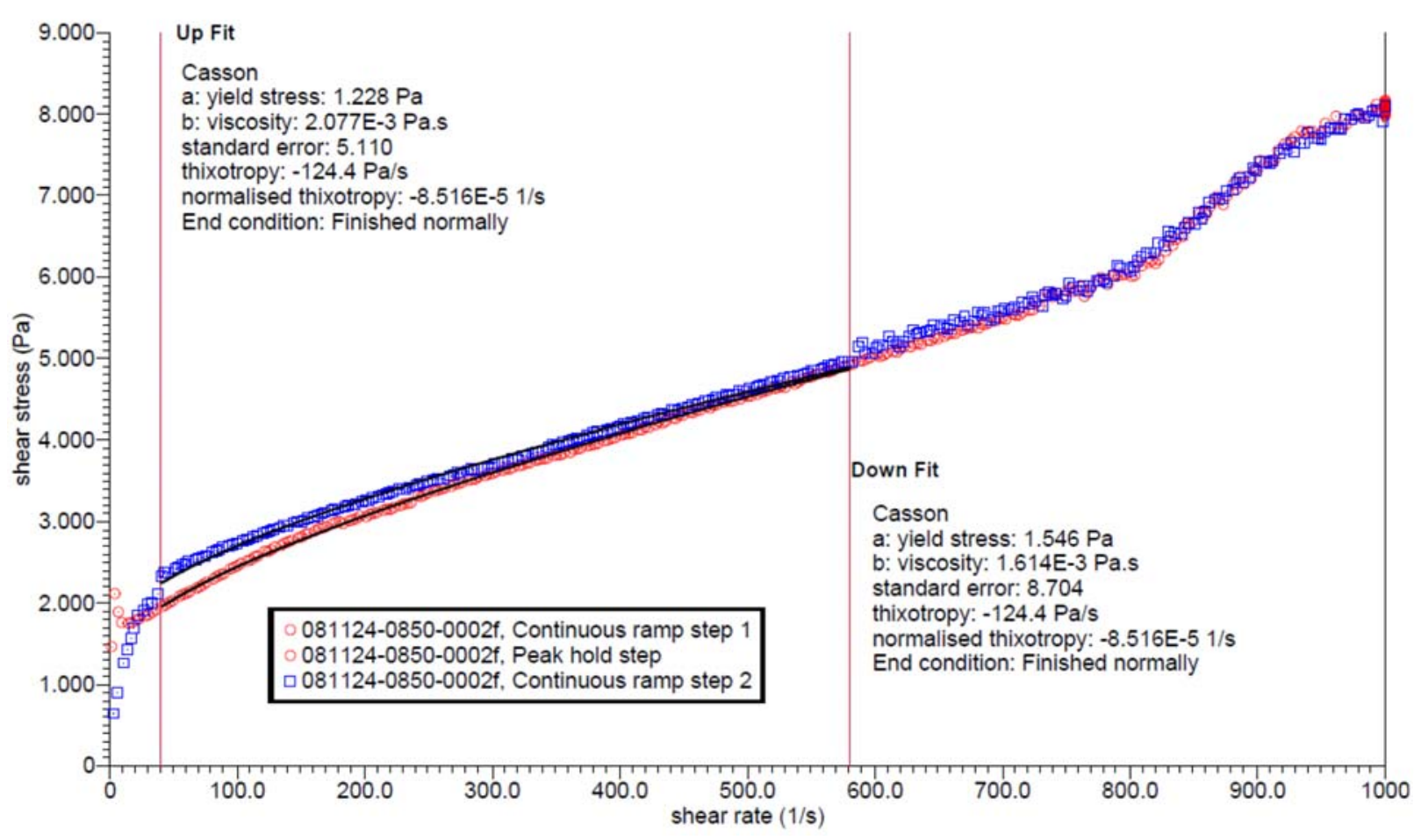

Figure D.17. Rheogram of Physical and Rheological Sample for TI-RPP-WTP-551

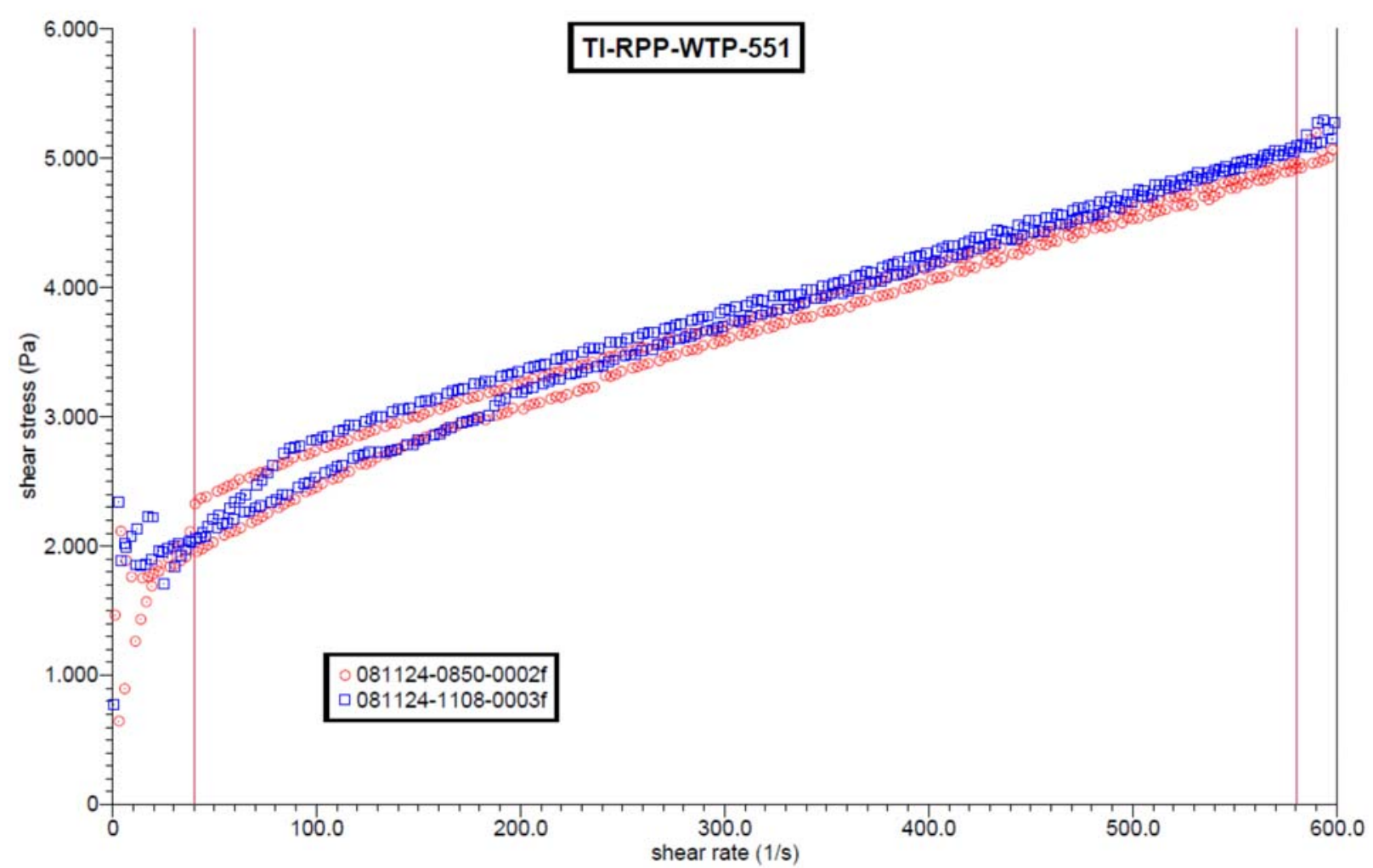

Figure D.18. Rheograms for All Samples Taken During TI-RPP-WTP-551 


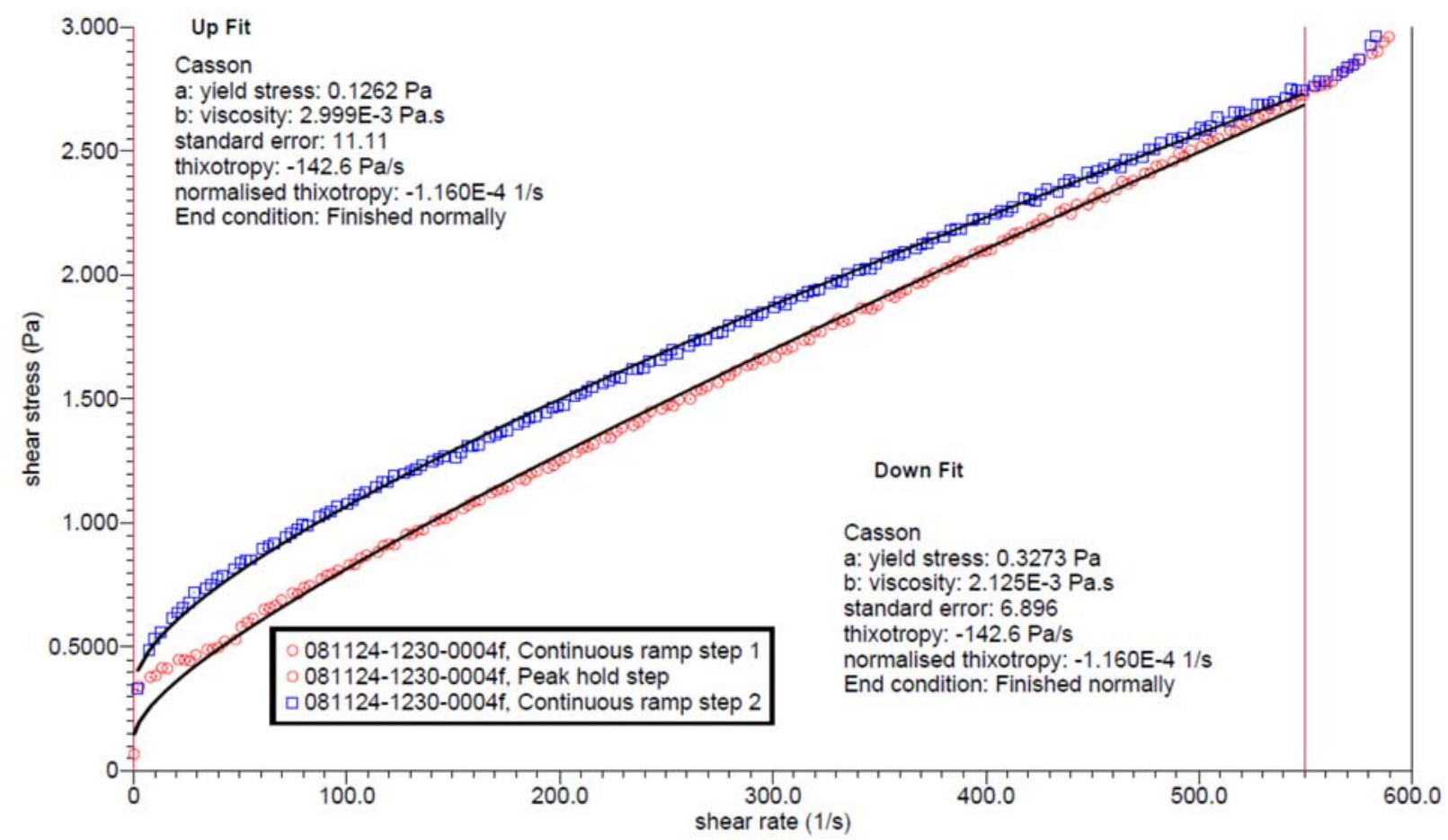

Figure D.19. Rheogram of Physical and Rheological Sample for TI-RPP-WTP-645

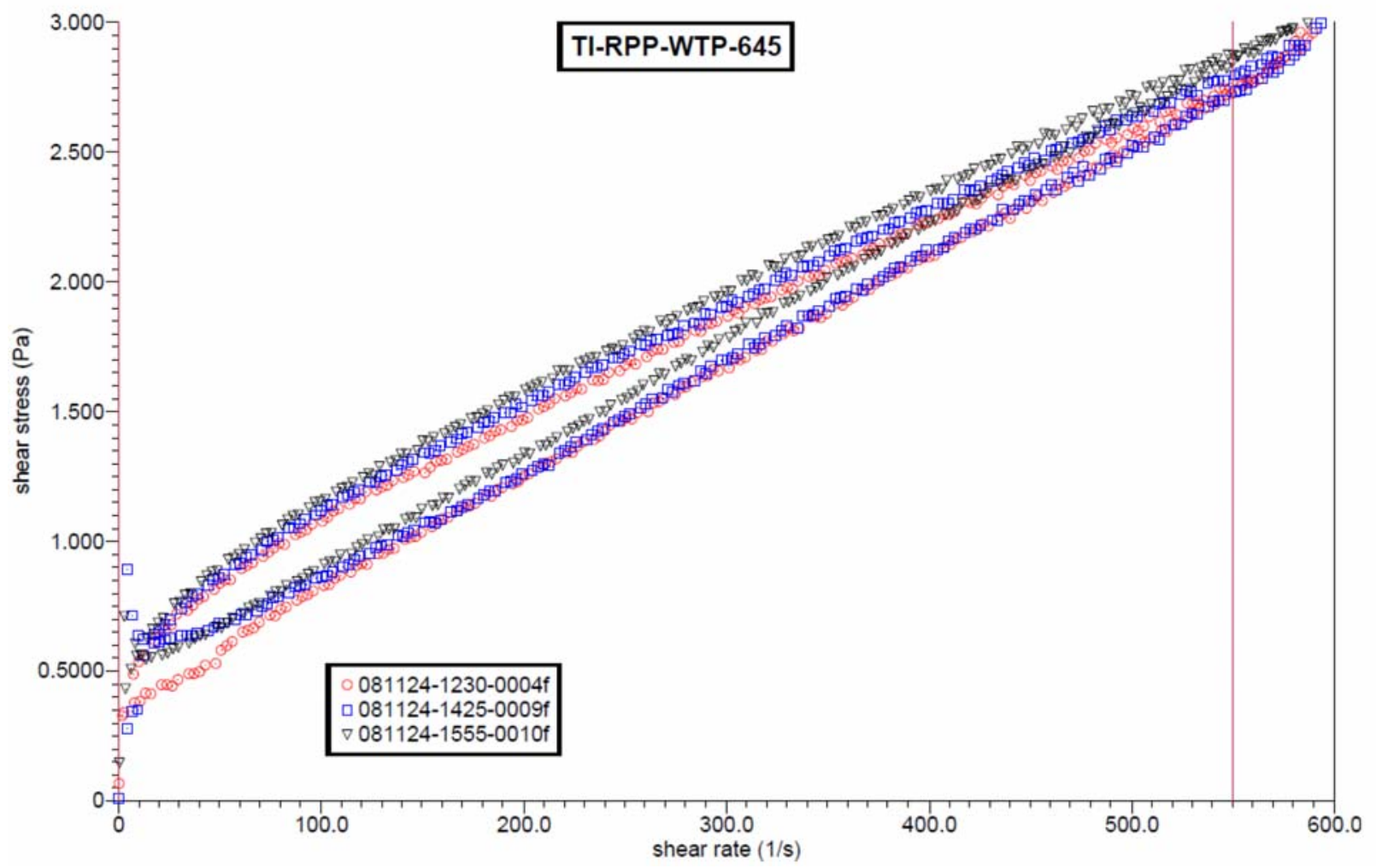

Figure D.20. Rheograms for All Samples Taken During TI-RPP-WTP-645 


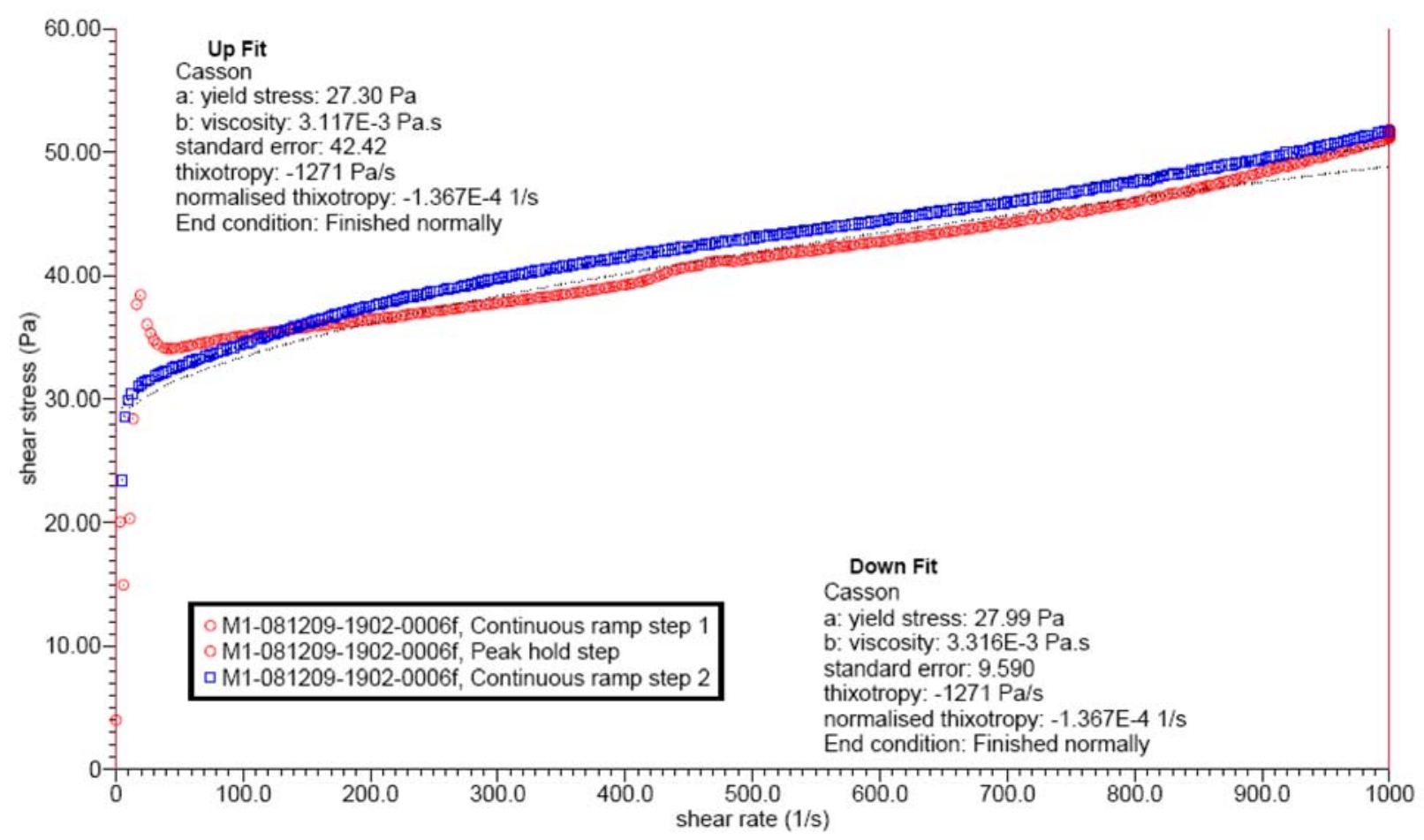

Figure D.21. Rheogram of Physical and Rheological Complex-Simulant Sample for TI-RPP-WTP-661

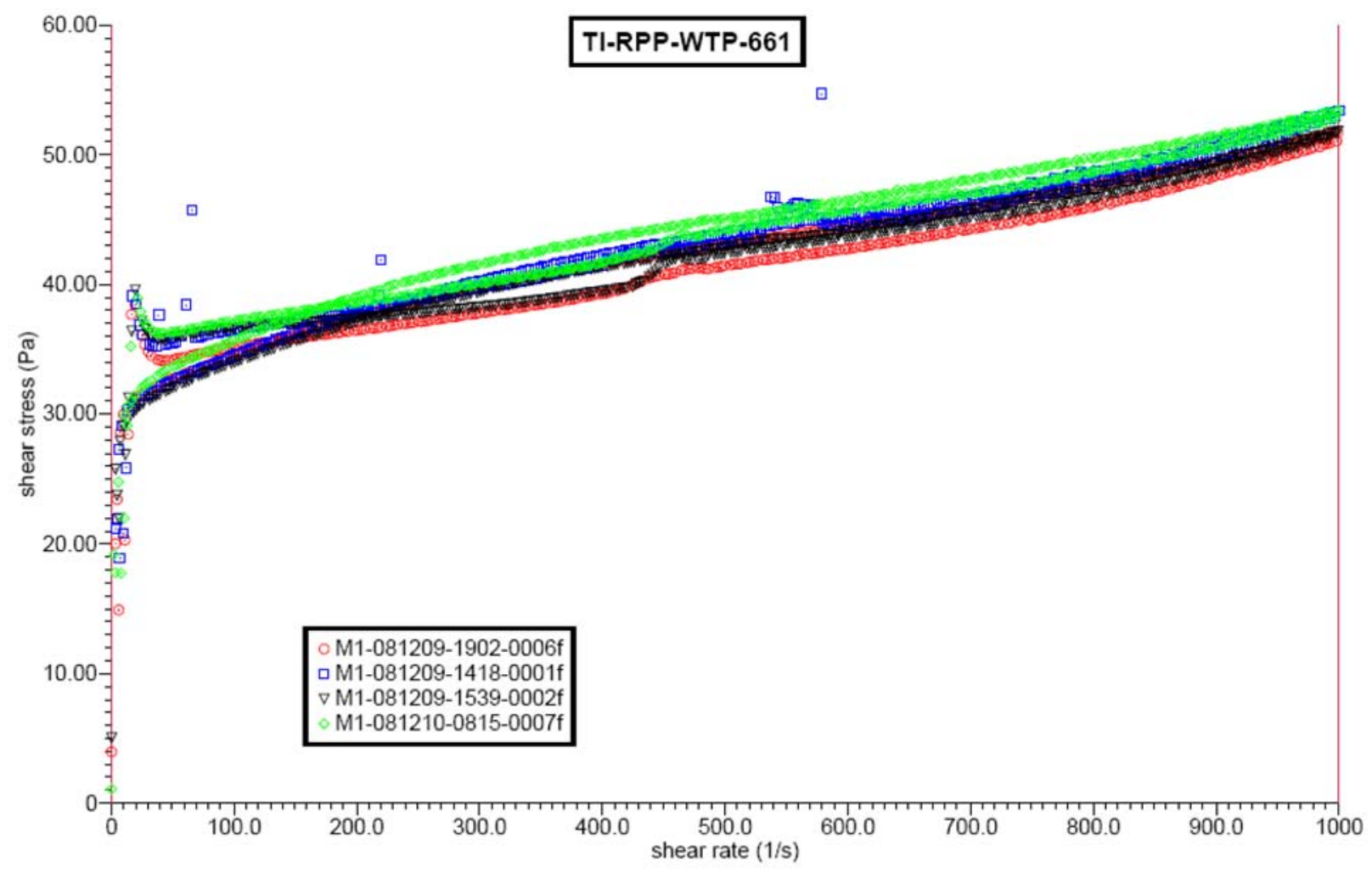

Figure D.22. Rheograms for All Samples Taken During TI-RPP-WTP-661 


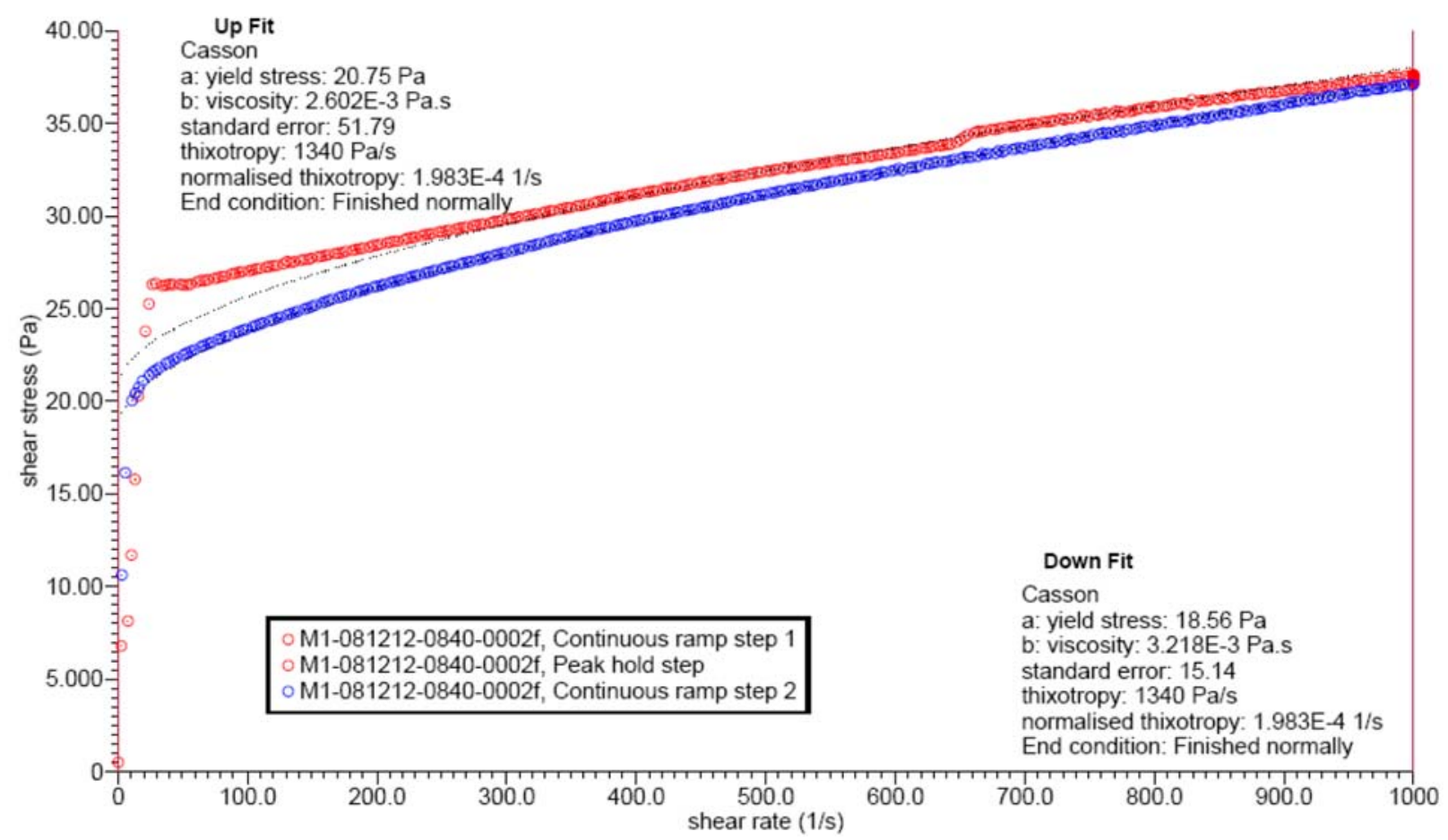

Figure D.23. Rheogram of Physical and Rheological Complex-Simulant Sample for TI-RPP-WTP-662

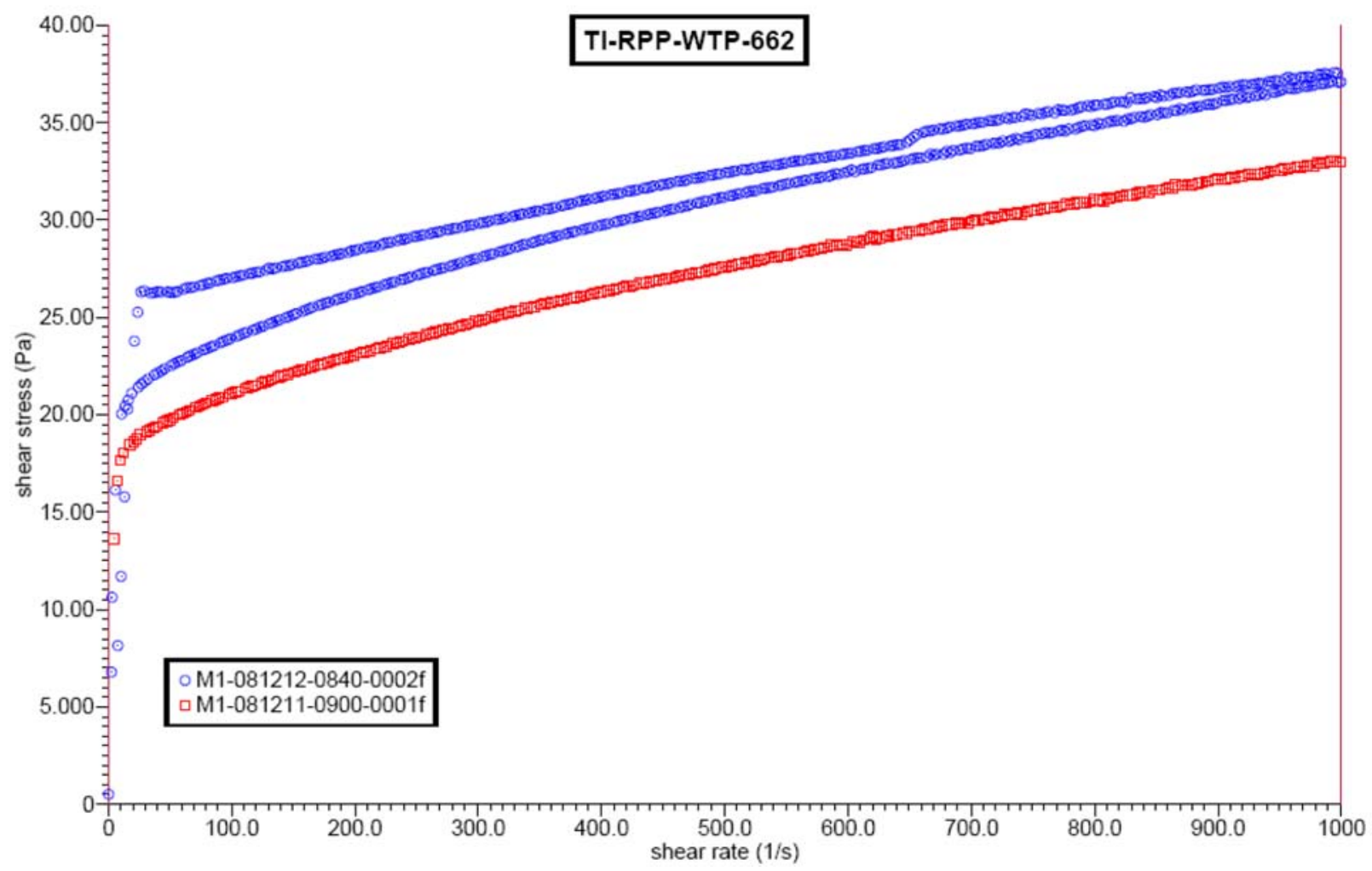

Figure D.24. Rheograms for All Samples Taken During TI-RPP-WTP-662 


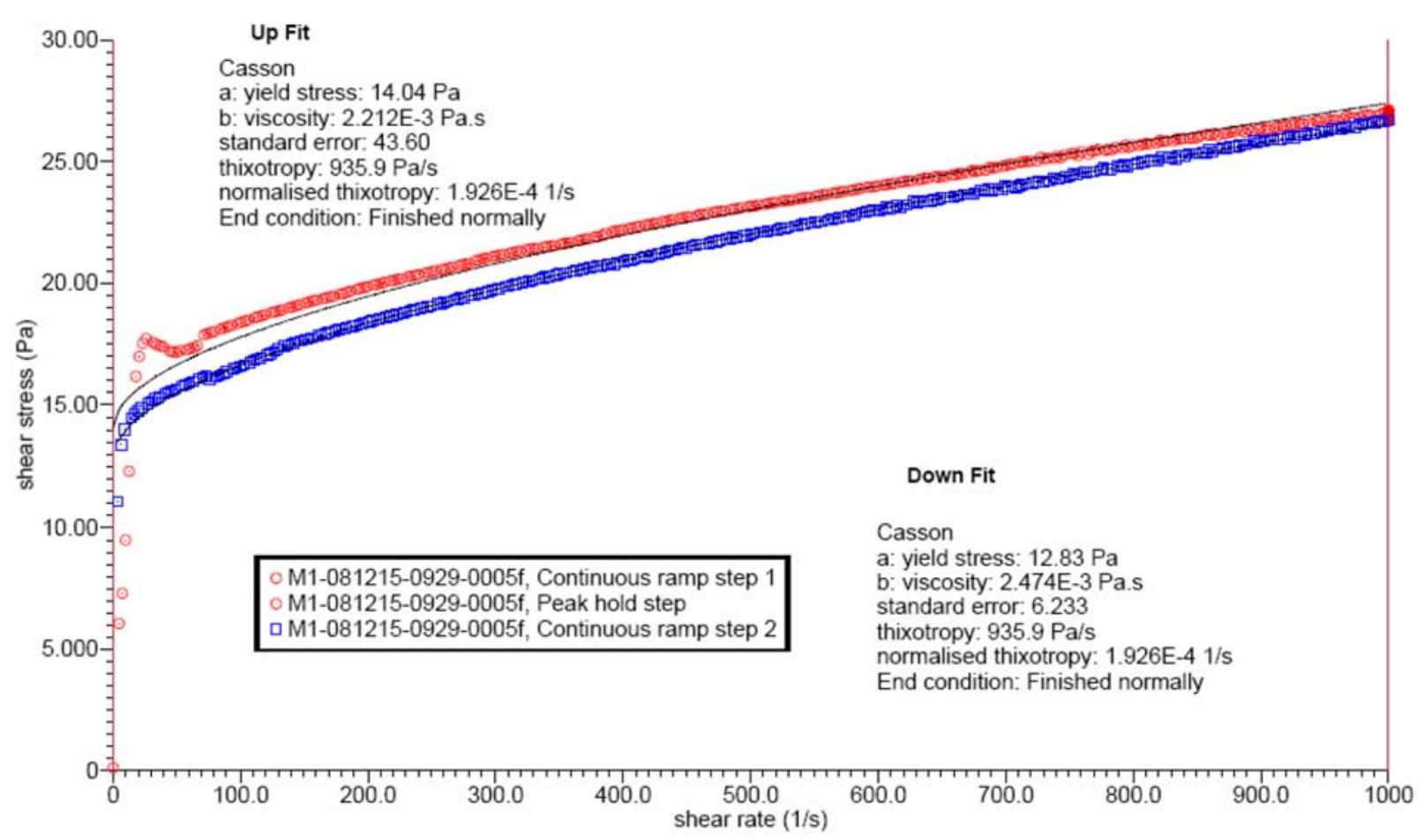

Figure D.25. Rheogram of Physical and Rheological Complex-Simulant Sample for TI-RPP-WTP-664

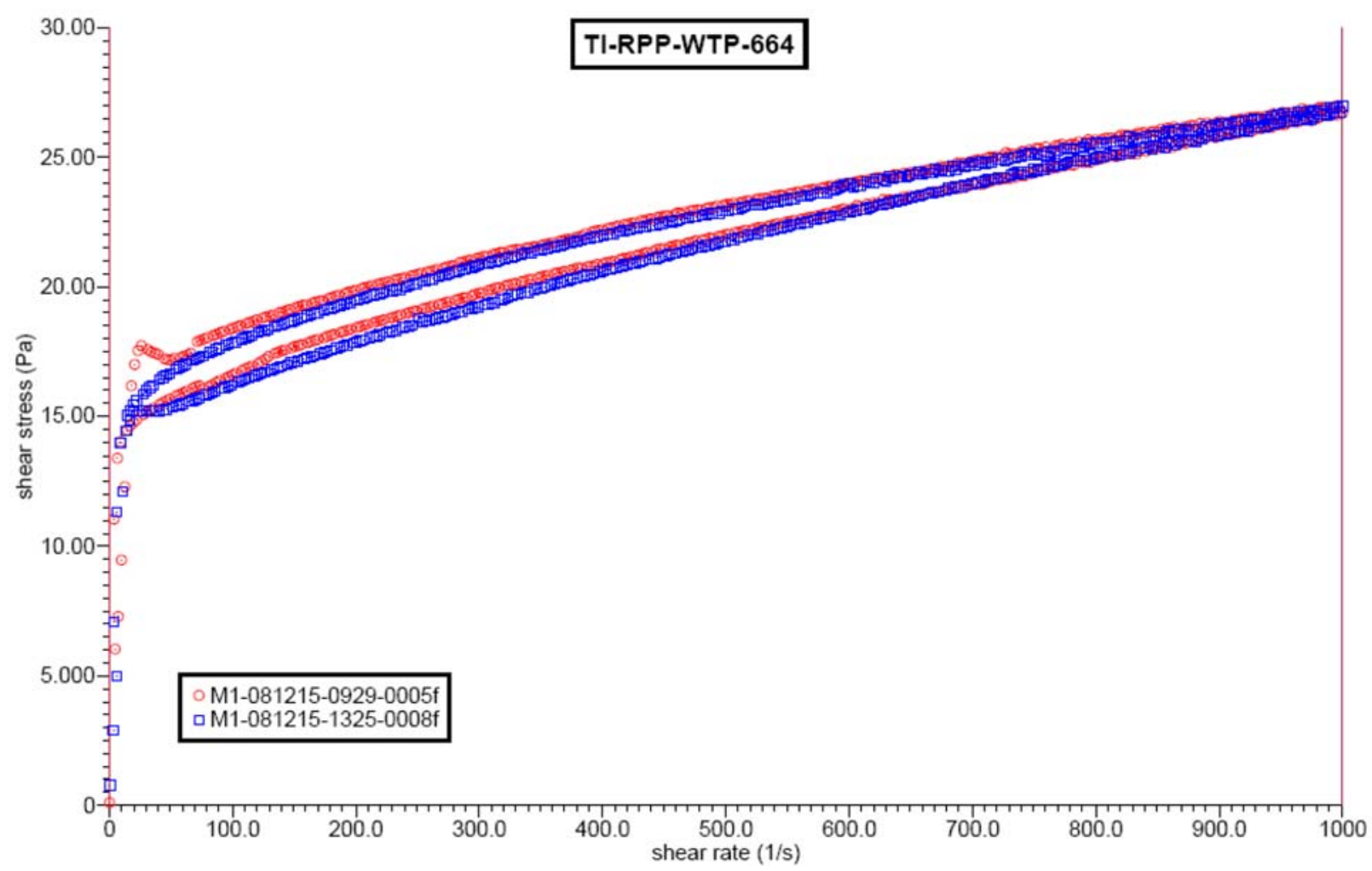

Figure D.26. Rheograms for All Samples Taken During TI-RPP-WTP-664 


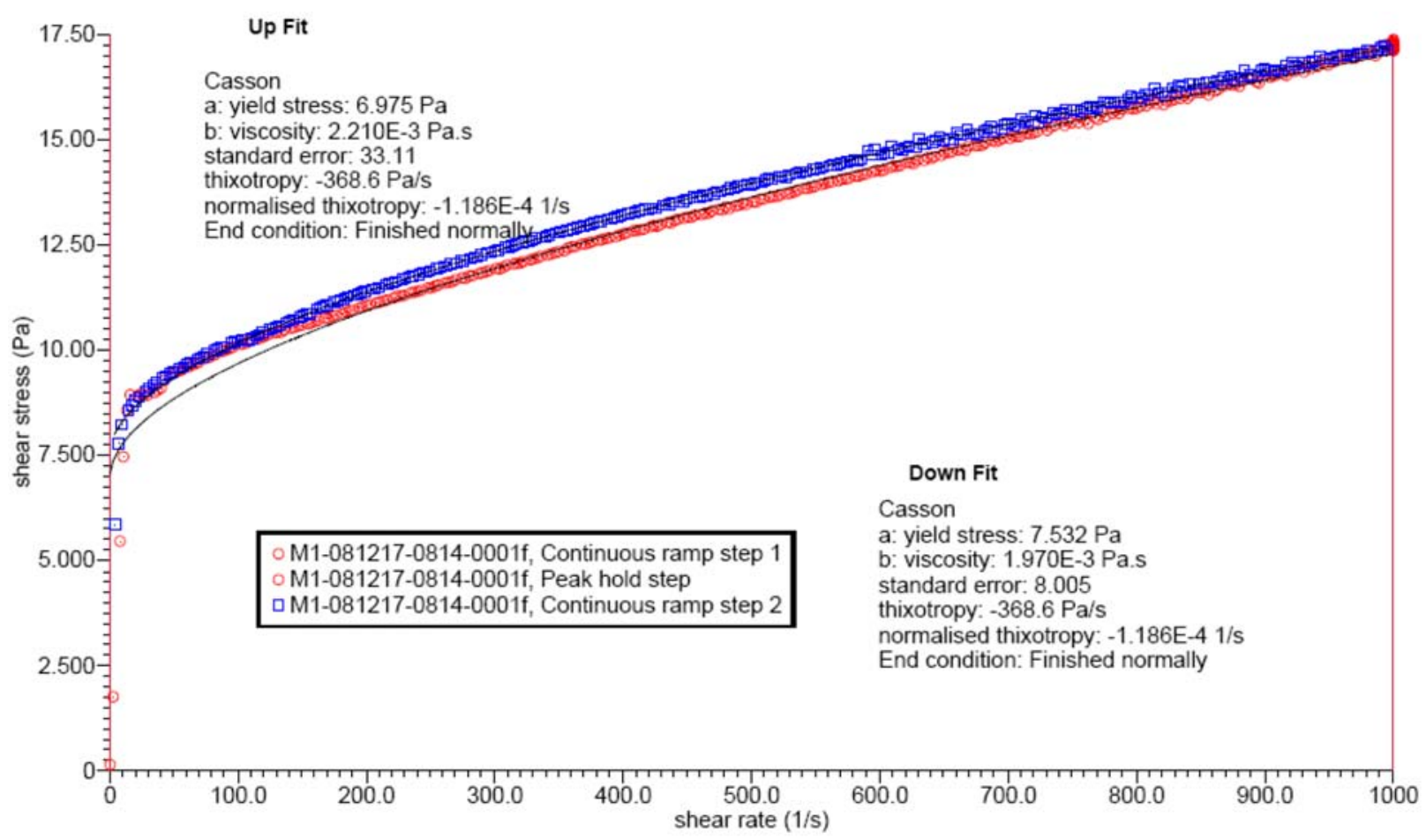

Figure D.27. Rheogram of Physical and Rheological Complex-Simulant Sample for TI-RPP-WTP-665

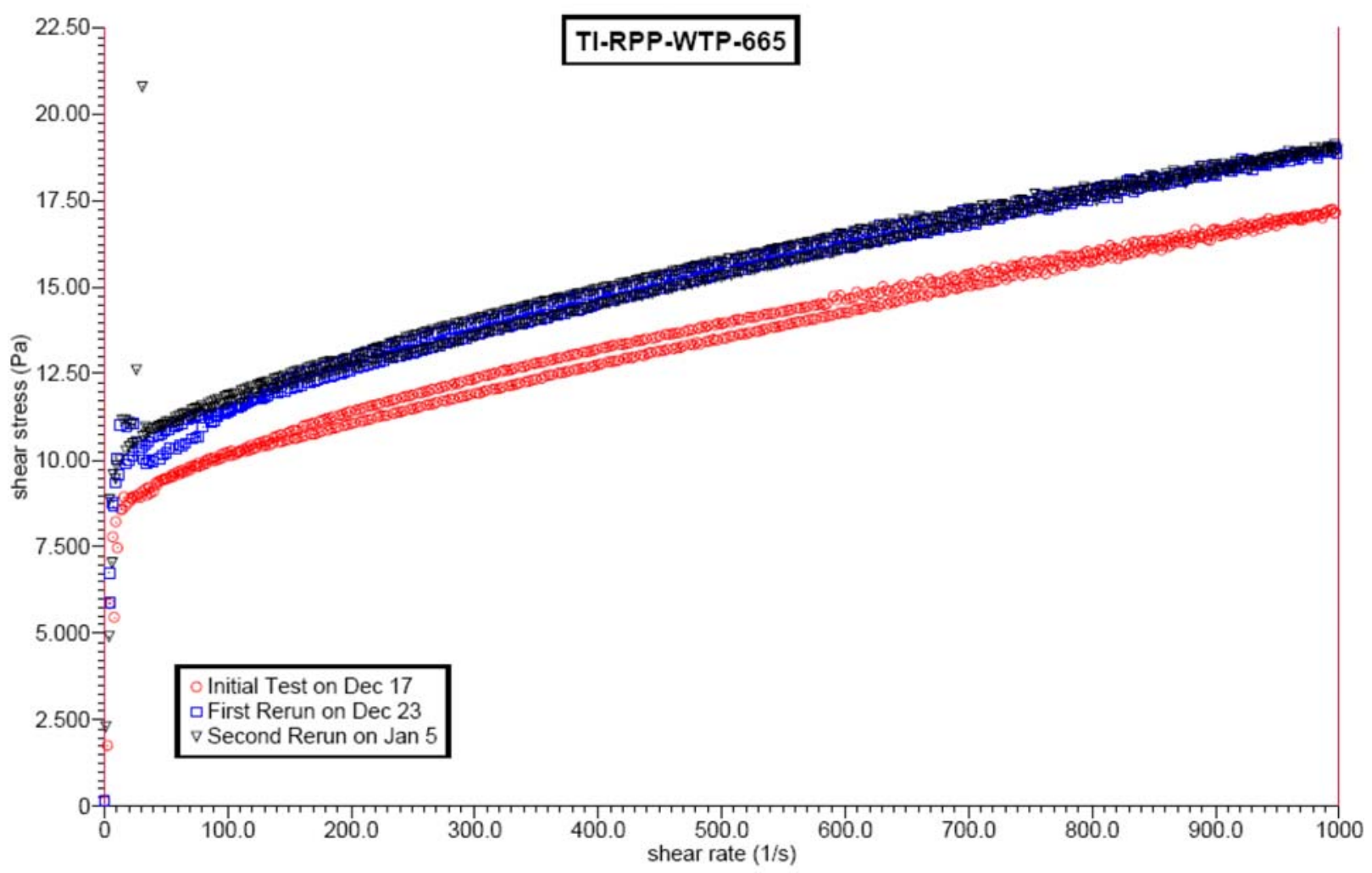

Figure D.28. Rheograms for All Samples Taken During TI-RPP-WTP-665 


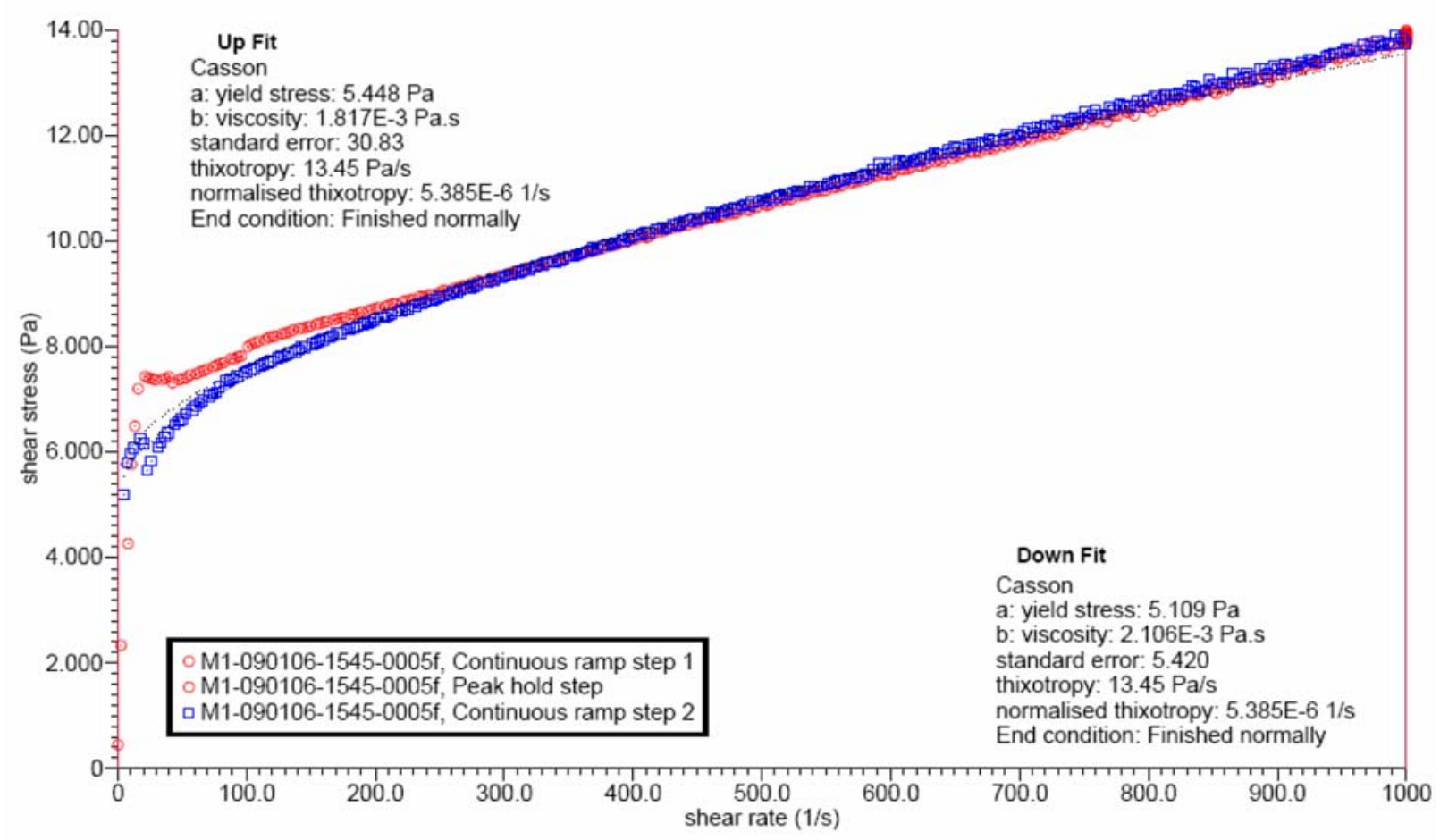

Figure D.29. Rheogram of Physical and Rheological Complex-Simulant Sample for TI-RPP-WTP-666

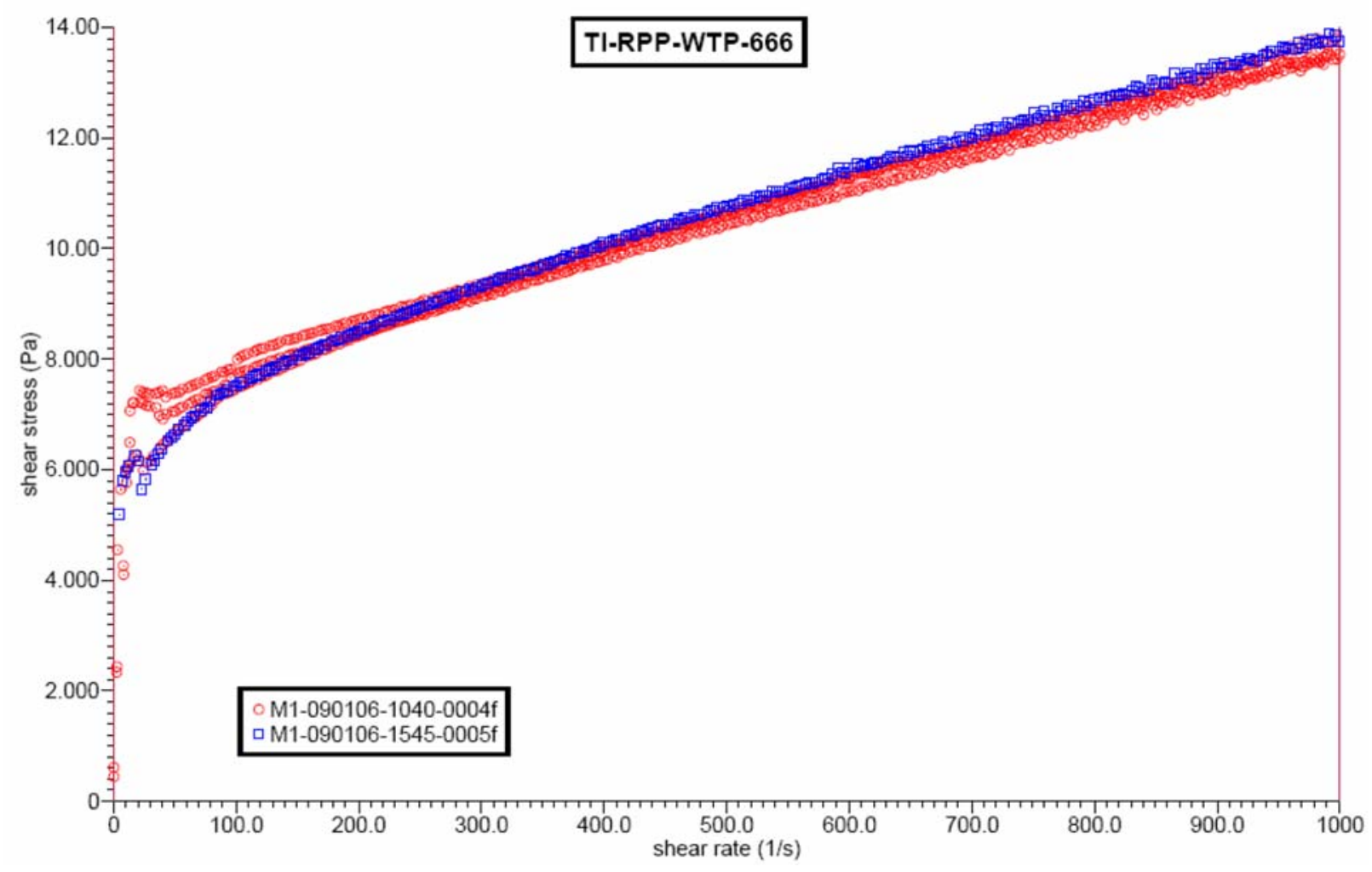

Figure D.30. Rheograms for All Samples Taken During TI-RPP-WTP-666 


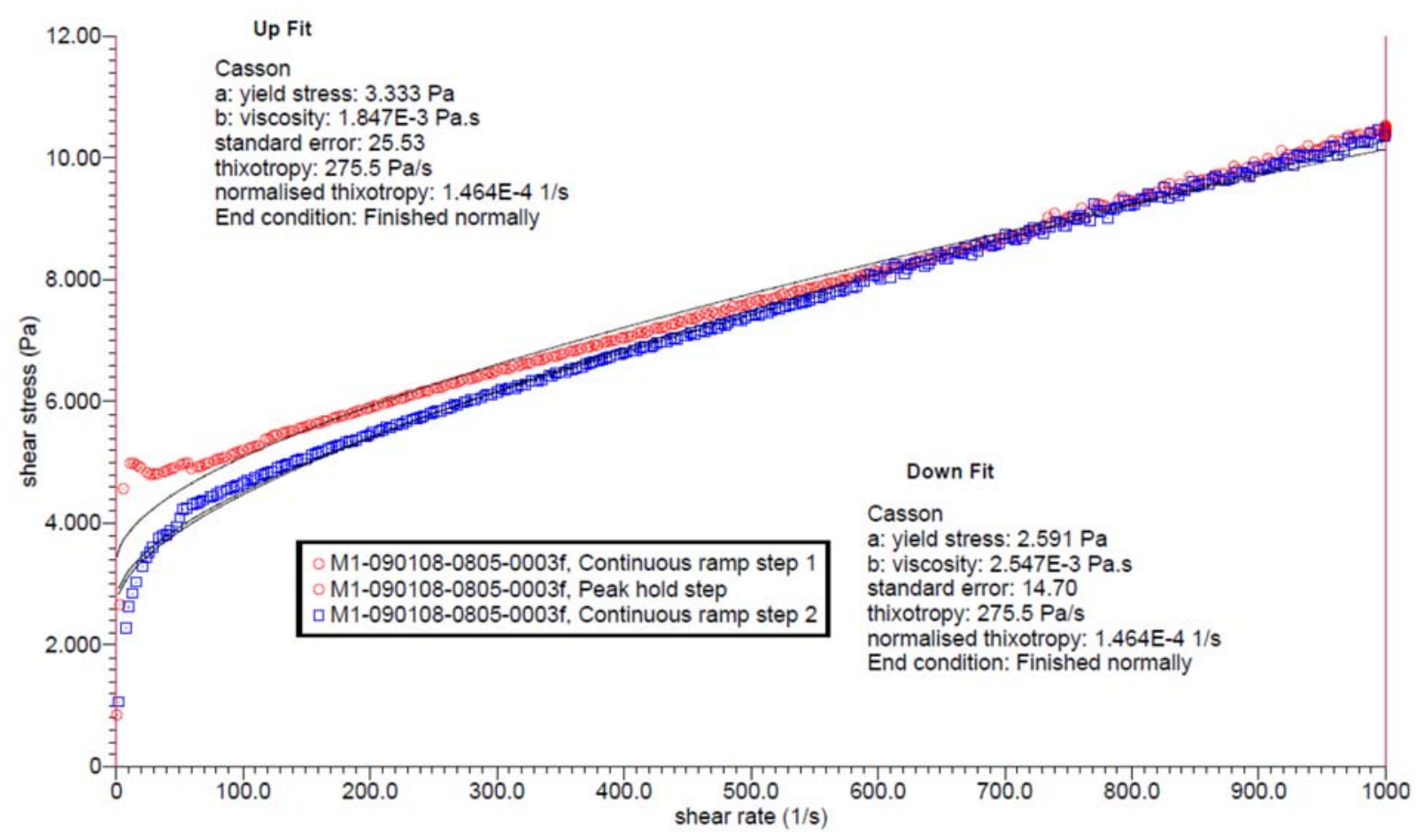

Figure D.31. Rheogram of Physical and Rheological Complex-Simulant Sample for TI-RPP-WTP-667 Prior to the Addition of AFA

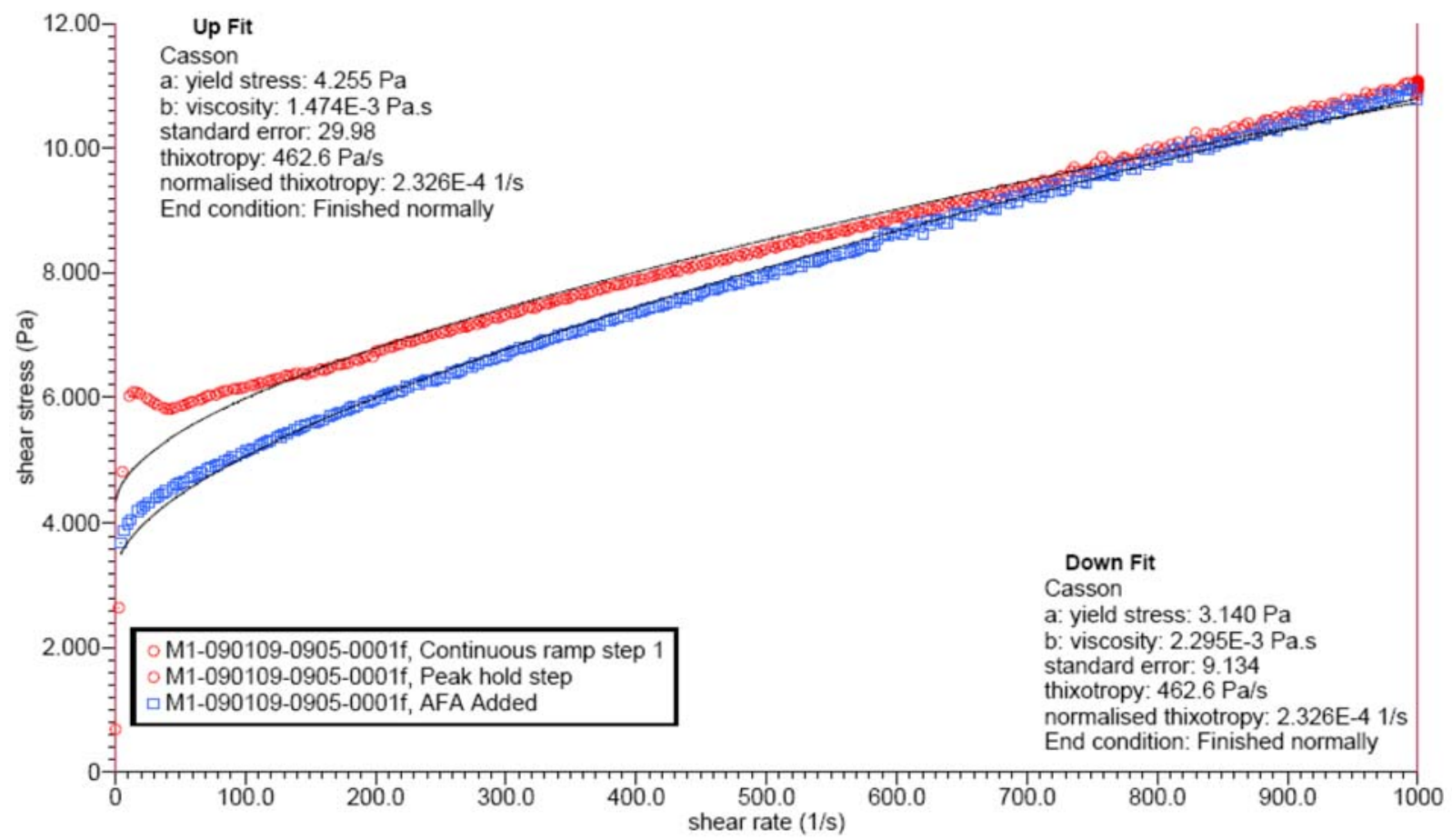

Figure D.32. Rheogram of Physical and Rheological Complex Simulant Sample for TI-RPP-WTP-667 After the Addition of AFA 


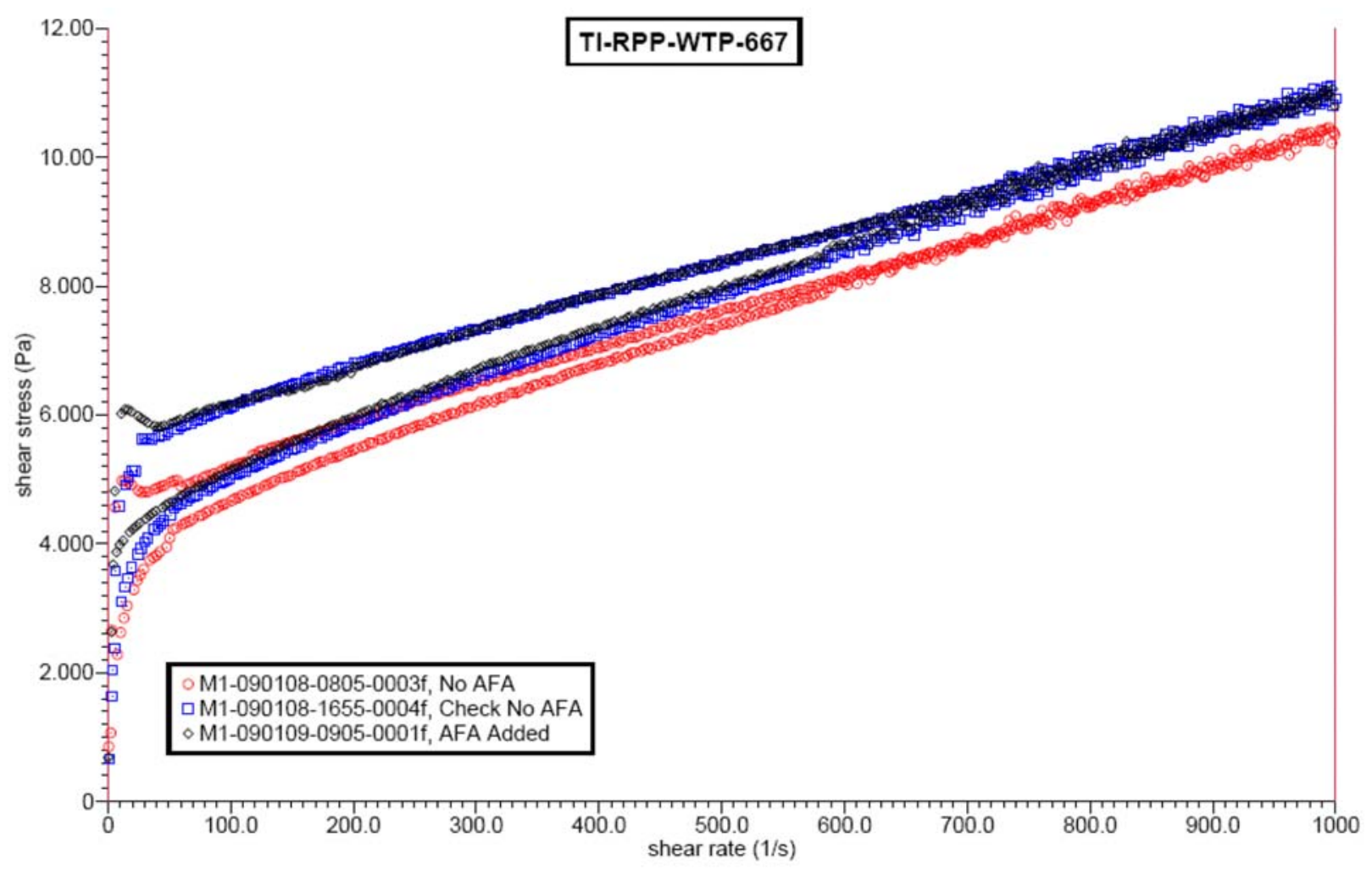

Figure D.33. Rheograms for All Samples Taken During TI-RPP-WTP-667

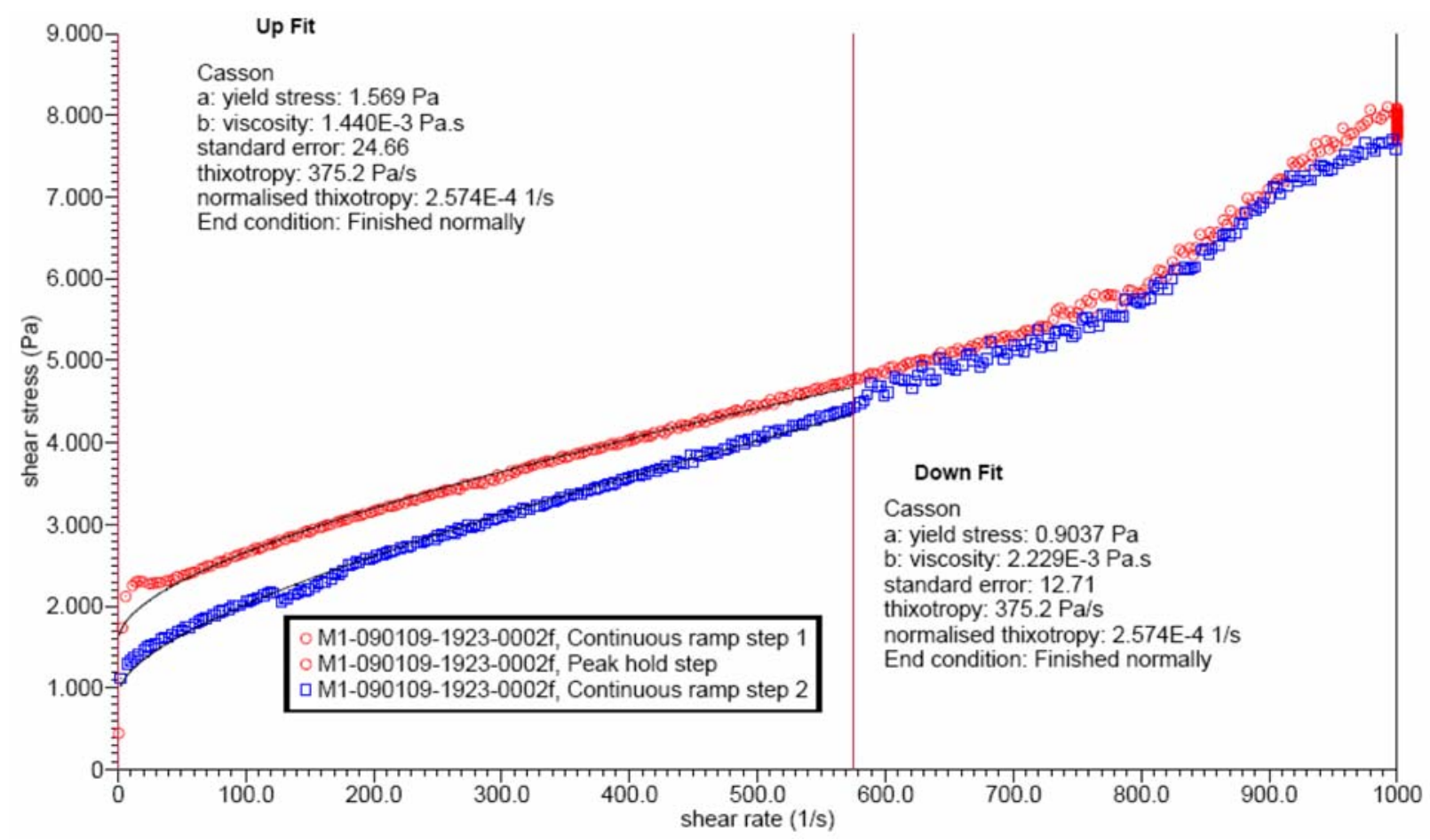

Figure D.34. Rheogram of the Only Physical and Rheological Complex-Simulant Sample Taken for TI-RPPWTP-668 

Appendix E

Third Party Review of WTP-RPT-175 Rev. A 



\section{Appendix E}

\section{Third Party Review of WTP-RPT-175 Rev. A}

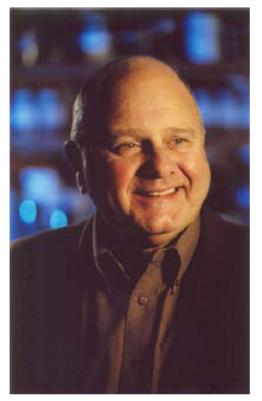

Professor David Vernon Boger

B.S.Chem.Eng., Bucknell University

M.S.Chem.Eng., University of Illinois

$\mathrm{Ph}$.D.Chem.Eng., University of Illinois

\section{Laureate Professor}

Email: dvboger@unimelb.edu.au

Telephone: (61) 383447440

Fax: (61) 383446233

David V Boger has held positions in Chemical Engineering at both Monash University and The University of Melbourne. Currently he is Laureate Professor and Professor of Chemical Engineering at The University of Melbourne. He is immediate past Director of the Particulate Fluids Processing Centre (a Special Research Centre of the ARC), past Head of Chemical Engineering and former Deputy Director of the Advanced Mineral Products Centre. His research is in non-Newtonian fluid mechanics with interests ranging from basic polymer and particulate fluid mechanics to applications in the minerals, coal, oil, food, and polymer industries. From 1991-2002 Professor Boger was Chairman of the Trade Waste Acceptance Advisory Committee, a group which advises the City of Melbourne on industrial trade waste discharges to the trunk sewer system. He held the position of BHP Billiton Fellow from 2000-2003.

\section{Professional Organisations:}

Fellow, The Royal Society

Fellow, Australian Academy of Science

Fellow, Australian Academy of Technological Sciences and Engineering

Member, Institute of Non-Newtonian Fluid Mechanics, The University of Wales (Aberystwyth , Bangor and Swansea)

Member, American Society of Rheology

Member, Australian Society of Rheology (Immediate Past President)

Member, British Society of Rheology

Publications:

$320+$ publications, which include books, book chapters, invited reviews, journal publications and conference

proceedings. The most recent book is "Rheological Phenomena in Focus" co-authored by Professor K Walters (FRS), published in 1993

Professional Experience:

International consultant - having consulted for over 90 companies worldwide

Recent international work has been with 3M Corporation in USA, Xerox Research Centre of Canada, Alcan

International Arvida Research Centre in Canada, Statoil in Norway and Tata Research Development \& Design Centre in India, and with BHP and Orica (formerly ICI) in Australia

Honours:

Annual Award of the British Society of Rheology "In acknowledgement of your notable contributions to Rheology", 1983

Royal Society of Victoria Medal for Research, 1985

Fellow, Australian Academy of Technological Sciences and Engineering, 1989

Esso Award for Excellence in Chemical Engineering, 1991

Fellow, Australian Academy of Science, 1993

Pol Eureka Prize for Environmental Research, 1993

Australian Society of Rheology Medallion, 1994

Walter Ahlström Environmental Prize $(\$ 80,000)$ of the Finnish Academies of Technology, 1995

1995 Alcoa (U.S.A.) Environmental Excellence Award

Special Chief Investigator Grant from the Australian Research Council, 1997-1999

CSIRO External Medal "for research excellence", 1998

Flinders Medal and Lecture, Australian Academy of Science, 2000

2000 Chemeca Medal

2002 Victoria Prize

Anne and Eric Smorgon Memorial Award 2002 (\$100,000 awarded in association with the Victoria Prize)

K L Sutherland Memorial Medal 2002

2003 Clunies Ross National Science and Technology Award

Commonwealth of Australia Centenary Medal, 2003

Gold Medal of the British Society of Rheology, 2004

The Prime Minister's Prize for Science, 2005

Donald L Katz Lectureship, The University of Michigan, 2006

Fellow, The Royal Society, 2007 
Report prepared for:

\section{Battelle Pacific Northwest Division \\ Richland, WA, USA}

to:

1. Provide a review of the WTP-RPT-175 report on deposition velocities of Newtonian and non-Newtonian slurries in pipelines

2. Provide a professional opinion on how the experimental results and the conclusions of WTP-RPT-175-175 investigation affect the waste treatment plant (WTP) Design Guide

by:

\section{David V Boger, FRS \\ Laureate Professor \\ The University of Melbourne \\ Australia}

In addition to the M1 Report (WTP-RTP-175) the following documents were also examined.

- Design Guide: Pipe sizing for lines with liquids containing solids - Bingham plastic model (24590-WTPGPG-M-016, Rev 2).

- Design Guide: Minimum flow velocity for slurry lines (24590-WTP-GPG-M-0058, Rev 0).

- Laminar flow settling: The potential for unexpected problems, R Cooke, Patterson \& Cooke Consulting Engineers Pty Ltd, BHR Group 2002, Hydrotransport 15, p.121.

- Coarse solids concentration in laminar pipe flow, L. Graham et al., CSIRO, Australia, BHR Group 2002, Hydrotransport 15, p.149.

- Review of M1 plugging in pipeline results, Principal Investigator: Adam Poloski, October 9, 2008, Pacific Northwest National Laboratory, Powerpoint presentation.

- Review of M1 plugging and pipeline results, Principal Investigator: Adam Poloski, October 18, 2008, Pacific Northwest National Laboratory, Powerpoint presentation. 
- Slurry transport: an overview, Robert Cooke, Patterson \& Cooke Consulting Engineers Pty Ltd, presentation at DOE Slurry Retrieval, Pipeline Transport, Plugging and Mixing Workshop, Orlando, January 14-18, 2008.

- Lowered expectations: the impact of yield stress on sand transport in laminar non-Newtonian slurry flows, R. Gillies et al., Hydrotransport 17, $17^{\text {th }}$ International Conference on Hydraulic Transport of Solids, BHR Group 2007, p. 1.

- Comments on M1 Slurry Transport, visit of 9/9/08 - A.W. Etchells

\section{Introduction}

The transfer of the nuclear waste suspensions from the 177 storage tanks at the Hanford site represents a significant challenge. A transfer pipeline is not being designed for one material but perhaps for 177 different materials ranging from low viscosity Newtonian suspensions, to moderate shear thinning non-Newtonian suspensions with a small Bingham yield stress of 0-6 Pa, up to viscous non-Newtonian materials with a yield stress of $30 \mathrm{~Pa}$ or more. No single set of operating conditions will be appropriate. This is not a conventional slurry pipeline where only one material with relatively constant rheology is to be handled, like a tailings dam discharge line in the minerals industry or a product pipeline in the iron or copper industries.

In conventional pipeline design, laminar flow is avoided by modifying the properties (rheology) of the feed so that pumping at a critical velocity will develop highly turbulent flow and minimal particle settling during flow. Critical velocities of the order of $4 \mathrm{ft} / \mathrm{sec}$ are often adequate and used for the design of such lines. At Hanford considerable changes in the operating conditions for the different feeds, ranging from perhaps highly turbulent flow to laminar flow will need to be made to avoid pipeline blocking. A good understanding of the rheological properties of the materials will be needed, not only in the feed from the tanks but also as the material passes through the plant.

\section{Discussion of the M1 Report}

The investigation of deposition velocities of Newtonian and non-Newtonian slurries in pipelines undertaken by the Pacific Northwest National Laboratory and presented in the M1 Report is an excellent achievement examining a very complex problem. It is very difficult to deal with the transport of a two-phase suspension, particularly if one cannot deal directly with the material to be transported, i.e., if one does not have samples of the material available on which to make the appropriate physical and chemical measurements. Therefore it has been necessary to generate a range of material samples representative of some of the materials to be handled at the Hanford facility. The report is thorough, complete and scientifically sound, with the experimental techniques being nicely justified for the range of materials examined. The ability to predict the pressure drop-superficial velocity observations up to the critical velocity for sedimentation for the four of the five Newtonian and ten non-Newtonian fluids with apparent viscosities ranging up to $6 \mathrm{Cp}$ and Bingham yield stresses ranging from 0 to $6 \mathrm{~Pa}$ from the Design Guide is encouraging. Also, the pressure drop data and the electrical resistivity tomagrams are consistent with the critical sedimentation 
velocities, except for the LLM sample (10 $\mu$ m glass in thin clay) and the LLH sample (10 $\mu \mathrm{m}$ glass in the thick clay). Inadequate pressure drop prediction for the Newtonian fluid constructed with the $100 \mu \mathrm{m}$ stainless particles needs further examination, as do the non-Newtonian results where sedimentation is not observed. These results need further clarification in the report.

The Executive Summary does not do justice to the work. For example, the summary concludes "experimental results indicate that for Newtonian fluids the Design Guide is conservative". The authors should clearly state what changes have been necessary in the Design Guide in order to result in a conservative prediction and for what range of material properties the conclusion is valid. There is no need to go into detail about particle size effects at this point as their predictions are conservative, based on the larger particle models which were not developed for small particle systems.

It is stated that the use of an average particle density as an input is not conservative. Which particle density should be used? Perhaps plutonium oxide since it is one of the target compounds.

There is a separate subset conclusion, "The viscosity correlation used in the WTP Design Guide has been shown to be inaccurate for Hanford-based materials". This is an important conclusion and should be pulled out and used as a separate conclusion in the Executive Summary. It implies that actual rheological measurements are required for each material.

The Executive Summary should be more positive, concise and precise, and to the point, like the review of the M1 plugging data presented in the Powerpoint presentations by Poloski.

The two non-Newtonian fluid conclusions are implying that none of the Design Guide correlations which have primarily been established for large particle Newtonian fluids is applicable or can be extended for the nonNewtonian fluids that will be encountered at the Hanford site where small particles will be encountered. Again, these conclusions should be very precise and concise. It is the overall conclusion that none of the existing literature is appropriate for non-Newtonian systems, particularly those encountered at the Hanford site where small particles and surface chemistry are issues that are important. The issue of small particles and colloidal forces is often absent in the engineering literature which deals with large hard sphere particles. I would not consider using large particle, hard sphere correlations when non-Newtonian suspensions are encountered for both the critical velocity and viscosity correlation.

\section{Conclusions from the M1 Report and the Design Guides}

- For Newtonian suspensions which generally will be of a low viscosity with a low solids concentration a design philosophy needs to be established. A critical velocity of $4 \mathrm{ft} / \mathrm{sec}$ is too low, $6 \mathrm{ft} / \mathrm{sec} \mathrm{might}$ be 
adequate, but I would go to higher velocities simply to be on the safe side. According to the Etchells Report, $8 \mathrm{ft} / \mathrm{sec}$ should not present significant erosion problems.

- For moderate non-Newtonian fluids dealt with in the M1 Report there is significant confusion in the documentation between the M1 Executive Summary and the Powerpoint presentation of Poloski and the report of Etchells, where both conclude that the Design Guide with sufficient modification can be used to predict with safety the critical velocity. I would not rely on predictions based on a method developed for large, hard, spherical particles because the systems that will be encountered will most likely contain small particles where colloidal forces become important.

- The region of real concern, like that shown in the LLM and LLH tests where little sedimentation was observed, is for the more concentrated fine particles suspensions which will be encountered. For these materials basic rheological data will be required, as will loop tests with the highest yield stress and viscosity material which will be encountered.

- More attention needs to be paid to what will happen to the fine particle systems as they pass through the process. My understanding is that the suspensions generally will be of a very high ionic strength. As the salts are removed there will most likely be a dramatic change in the rheology at the same solids concentration. Such behaviour needs to be anticipated. The fact that the process is dealing with fine particles, generally less than 78 microns, puts the system in a range where changes of surface chemistry are very important, which is not the case for large particles where there will be little effect.

- The big unknown in the transfer system will be how to deal with the more viscous non-Newtonian fluids both in the initial discharge in the process itself and in unplugging a line.

- Using a particle size as an indication of where one will anticipate a non-settling suspension as pointed out in the Report is wrong. There is no rule of thumb that will be applicable if surface chemistry forces come into play, which will be the case for the colloidal systems to be encountered. Unfortunately then, each suspension will be different, which is consistent with the behaviour of non-Newtonian fluids where it is very difficult to generalize from one material to another without having basic rheological measurements.

- It is important to establish the range of materials to be encountered and the range of rheological and density issues to be encountered. The M1 investigation and report has moved a significant way in examining the range of conditions to be encountered, but leaves open the most difficult, i.e., the materials which in my understanding will reach yield stress on the order of $30 \mathrm{~Pa}$. 

PNNL-18316

WTP-RPT-189 Rev. 0

\section{Distribution}

No. of

Copies

2 Bechtel National Inc.

Darin Ramsey (2) H4-02

15 Pacific Northwest National Laboratory

HE Adkins

K7-15

ML Bonebrake

P7-25

J Chun

K6-24

AM Casella

P7-25

KM Denslow

K5-26

MD Johnson

K6-96

ML Luna

K8-98

PJ MacFarlan

P7-27

JM Tingey

P7-25

JJ Toth

P7-22

MJ Minette

P7-25

DE Kurath

K3-52

Project Files

K3-52

Information Release (pdf) 


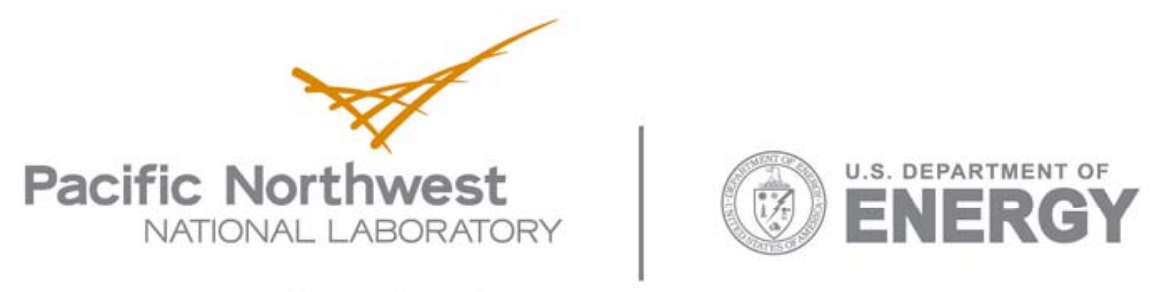

902 Battelle Boulevard

P.O. Box 999

Richland, WA 99352

1-888-375-PNNL (7665)

www.pnl.gov 